MICHELE ANZE

OTIMIZAÇÃO DO USO DE ÁGUA EM REFINARIAS DE PETRÓLEO

São Paulo

2013 
MICHELE ANZE

\section{OTIMIZAÇÃO DO USO DE ÁGUA EM REFINARIAS DE PETRÓLEO}

Tese apresentada à Escola Politécnica da Universidade de São Paulo para obtenção do título de Doutor em Engenharia

São Paulo 
MICHELE ANZE

OTIMIZAÇÃO DO USO DE ÁGUA EM REFINARIAS DE PETRÓLEO

Tese apresentada à Escola Politécnica da Universidade de São Paulo para obtenção do título de Doutor em Engenharia

Área de Concentração: Engenharia Química

Orientador: Prof. Dr. Claudio Augusto Oller do Nascimento

Coorientadora: Profa. Dra. Rita Maria de Brito Alves

São Paulo

2013 
Este exemplar foi revisado e alterado em relação à versão original sob responsabilidade única do autor e com anuência de seu orientador

São Paulo, 12 de junho de 2013

Michele Anze

(autora)
Prof. Dr. Claudio Augusto Oller do Nascimento (orientador)

\section{FICHA CATALOGRÁFICA}

Anze, Michele

Otimização do uso de água em refinarias de petróleo / M.

Anze. -- versão corr. -- São Paulo, 2013.

$160 \mathrm{p}$.

Tese (Doutorado) - Escola Politécnica da Universidade de São Paulo. Departamento de Engenharia Química.

1.Reuso de água 2.Refinarias 3.Otimização matemática 4.Heurística I.Universidade de São Paulo. Escola Politécnica. Departamento de Engenharia Química II.t. 


\section{DEDICATÓRIA}

Aos meus pais, Célia e Timóteo, que sempre fizeram o possível e o impossível pela minha educação. 


\section{AGRADECIMENTOS}

Ao meu orientador, professor Claudio Oller, pela oportunidade, ajuda e paciência.

À professora Rita Maria de Brito Alves pelos ensinamentos.

Ao Dr. Antonio Esio Bresciani pelo apoio tanto na parte técnica quanto moral e pelos conselhos sábios e sempre pertinentes.

Aos amigos do Departamento de Engenharia Química, Laboratório de Controle e Simulação de Processos, pela motivação e amizade. Especialmente a Patrícia, ao William e ao David.

Aos engenheiros e técnicos da refinaria, especialmente ao engenheiro Eduardo, pela colaboração durante a etapa realizada na refinaria.

Às minhas amigas que iniciaram essa jornada comigo, Marina, Hellen, Helena e Ana Cristina. E às minhas queridas Bruna e Celina, que mesmo a distância sempre estão tão perto.

Aos meus pais, Célia e Timóteo, e a minha irmã Melissa por todo apoio e por estarem sempre ao meu lado.

Ao meu marido, Flávio, por todo suporte, companheirismo e compreensão. 
"O que verdadeiramente somos é aquilo que o impossível cria em nós."

Clarice Lispector 


\section{RESUMO}

As refinarias de petróleo utilizam grandes quantidades de água em seus processos e por isso são impelidas a desenvolver fortes programas de redução de seu consumo. O objetivo do presente estudo é a aplicação de metodologia de otimização em problemas de alocação ótima e reuso de água em refinaria de petróleo. Diferentemente dos enfoques tradicionais que buscam tratar os efluentes gerados para atender às legislações ambientais ou para algum tipo de reuso na planta, a metodologia utilizada avalia os processos que usam água, questionando as causas da geração do efluente. Essa abordagem envolve o levantamento de dados industriais, análise dos processos de produção, identificação de oportunidades para aplicar as estratégias de otimização da alocação de água: racionalização, reuso e/ou reciclagem do efluente e, em seguida, a otimização da rede de água. Visando obter uma rede de água que seja aplicável na indústria, desenvolveu-se um procedimento específico baseado em regras heurísticas que representam as restrições reais dos processos. Através deste procedimento, o consumo de água fresca atingido é próximo do valor ótimo encontrado na literatura. As redes de água geradas são simples, com poucas interconexões e, consequentemente, os investimentos necessários para implementação são menores.

Palavras-chave: minimização do uso de água, refinaria de petróleo, regras heurísticas. 


\begin{abstract}
Oil refineries consume a large amount of water in their processes and because of that they are urged to develop strong programs to reduce their water consumption. The aim of this study is to apply an water optimization methodology in an oil refinery. Unlike traditional approaches that only search for treating the effluents in order to meet environmental legislation or to reuse in the plant, this methodology evaluates the processes that use water, questioning the causes of the wastewater generation. This approach involves the industrial data collection, analysis of production processes, identification of opportunities to optimize water use: rationalization, reuse and/or recycling of the effluent and, lastly, the water network optimization. Looking for a water network that is applicable in the industry, in this study it was also developed a specific optimization procedure based on heuristic rules representing the constraints of the actual processes. Through this procedure, freshwater consumption was found to be close to that of the theories found in the literature. The water networks generated are simple, with few interconnections and, consequently, the investments required to implement them are small.
\end{abstract}

Keywords: minimizing the use of water, oil refinery, heuristic rules. 


\section{LISTA DE ILUSTRAÇÕES}

Figura 1 - Reuso de água, regeneração com reuso e regeneração com reciclo. ........8 Figura 2 - Gráfico da variação da concentração do contaminante com a carga (adaptado de Hamaguchi, 2007) .................................................................10 Figura 3 - Curva composta de concentração (adaptado de Hamaguchi, 2007)........11 Figura 4 - Gráfico para a obtenção do ponto de mínimo consumo de água (adaptado de Hamaguchi, 2007) ........................................................................... 12 Figura 5 - Modelo de superestrutura geral para projeto de sistema de reuso de água (adaptado de Takama et al., 1980). ...............................................................15 Figura 6 - Utilização de água em processos industriais - tratamento fim de tubo (adaptado de Bagajewicz, 2000). .33

Figura 7 - Utilização de água em processos industriais - sistema com reuso parcial de água (adaptado de Bagajewicz, 2000) ....................................................33 Figura 8 - Utilização de água em processos industriais - sistema série-paralelo de utilização e tratamento de água de processos industriais (adaptado de Bagajewicz, 2000)

Figura 9 - Utilização de água em processos industriais - sistema série-paralelo de utilização e tratamento de água de processos industriais (adaptado de Bagajewicz,

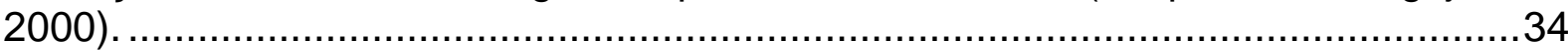

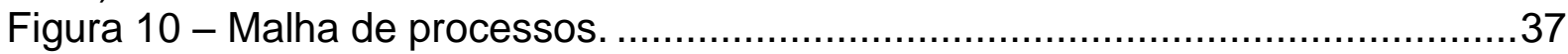

Figura 11 - Balanço de contaminante na entrada do processo j............................38

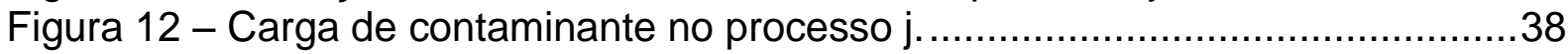

Figura 13 - Esquema de reuso de água sem regeneração. .....................................44

Figura 14 - Etapas do procedimento. ........................................................... 46

Figura 15 - Solução do sistema com único contaminante obtido por Bagajewicz (2000) - (vazões em t/h) ....................................................................50

Figura 16 - Solução para o problema com único contaminante - (vazões em $\mathrm{t} / \mathrm{h}$ )...54 Figura 17 - Solução para o problema com único contaminante após a verificação

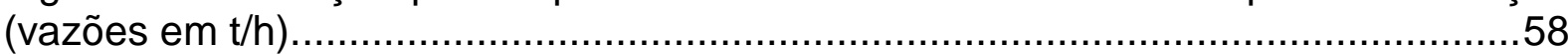
Figura 18 - Solução para o problema com múltiplos contaminantes - (vazões em

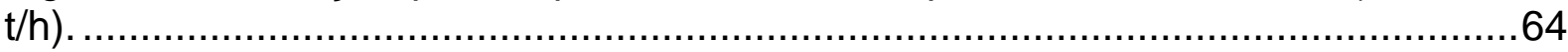
Figura 19 - Solução do sistema com múltiplos contaminantes obtido por Ulson de

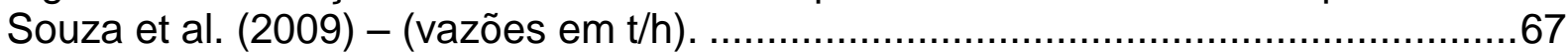
Figura 20 - Solução do sistema com múltiplos contaminantes obtido por Koppol et al. (2003) - (vazões em t/h)..................................................................67

Figura 21 - Diagrama de fontes, tratamentos, usos e tratamentos finais. ...............68

Figura 22 - Distribuição do consumo de água na refinaria estudada. ......................69

Figura 23 - Diagrama simplificado da distribuição das fontes de água na refinaria

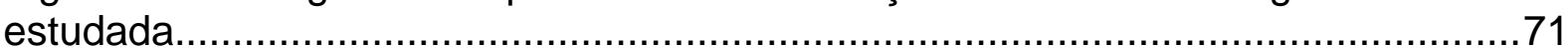

Figura 24 - Fluxograma simplificado da estação de tratamento de água e da

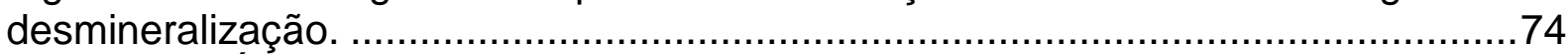

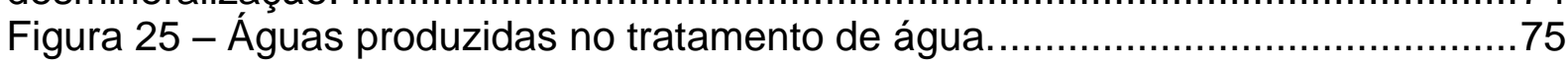

Figura 26 - Esquema simplificado de um sistema semiaberto de resfriamento. ........77

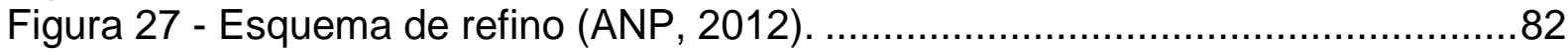


Figura 28 - Sistema de dessalgação em paralelo............................................... 83

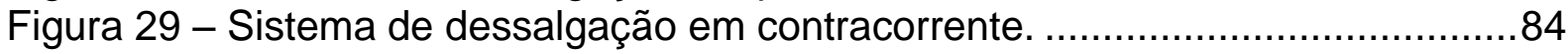

Figura 30 - Fluxograma simplificado da destilação atmosférica. .............................86

Figura 31 - Fluxograma simplificado da destilação a vácuo. ..................................8

Figura 32 - Fluxograma simplificado do craqueamento catalítico ............................90

Figura 33 - Fluxograma simplificado do coqueamento retardado.........................92

Figura 34 - Fluxograma simplificado do hidrotratamento......................................95

Figura 35 - Fluxograma simplificado do tratamento de águas ácidas......................98

Figura 36 - Distribuição da água ácida da refinaria. ............................................99

Figura 37 - Distribuição da água ácida retificada.............................................101

Figura 38 - Destino final da água captada....................................................101

Figura 39 - Diagrama simplificado do sistema de águas.....................................104

Figura 40 - Configurações dos trocadores de calor - (a) sistema atual com resfriamento com água; (b) sistema proposto com sistema híbrido ar-água...........107

Figura 41 - Sistema de torre de resfriamento .................................................108

Figura 42 - Economia de água de reposição em função do ciclo de concentração.

Figura 43 - Configurações das colunas de retificação - (a) sistema atual com injeção de vapor vivo; (b) sistema proposto com uso de refervedor.

Figura 44 - Operação das dessalgadoras em contracorrente..............................116

Figura 45 - Operação das dessalgadoras em contracorrente com maior grau de reciclagem (adaptado de Bresciani, 2009) ..................................................117

Figura 46 - Rede de água atual da unidade de hidrotratamento. ........................122

Figura 47 - Rede de água otimizada da unidade de hidrotratamento....................123

Figura 48 - Rede de água otimizada final da unidade de hidrotratamento. .............123

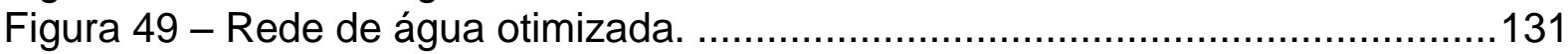

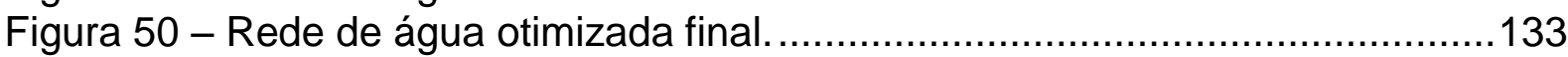

Figura 51 - Fluxograma para utilização de dados históricos. ..............................147

Figura 52 - Histograma para dados com distribuição normal (Bagajewicz, 2009). . 150

Figura 53 - Histograma para dados com pequena variância e outliers (Bagajewicz, 2009) 


\section{LISTA DE TABELAS}

Tabela 1 - Dados dos processos para o sistema com único contaminante..............49

Tabela 2 - Processos ordenados em ordem decrescente de consumo de água. .....50

Tabela 3 - Determinação dos possíveis pares i,j............................................51

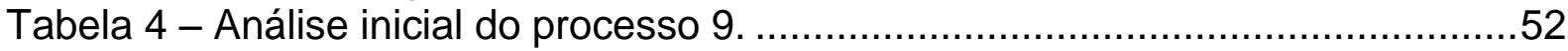

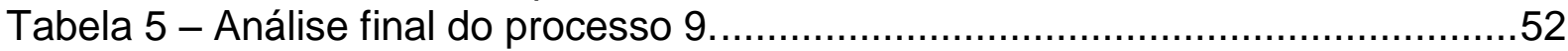

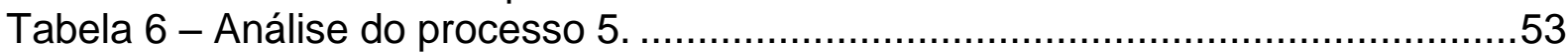

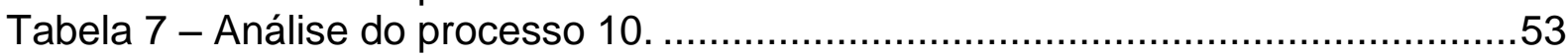

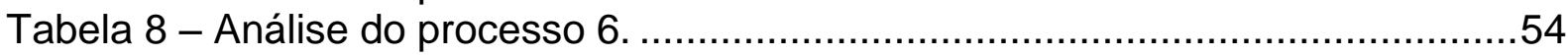

Tabela 9 - Dados do processo para a solução para o sistema com único

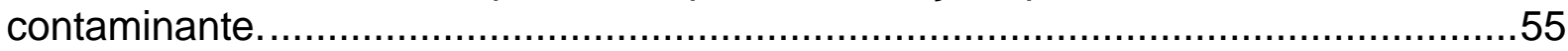

Tabela 10 - Verificação da posição do processo para o sistema com único

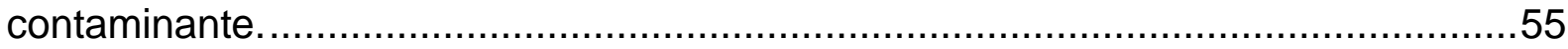

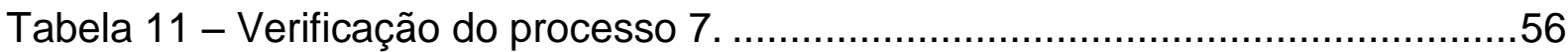

Tabela 12 - Verificação do processo 10 .......................................................5

Tabela 13 - Comparação das soluções para o problema com único contaminante. 58

Tabela 14 - Dados do sistema com múltiplos contaminantes................................60

Tabela 15 - Base de água fresca para cada contaminante em todos os processos. 61 Tabela 16 - Dados dos processos para o sistema com único contaminante considerando o contaminante chave..................................................................61

Tabela 17 - Processos ordenados em ordem decrescente de consumo de água. ...62

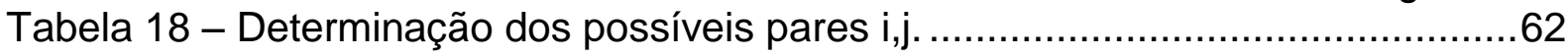

Tabela 19 - Análise do processo 6 - dessalgadora............................................63

Tabela 20 - Análise do processo 4 - adoçamento (Merox I). ..................................63

Tabela 21 - Dados do processo para a solução para o sistema com múltiplos

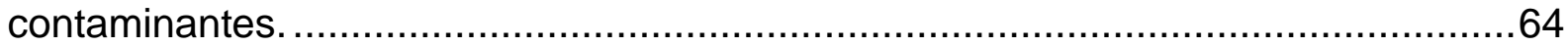

Tabela 22 - Verificação da posição do processo para o sistema com múltiplos

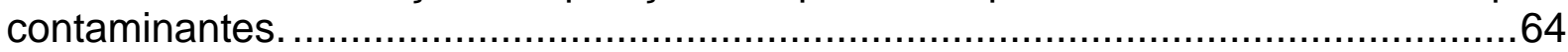

Tabela 23 - Verificação do processo 4 - adoçamento (Merox I) . ............................65

Tabela 24 - Verificação do processo 6 - dessalgadora...........................................66

Tabela 25 - Comparação das soluções para o problema com múltiplo

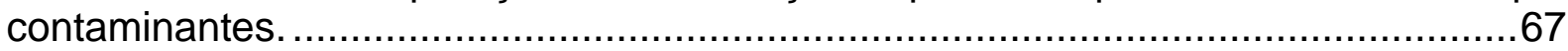

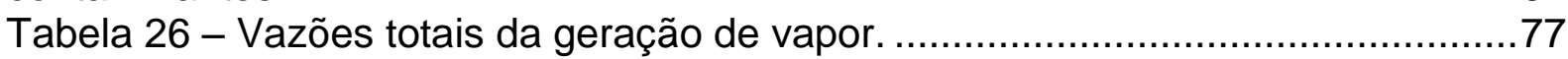

Tabela 27 - Ciclos de concentração das torres de resfriamento ...............................80

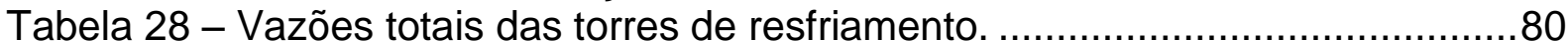

Tabela 29 - Consumo de água em cada sistema de dessalgação. ...........................84

Tabela 30 - Consumo de água no sistema de dessalgação...................................84

Tabela 31 - Vazões totais de consumo de água na destilação atmosférica. .............87

Tabela 32 - Faixa de contaminantes na água ácida gerada na destilação

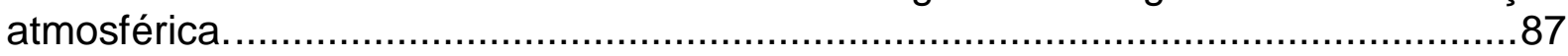

Tabela 33 - Vazões totais de consumo de água na destilação a vácuo. ...................89

Tabela 34 - Faixa de contaminantes na água ácida gerada na destilação a vácuo. 89

Tabela 35 - Vazões totais de consumo de água no craqueamento catalítico

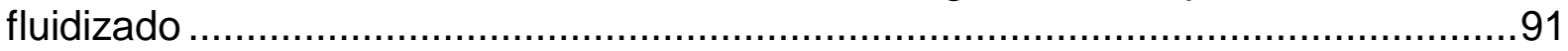

Tabela 36 - Faixa de contaminantes na água ácida gerada no craqueamento. .......91

Tabela 37 - Vazões totais de consumo de água no coqueamento...........................93 
Tabela 38 - Contaminantes na água ácida gerada no coqueamento. ......................94

Tabela 39 - Vazões totais de consumo de água no hidrotratamento.......................96

Tabela 40 - Faixa de contaminantes na água ácida gerada no hidrotratamento. .....97

Tabela 41 - Consumo de vapor para retificação da água ácida. ...........................100

Tabela 42 - Desempenho das unidades de tratamento de água ácida. .................100

Tabela 43 - Padrões para Lançamento de Efluentes - (CONAMA, 2005)..............103

Tabela 44 - Economia de água com o aumento do ciclo de concentração. ............111

Tabela 45 - Resumo das propostas de racionalização do uso de água ..................118

Tabela 46 - Procedência dos Contaminantes....................................................120

Tabela 47 - Dados do processo de hidrotratamento (referem-se ao $\mathrm{NH}_{3}$ ).............122

Tabela 48 - Processos ordenados em ordem decrescente de consumo de água...124

Tabela 49 - Determinação dos possíveis pares i,j...........................................124

Tabela 50 - Análise do processo lavagem de sais. ..........................................125

Tabela 51 - Dados da rede global (referem-se ao $\mathrm{NH}_{3}$ ) ...................................127

Tabela 52 - Processos ordenados em ordem decrescente de consumo de água. .127

Tabela 53 - Determinação dos possíveis pares i,j .............................................128

Tabela 54 - Análise do processo Dessalgação 1 ……......................................129

Tabela 55 - Análise do processo Conversão B...............................................129

Tabela 56 - Análise do processo Dessalgação 3 ………..................................130

Tabela 57 - Análise inicial do processo Dessalgação 2.......................................130

Tabela 58 - Análise final do processo Dessalgação 2 .........................................131

Tabela 59 - Faixa de contaminantes restritivos para a lavagem de coque (Nogueira,

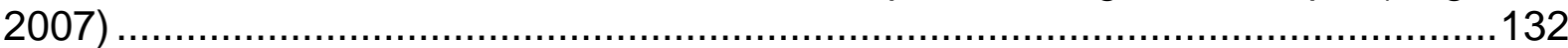




\section{LISTA DE ABREVIATURAS E SIGLAS}

\begin{tabular}{|c|c|}
\hline ANA & Agência Nacional das Águas \\
\hline ANP & Agência Nacional do Petróleo \\
\hline API & "American Petroleum Institute" \\
\hline CONAMA & Conselho Nacional do Meio Ambiente \\
\hline $\mathrm{CPI}$ & "Corrugated Plate Interceptor" \\
\hline DEA & Tratamento com Dietanolamina \\
\hline DFA & Diagrama de Fontes de Água \\
\hline ETA & Estação de Tratamento de Água \\
\hline ETDI & Estação de Tratamento de Despejos Industriais \\
\hline FCC & Craqueamento Catalítico em Leito Fluidizado \\
\hline GLP & Gás Liquefeito de Petróleo \\
\hline ICA & Indicador de Consumo de Água \\
\hline LP & Programação Linear (“Linear Programming”) \\
\hline LSCP/USP & $\begin{array}{l}\text { Laboratório de Simulação e Controle de Processos da Universidade } \\
\text { de São Paulo }\end{array}$ \\
\hline MILP & $\begin{array}{l}\text { Programação Linear Mista-Inteira (“Mixed-Integer Linear } \\
\text { Programming”) }\end{array}$ \\
\hline MINLP & $\begin{array}{l}\text { Programação Não-Linear Mista-Inteira ("Mixed-Integer Non-Linear } \\
\text { Programming") }\end{array}$ \\
\hline NLP & Programação Não Linear ("Non-Linear Programming”) \\
\hline PIMS & $\begin{array}{l}\text { Sistema de Gestão na Informação de Processos ("Process } \\
\text { Information Management System") }\end{array}$ \\
\hline REDUC & Refinaria de Duque de Caxias \\
\hline REPLAN & Refinaria de Paulínia \\
\hline REVAP & Refinaria Henrique Lage \\
\hline SABESP & Companhia de Saneamento Básico do Estado de São Paulo \\
\hline UTAA & Unidade de Tratamento de Águas Ácidas \\
\hline
\end{tabular}




\section{LISTA DE SÍMBOLOS}

\begin{tabular}{|c|c|c|}
\hline Símbolo & Unidade & Descrição \\
\hline $\mathrm{C}_{\mathrm{i}, \text { out }}$ & \multirow{9}{*}{ ppm } & Concentração do contaminante na água de saída do processo i \\
\hline $\mathrm{C}_{\mathrm{i}, \mathrm{s}, \text { out }}$ & & Concentração do contaminante $s$ na água de saída do processo i \\
\hline $\mathrm{C}_{\mathrm{j}, \mathrm{in}}$ & & Concentração do contaminante na água de entrada do processo j \\
\hline $\mathrm{C}_{\mathrm{j}, \mathrm{in}} \max$ & & Concentração máxima do contaminante na entrada no processo j \\
\hline $\mathrm{C}_{\mathrm{j}, \text { out }} \max$ & & $\begin{array}{l}\text { Concentração máxima do contaminante na saída do contaminante } \\
\qquad \text { do processo j }\end{array}$ \\
\hline $\mathrm{C}_{\mathrm{j}, \mathrm{s}, \mathrm{in}}$ & & Concentração do contaminante $s$ na água de entrada do processo j \\
\hline $\mathrm{C}_{\mathrm{j}, \mathrm{s}, \mathrm{in}}{ }^{\max }$ & & Concentração máxima do contaminante s na entrada no processo j \\
\hline $\mathrm{C}_{\mathrm{j}, \mathrm{s}, \text { out }} \max$ & & $\begin{array}{l}\text { Concentração máxima do contaminante s na saída do } \\
\text { contaminante do processo j }\end{array}$ \\
\hline $\mathrm{C}_{\mathrm{w}}$ & & Concentração do contaminante na água fresca \\
\hline$F_{i, j}$ & \multirow{6}{*}{$\mathrm{t} / \mathrm{h}$} & Vazão de água do processo i para j \\
\hline$F_{j, h}$ & & Vazão de água efluente do processo j que alimenta o processo h \\
\hline $\mathrm{F}_{\mathrm{j}, \mathrm{in}}$ & & Vazão de água total que alimenta o processo j \\
\hline $\mathrm{F}_{\mathrm{j}, \text { out }}$ & & Vazão de água efluente do processo j \\
\hline$F_{j, w}$ & & Vazão de água fresca que alimenta o processo j \\
\hline $\mathrm{F}_{\mathrm{j}, \mathrm{ww}}$ & & $\begin{array}{l}\text { Vazão de água efluente do processo j que segue para o tratamento } \\
\qquad \text { de efluentes }\end{array}$ \\
\hline $\mathrm{L}_{\mathrm{j}}$ & g/h & Carga de contaminante transferida para a água no processo j \\
\hline $\mathrm{h}$ & & Processo que recebe água do processo j \\
\hline $\mathrm{i}$ & & Processo que envia água para o processo j \\
\hline j & & Processo que recebe água de reuso \\
\hline S & & Contaminante s \\
\hline $\mathrm{CC}$ & & Ciclo de concentração \\
\hline $\mathrm{C}_{\text {purga }}$ & \multirow{4}{*}{ ppm } & Concentração da purga da torre de resfriamento \\
\hline Creposição & & Concentração da água de reposição da torre de resfriamento \\
\hline $\mathrm{C}_{\text {arraste }}$ & & Concentração da água de arraste da torre de resfriamento \\
\hline $\mathrm{C}_{\text {evaporação }}$ & & Concentração da água evaporada da torre de resfriamento \\
\hline
\end{tabular}




\begin{tabular}{|c|c|c|}
\hline$Q_{\text {purga }}$ & & Vazão da purga da torre de resfriamento \\
\hline$Q_{\text {reposição }}$ & $\mathrm{m}^{3 / \mathrm{h}}$ & Vazão da água de reposição da torre de resfriamento \\
\hline Qarraste & 17. & Vazão da água de arraste da torre de resfriamento \\
\hline$Q_{\text {evaporação }}$ & & Vazão da água evaporada da torre de resfriamento \\
\hline
\end{tabular}




\section{SUMÁRIO}

1 INTRODUÇÃO

1.1 USO DE ÁGUA EM REFINARIAS DE PETRÓLEO ......................................

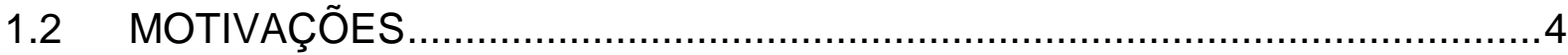

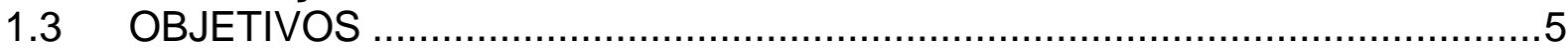

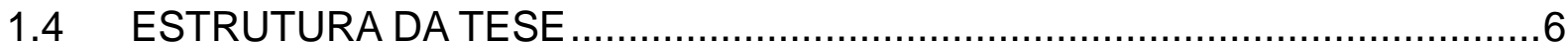

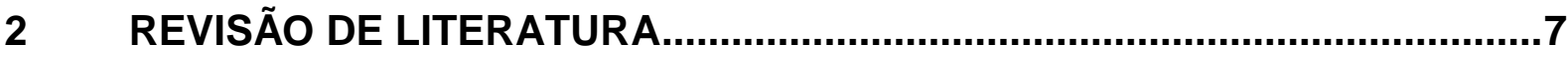

2.1 PLANEJAMENTO DA ALOCAÇÃO DE ÁGUA .........................................

2.2 MINIMIZAÇÃO DO CONSUMO DE ÁGUA EM REFINARIAS DE PETRÓLEO 19

2.3 CONSIDERAÇÕES

3 METODOLOGIA DE OTIMIZAÇÃO EM PROBLEMAS DE ALOCAÇÃO ÓTIMA E REUSO DE ÁGUA EM REFINARIA DE PETRÓLEO ...............................26

3.1 MAPEAMENTO DA REDE DE ÁGUA .................................................27

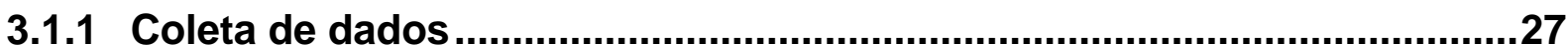

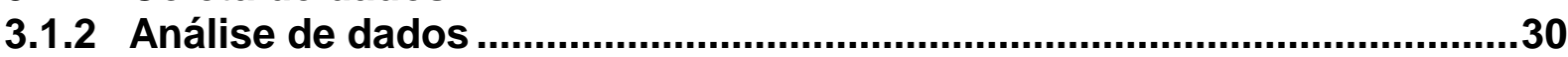

3.2 RACIONALIZAÇÃO DO USO DE ÁGUA ATRAVÉS DE ANÁLISE DE

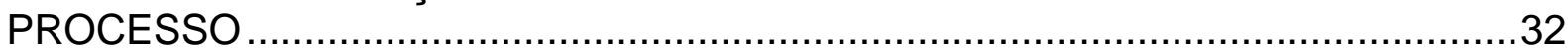

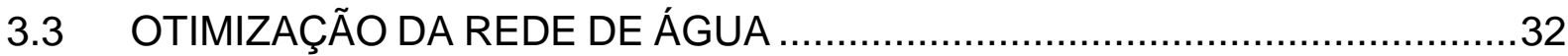

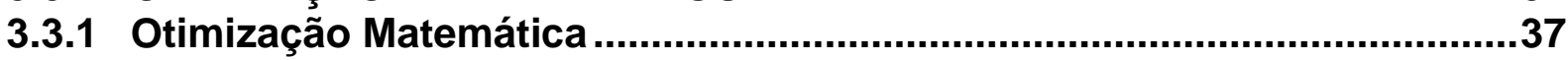

4 PROCEDIMENTO DESENVOLVIDO PARA A OTIMIZAÇÃO DE REDE DE ÁGUA CONSIDERANDO REGRAS HEURÍSTICAS 43

4.1 HEURÍSTICAS CONSIDERADAS PARA A OTIMIZAÇÃO DA REDE DE ÁGUA 43

4.2 NOVO PROCEDIMENTO PARA OTIMIZAÇÃO DE REDE DE ÁGUA .............45

4.3 APLICAÇÃO DO PROCEDIMENTO .......................................................49

4.3.1 Sistema com único contaminante...........................................................49

4.3.2 Sistema com múltiplos contaminantes ….........................................59

5 REDE DE USOS DE ÁGUA DA REFINARIA ESTUDADA.........................68

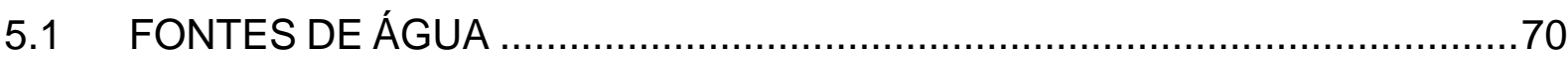

5.2 ESTAÇÃO DE TRATAMENTO DE ÁGUA (ETA) E DESMINERALIZAÇÃO ....71

5.3 GERAÇÃO DE VAPOR …….............................................................

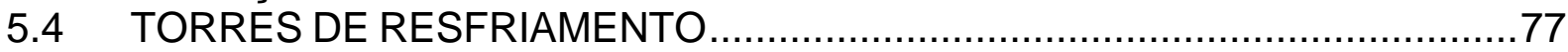

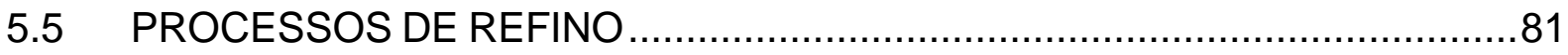

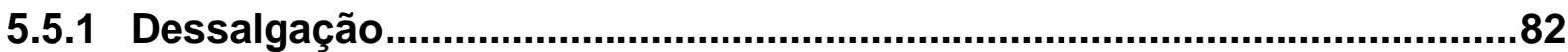

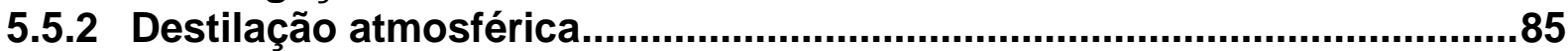

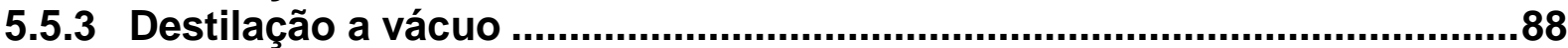

5.5.4 Craqueamento catalítico fluidizado .....................................................90

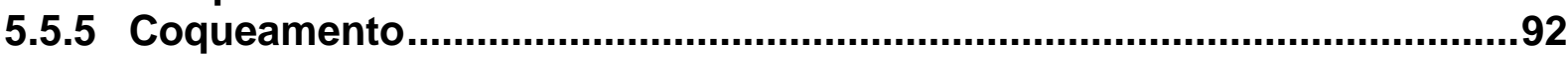




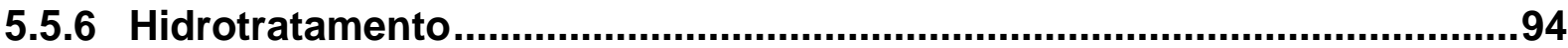

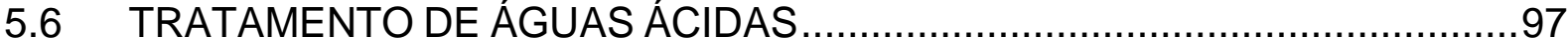

5.7 TRATAMENTO DE DESPEJOS INDUSTRIAIS (ETDI) .............................101

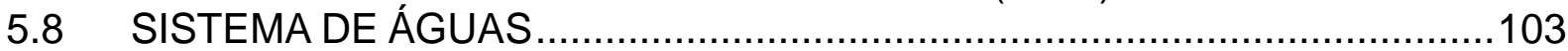

6 RACIONALIZAÇÃO DO USO DE ÁGUA ATRAVÉS DE ANÁLISE DE

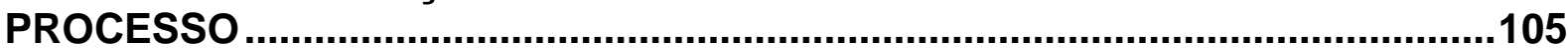

6.1 TORRES DE RESFRIAMENTO..............................................................106

6.1.1 Uso de trocadores de calor resfriados a ar ..........................................106

6.1.2 Aumento do ciclo de concentração .....................................................108

6.2 USO E GERAÇÃO DE VAPOR .....................................................112

6.2.1 Aumento da recuperação do condensado ...........................................112

6.2.2 Aproveitamento da purga das caldeiras..............................................113

6.2.3 Uso de refervedor nas colunas de retificação .......................................114

6.3 OPERACCÃO DAS DESSALGADORAS .................................................115

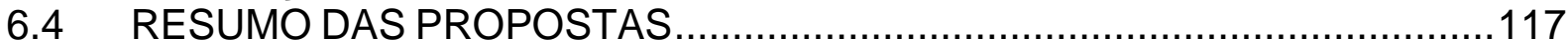

7 OTIMIZAÇÃO DA REDE DE ÁGUA

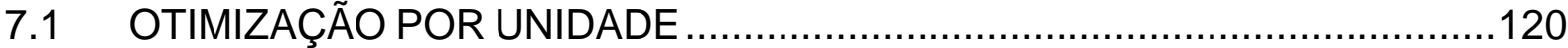

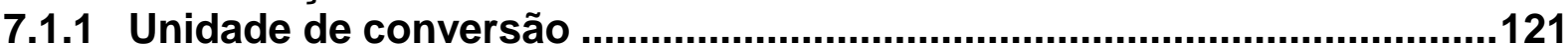

7.1.2 Unidade de hidrotratamento .............................................................121

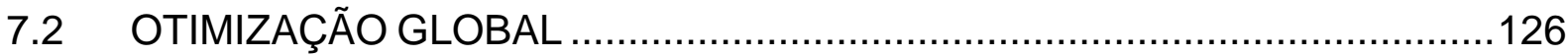

8 CONCLUSÕES E RECOMENDAÇÕES …..........................................134

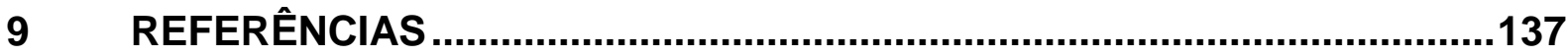

ANEXO 1

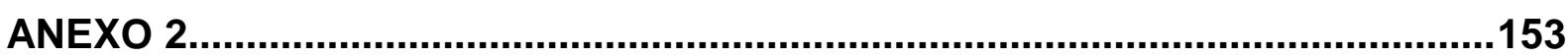

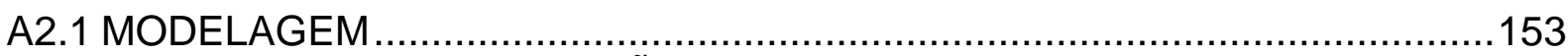

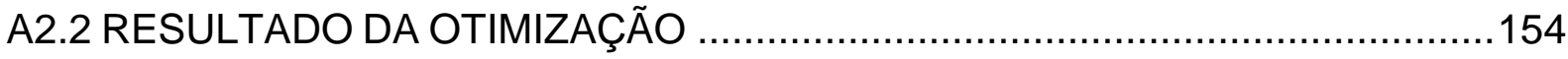




\section{INTRODUÇÃO}

A água, essencial ao surgimento e à manutenção da vida em nosso planeta, é indispensável para o desenvolvimento das diversas atividades realizadas pelo ser humano, e apresenta, por essa razão, valores econômicos, sociais e culturais. Além de dar suporte à vida, a água pode ser utilizada para o transporte de pessoas, mercadorias, geração de energia, produção e processamento de alimentos, processos industriais diversos, recreação e paisagismo, além de assimilação de poluentes, sendo essa, talvez, uma das aplicações menos nobres deste recurso tão essencial (Hespanhol e Mierzwa, 2005).

Cerca de $70 \%$ da superfície da Terra é coberta pela água, contudo apenas uma pequena parcela pode ser aproveitada na maior parte das atividades humanas sem que sejam necessários grandes investimentos para adequar suas características físicas, químicas e/ou biológicas. A disponibilidade de água, além de variar com o espaço, pode variar no tempo em razão das condições climáticas de cada região e período do ano, e pode ser afetada pelas atividades humanas - seja pela demanda excessiva ou por problemas de poluição resultantes do lançamento de esgotos domésticos e efluentes industriais.

Entre as diversas atividades desenvolvidas pelo ser humano, as indústrias são grandes consumidoras de água, sendo responsável por $7 \%$ do consumo de água no Brasil (ANA, 2012). Consequentemente, as indústrias são também grandes geradoras de efluentes líquidos, os quais podem apresentar em sua composição os mais variados tipos de substâncias, muitas das quais são extremamente tóxicas e podem produzir efeitos adversos em seres vivos, caso as mesmas atinjam qualquer recurso hídrico.

Para regulamentar o uso de água no Brasil, em 1997, foi instituída a Política Nacional de Recursos Hídricos pela Lei no 9.433, conhecida como Lei das Águas. Esta lei organiza o setor de planejamento da gestão de recursos hídricos em âmbito 
nacional, introduzindo vários instrumentos de política para o setor, dentre os instrumentos destacam-se dois (ANA, 2012):

- $\quad$ Outorga de Direito de Uso de Recursos Hídricos: A outorga de direito de uso dos recursos hídricos é o mecanismo pelo qual o usuário recebe uma autorização, ou uma concessão, para fazer uso da água. A outorga está condicionada às prioridades de uso definidas nos Planos de Recursos Hídricos e visa assegurar o controle quantitativo e qualitativo dos usos da água e o efetivo exercício dos direitos de acesso à água.

- Cobrança pelo Uso de Recursos Hídricos: A cobrança pelo uso de água tem como objetivos reconhecer o valor econômico da água e dar ao usuário uma indicação de seu real valor e incentivar a racionalização do uso de água.

Segundo Barbosa (2007) a necessidade da autorização da captação de água pela outorga pode ser mais eficaz que a cobrança pelo uso dos recursos hídricos, visto que uma vez concedida a outorga para uma vazão limitada no tempo com a demanda de água crescente, os usuários acabarão por ser pressionados a racionalizar o uso da água.

Dessa forma, atualmente, um dos grandes desafios das indústrias químicas é a redução do uso de água. Faz-se, então, necessária a adoção de estratégias como a racionalização do uso e reuso de água como alternativa para enfrentar os problemas de escassez de água e poluição dos recursos hídricos, tornando-se elementos essenciais de garantia à continuidade das atividades humanas.

\subsection{USO DE ÁGUA EM REFINARIAS DE PETRÓLEO}

Para que o potencial energético do petróleo seja aproveitado ao máximo, ele deve ser submetido a uma série de processos, a fim de se desdobrar nos seus diversos derivados com o maior valor agregado possível. 
O processamento de petróleo requer grandes volumes de água, ainda que bastante variáveis conforme a refinaria (sua configuração, complexidade, capacidade e localização).

De forma geral são encontrados os seguintes usos de água em ordem decrescente da quantidade relativa consumida na maioria das refinarias:

- $\quad$ Água de resfriamento: Usada para remoção de calor de produtos, correntes internas de processo e equipamentos. Representa, em média, metade do consumo total de água fresca.

- Água para geração de vapor: O segundo maior consumidor de água em refinarias é a alimentação das caldeiras para geração de vapor, utilizado, por exemplo, em processos de retificação com vapor. Requerem água de melhor qualidade, demandando tratamentos mais rigorosos.

- Água para processo: A água denominada "água para processo" é aquela utilizada diretamente nos processos industriais, no refino de petróleo especificamente, é qualquer corrente de água que tenha entrado em contato com o óleo. A qualidade da água utilizada como água de processo depende do uso especifico desta água.

- Água para combate a incêndio: Essa água geralmente não passa por tratamento e deveria ser usada esporadicamente apenas para prevenção e combate a emergência. No entanto, esta água muitas vezes é utilizada de forma errônea, o que pode elevar o seu consumo. Segundo Amorim (2005) isso decorre do fato da rede que faz sua distribuição estar presente em praticamente todos os pontos da refinaria, esta facilidade faz com que a água seja utilizada também para outros usos, por exemplo, realização de testes hidrostáticos de tanques e equipamentos, lavagem de equipamentos para liberação para manutenção, deslocamento de óleo derramado em tubovias, etc.

- $\quad$ Água potável para uso humano: Usada nos banheiros, cozinhas, copas, etc. Geralmente é adquirida de concessionária pública.

- $\quad$ Água de serviço: Dá-se o nome de água de serviço para a água utilizada em demandas diversas daquela prevista no projeto, tais como serviços de manutenção, 
lavagem de pisos e equipamentos, resfriamento externos em permutadores, deslocamentos e diluição de líquidos contaminados, testes hidrostáticos, rega de jardins etc.

Segundo Diepolder (1992), a referência mundial de consumo de água em refinarias está entre 0,7 e 1,2 $\mathrm{m}^{3}$ água $/ \mathrm{m}^{3}$ de petróleo processado. Para uma refinaria que opera com $10 \mathrm{mil} \mathrm{m}$ /dia de petróleo, o seu consumo de água é da ordem de 10 milhões de litros por dia. Conforme o índice de consumo de água por habitante estipulado pela SABESP (2012) de 150 litros de água/habitante, esta quantidade é suficiente para suprir as necessidades humanas de uma cidade de 60 mil habitantes.

É um volume significativo de água e o seu gerenciamento ganha importância com o fato de que as refinarias de petróleo geralmente encontram-se localizadas próximas aos centros consumidores de seus produtos, juntamente com outras indústrias que utilizam seus derivados como matéria-prima, possibilitando o desenvolvimento econômico e social da região, porém causando maior uso dos recursos hídricos locais e, em algumas situações, competindo com o consumo urbano/humano da comunidade local.

Além disso, as empresas constantemente investem em grandes projetos de curto e médio prazo de novas unidades e/ou na ampliação de algumas unidades já existentes que pode requerer um volume maior de água fresca.

Este cenário evidencia a importância das refinarias desenvolverem um forte programa de otimização do uso/reuso de água.

\subsection{MOTIVAÇÕES}

Os pilares do desenvolvimento sustentável são as motivações para a minimização do consumo de água e consequente geração de efluentes em refinarias de petróleo: 
- Econômico

Os custos com a água tendem a aumentar devido à cobrança pelo seu uso, aos tratamentos internos para sua utilização nos processos e aos tratamentos finais dos efluentes para reduzir o impacto nos corpos receptores. Além disso, a escassez ou limitação do consumo de água pode ocasionar risco de continuidade ou ampliação de processo.

\section{- Social}

O consumo de água e a geração de efluentes provoca impacto social nas comunidades vizinhas. Podem-se citar os danos à saúde humana, podendo o corpo receptor tornar-se veículo de doenças, desvalorização de propriedades do entorno, degradação da paisagem, prejuízos a outros usos da água, tais como: irrigação, pesca, recreação, etc.

- $\quad$ Ambiental

O consumo de água pela refinaria tem diversas consequências para o meio ambiente, como, por exemplo, o uso de recurso natural; prejuízo da qualidade dos corpos receptores e consequentemente, danos aos organismos aquáticos.

\subsection{OBJETIVOS}

Os objetivos do presente estudo são:

- Consolidação da metodologia geral de otimização em problemas de alocação ótima e reuso de água desenvolvida pelo Laboratório de Simulação e Controle de 
Processos (LSCP) do Departamento de Engenharia Química da Escola Politécnica da USP, apresentado por Bresciani et al. (2006a), através da aplicação em uma refinaria de petróleo.

- Desenvolvimento de procedimento específico de otimização do uso de água, baseado em regras heurísticas que representam restrições reais dos processos e com isso simplificam a configuração da solução.

\subsection{ESTRUTURA DA TESE}

No Capítulo 2 é apresentada a revisão de literatura sobre metodologias de otimização de redes de água e sobre trabalhos de redução do uso de água realizados em refinarias de petróleo.

No Capítulo 3 a metodologia de otimização do uso e reuso de água aplicada nesse trabalho é descrita detalhadamente.

No Capítulo 4 é apresentado o procedimento desenvolvido para otimização de rede de água baseado em regras heurísticas, em seguida o procedimento é aplicado em dois casos da literatura.

No Capítulo 5 são identificados os usos de água na refinaria estudada.

No Capítulo 6 são identificadas e estudadas ações imediatas a serem implementadas e oportunidades de racionalização, reuso/reciclagem e regeneração.

No Capítulo 7 é apresentada a otimização do uso de água da refinaria estudada. São empregados a otimização matemática e o procedimento algorítmico proposto no Capítulo 4.

No Capítulo 8 são apresentadas as principais conclusões e recomendações do trabalho. 


\section{REVISÃO DE LITERATURA}

\subsection{PLANEJAMENTO DA ALOCAÇÃo DE ÁGUA}

Técnicas de redução de água e efluentes podem efetivamente reduzir a demanda de água fresca e consequentemente a geração de efluentes. Excluindo as mudanças nos processos, existem três possibilidades (ilustradas na Figura 1) para reduzir o consumo de água e geração de efluentes:

- Reuso de água: a água de saída de alguns processos pode ser utilizada diretamente como corrente de entrada em outras operações, desde que o nível de contaminantes seja aceitável. Isso pode requerer que esta corrente seja misturada com água residual de outra operação e/ou água fresca. O resultado é a redução de quantidade de água fresca necessária e de efluentes gerados, enquanto a carga final de contaminante não é afetada.

- Regeneração com reuso: a água residual pode ser regenerada através de tratamento para remover os contaminantes, o que, caso contrário, poderia evitar o seu reuso, e então reutilizada em outras operações. Consequentemente, a carga de contaminante de água/água residual é reduzida. A água não pode ser utilizada no mesmo processo.

- Regeneração com reciclo: a água residual pode ser regenerada para remover os contaminantes acumulados e, em seguida, a água é reciclada. Neste caso, a água pode alimentar o processo em que foi utilizada anteriormente.

Considerando uma malha de processos consumidores de água, deseja-se determinar uma nova configuração dos processos a fim de reduzir o consumo total de água fresca, enquanto que cada processo recebe água de qualidade adequada. Este problema tem recebido o nome de Planejamento da Alocação de Água e Água 
Residual. O objetivo é reduzir o consumo de água e a geração de efluentes empregando reuso, regeneração com reuso e regeneração com reciclo.
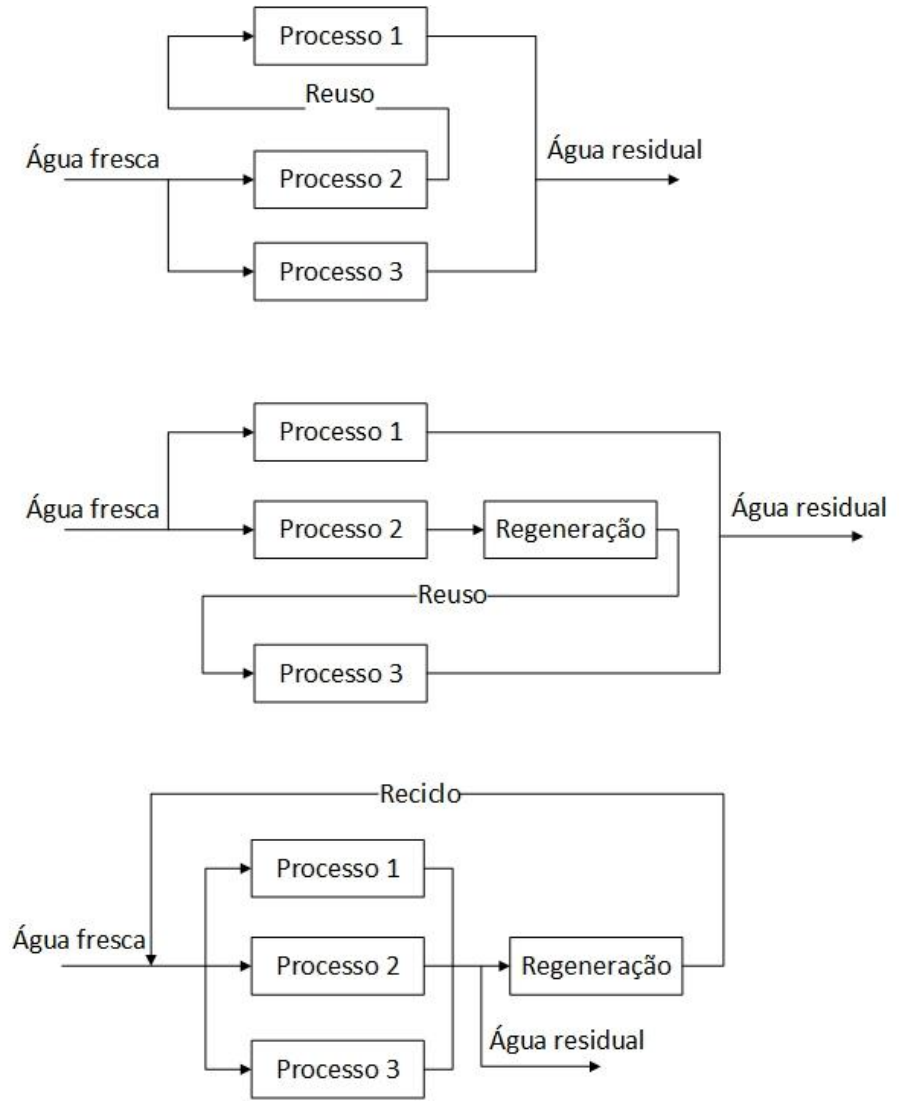

Figura 1 - Reuso de água, regeneração com reuso e regeneração com reciclo.

Este problema foi formulado pela primeira vez no artigo seminal de Takama et al. (1980). A rede de água foi modelada como uma superestrutura, uma malha de correntes que engloba todas as possibilidades de conexão entre os processos, através da utilização de misturadores e separadores de correntes. Os autores fizeram uma grande contribuição ao considerarem o problema de rede de água como uma combinação entre alocação de água e água residual entre os processos e a distribuição de efluentes para as unidades de tratamento. Em virtude dos algoritmos de otimização disponíveis na época, os autores tiveram uma série de dificuldades na resolução do problema não linear para superá-los, transformaram o modelo em uma série de problemas em que funções de penalidade substituiram as desiguldades que representam os limites de concentração dos contaminantes na 
entrada dos processos. Também adicionaram uma etapa de redução da estrutura do sistema removendo as conexões irrelevantes e não econômicas, evitando que o método Complex terminasse a busca prematuramente.

Cinco anos depois, Wang e Smith (1994a) abordaram o problema de minimização de água residual a partir dos conceitos de rede de troca de massa apresentados por El-Halwagi e Manousiouthakis (1989) para a otimização de redes de calor. Com isso, apresentaram as formulações teóricas fundamentais para a aplicação da análise pinch em problemas de água: o problema de minimização de água é considerado um problema de transferência de contaminantes de correntes de processo para correntes de água. Dhole et al. (1996) popularizaram esta metodologia chamando-a de "water pinch". Diferente da metodologia proposta por Takama et al. (1980) baseada em programação matemática, esta é uma abordagem com base conceitual e fundamentou a maioria dos procedimentos algorítmicos abordados na literatura para a otimização da rede de água.

\section{Abordagem conceitual baseada em análise pinch}

Análise pinch é uma técnica sistemática para avaliar as redes de água e reduzir custos de água para os processos. Utiliza um método gráfico para identificar e otimizar as melhores oportunidades de reuso e regeneração de água e tratamento de efluentes e fundamenta-se nas seguintes suposições: carga de poluente constante em cada processo e concentração máxima de entrada e saída em cada processo.

O método (Wang e Smith, 1994a) consiste na construção de uma curva composta de concentração que relaciona a variação da concentração do contaminante na água utilizada nos processos com a carga transferida. A partir desta curva é encontrado o ponto de mínimo consumo de água no sistema e então a rede de água é estabelecida. 
Para a construção da curva composta de concentração, primeiramente, é construído um gráfico da concentração de contaminantes em função da carga de contaminante acumulada para todos os processos em que a água é utilizada. Neste gráfico, a variação da concentração é absoluta, enquanto a da carga é relativa, ou seja, um processo é iniciado no ponto em que o anterior foi encerrado, de modo que as setas não se sobreponham com relação à carga de contaminante (Figura 2).

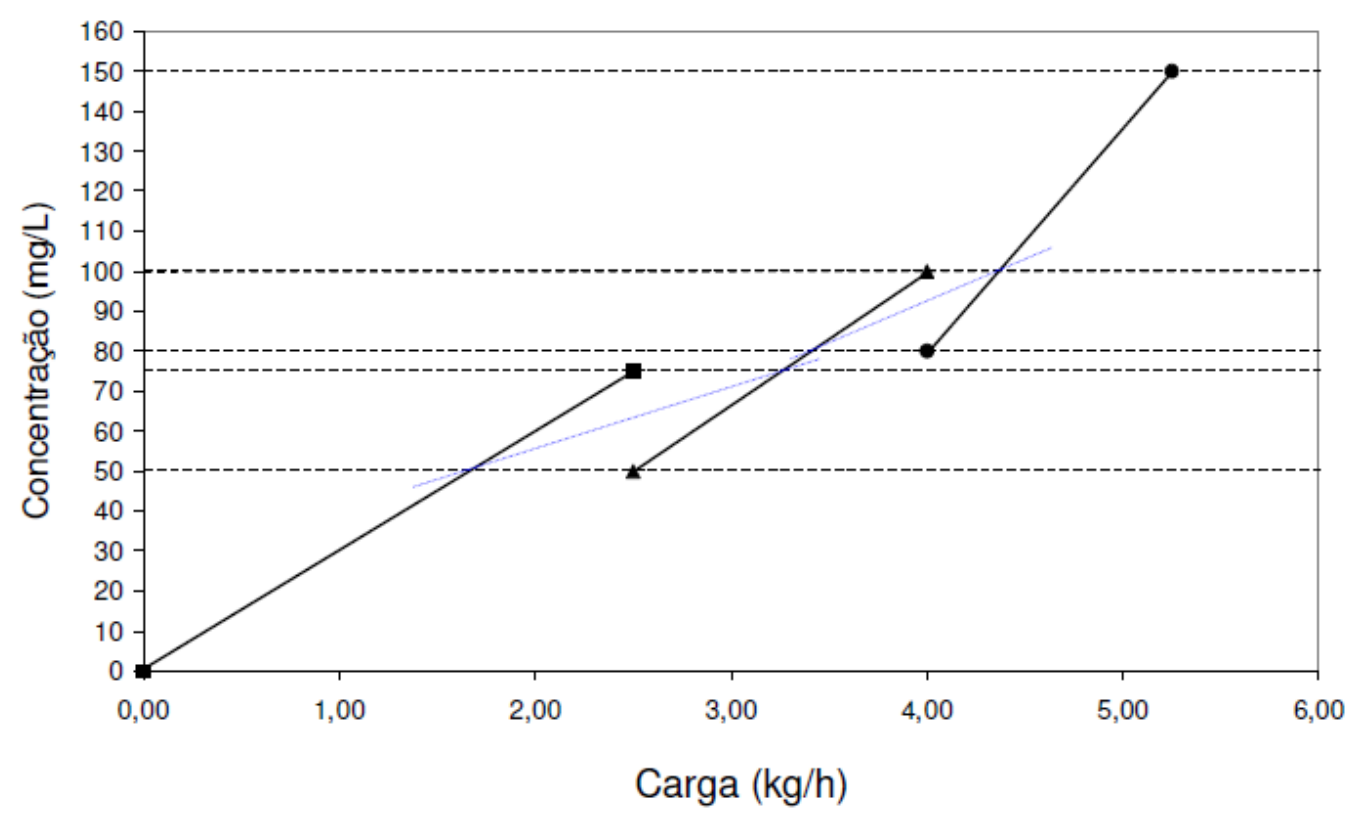

Figura 2 - Gráfico da variação da concentração do contaminante com a carga (adaptado de Hamaguchi, 2007).

Em seguida, o eixo em que estão representados os valores de concentração do contaminante é dividido em intervalos correspondentes às concentrações limite do contaminante na entrada e saída de cada processo. Para cada intervalo de concentração é determinada a carga de contaminante. Finalmente, a curva composta de concentração é construída, eliminando-se as curvas originais de variação da concentração do contaminante com a carga (Figura 3). 


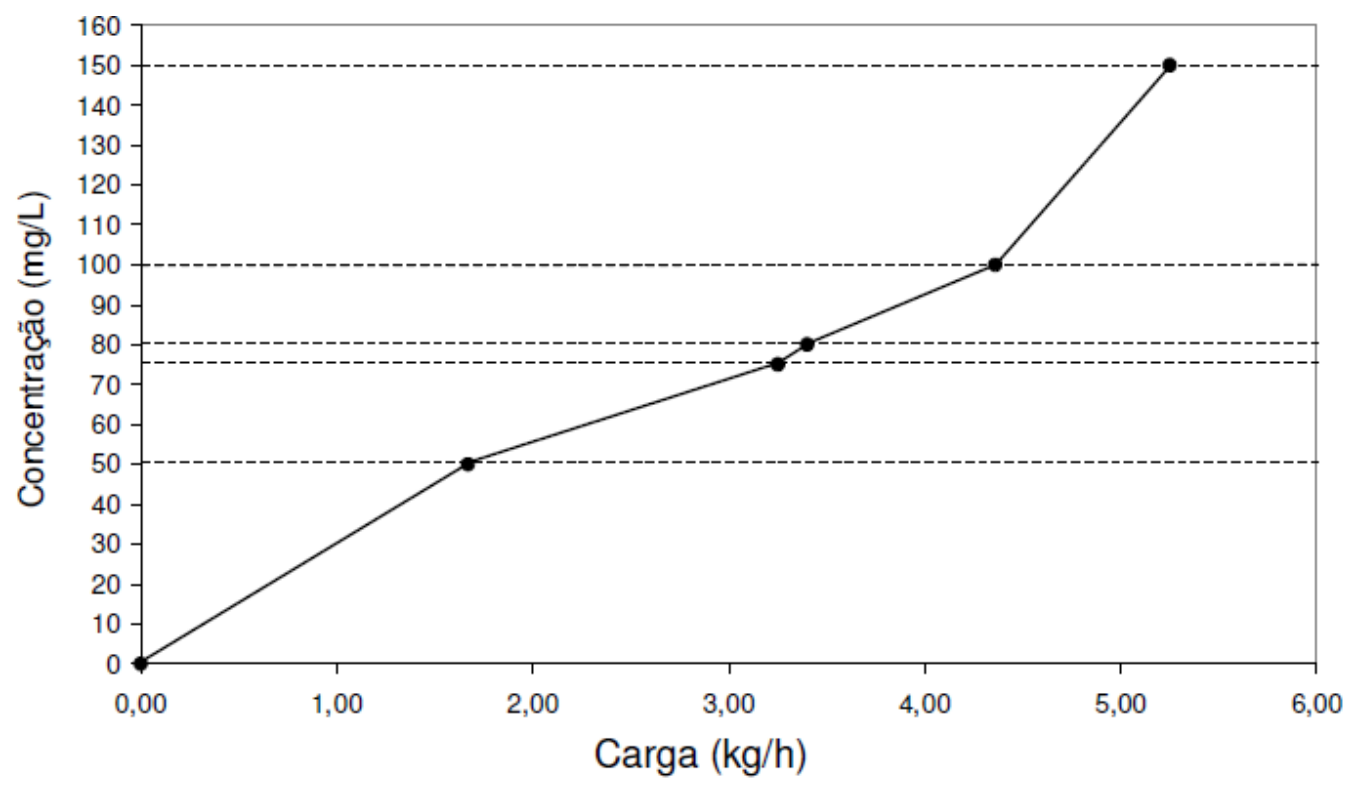

Figura 3 - Curva composta de concentração (adaptado de Hamaguchi, 2007).

Uma vez definida a curva composta de concentração, determina-se o ponto de mínimo consumo de água construindo uma curva que representa a variação da concentração do contaminante na água utilizada no sistema em função da carga de contaminante acumulada.

A curva relacionada à água de alimentação passa pela origem, ou seja, a concentração inicial do contaminante é zero e aumenta à medida que a água vai incorporando o contaminante. Quanto menor a vazão de água limpa utilizada no sistema, para a mesma carga de contaminante transferida, maior será a inclinação da curva de alimentação.

Desta forma, quanto mais próxima da curva composta de concentração estiver desta curva de água de alimentação, menor será a necessidade de água limpa, ressaltando-se que a curva de água de alimentação deve permanecer abaixo ou no mesmo nível da curva composta de concentração, para que o contaminante possa ser transferido.

Com base nesses conceitos, quando a curva de água de alimentação sofre uma rotação em relação à origem, aproximando-se da curva composta de concentração, o ponto de mínimo consumo de água será aquele em que a curva de alimentação 
tangencia a curva composta de concentração. Esta condição indica que não é necessário adicionar água limpa ao sistema acima do ponto de mínimo consumo de água. A leitura dos valores relacionados à carga de contaminante e à respectiva concentração proporciona a mínima vazão de água a ser alimentada. A Figura 4 ilustra este procedimento.

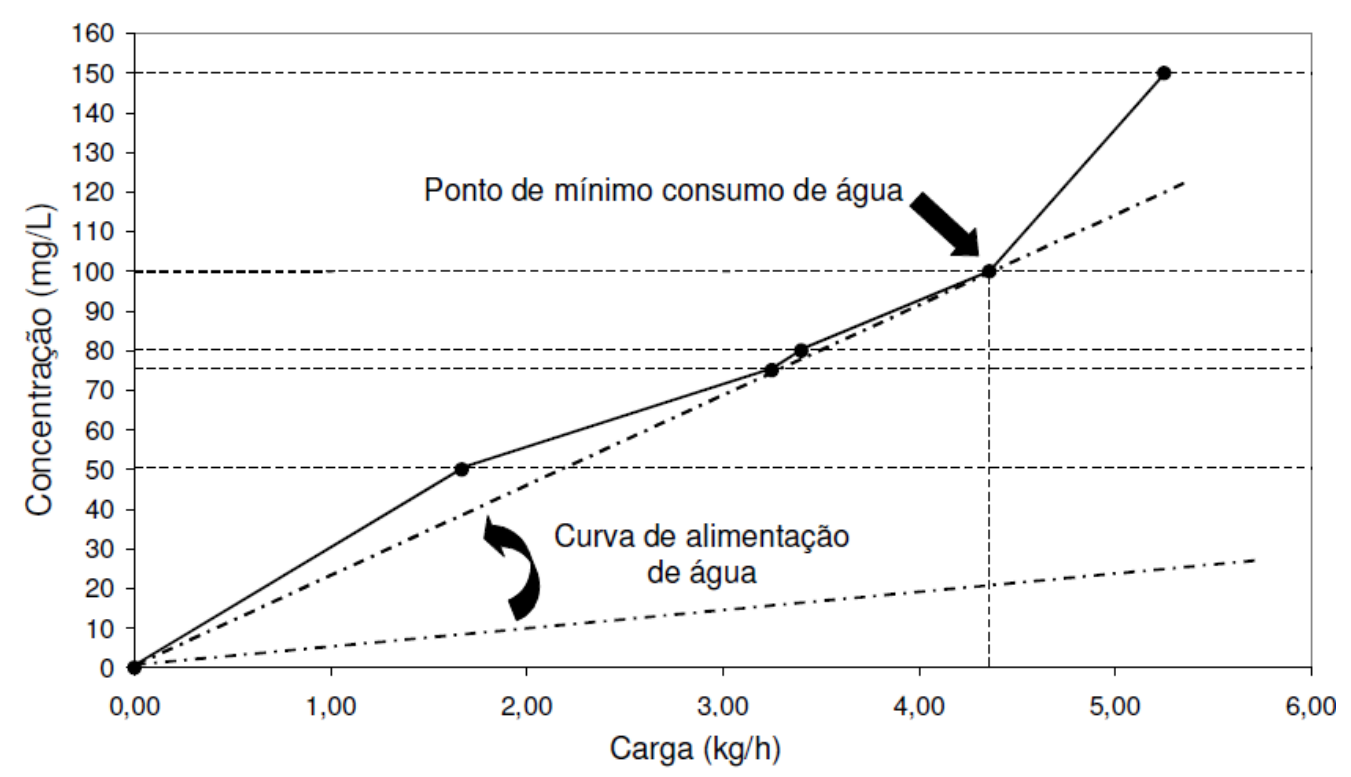

Figura 4 - Gráfico para a obtenção do ponto de mínimo consumo de água (adaptado de Hamaguchi, 2007).

No mesmo ano, Wang e Smith (1994b) propuseram uma metodologia semelhante para tratar de redes de tratamento de efluentes distribuídos no processo. Ao dividirem a rede de água tratada por Takama et al. (1980), Wang e Smith (1994a,b) seguiram a sequência utilizada tradicionalmente na indústria: primeiramente uma rede de processos consumidores de água em seguida a rede de tratamento de efluentes. Essa abordagem foi utilizada na maioria dos estudos realizados, apenas alguns consideraram a rede integrada. Apenas recentemente a discussão sobre a arquitetura adequada foi retomada, ao levantar a questão da inclusão dos processos de pré-tratamento de água fresca na rede (Bagajewicz e Faria, 2009). 
Posteriormente, Wang e Smith (1995) apresentaram uma extensão do método pinch para considerar correntes com restrição de vazão, ganho e/ou perda de água ao longo do processo e múltiplas fontes de água, também introduziram os conceitos de reciclo local e divisão de operações.

Apesar dos trabalhos de Wang e Smith (1994a, 1994b e 1995) serem considerados referência na análise pinch de redes de água, o método falha em algumas situações, como o deslocamento do ponto pinch quando são considerados processos de regeneração e o problema da divisão de operações para atender a meta de consumo mínimo de água, ou seja, há mais de uma alimentação em diferentes pontos da operação, o que é inviável dependendo da aplicação.

Várias técnicas foram propostas com base na metodologia proposta por Wang e Smith (1994a,b) de modo a simplifica-la e/ou aprimora-la. Destacam-se as seguintes:

Olesen e Polley (1997) simplificaram o procedimento de Wang e Smith (1994a,b) para sistemas com único contaminante. Primeiramente a meta mínima de vazão é obtida a partir da Tabela de Cargas ('Load Table”), em seguida a rede de água é obtida por inspeção.

Kuo e Smith (1998) desenvolveram um novo método, o qual previne a divisão de operações e torna mais fácil a compreensão do impacto causado pela introdução da regeneração (localização e número de unidades). Foi proposta a síntese de redes que combinam a distribuição de água limpa e de efluente tratado, introduzindo fontes e sumidouros intermediários de água denominados fontes principais de água ("water mains").

Sorin e Bernard (1999) apresentaram um procedimento de dois passos para sistemas com único contaminante. No primeiro passo, a denominada Tabela Evolucionária ("Evolutionary Table"), em substituição aos gráficos de Wang e Smith, identifica o chamado ponto global pinch. Em seguida, são aplicadas estratégias a fim de projetar alternativas redes de reuso de água com o mesmo consumo de água e geração de efluentes. Posteriormente, Hallale (2002) mostrou que quando mais de um ponto pinch global ocorre em processos de uso de água, a tabela evolucionária falha em localiza-los corretamente. 
Gomes et al. (2007) apresentaram a metodologia Diagrama de Fontes de Água (DFA) baseada nos métodos proposto por Castro (1999) e Gómez et al. (2001). O DFA consiste na representação das concentrações das operações de entrada e saída em intervalos e utiliza regras heurísticas para o cálculo de vazões que atendam a transferência de massa em cada intervalo. O método pode ser aplicado na solução de problemas com um contaminante e com múltiplos contaminantes para os casos de reuso, regeneração com reuso e regeneração com reciclo em processos com restrição de vazão, com múltiplas fontes de agua e com perdas inerentes ao processo. $O$ procedimento pode ser resolvido manualmente e não resulta em divisão de processos.

Uma revisão detalhada do emprego da análise pinch em síntese de redes de água foi apresentada por Foo (2009).

As abordagens conceituais baseadas em análise pinch apresentam limitações quando se trata de múltiplos contaminantes, em decorrência da complexidade das interações que podem ocorrer, e de avaliação econômica. Para superar estas dificuldades, a partir de meados da década de 90 , os estudos começaram a focar nos procedimentos baseados em otimização matemática .

\section{Abordagem baseada em programação matemática}

Após o trabalho pioneiro de Takama et al. (1980) nenhum trabalho sobre formulação de programação matemática para o problema de reuso de água foi publicado durante anos, até que Doyle e Smith (1997) desenvolveram um procedimento baseado em otimização matemática em que as correntes foram definidas em função dos limites máximos permitidos de concentração de entrada e de saída dos contaminantes. Os autores também adaptaram o método gráfico, apresentado por Wang e Smith (1994), para fornecer uma representação do problema por eles analisado, permitindo assim a identificação de alguns aspectos não percebidos com 
a utilização de procedimentos numéricos. Apesar do método de Doyle e Smith (1997) ser pouco confiável, forneceu um ponto de partida para outras propostas.

Man e Liu (1999) utilizaram o método da superestrutura para formular a rede de água como a programação linear (LP - "linear programming") e de programação não-linear (NLP- "nonlinear programming") para sistemas com único e múltiplos contaminantes, respectivamente. A solução desses modelos é a alocação ótima de contaminantes e correntes ao longo do processo, com mínima vazão água fresca.

O modelo de superestrutura gera todas as configurações possíveis de rede de água e elimina desfavoráveis e inviáveis conexões entre uma fonte de água e uma operação que utiliza água. A Figura 5 ilustra a superestrutura geral do sistema em consideração. Entre $\mathrm{N}$ subsistemas, os subsistemas 1 e $\mathrm{N}$ são, respectivamente, uma fonte de água fresca fornecida para qualquer subsistema e uma bacia final que recolhe a água residual de todos os outros subsistemas para despejar para o meio ambiente (Takama et al., 1980).

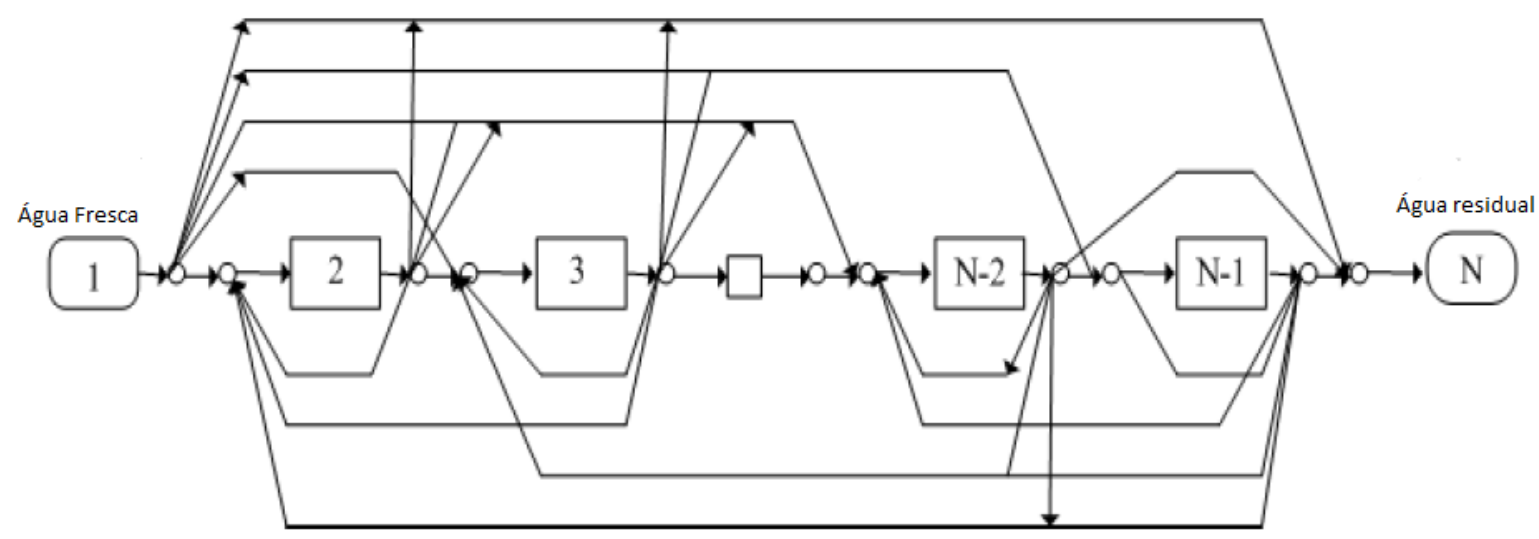

Figura 5 - Modelo de superestrutura geral para projeto de sistema de reuso de água (adaptado de Takama et al., 1980).

Todas as possibilidades de reuso da água, regeneração, reciclagem e tratamento estão incluídos na formulação matemática. $O$ modelo inclui balanços de massa para cada contaminante em torno de cada ponto de mistura e separação, bem como balanços de massa em torno de cada operação. A fim de controlar a característica estrutural do desenho, variáveis binárias associadas com cada possível ligação são 
introduzidas. Logo, o problema é formulado como um modelo de programação misto inteiro não linear (MINLP - "mixed-integer nonlinear programming") que é então decomposto em sequência de problemas misto inteiro linear (MILP- "mixed-integer linear programming"). O custo de investimento de capital e de tubulação, as limitações operacionais da rede, as limitações das conexões proibidas e pequenas vazões podem ser adicionadas à formulação matemática do problema de otimização. A solução para este problema será o consumo mínimo de água fresca e a rede de reuso. Além disso, todas as vazões e as concentrações para cada contaminante em cada corrente são identificados (Alva-Argaez et al., 1998).

Numerosas ténicas matemáticas têm sido desenvolvidas para a resolução dos modelos criados na modelagem das superestruturas, como nos estudos de: Galan e Grossmann (1998), Huang et al. (1999), Bagajewicz e Savelski (2001), Gunaratnam et al. (2005), Karuppiah e Grossmann (2006), Teles et al. (2008) e Poplewski et al. (2010).

Trabalhos recentes desta area são dominadas por abordagens de otimização matemática avançadas, como a programação fuzzy (Tan e Cruz, 2004), algoritmo genético (Tsai e Chang, 2001; Prakotpol e Srinophakun, 2004; Shafiei et al., 2004) e busca randômica (Jezowski et al., 2003).

A abordagem baseada em otimização matemática aborda sistemas mais complexos que os métodos gráficos baseados em análise pinch, como sistemas com grande número de processos consumidores de água (Bagajewicz e Savelski, 2001), estimativa de custo de capital (Alva-Argaez et al., 1998; Jodicke et al., 2001; Feng e Chu, 2004), assim como sistemas de tratamento de água (Huang et al., 1999; Tsai e Chang, 2001; Karuppiah e Grossmann, 2006).

A otimização para sistemas com múltiplos contaminantes foi abordada em muitos estudos destacando-se os procedimentos propostos por Doyle e Smith (1997), AlvaArgáez et al. (1999), e Koppol et al. (2003). Salvelski e Bagajewicz (2003) apresentaram as condições necessárias de otimalidade para esse tipo de sistema, 
foi demonstrado que pelo menos um contaminante atinge a concentração máxima na saída de uma operação que usa água limpa, considerado o contaminante chave.

Bagajewicz e Savelski (2001) observaram que algumas conexões geradas na solução ótima são muito pequenas e então resolveram o problema objetivando o número mínimo de interconexões entre os processos. Também limitaram a divisão de correntes de modo que um processo não possa mandar sua água residual para mais de dois processos (incluindo unidades de tratamento de efluentes). No entanto a solução apresentada para esse último caso não respeita as condições impostas.

Outro aspecto considerado no problema de otimização de redes de água é a descarga zero de efluentes líquidos. Bagajewicz e Savelski (2001) apresentaram modelos para a minimização de água que incluem regeneração com e sem reciclo. Os resultados mostraram que a descarga de líquidos zero é viável apenas se a concentração de saída da regeneração é suficientemente pequena. Koppol et al. (2003) analisaram as vantagens e desvantagens da descarga zero de líquido, utilizando a abordagem de programação matemática estudaram as possibilidades de descarga de líquido zero para diferentes indústrias e projetaram a rede de água com descarga zero de efluentes em uma fábrica de papel.

Bagajewicz (2000) apresentou uma revisão dos procedimentos de programação matemática para projetos de redes de água, com ênfase em refinarias e plantas de processo. Liu et al. (2004) apresentaram uma revisão das ferramentas básicas utilizadas na solução de problemas de otimização de sistemas de água, incluindo tecnologia pinch e programação matemática. Finalmente, Jezowski (2010) apresentou uma revisão dos trabalhos mais importantes na área, com os diversos tipos de abordagem.

\section{Combinação entre as abordagens (análise pinch e programação matemática)}

Segundo Bagajewicz (2000) embora o paradigma dos projetos conceituais apresente limitações para resolver a complexidade do problema, fornece uma descrição simplificada do problema que tem sido de grande valor para construir eficientes 
modelos de programação matemática para gerar soluções globalmente ótimas e sub-ótimas. Desse modo, a combinação da abordagem conceitual com a programação matemática, ou seja, o uso de ideias conceituais na construção de modelos para a construção matemática (pontos iniciais ótimos, heurísticas para ajudar procedimentos de "branch and bound", uso de condições necessárias de otimalidade) tem se mostrado a alternativa mais efetiva, como nos estudos de AlvaArgáez et al. (1999), Jacob et al. (2002), e Cao et al. (2007). Assim, é muito útil analisar os processos que usam água a partir das regras de análise pinch antes de resolver o problema de otimização. Essas regras são descritas a seguir (Li e Yao, 2004):

1) Para os sistemas com único contaminante, se um processo que utiliza água está abaixo do ponto pinch, sua água residual não é descartada. Para sistemas com múltiplos contaminantes, se um processo que utiliza água está abaixo do ponto pinch para cada contaminante, sua água residual não é descartada.

2) Para os sistemas com único contaminante, se um processo que utiliza água está acima do ponto pinch, não recebe água fresca. Para sistemas com múltiplos contaminantes, se um processo que utiliza água está acima do ponto pinch para cada contaminante, não recebe água fresca.

3) Se o processo que usa água i está acima ou no ponto pinch para cada contaminante, e o processo que usa água j está abaixo do ponto pinch para cada contaminante, a vazão de água de reuso de i para j é zero.

4) Para os sistemas com único contaminante, se a concentração máxima permitida de saída do processo i é maior do que do processo j, a vazão de água de reuso de i para jé zero.

\section{Abordagem conceitual}

Entre as abordagens conceituais não baseadas na análise pinch destacam-se o procedimento algorítmico de Savelski e Bagajewicz (2001) e o procedimento heurístico de Liu et al. (2004). As vantagens destes procedimentos são a facilidade 
de implementação e resultados próximos aos obtidos com os outros métodos apresentados.

Savelski e Bagajewicz (2001) apresentaram um procedimento algorítmico não iterativo para o projeto de redes de utilização de água com um contaminante. $O$ procedimento é baseado nas condições necessárias e suficientes para a otimização, apresentadas por Savelski e Bagajewicz (2000a) e permite a construção de uma solução ótima global, sem a necessidade da meta de mínimo consumo de água. $O$ procedimento não apresenta nenhuma restrição com relação ao tamanho do problema.

Liu et al. (2004) desenvolveram um processo de duas fases: na primeira etapa, um fluxograma inicial é proposto com base em regras heurísticas. Em seguida, na segunda fase, as vazões das correntes no fluxograma são calculadas através de balanço de massa. As operações consideradas incluem reuso, regeneração, mistura e bypass de correntes de água. Utilizando regras heurísticas similares, Liu (2009) propuseram um procedimento heurístico para múltiplos contaminantes. São introduzidos os conceitos de concentração demanda (entrada) e de fonte (saída). O potencial de concentração de demanda reflete a possibilidade global da demanda reutilizar as correntes de fonte e a concentração de fonte reflete a possibilidade global da fonte ser reutilizada pelas demandas. Os processos com menores potencial de concentração de entrada são avaliados primeiro.

\subsection{MINIMIZAÇÃO DO CONSUMO DE ÁGUA EM REFINARIAS DE PETRÓLEO}

As refinarias de petróleo, como mostrado no Capítulo 1, são grandes consumidoras de água e por isso a minimização do consumo é abordada em diversos estudos. 


\section{Planejamento de alocação de água/água residual}

Diversos estudos que abordaram o problema de Planejamento da Alocação de Água e Água Residual aplicaram suas metodologias em problemas de refinaria de petróleo. No entanto a maior parte destes estudos utilizaram as mesmas bases de dados que foram apresentadas em estudos anteriores como Wang e Smith (1994), Huang et al. (1999) e Koppol et al. (2003). Apenas alguns estudos da aplicação de caso real foram apresentados na literatura.

O primeiro trabalho desenvolvido na área de otimização de rede de água realizado por Takama et al. (1980) aplicou a metodologia de otimização de rede de água desenvolvida em um estudo de caso de refinaria de petróleo. Obteve-se uma redução de $24 \%$ no consumo de água através de reuso e regeneração.

Zbontar e Glavic (2000) apresentaram um estudo de caso de um complexo petroquímico com refinaria. Com base nos fluxogramas de água, foram averiguadas as possibilidades de uso de correntes efluentes de processos no mesmo ou em outros processos, considerando a possibilidade de regeneração preliminar da corrente de saída e seu reuso. No entanto, não são explicados como os fluxogramas propostos foram obtidos. Verificou-se uma possível redução de consumo de água fresca do complexo de 7\% com um período de retorno de investimento de seis meses para a petroquímica e 11 dias para a refinaria.

Al-Redhwan et al. (2005) propuseram uma metodologia que considera as incertezas da rede de água, por exemplo, a variação dos níveis de contaminantes no efluente devido a mudanças de carga. A metodologia envolve um modelo determinístico seguido de modelo estocástico e foi aplicada em uma refinaria localizada no Kuwait com capacidade de 400 mil barris/dia. A rede de água incluiu nove unidades e considerou como contaminantes: amônia, cloro, ácido cianídrico, e sulfeto de hidrogênio. Foi atingida uma redução de $58 \%$ no consumo de água fresca ao incorporar operações de reuso e reciclagem.

Alva-Argáez et al. (2007) desenvolveram uma metodologia sistemática baseada na análise pinch com otimização matemática de superestrutura. A aplicação em 
refinaria de petróleo indicou potencial de redução de consumo de água fresca superior a $10 \%$ com investimento de capital mínimo.

Sujo-Nava et al. (2009) estudaram a rede de água ácida de uma refinaria de petróleo de modo a reduzir o consumo de água fresca e a geração de água ácida. $A$ rede otimizada foi obtida a partir de heurísticas desenvolvidas de acordo com as demandas de gestão. O objetivo é demonstrar o potencial de redução de água sem a necessidade de aplicar no começo do estudo um método rigoroso. Foi alcançado um potencial de redução do consumo de água de $83 \%$.

Matijasevic et al. (2010) analisou a rede de água de uma refinaria de petróleo e reduziu o consumo de água através da otimização da superestrutura do processo. $O$ modelo utilizado é do tipo MILP simplificado através de regras heurísticas. As regras heurísticas são baseadas no conhecimento do processo. Foi atingida uma redução de $34 \%$ do consumo de água.

Mohammadnejad et al. (2011) realizaram a minimização de água e efluente em uma refinaria de petróleo no Teerã através da análise pinch. Os contaminantes considerados foram sólidos suspensos e dureza. Primeiramente analisou-se o sistema com base em um contaminante por vez e em seguida considerando os dois simultaneamente. Ao aplicar a metodologia para múltiplos contaminantes atingiu-se uma redução de $42 \%$ no consumo de água fresca.

\section{Aplicação em refinarias brasileiras}

A minimização do uso de água em refinarias brasileiras ganhou importância nos últimos sendo abordada tanto por empresas quanto em trabalhos acadêmicos.

Mariano (2001) aborda, a partir de uma extensa revisão bibliográfica, os impactos da atividade do refino do petróleo no meio ambiente. Para cada atividade do refino são apresentados os efluentes gerados e sua caracterização. Diferentemente das abordagens convencionais realizadas até então, em que apenas os métodos de 
tratamentos de efluentes eram estudados, o autor enfoca na redução da quantidade de efluente gerada a partir da gestão do uso de água. São sugeridas medidas de gestão do uso de água aplicadas para todo tipo de indústria e modificações específicas da indústria de refino do petróleo. O autor destaca o potencial da substituição dos sistemas de refrigeração a água por sistemas de refrigeração a ar. Alguns anos depois, a equipe do LSCP/USP (Bresciani, 2006b) desenvolveu um estudo para a substituição de trocadores de calor com água para um sistema híbrido composto por resfriador a ar seguido de permutador convencional a água mostrando um potencial de redução de água de resfriamento de 80 a 100\%.

Collares (2004) avalia algumas ações no circuito hídrico da REDUC e propõe, com base no conhecimento e experiência, modificações no circuito através de reuso interno e em seguida através de regeneração do efluente final. Segundo o autor, outras opções podem ser propostas para o circuito de água, sendo que o arranjo ideal pode ser obtido com a aplicação de metodologia de otimização.

Vanelli (2004) ao realizar o balanço de água da REVAP verificou pontos de consumo acima do esperado de água de incêndio e de água potável e começou o estudo pela redução do desperdício destes tipos de água. Em seguida sugeriu e avaliou economicamente rotas para reduzir o consumo entre os maiores consumidores: torres de resfriamento (configuração, ciclo de concentração, tratamento da purga através de osmose reserva, troca iônica e de soda-cal, regeneração evaporativa), reutilização de água ácida retificada, reutilização direta de efluente da estação de tratamento de despejos industriais (ETDI). O autor mostra como a racionalização do uso de água na refinaria estudada propicia a expansão desta sem a necessidade de ampliação da estação de tratamento de água (ETA) e da ETDI.

Amorim (2005) identifica alternativas ambientalmente viáveis que garantam o abastecimento de água necessário para atender as ampliações de carga e a implantação de novas unidades previstas da REPLAN, visto que esta refinaria passou anteriormente por estudo de uso racional de água. As alternativas viáveis, mas que ainda precisam ser profundamente estudados, são: reuso de esgoto municipal, reuso do efluente da refinaria e captação de água subterrânea. $O$ autor 
aborda de maneira profunda as dificuldades no reuso do efluente final da refinaria (devido sua alta salinidade) e o que está sendo feito para viabilizar esta prática.

Carvalho (2006) analisa o conjunto de ações desenvolvidas na refinaria de Manguinhos, mostrando que a partir delas foi atingida uma redução de $80 \%$ na geração de efluentes em relação à vazão de efluente antes do início da implantação do programa. O destaque é o reciclo de correntes aquosas nas torres de resfriamento que além de resultar em uma redução de geração do efluente final de $56 \%$, proporcionou melhoria operacional dos trocadores de calor.

Nogueira (2007) realiza um balanço hídrico detalhado de todas as unidades do processo da REPLAN e mostra como medidas de manutenção de alguns equipamentos reduz a quantidade de água bruta captada e de efluentes gerados. $\mathrm{O}$ trabalho apresenta alternativas para reuso de água que ainda não realizadas pela refinaria estudada como reciclagem de esgoto doméstico para o sistema de resfriamento e reuso de água ácida retificada nas piscinas dos coques.

Bresciani (2009) mostra a viabilidade do aumento na taxa de reciclagem da água de diluição das dessalgadoras, dessa forma a água ácida retificada utilizada para tal finalidade pode ser empregada em outra finalidade reduzindo a vazão de água bruta consumida pela refinaria.

\subsection{CONSIDERAÇÕES}

Desde 1980 muitos estudos tem sido realizados na área de otimização de rede de água, sendo que diversas metodologias, utilizando tanto procedimentos algorítmicos quanto abordagens baseadas na programação matemática, foram criadas e reformuladas. Modelos sofisticados foram desenvolvidos para otimização matemática de modo a abordar sistemas complexos, custo de investimento, limitações operacionais. Por outro lado, abordagens conceituais apresentam 
procedimentos mais fáceis e oferecem soluções mais simples e adequadas para a implementação.

Observa-se que a maioria das metodologias aborda a busca da solução ótima, não havendo preocupação com a viabilidade da aplicação da solução na planta industrial. As soluções geradas não são avaliadas técnica e/ou economicamente, sendo que alguma recomendação pode não ser aplicável em casos reais, alterando a solução ideal e com isso reduzindo o seu benefício final. Tanto é que a maioria dos estudos foi desenvolvida utilizando as mesmas bases de dados, muitas vezes fictícias, e pouquíssimos estudos aplicaram um estudo de caso real.

Apesar de vários trabalhos brasileiros terem abordado refinarias de petróleo, estes apenas analisam o consumo de água, riscos futuros na oferta da água e apresentam ações que resultem na redução do consumo. Estas ações focam, basicamente, na eliminação de desperdícios e identificação de oportunidades de redução da troca de alguns equipamentos por outros que consumam menos água e/ou modificações nos métodos operacionais.

Diferentemente dos estudos apresentados, acredita-se que um estudo de minimização do uso de água em uma indústria deve englobar ações para redução do uso de água seguidas da otimização da rede de água. $O$ presente trabalho pretende cobrir essa lacuna ao aplicar a metodologia proposta pelo grupo LSCP/USP em uma refinaria de petróleo.

Inicialmente são identificadas as situações no processo onde ocorrem vazamentos ou flagrantes desperdícios. Grandes quantidades de água podem ser economizadas pela eliminação de vazamentos e mudanças de hábitos das pessoas. Uma vez essas tarefas tenham sido realizadas, um estudo mais rigoroso deve ser feito para identificar outras oportunidades de redução de consumo de água.

Segundo Bresciani et al. (2006a) as etapas básicas desse estudo são:

- Mapeamento das fontes de água usadas pela indústria, 
- Mapeamento de todos os processos que usam água, estabelecendo a vazão mínima de água e as concentrações máximas e mínimas dos contaminantes na entrada e na saída de cada processo.

- $\quad$ Otimização individual de cada processo que utiliza água.

- $\quad$ Elaboração de modelo global dos processos que utilizam água.

- Otimização do conjunto, através de ferramentas matemáticas como, por exemplo, técnicas para problemas de MINLP ("mixed-integer non-linear programming").

- $\quad$ Análise prática das soluções geradas na otimização e elaboração de projeto conceitual das alterações propostas.

Essa abordagem representa uma evolução em relação ao conceito anterior de misturar todas as correntes de água contaminada e aplicar os diversos tipos de tratamentos à vazão total de modo a atender os efluentes às legislações para descarte em rios ou algum tipo de reuso na planta. 


\section{METOdOLOGIA DE OTIMIZAÇÃO EM PROBLEMAS DE ALOCAÇÃo ÓtIMA E REUSO DE ÁGUA EM REFINARIA DE PETRÓLEO}

A metodologia geral do LSCP/USP aborda o problema em duas etapas sequenciais. Primeiramente os processos que consomem água são estudados. Nesta fase os dados industriais são consolidados e são identificadas e estudadas ações imediatas a serem implementadas e oportunidades de racionalização, reuso/reciclagem e regeneração. Representa uma depuração do sistema, preparando-o para a etapa de otimização.

Em seguida é realizada a otimização da rede de água. A caracterização dos requisitos de qualidade para uso da água em cada processo, bem como a concentração máxima tolerável dos contaminantes, associadas a ferramentas matemáticas possibilita a otimização da rede de consumo.

A sinergia entre análise de processo e ferramentas de otimização pode contribuir para a efetiva redução do consumo específico de água por metro cúbico de petróleo. A solução obtida dessa forma deve passar por uma avaliação técnica para torná-la aplicável em casos reais. Essa avaliação pode considerar que alguma recomendação tenha sua aplicação considerada inviável, alterando a solução ideal, reduzindo o seu benefício final.

A metodologia pode ser dividida em três fases descritas a seguir:

I. Mapeamento da rede de água

II. Racionalização do uso de água através de análise de processo

III. Otimização da rede de água 


\subsection{MAPEAMENTO DA REDE DE ÁGUA}

\subsubsection{Coleta de dados}

Antes do desenvolvimento de qualquer iniciativa que busque otimizar o uso da água é necessário conhecer as atividades nas quais a água é utilizada, de modo a identificar os principais pontos de consumo de água, a quantidade e a qualidade exigidas para cada aplicação e os pontos de geração de efluentes. Especialmente para as atividades industriais, é imprescindível uma análise pormenorizada dos processos que requerem água por meio de um estudo completo dos processos produtivos.

Os dados obtidos na etapa de avaliação devem ser suficientes para permitir a construção de um diagrama de distribuição do consumo de água por tipo de uso. Para tanto, é necessário um estudo detalhado sobre o processo em questão. A análise das atividades industriais é mais eficaz se forem integrados os seguintes procedimentos:

\section{Avaliação com base em dados de literatura}

$\mathrm{Na}$ literatura específica, encontra-se facilmente descrição de processos de fabricação de um determinado produto, fluxogramas de processo e informações visando otimizar o uso de recursos naturais e prevenção à poluição. No entanto, como destacaram Hespanhol e Mierzwa (2005), embora as informações disponíveis em literatura sejam bastante úteis na maioria dos casos, elas se referem aos processos industriais de outros países, cujas condições operacionais e nível de desenvolvimento são completamente diferentes das brasileiras. Além disso, a atividade pode já estar ultrapassada, principalmente em virtude dos grandes 
avanços tecnológicos, de restrições de ordem legal e econômica ou da escassez de recursos naturais.

\section{Avaliação de documentos disponíveis na indústria}

A avaliação de documentos disponíveis na indústria é imprescindível para a coleta de dados sobre quantidade e qualidade de consumo de água e geração de efluentes. Devem constar descrição de sistemas, fluxogramas de processo, manuais de operação e rotinas operacionais. Quanto maior o nível de detalhamento, melhor será a compreensão das atividades industriais em questão, pois se pode estabelecer uma relação lógica entre todas as etapas de produção e lhes vincular o consumo de água em cada etapa, o grau de qualidade exigido e a geração e composição dos efluentes.

\section{Visitas de campo}

A visita a instalações industriais é necessária para confrontar as informações teóricas com a realidade e a rotina vivenciadas na pratica. Segundo Hespanhol e Mierzwa (2005), essa etapa é de fundamental importância visto que muitos aspectos desconsiderados no projeto original de implantação de um processo industrial, que poderiam interferir no desempenho global da unidade, muitas vezes não são incorporados aos respectivos documentos de engenharia. Além disso, alterações e otimizações de processos vão sendo feitas ao longo do tempo, em razão de avanços tecnológicos, restrições legais, diminuição ou aumento da capacidade de produção, incorporação de novos produtos à linha de produção etc.

\section{Coleta de dados históricos}

Para monitorar efetivamente uma planta industrial, controlar a produção e garantir sua operação é necessário que se saiba o estado real da planta em qualquer 
momento desejado. Com este propósito, um grande número de variáveis de processos são medidas e seus valores armazenados em banco de dados em tempo real. Com o avanço das técnicas de medição e modelagem, atreladas ao avanço das técnicas computacionais, a quantidade de dados de processo armazenadas só tende a aumentar (Kongsjahju et al., 2000).

A coleta desses dados é essencial para o mapeamento da rede de água, através deles pode-se obter o estado do real funcionamento do processo. A frequência de dados históricos é muito importante. Um conjunto formado por diversas medidas ao longo do dia representa melhor o processo pois torna possível detectar problemas de amostragem em períodos curtos do dia. Além disso, é possível identificar períodos de operação em estado estacionário e detectar problemas nos instrumentos de medida.

A otimização da rede de água é feita diretamente com os dados industriais, sendo assim, a baixa qualidade dos dados pode resultar em tomadas de decisão baseada em dados pouco confiáveis e ocasionar prejuízos financeiros. Como todas as medições de processo estão sujeitas a algum tipo de erro, todos estes dados armazenados podem estar corrompidos de alguma maneira, seja com pequenos erros aleatórios como com grandes erros grosseiros. E assim não se pode esperar que os dados obedeçam às leis de conservação de massa ou de energia. O uso racional de grandes volumes de dados requer a aplicação de técnicas adequadas para aumentar a sua precisão (Wang e Romagnoli, 2003).

O objetivo do tratamento dos dados é tornar este enorme banco de dados do processo mais preciso, de menor dimensão, e com a presença de todas as informações relevantes. Com isso é possível aplicar os dados de modo a representar o estado real da planta. 


\subsubsection{Análise de dados}

Segundo Smith (2005) a análise dos dados de um estudo de otimização do uso de água compreende as seis etapas descritas a seguir.

\section{Determinação do balanço hídrico}

O primeiro passo é fazer um balanço de água confiável do processo. O balanço de água só pode ser obtido com precisão a partir de um estudo específico - seja na fase de projeto, analisando-se documentos disponíveis, ou então na própria indústria, depois de ter sido implantada e estar operando.

\section{Determinação dos tipos de contaminantes e suas quantidades}

O menor número possível de contaminantes para serem analisados deve ser especificado. A mera existência de um contaminante não é razão para sua inclusão. Devem ser incluídos aqueles que estão representados em maior quantidade e os que limitam a reutilização da água de processo ou a sua reciclagem. Quando se trata de unidades de tratamento, apenas os contaminantes cuja liberação para o meio ambiente é controlada pela legislação devem ser levados em consideração.

\section{Determinação das vazões limitantes}

Alguns processos exigem fluxo contínuo de água, por exemplo, torres de resfriamento, ejetores de vapor, etc. Esses dados devem ser observados durante a coleta de dados. Se a otimização visa minimizar o uso de água fresca, então 
correntes com pequenas vazões devem ser negligenciadas devido ao frequente relação custo-ineficiência de sua reutilização e reciclagem.

\section{Determinação de outras condições limitantes}

A fim de determinar a possibilidade de reutilização / reciclagem de água, com ou sem regeneração, os dados sobre as concentrações-limite de impurezas nas correntes de água devem ser coletadas primeiramente para cada processo separadamente. Não existe uma regra única para isso e muitos fatores são influentes, por exemplo, limitações relacionadas com corrosão, máxima solubilidade, simulação baseada em estudos, pesquisas de laboratório, testes nas plantas e análise paramétrica.

\section{Estimativa do desempenho das estações de tratamento de água disponíveis}

A informação mais importante sobre as plantas de tratamento é, sem dúvida a sua eficiência na remoção dos poluentes monitorados. Esta informação é usada para determinar as concentrações na correntes de saída e seu potencial de reutilização / reciclagem no processo.

\section{Especificação dos limites ambientais}

Os limites ambientais para um determinado corpo receptor são especificados por lei. Geralmente os limites ambientais se referem à concentração do contaminante, que difere para cada categoria de corpo receptor. Estes valores representam o estado que a água tem ao ser retirada da planta de tratamento. Devido à natureza dinâmica dos sistemas de água, recomenda-se que os cálculos sejam feitos em $60 \%$ dos limites permitidos (Smith, 2005). 


\subsection{RACIONALIZAÇÃO DO USO DE ÁGUA ATRAVÉS DE ANÁLISE DE PROCESSO}

O primeiro passo para a minimização do uso de água e de geração de efluentes em uma planta com rede complexa de consumo de água é o estudo individual de cada processo, buscando a racionalização do uso de água e a identificação de oportunidades para a redução do consumo de água dentro de cada processo. Todos os processos que usam água devem ser avaliados e, para isso, é necessário conhecer cada operação unitária envolvida nesses processos. Podem ser identificadas situações em que a recomendação seja a adoção de estratégias relacionadas ao reuso de água no mesmo processo. Muitas vezes pode ser necessária a mudança nos procedimentos operacionais que demandam água. Outra alternativa possível é a substituição de equipamentos.

\subsection{OTIMIZAÇÃO DA REDE DE ÁGUA}

O projeto de um sistema de água industrial envolve a utilização de várias fontes de água fresca de modo a satisfazer as diferentes demandas de cada operação unitária, da maneira mais eficiente, tanto em termos de volume e nível de concentração de certos contaminantes. Um conjunto de operações de tratamento de água é disponível para a redução do consumo de água fresca e/ou para atender aos limites ambientais impostos no descarte de águas residuais. O objetivo é, então, determinar uma configuração de rede que combine reuso e tratamentos específicos, e com mínimo consumo global de água fresca e consequentemente, de geração de água residual.

Segundo Bagajewicz (2000) até alguns anos atrás o problema de tratamento de água era considerado como um conjunto de operações de tratamento sequenciais 
de uma única corrente de água residual proveniente de todas as unidades do processo, conhecido como tratamento fim de tubo. Sem o conceito de reuso de água, estes processos eram alimentados apenas com água fresca. A Figura 6 ilustra este tipo de sistema de água, considerando, hipoteticamente, três processos consumidores de agua $(\mathrm{Pi})$ e três unidades de tratamento de água residual (Ti).

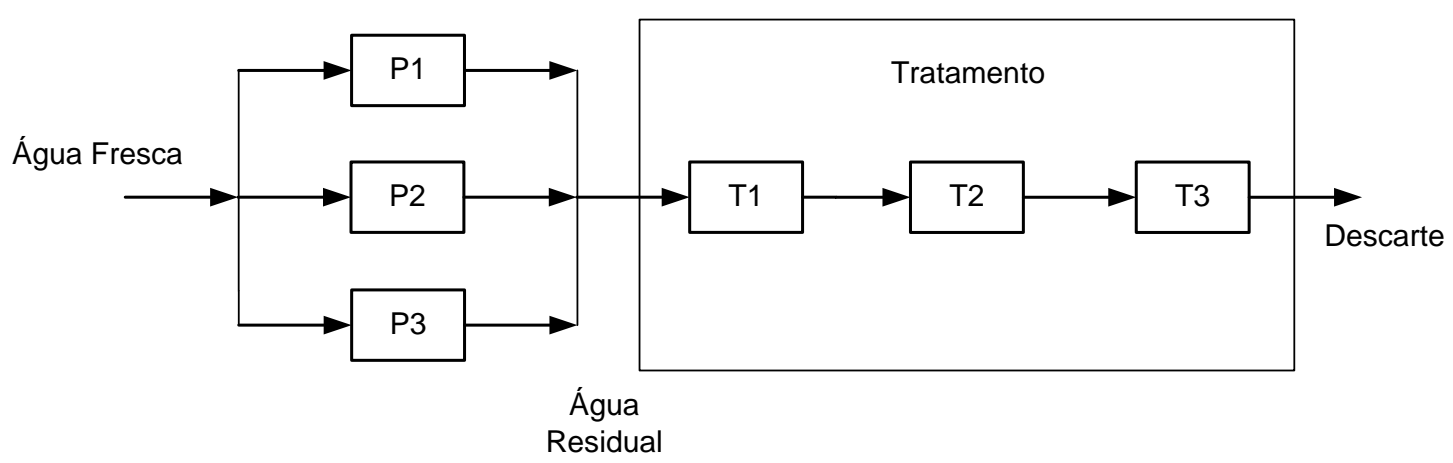

Figura 6 - Utilização de água em processos industriais - tratamento fim de tubo (adaptado de Bagajewicz, 2000).

Uma possibilidade de melhoria desse sistema é a implementação de reuso de água de um processo para o outro diretamente, como ilustrado na Figura 7. Isto reduz os custos visto que tanto o consumo de água e o volume de efluente a ser tratado são minimizados. $\mathrm{O}$ tratamento de água residual continua sendo feito em série para descarte posterior.

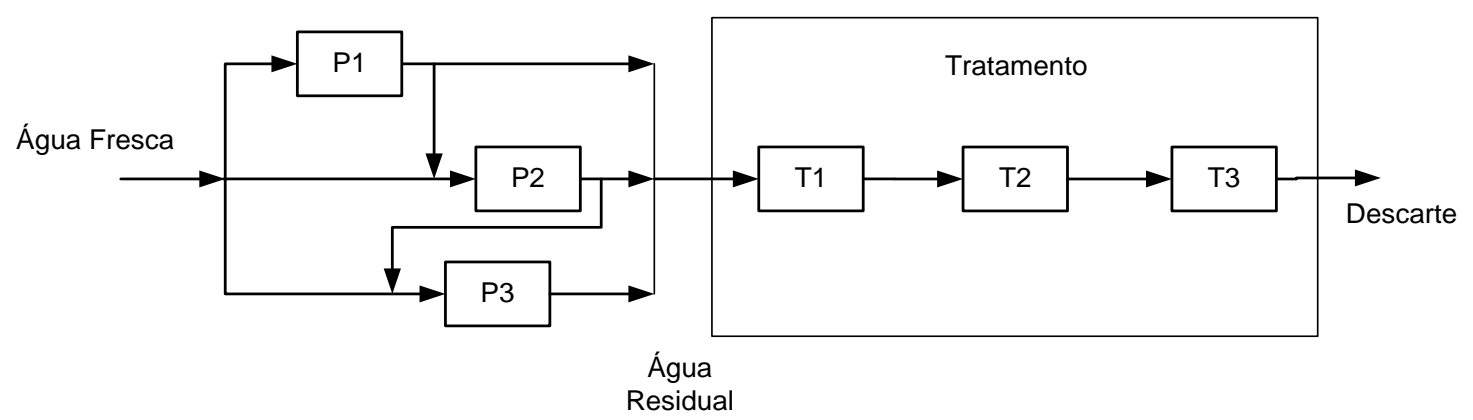

Figura 7 - Utilização de água em processos industriais - sistema com reuso parcial de água (adaptado de Bagajewicz, 2000). 
Uma próxima etapa é a introdução de sistemas de tratamento de água residual em série/paralelo sem a mistura de todas as correntes de água residual dos processos. (Figura 8).

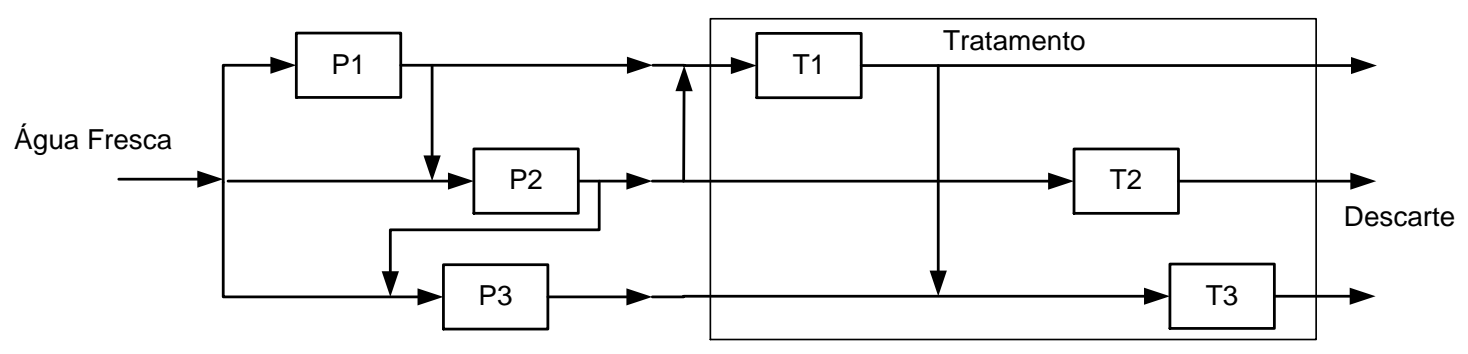

Figura 8 - Utilização de água em processos industriais - sistema série-paralelo de utilização e tratamento de água de processos industriais (adaptado de Bagajewicz, 2000).

Finalmente, o tratamento de água residual pode ser descentralizado, de forma que são removidos apenas alguns contaminantes da água residual de processos selecionados, permitindo a reutilização desta água em outros processos (regeneração com reuso), como mostrado na Figura 9.

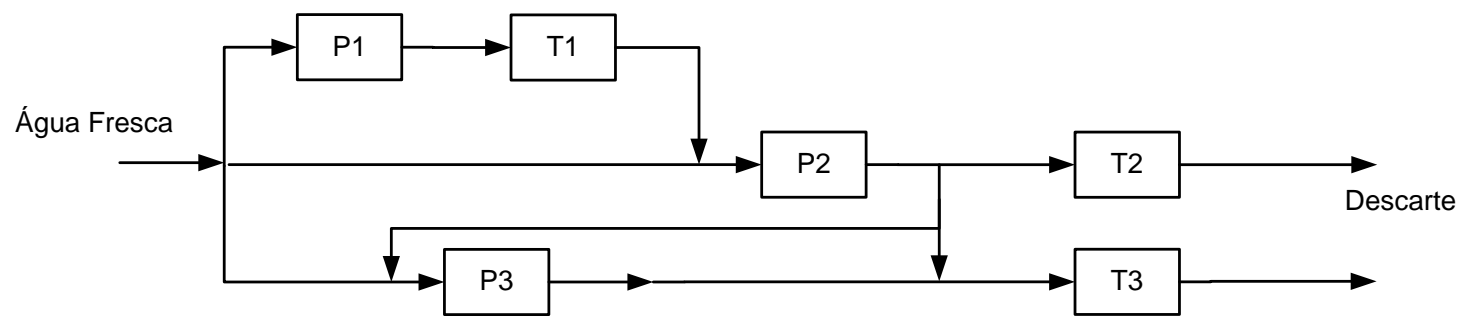

Figura 9 - Utilização de água em processos industriais - sistema série-paralelo de utilização e tratamento de água de processos industriais (adaptado de Bagajewicz, 2000).

Em caso de plantas existentes, o problema necessita ser analisado de modo diferente do problema de projeto. Reuso de água pode ser limitado por restrições geográficas, de processo e/ ou projeto. Restrições geográficas podem ser relacionadas às distâncias reais ou limitações de interconexão entre unidades. Em tais casos, conexões necessitam ser impostas ou esquecidas. $O$ reuso ótimo pode demandar conexões que são tecnicamente impossíveis de serem atendidas. Consequentemente, o reuso de água pode ser reduzido, forçando um aumento no uso de água fresca. Restrições de projeto referem-se à capacidade de vasos, 
tubulações e bombas/compressores, bem como limitações de corrosão. Por exemplo, substituindo água fresca por água residual reutilizável implica, geralmente, em aumento de vazões e / ou tempos de residência. Tais acréscimos podem ser inviáveis para um equipamento existente. Assim, um esquema ótimo de reuso de água necessita incluir outras variáveis importantes tais como redimensionamento de tubulações e novos custos de bombeamento (Bagajewicz, 2000).

\section{Definição do problema}

Dado um conjunto de processos que utilizam/eliminam água e um conjunto de processos de tratamento, o objetivo é determinar uma nova rede de interconexões de correntes de água entre os processos e entre os processos de tratamento, de modo que o consumo total de água fresca é reduzido, enquanto que cada processo recebe água de qualidade adequada.

Segundo Alva-Argáez et al. (1998) a avaliação de um sistema de água pode ser estruturado da seguinte forma, dados:

- Um conjunto de operações unitárias, incluindo todas aquelas que utilizam água bem como todas as operações de tratamento disponíveis para o projeto. Restrições de vazão podem ser impostas em cada operação unitária.

- Um conjunto de contaminantes que podem estar presentes nas diferentes fontes de água fresca e/ou incorporados nas operações que utilizam água.

- Um conjunto de fontes disponíveis de água fresca para atender as demandas de água, incluindo suas composições de fornecimento em termos de cada contaminante. Além disso, podem ser dados os limites superiores de vazão que pode ser utilizada na rede e os custos associados com o consumo de cada fonte.

O conjunto de operações é então separado em dois subconjuntos: (1) Um subconjunto de operações que utilizam água, cada uma descrita pelo perfil limite de cada contaminante na água, em termos de concentração máxima de entrada, concentração máxima de saída e, ou a quantidade de contaminante a ser transferida 
ou a vazão limite para a dada operação. (2) Um subconjunto de operações de tratamento de água, seu desempenho na remoção de contaminantes especificada como razão de remoção, podendo também apresentar uma restrição de concentração de entrada.

O objetivo, então, é sintetizar uma rede de água com mínimo consumo de água fresca que satisfaça as especificações do problema.

A solução deste problema assume carga constante de contaminantes removidos nos processos e limites de concentrações de entrada e de saída de contaminantes. $O$ limite de concentração de saída considera corrosão, incrustação, solubilidade máxima, etc., enquanto que o limite de entrada é ajustado para limitar a vazão através dos processos (Koppol et al., 2003).

\section{Resolução do problema}

Tradicionalmente, há duas maneiras para se otimizar um sistema de água:

- Abordagem Conceitual

- Programação Matemática

Como apresentado no Capítulo 2, a abordagem conceitual destaca-se pela análise gráfica conhecida como pinch e diversas metodologias baseadas em pinch, além de englobar metodologias heurísticas. Em virtude das limitações deste tipo de abordagem, emprega estruturas como as apresentadas na Figura 8, muitas vezes dividindo em dois subproblemas: minimização do uso de água através de reuso e alocação ótima de rejeitos líquidos.

Por outro lado, a programação matemática, por ser uma ferramenta mais robusta, projeta um sistema semelhante ao mostrado na Figura 9. O modelo do problema de minimização de águas residuais pode ser formulado como um problema de programação linear (LP) ou a representação matemática pode estar na classe de programação não linear (NLP) ou programação não linear mista-inteira (MINLP), 
cujo objetivo é minimizar a alimentação total de água fresca ao processo, sujeita aos balanços de água e contaminantes ao redor de cada operação unitária e máxima concentração de entrada em cada uma.

A seguir são apresentados os modelos para os sistemas de água com único e múltiplos contaminantes para a otimização baseada em programação matemática. $\mathrm{E}$ em seguida, no Capítulo 4, é apresentado um novo procedimento algorítmico baseado em regras heurísticas.

\subsubsection{Otimização Matemática}

Considerando apenas o subconjunto de operações que utilizam água, os modelos utilizados para otimizar a malha são baseados no balanço de massa da água e dos contaminantes.

\section{Sistema com único contaminante}

Considerando o esquema de processos da Figura 10.

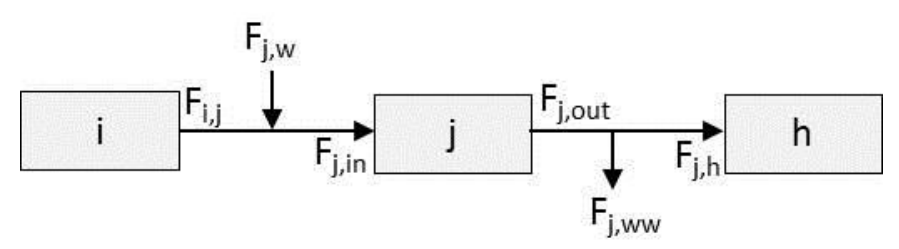

Figura 10 - Malha de processos.

- Consumo de água fresca total nos processos:

$\sum_{j} F_{j, w}$

- Balanço de massa para mistura de correntes na entrada do processo j: 
$F_{j, i n}=F_{j, w}+\sum_{i} F_{i, j} \quad \forall j \in N$

- $\quad$ Balanço de massa para divisão de uma corrente na saída do processo j:

$$
F_{j, o u t}=F_{j, w w}+\sum_{j} F_{j, h} \quad \forall j \in N
$$

- $\quad$ Balanço de massa no processo j:

$$
F_{j, \text { in }}=F_{j, \text { out }} \quad \forall j \in N
$$

Considerando o balanço de contaminante na entrada do processo j, representado na Figura 11.

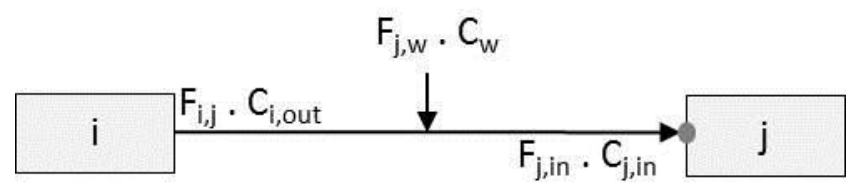

Figura 11 - Balanço de contaminante na entrada do processo j.

Tem-se:

- $\quad$ Balanço de massa do contaminante na entrada do processo j:

$\sum_{i} F_{i, j} \cdot C_{i, o u t}+F_{j, w} C_{w}=F_{j, i n} C_{j i n} \quad \forall j \in N$

Considerando que a água fresca seja isenta do contaminante ou seja, $\mathrm{C}_{\mathrm{w}}=0$, logo:

$$
\sum_{i} F_{i, j} \cdot C_{i, \text { out }}=F_{j, \text { in }} C_{j, \text { in }} \quad \forall j \in N
$$

Considerando a carga do contaminante transferida à água no processo j, representado na Figura 12.

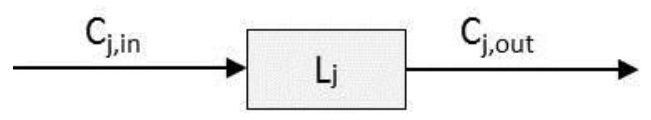

Figura 12 - Carga de contaminante no processo j. 
Tem-se:

- $\quad$ Balanço de massa do contaminante na saída do processo j:

$\sum_{i} F_{i, j} \cdot C_{i, \text { out }}+L_{j}=F_{j, \text { out }} C_{j, \text { out }} \quad \forall j \in N$

Considerando as restrições:

- Restrições ambientais e de processo:

$C_{j, \text { in }} \leq C_{j, \text { in }}^{\max } \quad \forall j \in N$

$C_{j, \text { out }} \leq C_{j, \text { out }}^{\max } \quad \forall j \in N$

- Restrições de vazões

$F_{j, w}, F_{i, j}, F_{j, \text { out }} \geq 0 \quad \forall j \in N$

O problema tem então a seguinte formulação NLP ("non-linear programming"):

$\operatorname{Min} \sum_{j} F_{j, w}$

Sujeito a:

$F_{j, w}+\sum_{i} F_{i, j}-\sum_{h} F_{j, h}-F_{j, \text { out }}=0 \quad \forall j \in N$

$\sum_{i} F_{i, j}\left(C_{i, \text { out }}-C_{j, \text { in }}\right)-F_{j, w} C_{j, \text { in }}=0$

$\forall j \in N$

$\sum_{i} F_{i, j}\left(C_{i, \text { out }}-C_{j, \text { out }}\right)-F_{j, w} C_{j, \text { out }}+L_{j}=0 \quad \forall j \in N$

$C_{j, \text { in }} \leq C_{j, \text { in }}^{\max }$

$C_{j, \text { out }} \leq C_{j, \text { out }}^{\max }$

$F_{j, w}, F_{i, j}, F_{j, \text { out }} \geq 0$

Este modelo tem termos não lineares nas restrições de igualdade em que a vazão e a concentração estão presentes simultaneamente. Mesmo que o problema seja resolvido com sucesso não há garantia do ótimo global (Savelski e Bagajewicz, 
2000b). Contudo, a não linearidade pode ser eliminada usando a condição necessária de otimalidade de concentração máxima de saída, desenvolvida por Savelski e Bagajewicz (2000b), em que as concentrações de saída são definidas como seu valor máximo.

As restrições podem ser combinadas da seguinte forma:

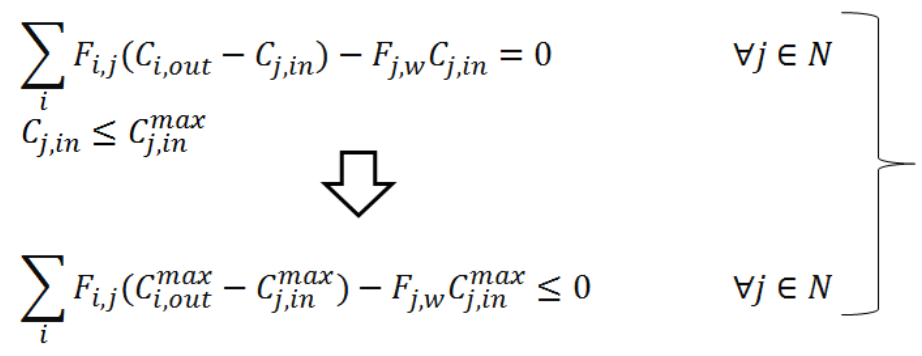

Com isso obtém-se o modelo linear para a minimização do consumo de água fresca:

$$
\left.\begin{array}{ll}
\operatorname{Min} \sum_{j} F_{j, w} & \\
\text { Sujeito a: } & \\
F_{j, w}+\sum_{i} F_{i, j}-\sum_{h} F_{j, h}-F_{j, \text { out }}=0 & \forall j \in N \\
\sum_{i} F_{i, j}\left(C_{i, \text { out }}^{\max }-C_{j, \text { in }}^{\max }\right)-F_{j, w} C_{j, \text { in }}^{\max } \leq 0 & \forall j \in N \\
\sum_{i} F_{i, j}\left(C_{i, \text { out }}^{\max }-C_{j, \text { out }}^{\max }\right)-F_{j, w} C_{j, \text { out }}^{\max }+L_{j}=0 & \forall j \in N \\
F_{j, w}, F_{i, j}, F_{j, \text { out }} \geq 0 &
\end{array}\right]
$$

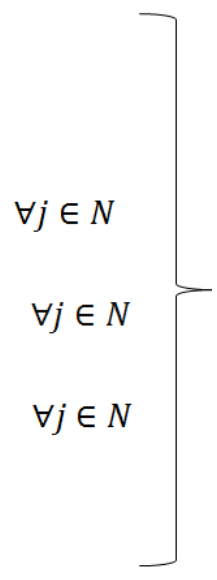

Esse modelo é rigoroso e não assume aproximações além daquelas anteriormente mencionadas de carga constante e concentrações máximas de entrada e saída. A solução deste problema fornece o consumo de água fresca bem como o reuso de água residual de cada processo. No entanto, este modelo não inclui nenhuma regeneração ou processo de tratamento. Assume-se que a água efluente $\left(F_{j, w}\right)$ de cada processo se misturam em uma só corrente, a qual é tratada com tecnologias de tratamento adequadas antes de ser descartada. Este esquema é também chamado de tratamento centralizado ou tratamento fim de tubo. Savelski e 
Bagajewicz (2001) mostraram também que este problema normalmente tem várias soluções alternativas, e proporcionaram meios para determinar qual destas soluções minimiza o custo de capital. Para isso, propuseram uma segunda fase em que a função objetivo minimiza o número de ligações, que é um substituto simplificado para o custo de tubulação, enquanto o consumo de água fresca é limitado para no valor obtido com a primeira fase.

\section{Sistema com múltiplos contaminantes}

De modo similar obtém-se o modelo para o sistema com múltiplos contaminantes:

$\operatorname{Min} \sum_{j} F_{j, w}$

Sujeito a:

$F_{j, w}+\sum_{i} F_{i, j}-\sum_{h} F_{j, h}-F_{j, o u t}=0$

$\sum_{i} F_{i, j}\left(C_{i, s, \text { out }}-C_{j, s, \text { in }}\right)-F_{j, w} C_{j, s, \text { in }}=0$

$\sum_{i} F_{i, j}\left(C_{i, s, \text { out }}-C_{j, s, \text { out }}\right)-F_{j, w} C_{j, s, \text { out }}+L_{j}=0$

$C_{j, s, i n} \leq C_{j, s i n}^{\max }$

$C_{j, s, \text { out }} \leq C_{j, s, \text { out }}^{\max }$

$F_{j, w}, F_{i, j}, F_{j, \text { out }} \geq 0$ $\forall j \in N$

$\forall j \in N$

$\forall j \in N$

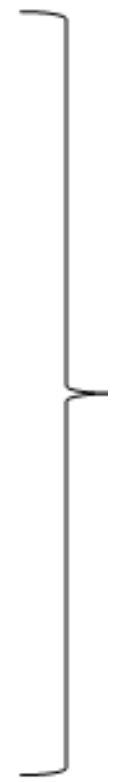

O problema apresenta não linearidade e não convexidade devido aos termos formados pela multiplicação das variáveis vazão e concentração. Para resolver este problema diversas estratégias foram empregadas, no entanto, não há garantia de ótimo global, sendo que há indícios de que o problema apresenta várias soluções sub-ótimas próximas ao ótimo global (Savelski e Bagajewicz, 2000b). Por esta razão, Savelski e Bagajewicz (2003) investigaram as propriedades do problema e apresentaram as condições necessárias de otimalidade para esse tipo de sistema. 
Segundo as condições, se uma solução é ótima, nos processos consumidores de água fresca pelo menos um contaminante (denominado contaminante chave) atinge sua concentração máxima. 


\section{PROCEDIMENTO DESENVOLVIDO PARA A OTIMIZAÇÃO DE REDE DE ÁGUA CONSIDERANDO REGRAS HEURÍSTICAS}

As metodologias encontradas na literatura apesar de obterem uma solução ótima não levam em consideração importantes restrições que limitam a sua aplicação prática na planta industrial. Logo, antes da implementação da rede de água otimizada na unidade industrial, é necessário realizar uma avaliação técnica da solução que pode resultar em uma rede em que o consumo de água não seja o ótimo.

Para obter uma solução em que a rede de água otimizada seja mais aplicável na indústria, foi desenvolvido um novo procedimento que complementa ou substitui as metodologias matemáticas para otimização da rede de água. Esse novo procedimento considera, além do balanço de massa de água e dos contaminantes, regras heurísticas que representam restrições reais dos processos e com isso simplificam a configuração da solução. Apesar do procedimento não atingir o consumo ótimo, ele gera uma solução viável sob o ponto de vista da complexidade e consequentemente com custos de investimentos e de operação (tubulações, sistema de controle) menores.

\subsection{HEURÍSTICAS CONSIDERADAS PARA A OTIMIZAÇÃO DA REDE DE ÁGUA}

As regras heurísticas consideradas são baseadas em conceitos das operações unitárias envolvidas em cada processo e no estudo de plantas químicas que utilizam água. Para apresentá-las, considera-se a rede de água mostrada na Figura 13: um processo i alimentado por água fresca e um processo j que recebe água de reuso de i e/ou água fresca. 


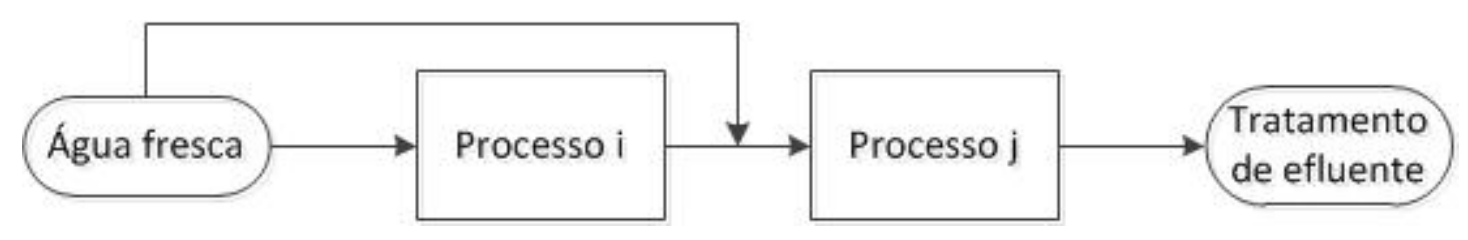

Figura 13 - Esquema de reuso de água sem regeneração.

I. Um processo i pode alimentar apenas um processo j e deve ser priorizado o reuso da corrente inteira, ou seja, deve-se evitar que uma corrente seja dividida em duas. Isso porque, para cada ramal é necessário um sistema de controle de vazão, elevando o custo de investimento e a complexidade operacional.

II. O efluente do processo j, que já foi alimentado com água de reuso, deve ser enviado para o tratamento, não podendo ser reutilizado em outro processo. Quanto maior o número de processos em série maior a perda de carga no escoamento além disso, maior a probabilidade de propagar alguma perturbação operacional. Ademais, não pode haver retroalimentação (i $\mathrm{i} \mathrm{j})$.

III. No máximo dois processos i podem alimentar um processo j. A limitação no número de processos resulta em uma planta operacional mais simples, em que um processo não é dependente de mais de dois outros processos. Além disso, esse tipo de configuração facilita a identificação de algum problema (ex. contaminante indesejável) que propague no sistema.

IV. Os maiores consumidores de água fresca devem ser priorizados para receber água de reuso. Com isso, o impacto na redução de água fresca é mais significativo.

V. Processos com baixo impacto no consumo de água não serão considerados inicialmente no modelo, sendo analisados individualmente após o estudo dos processos. O ganho com a análise destas correntes não seria significativo para compensar o aumento da complexidade do modelo. Isso é especialmente importante para plantas que apresentam grande número de processos.

VI. Sempre que possível, a temperatura dos processos deve ser considerada. Caso não haja restrição de temperatura mínima ou máxima em cada processo, a água deve fluir da temperatura menor para a maior, minimizando o consumo energético. 
VII. As correntes de água que apresentam contaminantes extremamente tóxicos devem ser eliminadas na avaliação do modelo. Dessa forma evita-se a contaminação de outras correntes com o componente tóxico e o modelo é simplificado.

VIII. As correntes de água que apresentam contaminantes que necessitam tratamentos muito diferentes não devem ser misturadas. Quanto menor a vazão da corrente menor o sistema de tratamento necessário.

IX. O layout deve ser considerado de modo a reduzir comprimento de tubulações, reduzir perda de carga e evitar a interferência de uma área operacional em outra.

$X$. A água fresca não pode ser enviada diretamente para a unidade de tratamento para evitar um uso ambientalmente insustentável de um valioso recurso natural, ou seja, é proibida a diluição da mistura de efluentes de modo a facilitar o tratamento de águas residuais (Khor et al., 2012).

\subsection{NOVO PROCEDIMENTO PARA OTIMIZAÇÃO DE REDE DE ÁGUA}

A seguir são descritas as etapas do novo procedimento algorítmico para a otimização da rede de água. O diagrama do procedimento proposto está apresentado na Figura 14.

É importante destacar que se o sistema envolve múltiplos contaminantes, a análise deve ser feita baseada no contaminante chave de cada processo, que é o contaminante que requer a maior vazão de água fresca para ser removido. Desse modo os demais contaminantes serão transferidos na mesma proporção que o contaminante chave, tendo suas concentrações limites garantidas. 


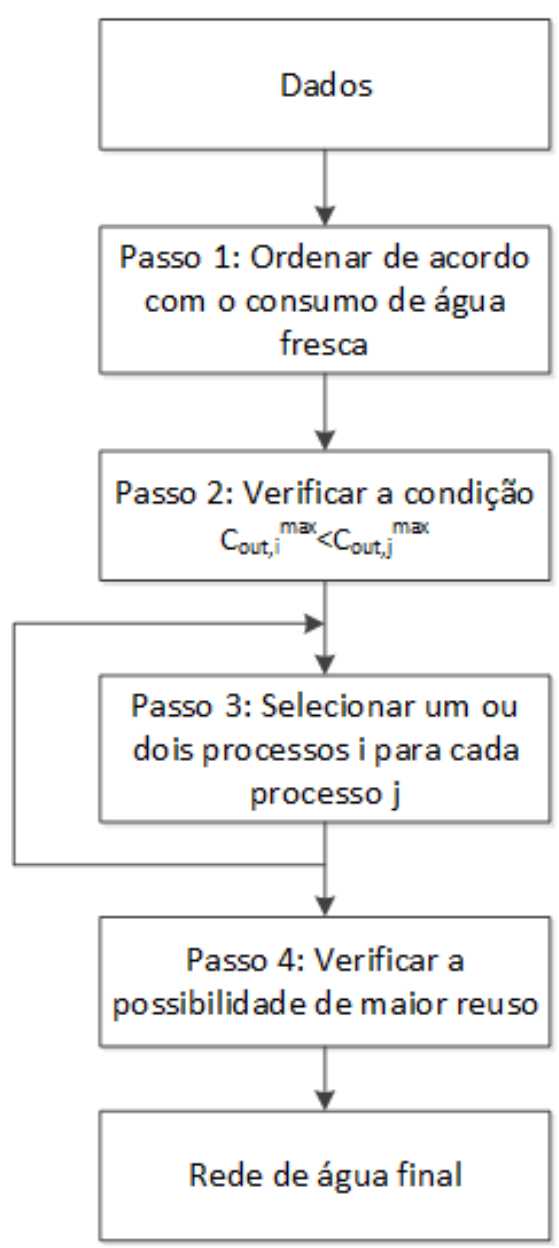

Figura 14 - Etapas do procedimento.

Passo 1 - Organizar os processos em ordem decrescente de acordo com o consumo de água fresca sem reuso $\left(F_{W}\right)$.

Este ordenamento é importante visto que, de acordo com a heurística IV, os maiores consumidores de água fresca devem ser priorizados.

Passo 2 - Para todos os pares de processo i,j possíveis, verificar a condição $\mathrm{C}_{\mathrm{i}, \text { out }}{ }^{\text {max }}<\mathrm{C}_{\mathrm{j}, \text { out }}{ }^{\max }$.

Se $C_{i, \text { out }}{ }^{\max }<C_{j, \text { out }}{ }^{\max }$ (status $=1$ ) o processo $i$ pode enviar sua água residual para 0 processo $\mathrm{j}$, caso contrário, $\mathrm{C}_{\mathrm{i}, \text { out }}{ }^{\max }>\mathrm{C}_{\mathrm{j}, \text { out }}{ }^{\max }$ (status $=0$ ), o reuso de $i$ para j não é possível. Visto que a retroalimentação é proibida, quando $i=\mathrm{j}$, status $=0$. 
Passo 3 - Construir a nova rede de água executando os seguintes procedimentos para todos os processos de acordo com a ordem gerada no Passo 1 :

a. Selecionar processo $j$ (maior consumidor de água fresca)

b. Selecionar processo $i$ (maior consumidor de água fresca com status $=1$ )

c. Calcular:

$F w_{j}=\frac{\sum L_{i}+L_{j}}{C_{\text {out }}^{\text {max }} j}-\sum F_{i, j}$

$\operatorname{Cin}_{j}=\frac{\sum L_{i}}{\sum F_{i, j}+F w_{j}}$

Economia $=F w_{j}^{\text {sem reuso }}-F w_{j}$

Se a concentração de entrada do processo j for menor que a máxima permitida, ou seja, $C_{j, i n} \leq C_{j, i n}{ }^{\max }$, selecionar o processo $i$. Caso contrário, repetir o procedimento para o próximo processo $i$ com status $=1$.

d. Se $\mathrm{C}_{\mathrm{j}, \mathrm{in}}<\mathrm{C}_{\mathrm{j}, \mathrm{in}}{ }^{\max }$, repetir o item $c$ para o próximo processo $i$ com status $=1$, caso contrário repetir o item a. No máximo, dois processos i podem ser selecionados.

Passo 4 - Verificar a solução:

a. Verificar a posição de cada processo:

Savelski e Bagajewicz (2000) definiram os processos como:

- $\quad$ Processos iniciais: processos que utilizam apenas água fresca.

- Processos terminais: processos que são alimentados por água de reuso e descartam os seus efluentes para tratamento. 
A posição de cada processo na rede de água pode ser definida pelas concentrações máxima de contaminantes de entrada e de saída. Por exemplo, os processos com menores concentrações máximas e baixa carga de poluente tendem a receber apenas água fresca, como os processos iniciais. Por outro lado, os processos com concentrações máximas maiores e maior carga poluente tendem a receber águas residuais, como os processos de terminais.

Um critério arbitrário foi estabelecido para avaliar a posição dos processos Primeiramente é calculada a media geométrica entre a carga de contaminante e a concentração do contaminante na entrada (A) e na saída (B) de cada processo. Os processos são então ordenados de acordo com A e B. A posição de cada processo é dada de acordo com a soma das ordens obtidas; baixos valores representam os processos iniciais (carga baixa e baixa concentração máxima de contaminantes) e número maiores representam os processos terminais (carga alta e alta concentração máxima de contaminantes). Os processos com valores intermediários podem ser tanto iniciais quanto terminais e, portanto não são identificados nesse momento.

b. Verificar a possibilidade de maior reuso de água:

- Verificar, entre os processos que recebem água fresca e enviam seus efluentes para tratamento, quais têm concentração de entrada menor que a máxima permitida, ou seja, $\mathrm{C}_{\text {in }}<\mathrm{C}_{\text {in }}{ }^{\max }$.

- Dividir estes processos entre processos iniciais e terminais. Aqueles que atualmente apenas recebem água fresca sem enviar água residual para outro processo são definidos de acordo com a sua relação com os outros processos através da tabela construída no Passo 2.

- Analisar a possibilidade de reuso de água entre estes processos conforme o Passo 3. 


\subsection{APLICAÇÃO DO PROCEDIMENTO}

Para melhor compreensão do procedimento, são resolvidos dois exemplos encontrados na literatura, primeiramente um sistema com único e em seguida um sistema com múltiplo contaminantes.

\subsubsection{Sistema com único contaminante}

O exemplo escolhido foi estudado por Bagajewicz (2000) e considera dez operações que consomem água. As operações envolvidas, com suas respectivas cargas mássicas $(L)$ e concentrações máximas de entrada $\left(C_{\text {in }}{ }^{\text {max }}\right)$ e saída $\left(C_{\text {out }}{ }^{\text {max }}\right)$, além da vazão de água fresca necessária quando nenhum reuso é realizado $\left(F_{W}\right)$, estão apresentadas na Tabela 1. A solução ótima, obtida por programação matemática, está apresentada na Figura 15.

Tabela 1 - Dados dos processos para o sistema com único contaminante.

\begin{tabular}{c|cccc}
\hline Processo & $L(g / h)$ & $C_{i n}{ }^{\max }(p p m)$ & $C_{\text {out }}{ }^{\max }(\mathbf{p p m})$ & $\boldsymbol{F}_{W}(\mathbf{t} / \mathbf{h})$ \\
\hline $\mathbf{1}$ & 2000 & 25 & 80 & 25,00 \\
$\mathbf{2}$ & 2880 & 25 & 90 & 32,00 \\
$\mathbf{3}$ & 4000 & 25 & 200 & 20,00 \\
$\mathbf{4}$ & 3000 & 50 & 100 & 30,00 \\
$\mathbf{5}$ & 30000 & 50 & 800 & 37,50 \\
$\mathbf{6}$ & 5000 & 400 & 800 & 6,25 \\
$\mathbf{7}$ & 2000 & 400 & 600 & 3,33 \\
$\mathbf{8}$ & 1000 & 0 & 100 & 10,00 \\
$\mathbf{9}$ & 20000 & 50 & 300 & 66,67 \\
$\mathbf{1 0}$ & 6500 & 150 & 300 & 21,67 \\
\hline \multicolumn{7}{|}{} \\
\hline
\end{tabular}




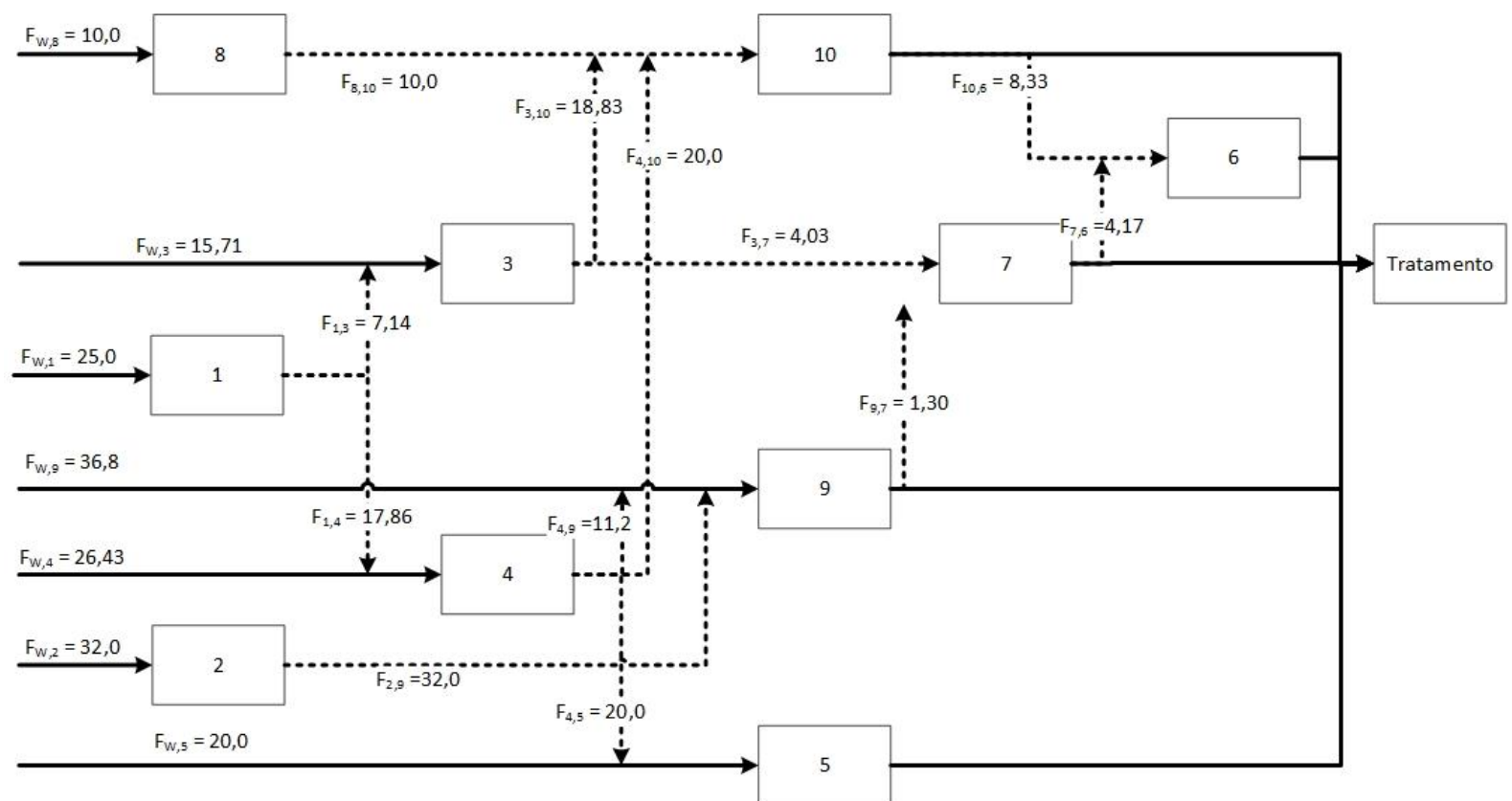

Figura 15 - Solução do sistema com único contaminante obtido por Bagajewicz (2000) - (vazões em $\mathrm{t} / \mathrm{h})$

Passo 1: Ordenar os processos em ordem decrescente de consumo de água fresca sem reuso $\left(F_{W}\right)$.

O resultado está apresentado na Tabela 2.

Tabela 2 - Processos ordenados em ordem decrescente de consumo de água.

\begin{tabular}{c|cccc}
\hline Processo & $L(g / h)$ & $C_{\text {in }}{ }^{\max }(\mathbf{p p m})$ & $\boldsymbol{C}_{\text {out }}{ }^{\max }(\mathbf{p p m})$ & $\boldsymbol{F}_{W}(\mathbf{t} / \mathbf{h})$ \\
\hline $\mathbf{9}$ & 20000 & 50 & 300 & 66,67 \\
$\mathbf{5}$ & 30000 & 50 & 800 & 37,50 \\
$\mathbf{2}$ & 2880 & 25 & 90 & 32,00 \\
$\mathbf{4}$ & 3000 & 50 & 100 & 30,00 \\
$\mathbf{1}$ & 2000 & 25 & 80 & 25,00 \\
$\mathbf{1 0}$ & 6500 & 150 & 300 & 21,67 \\
$\mathbf{3}$ & 4000 & 25 & 200 & 20,00 \\
$\mathbf{8}$ & 1000 & 0 & 100 & 10,00 \\
$\mathbf{6}$ & 5000 & 400 & 800 & 6,25 \\
$\mathbf{7}$ & 2000 & 400 & 600 & 3,33 \\
\hline
\end{tabular}


Passo 2: Para todos os pares de processos $i, j$ possíveis, verificar a condição $\mathrm{C}_{\text {out }, i}{ }^{\text {max }}<\mathrm{C}_{\text {out }, j}$ max .

Os resultados são mostrados na Tabela 3. Por exemplo, o processo 9 pode receber água dos processos 2, 4, 1, 3 e 8 (status = 1), mas não dos outros (status = 0).

Tabela 3 - Determinação dos possíveis pares i,j.

\begin{tabular}{c|ccccccccccccc}
\hline \multicolumn{1}{c}{ Processo } & $j$ & 9 & 5 & 2 & 4 & 1 & 10 & 3 & 8 & 6 & 7 \\
\hline $\mathbf{i}$ & $\mathrm{C}_{\text {out }}{ }^{\max }(\mathrm{ppm})$ & 300 & 800 & 90 & 100 & 80 & 300 & 200 & 100 & 800 & 600 \\
9 & 300 & 0 & 1 & 0 & 0 & 0 & 0 & 0 & 0 & 1 & 1 \\
5 & 800 & 0 & 0 & 0 & 0 & 0 & 0 & 0 & 0 & 0 & 0 \\
2 & 90 & 1 & 1 & 0 & 1 & 0 & 1 & 1 & 1 & 1 & 1 \\
4 & 100 & 1 & 1 & 0 & 0 & 0 & 1 & 1 & 0 & 1 & 1 \\
1 & 80 & 1 & 1 & 1 & 1 & 0 & 1 & 1 & 1 & 1 & 1 \\
10 & 300 & 0 & 1 & 0 & 0 & 0 & 0 & 0 & 0 & 1 & 1 \\
3 & 200 & 1 & 1 & 0 & 0 & 0 & 1 & 0 & 0 & 1 & 1 \\
8 & 100 & 1 & 1 & 0 & 0 & 0 & 1 & 1 & 0 & 1 & 1 \\
6 & 800 & 0 & 0 & 0 & 0 & 0 & 0 & 0 & 0 & 0 & 0 \\
7 & 600 & 0 & 1 & 0 & 0 & 0 & 0 & 0 & 0 & 1 & 0 \\
\hline
\end{tabular}

Passo 3: Construir a nova rede de água.

Conforme a Tabela 2 o primeiro processo a ser analisado é o processo 9 . De acordo com a Tabela 3 os processos que podem enviar água para 9 são 2, 4, 1, 3 e 8 . A análise é iniciada com o maior consumidor de água fresca com status $=1$, ou seja, processo 2. A Tabela 4 apresenta os resultados dos cálculos realizados. A concentração de entrada é menor que a concentração máxima permitida, ou seja, $\mathrm{C}_{\mathrm{in}, 9}<\mathrm{C}_{\mathrm{in}, 9}{ }^{\max }(37,76 \mathrm{ppm}<50 \mathrm{ppm})$, logo o processo 2 é selecionado. 
Tabela 4 - Análise inicial do processo 9.

\begin{tabular}{|c|c|c|c|c|c|c|c|}
\hline \multicolumn{2}{|c|}{ Processo } & \multirow{2}{*}{$\frac{L(g / h)}{20000}$} & \multirow{2}{*}{$\frac{\mathrm{C}_{\mathrm{in}}^{\max }(\mathrm{ppm})}{50}$} & \multirow{2}{*}{$\frac{\mathrm{C}_{\text {out }}{ }^{\max }(\mathbf{p p m})}{300}$} & \multirow{2}{*}{$\frac{F_{w}(t / h)}{66,67}$} & \multirow{2}{*}{$\frac{L_{i}(g / h)}{-}$} & \multirow{2}{*}{$\frac{F_{i, j}(t / h)}{-}$} \\
\hline $\mathrm{j}$ & 9 & & & & & & \\
\hline \multirow{5}{*}{$\mathbf{i}$} & 2 & 2880 & 25 & 90 & 32,00 & 2880 & 32,00 \\
\hline & 4 & 3000 & 50 & 100 & 30,00 & & \\
\hline & 1 & 2000 & 25 & 80 & 25,00 & & \\
\hline & 3 & 4000 & 25 & 200 & 20,00 & & \\
\hline & 8 & 1000 & 0 & 100 & 10,00 & & \\
\hline \multirow{2}{*}{$F_{W, j}(t / h)$} & \multirow{2}{*}{44,27} & \multirow{2}{*}{$C_{\text {in }}(p p m)$} & \multirow{2}{*}{37,76} & \multirow{2}{*}{$F_{W, j}$ economia $(t / h)$} & \multirow{2}{*}{22,40} & 2880 & 32 \\
\hline & & & & & & \multicolumn{2}{|c|}{ Total } \\
\hline
\end{tabular}

O mesmo cálculo é realizado para os outros processos $i$. O processo 8 é selecionado para enviar água para o processo 9 respeitando a concentração máxima de entrada, como apresentado na Tabela 5.

Tabela 5 - Análise final do processo 9.

\begin{tabular}{|c|c|c|c|c|c|c|c|}
\hline \multicolumn{2}{|c|}{ Processo } & \multirow{2}{*}{$\frac{L(g / h)}{20000}$} & \multirow{2}{*}{$\frac{\mathrm{C}_{\text {in }}^{\max }(\mathrm{ppm})}{50}$} & \multirow{2}{*}{$\frac{\mathrm{C}_{\text {out }}{ }^{\max }(\mathbf{p p m})}{300}$} & \multirow{2}{*}{$\frac{F_{w}(t / h)}{66,67}$} & \multirow{2}{*}{$\frac{\mathrm{L}_{\mathrm{i}}(\mathrm{g} / \mathrm{h})}{-}$} & \multirow{2}{*}{$\frac{\mathrm{F}_{\mathrm{i}, \mathrm{j}}(\mathrm{t} / \mathrm{h})}{-}$} \\
\hline j & 9 & & & & & & \\
\hline \multirow{5}{*}{$\mathbf{i}$} & 2 & 2880 & 25 & 90 & 32,00 & 2880 & 32,00 \\
\hline & 4 & 3000 & 50 & 100 & 30,00 & & \\
\hline & 1 & 2000 & 25 & 80 & 25,00 & & \\
\hline & 3 & 4000 & 25 & 200 & 20,00 & & \\
\hline & 8 & 1000 & 0 & 100 & 10,00 & 1000 & 10 \\
\hline$F_{W, j}(t / h)$ & 37,60 & $C_{\text {in }}(p p m)$ & 48,74 & $F_{W, j}$ economia $(t / h)$ & 29,07 & 3880 & 42 \\
\hline
\end{tabular}

Similarmente o processo 5 é analisado, o resultado é apresentado na Tabela 6. 
Tabela 6 - Análise do processo 5.

\begin{tabular}{|c|c|c|c|c|c|c|c|}
\hline \multicolumn{2}{|c|}{ Processo } & \multirow{2}{*}{$\begin{array}{l}\mathrm{L}(\mathrm{g} / \mathrm{h}) \\
30000\end{array}$} & \multirow{2}{*}{$\frac{\mathrm{C}_{\mathrm{in}}{ }^{\mathrm{max}}(\mathrm{ppm})}{50}$} & \multirow{2}{*}{$\frac{\text { Cout }^{\max }(p p m)}{800}$} & \multirow{2}{*}{$\begin{array}{c}\mathbf{F}_{\mathrm{w}}(\mathbf{t} / \mathbf{h}) \\
37,50\end{array}$} & \multirow{2}{*}{$\frac{\mathrm{Li}_{\mathrm{i}}(\mathrm{g} / \mathrm{h})}{-}$} & \multirow{2}{*}{$\begin{array}{c}\mathrm{Fi}, \mathrm{j}(\mathrm{t} / \mathrm{h}) \\
-\end{array}$} \\
\hline $\mathrm{j}$ & 5 & & & & & & \\
\hline \multirow{7}{*}{ i } & 2 & 2880 & 25 & 90 & 32,00 & \multirow{7}{*}{2000} & \multirow[t]{2}{*}{-} \\
\hline & 4 & 3000 & 50 & 100 & 30,00 & & \\
\hline & 1 & 2000 & 25 & 80 & 25,00 & & 25 \\
\hline & 10 & 6500 & 150 & 300 & 21,67 & & \\
\hline & 3 & 4000 & 25 & 200 & 20,00 & & \\
\hline & 8 & 1000 & 0 & 100 & 10,00 & & \\
\hline & 7 & 2000 & 400 & 600 & 3,33 & & \\
\hline$F_{w, j}(t / h)$ & 15,00 & $C_{\text {in }}(p p m)$ & 50,00 & $\mathrm{~F}_{\mathrm{W}, \mathrm{j}}$ economia $(\mathrm{t} / \mathrm{h})$ & 22,50 & 2000 & 25 \\
\hline
\end{tabular}

O próximo processo seria o 2 contudo este já foi usado para enviar água para o processo 9. Em seguida seria o processo 4, no entanto não existe processo disponível que possa enviar água de reuso (processo 1 alimentou processo 5 e processo 2 alimentou processo 9). O processo 10 é então analisado conforme a Tabela 7.

Tabela 7 - Análise do processo 10.

\begin{tabular}{|c|c|c|c|c|c|c|c|}
\hline \multicolumn{2}{|c|}{ Processo } & \multirow{2}{*}{$\frac{\mathrm{L}(\mathrm{g} / \mathrm{h})}{6500}$} & \multirow{2}{*}{$\frac{\mathrm{C}_{\text {in }}{ }^{\max }(\mathbf{p p m})}{150}$} & \multirow{2}{*}{$\frac{\mathrm{C}_{\text {out }}{ }^{\max }(\mathbf{p p m})}{300}$} & \multirow{2}{*}{$\frac{\mathbf{F}_{\mathrm{w}}(\mathbf{t} / \mathbf{h})}{21,67}$} & \multirow{2}{*}{$\frac{\mathrm{L}_{\mathrm{i}}(\mathrm{g} / \mathrm{h})}{-}$} & \multirow{2}{*}{$\frac{F i, j(t / h)}{-}$} \\
\hline $\mathbf{j}$ & 10 & & & & & & \\
\hline \multirow{5}{*}{$\mathbf{i}$} & 2 & 2880 & 25 & 90 & 32,00 & & - \\
\hline & 4 & 3000 & 50 & 100 & 30,00 & 3000 & 30 \\
\hline & 1 & 2000 & 25 & 80 & 25,00 & & - \\
\hline & 3 & 4000 & 25 & 200 & 20,00 & & \\
\hline & 8 & 1000 & 0 & 100 & 10,00 & & \\
\hline$F_{w, j}(t / h)$ & 1,67 & $C_{\text {in }}(p p m)$ & 94,74 & $F_{W, j}$ economia $(t / h)$ & 20,00 & 3000 & 30 \\
\hline
\end{tabular}

Apenas o processo 1 poderia enviar água para o processo 3 , logo o próximo processo analisado é o 6. Quando toda a vazão do processo 3 é utilizada , a vazão 
de água fresca necessária é negativa, ou seja, apenas parte da corrente de reuso é necessária. $O$ resultado é mostrado na Tabela 8.

Tabela 8 - Análise do processo 6.

\begin{tabular}{|c|c|c|c|c|c|c|c|}
\hline \multicolumn{2}{|c|}{ Processo } & \multirow{2}{*}{$\frac{\mathrm{L}(\mathrm{g} / \mathrm{h})}{5000}$} & \multirow{2}{*}{$\frac{\mathrm{C}_{\text {in }}{ }^{\max }(\mathrm{ppm})}{400}$} & \multirow{2}{*}{$\frac{\mathrm{C}_{\text {out }}{ }^{\max }(\mathbf{p p m})}{800}$} & \multirow{2}{*}{$\frac{F_{w}(t / h)}{6,25}$} & \multirow{2}{*}{$\frac{\mathrm{Li}_{\mathrm{i}}(\mathrm{g} / \mathrm{h})}{-}$} & \multirow{2}{*}{$\frac{F i, j(t / h)}{-}$} \\
\hline j & 6 & & & & & & \\
\hline \multirow{8}{*}{$\mathbf{i}$} & 9 & 20000 & 50 & 300 & 66,67 & & - \\
\hline & 2 & 2880 & 25 & 90 & 32,00 & & - \\
\hline & 4 & 3000 & 50 & 100 & 30,00 & & - \\
\hline & 1 & 2000 & 25 & 80 & 25,00 & & - \\
\hline & 10 & 6500 & 150 & 300 & 21,67 & & - \\
\hline & 3 & 4000 & 25 & 200 & 20,00 & 1667 & 8,33 \\
\hline & 8 & 1000 & 0 & 100 & 10,00 & & - \\
\hline & 7 & 2000 & 400 & 600 & 3,33 & & \\
\hline$F W, j(t / h)$ & 0,00 & $C_{\text {in }}(p p m)$ & 200,00 & $F_{W, j}$ economia $(t / h)$ & 6,25 & 1667 & 8,33 \\
\hline
\end{tabular}

O passo 3 é encerrado pois não há processo disponível para enviar água para o processo 7.

A Figura 16 apresenta a rede gerada e a Tabela 9 os dados de cada processo.

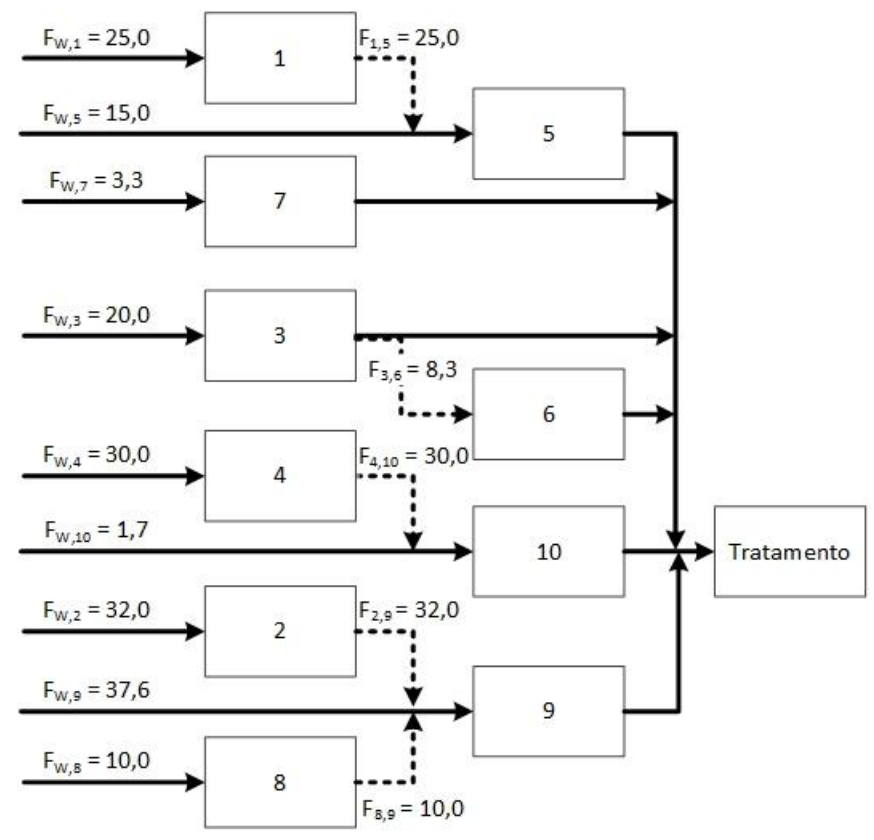

Figura 16 - Solução para o problema com único contaminante - (vazões em t/h). 
Tabela 9 - Dados do processo para a solução para o sistema com único contaminante.

\begin{tabular}{|c|c|c|c|c|c|c|c|c|c|}
\hline Processo & $L(g / h)$ & $\begin{array}{l}C_{i n}^{\max } \\
(p p m)\end{array}$ & $\begin{array}{l}C_{\text {out }}^{\max } \\
\text { (ppm) }\end{array}$ & $F_{w}(t / h)$ & $\begin{array}{c}\text { Água de reuso } \\
(t / h)\end{array}$ & $\begin{array}{c}\text { Água total } \\
(t / h)\end{array}$ & $\begin{array}{c}C_{i n} \\
(p p m)\end{array}$ & $\begin{array}{c}C_{\text {out }} \\
\text { (ppm) }\end{array}$ & $\begin{array}{l}\text { Efluente } \\
(t / h)\end{array}$ \\
\hline 1 & 2000 & 25 & 80 & 25.00 & 0.00 & 25.00 & 0 & 80 & 0.00 \\
\hline 2 & 2880 & 25 & 90 & 32.00 & 0.00 & 32.00 & 0 & 90 & 0.00 \\
\hline 3 & 4000 & 25 & 200 & 20.00 & 0.00 & 20.00 & 0 & 200 & 11.67 \\
\hline 4 & 3000 & 50 & 100 & 30.00 & 0.00 & 30.00 & 0 & 100 & 0.00 \\
\hline 5 & 30000 & 50 & 800 & 15.00 & 25.00 & 40.00 & 50 & 800 & 40.00 \\
\hline 6 & 5000 & 400 & 800 & 0.00 & 8.33 & 8.33 & 200 & 800 & 8.33 \\
\hline 7 & 2000 & 400 & 600 & 3.33 & 0.00 & 3.33 & 0 & 600 & 3.33 \\
\hline 8 & 1000 & 0 & 100 & 10.00 & 0.00 & 10.00 & 0 & 100 & 0.00 \\
\hline 9 & 20000 & 50 & 300 & 37.60 & 42.00 & 79.60 & 49 & 300 & 79.60 \\
\hline 10 & 6500 & 150 & 300 & 1.67 & 30.00 & 31.67 & 95 & 300 & 31.67 \\
\hline & & & Total: & 174.60 & & & & & \\
\hline
\end{tabular}

Passo 4: Verificar a solução:

\section{a. Verificar a posição de cada processo}

Tabela 10 - Verificação da posição do processo para o sistema com único contaminante.

\begin{tabular}{|c|c|c|c|c|c|c|c|c|c|}
\hline Processo & $\stackrel{L}{L}$ & $\begin{array}{l}C_{\text {in }}^{\max } \\
(p p m)\end{array}$ & $\begin{array}{l}C_{\text {out }}^{\max } \\
\text { (ppm) }\end{array}$ & $\left(C_{i n}{ }^{\operatorname{Aax}} \times L\right)^{1 / 2}$ & $\begin{array}{l}\text { Ordem } \\
\quad A\end{array}$ & $\left(C_{\text {out }}{ }^{\max } X L\right)^{1 / 2}$ & $\begin{array}{c}\text { Ordem } \\
\text { B }\end{array}$ & $\begin{array}{c}\text { Soma das } \\
\text { ordens }\end{array}$ & $\begin{array}{l}\text { Posição } \\
\text { na rede }\end{array}$ \\
\hline 1 & 2000 & 25 & 80 & 224 & 2 & 400 & 2 & 4 & Inicial \\
\hline 2 & 2880 & 25 & 90 & 268 & 3 & 509 & 3 & 6 & Inicial \\
\hline 3 & 4000 & 25 & 200 & 316 & 4 & 894 & 5 & 9 & \\
\hline 4 & 3000 & 50 & 100 & 387 & 5 & 548 & 4 & 9 & \\
\hline 5 & 30000 & 50 & 800 & 1225 & 9 & 4899 & 10 & 19 & Terminal \\
\hline 6 & 5000 & 400 & 800 & 1414 & 10 & 2000 & 8 & 18 & Terminal \\
\hline 7 & 2000 & 400 & 600 & 894 & 6 & 1095 & 6 & 12 & \\
\hline 8 & 1000 & 0 & 100 & 0 & 1 & 316 & 1 & 2 & Inicial \\
\hline 9 & 20000 & 50 & 300 & 1000 & 8 & 2449 & 9 & 17 & Terminal \\
\hline 10 & 6500 & 150 & 300 & 987 & 7 & 1396 & 7 & 14 & \\
\hline
\end{tabular}

Conforme a soma das ordens de $A$ e $B$ os processos iniciais e terminais são identificados. A partir da Tabela 10 é possível verificar que a rede gerada obedece à posição de cada processo. 
b. Verificar a possibilidade de maior reuso

De acordo com a Figura 16 os processos 7, 3 e 10 recebem água fresca e enviam seus efluente para tratamento além disso, apresentam concentração de entrada menor que a máxima permitida, ou seja, $\mathrm{C}_{\mathrm{in}}<\mathrm{C}_{\mathrm{in}}{ }^{\max }$. $\mathrm{O}$ processo 9 não foi considerado pois a concentração de entrada é praticamente a máxima. Segundo a solução o processo 3 é um processo inicial e o processo 10 um processo terminal.

Atualmente o processo 7 apenas recebe água fresca e descarta totalmente para 0 tratamento. De acordo com a Tabela 3, o processo 7 pode receber água do processo 3 e não pode enviar água para o processo 10, sendo, portanto, um processo terminal.

São analisadas então as possibilidades de reuso do processo 3 para os processos 10 e 7, conforme a Tabela 11 e a Tabela 12 , respectivamente. A nova solução obtida para o problema está apresentada na Figura 17.

Tabela 11 - Verificação do processo 7.

\begin{tabular}{|c|c|c|c|c|c|c|c|}
\hline \multicolumn{2}{|c|}{ Processo } & $L(g / h)$ & $\begin{array}{l}C_{\text {in }}^{{ }^{\max }} \\
(p p m)\end{array}$ & $C_{\text {out }}{ }^{\max }(p p m)$ & $F_{w}(t / h)$ & $L_{i}(g / h)$ & $F i, j(t / h)$ \\
\hline j & 7 & 2000 & 400 & 600 & 3,33 & - & - \\
\hline \multirow{8}{*}{$\mathbf{i}$} & 9 & 20000 & 50 & 300 & 66,67 & & - \\
\hline & 5 & 30000 & 50 & 800 & 37,50 & & - \\
\hline & 2 & 2880 & 25 & 90 & 32,00 & & - \\
\hline & 4 & 3000 & 50 & 100 & 30,00 & & - \\
\hline & 1 & 2000 & 25 & 80 & 25,00 & & - \\
\hline & 10 & 6500 & 150 & 300 & 21,67 & & - \\
\hline & 3 & 4000 & 25 & 200 & 20,00 & 1000 & 5,00 \\
\hline & 8 & 1000 & 0 & 100 & 10,00 & & - \\
\hline$F_{w, j}(t / h)$ & 0,00 & $C_{\text {in }}(p p m)$ & 200,00 & $F_{W, j}$ economia $(t / h)$ & 3,33 & 1000 & 5,00 \\
\hline
\end{tabular}


Tabela 12 - Verificação do processo 10.

\begin{tabular}{|c|c|c|c|c|c|c|c|}
\hline \multicolumn{2}{|c|}{ Processo } & \multirow{2}{*}{$\frac{L(g / h)}{6500}$} & \multirow{2}{*}{ 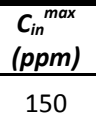 } & \multirow{2}{*}{$\frac{C_{\text {out }}{ }^{\max }(\mathbf{p p m})}{300}$} & \multirow{2}{*}{$\frac{F_{w}(t / h)}{21,67}$} & \multirow{2}{*}{$\frac{L_{i}(g / h)}{-}$} & \multirow{2}{*}{$\begin{array}{c}F i, j(t / h) \\
-\end{array}$} \\
\hline j & 10 & & & & & & \\
\hline \multirow{5}{*}{$\mathbf{i}$} & 2 & 2880 & 25 & 90 & 32,00 & & - \\
\hline & 4 & 3000 & 50 & 100 & 30,00 & 3000 & 30 \\
\hline & 1 & 2000 & 25 & 80 & 25,00 & & - \\
\hline & 3 & 4000 & 25 & 200 & 20,00 & 1000 & 5 \\
\hline & 8 & 1000 & 0 & 100 & 10,00 & & - \\
\hline$F_{w, j}(t / h)$ & 0,00 & $C_{\text {in }}(p p m)$ & 114,29 & $F_{w, j}$ economia $(t / h)$ & 21,67 & 4000 & 35 \\
\hline
\end{tabular}

Quando a corrente de efluente do processo 3 é dividida em três para alimentar os processos 6, 7 e 10, a economia de água é ainda maior. Contudo essa divisão viola uma das regras heurísticas, sendo necessário analisar se a redução extra de água compensa a instalação dos novos ramais. Nesse caso, a divisão de correntes resulta em uma redução de apenas $2 \%$ em relação à configuração anterior. Logo, a solução final considerada é a obtida antes da etapa de verificação, apresentada na Figura 16. É importante enfatizar que a etapa de verificação aproxima ainda mais a solução da solução ótima e se a nova redução tiver um impacto significante no consumo de água, a divisão da corrente deve ser economicamente avaliada. 


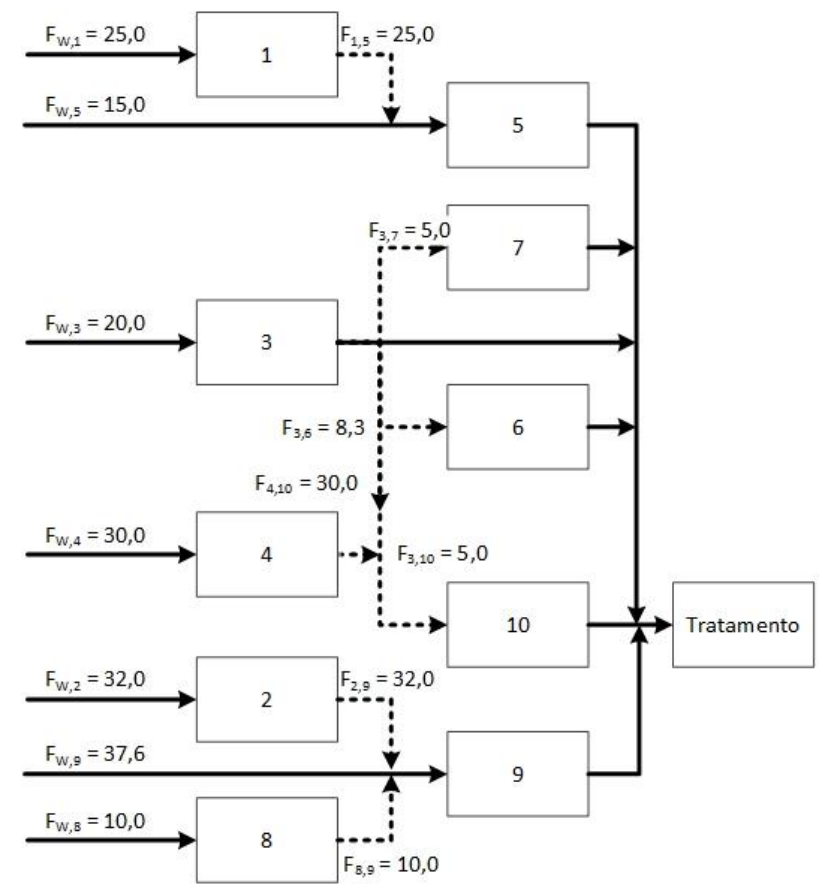

Figura 17 - Solução para o problema com único contaminante após a verificação (vazões em t/h).

Como apresentado na Tabela 13, o consumo de água da rede obtida pelo novo procedimento é igual a 174,6 t/h, o que representa uma redução de 30,83\% quando comparado com a configuração sem reuso. Embora o consumo de água seja aproximadamente 3\% maior que a solução ótima obtida por Bagajewicz (2000) através de otimização matemática, a nova configuração necessita de menos da metade de conexões entre os processos.

Tabela 13 - Comparação das soluções para o problema com único contaminante.

\begin{tabular}{c|ccc}
\hline Comparação & $\begin{array}{c}\text { Novo procedimento } \\
\text { (Figura 16) }\end{array}$ & $\begin{array}{c}\text { Bagajewicz (2000) - Mínimo } \\
\text { consumo de água fresca }\end{array}$ & $\begin{array}{c}\text { Bagajewicz e Savelski (2001) - } \\
\text { Mínimo número de conexões }\end{array}$ \\
\hline Água fresca (t/h) & 174,6 & 165,94 & 165,94 \\
Redução de água fresca & $30,83 \%$ & $34,26 \%$ & $34,26 \%$ \\
Número de conexões & 5 & 12 & 9 \\
\hline
\end{tabular}

Bagajewicz e Savelski (2001) notaram que algumas conexões da solução ótima são muito pequenas, requerendo, por exemplo, uma tubulação de diâmetro de apenas $15 \mathrm{~mm}$. Por isso, eles também resolveram o problema de forma a minimizar o número de conexões para o mesmo mínimo consumo de água fresca. O número de 
conexões obtido foi de 9 conexões, maior que o atingido pelo procedimento heurístico.

Para este exemplo podemos realizar apenas a verificação geral, visto que não temos dados disponíveis da planta industrial para fazer uma verificação específica posterior.

\subsubsection{Sistema com múltiplos contaminantes}

Aplicou-se também a metodologia em um sistema com múltiplos contaminantes. $\mathrm{O}$ estudo de caso escolhido, proposto por Koppol (2003), aborda seis operações em uma refinaria de petróleo. As operações envolvidas, com suas respectivas cargas mássicas $(L)$ e concentrações máximas de entrada $\left(C_{i n}{ }^{\text {max }}\right)$ e saída $\left(C_{\text {out }}{ }^{\text {max }}\right)$, dos quatro tipos de contaminantes presentes (sais, orgânicos, $\mathrm{H}_{2} \mathrm{~S}$ e amônia) estão apresentadas na Tabela 14. 
Tabela 14 - Dados do sistema com múltiplos contaminantes.

\begin{tabular}{|c|c|c|c|c|}
\hline Processo & Contaminante & $L(g / h)$ & $C_{i n}^{\max }(p p m)$ & $C_{\text {out }}^{\max }(p p m)$ \\
\hline \multirow{4}{*}{ (1) Tratamento cáustico } & Sais & 180 & 300 & 500 \\
\hline & Orgânicos & 1200 & 50 & 500 \\
\hline & $\mathrm{H}_{2} \mathrm{~S}$ & 750 & 5000 & 11000 \\
\hline & Amônia & 100 & 15000 & 3000 \\
\hline \multirow{4}{*}{ (2) Destilação } & Sais & 3610 & 10 & 200 \\
\hline & Orgânicos & 100000 & 1 & 4000 \\
\hline & $\mathrm{H}_{2} \mathrm{~S}$ & 250 & 0 & 500 \\
\hline & Amônia & 800 & 0 & 1000 \\
\hline \multirow{4}{*}{ (3) Adoçamento com amina } & Sais & 600 & 10 & 1000 \\
\hline & Orgânicos & 30000 & 1 & 3500 \\
\hline & $\mathrm{H}_{2} \mathrm{~S}$ & 1500 & 0 & 2000 \\
\hline & Amônia & 1000 & 0 & 3500 \\
\hline \multirow{4}{*}{ (4) Adoçamento (Merox I) } & Sais & 2000 & 100 & 400 \\
\hline & Orgânicos & 60000 & 200 & 6000 \\
\hline & $\mathrm{H}_{2} \mathrm{~S}$ & 800 & 50 & 2000 \\
\hline & Amônia & 1000 & 1000 & 3500 \\
\hline \multirow{4}{*}{ (5) Hidrotratamento } & Sais & 3800 & 85 & 350 \\
\hline & Orgânicos & 45000 & 200 & 1800 \\
\hline & $\mathrm{H}_{2} \mathrm{~S}$ & 1100 & 300 & 6500 \\
\hline & Amônia & 2000 & 300 & 1000 \\
\hline \multirow{4}{*}{ (6) Desssalgadora } & Sais & 120000 & 1000 & 9500 \\
\hline & Orgânicos & 480000 & 1000 & 6500 \\
\hline & $\mathrm{H}_{2} \mathrm{~S}$ & 1500 & 150 & 450 \\
\hline & Amônia & 0 & 200 & 400 \\
\hline
\end{tabular}

A Tabela 15 apresenta a base de água fresca necessária para cada contaminante em cada processo, neste caso, em todos os processos o contaminante chave são os orgânicos. A Tabela 16 reúne os dados considerando apenas o contaminante chave. 
Tabela 15 - Base de água fresca para cada contaminante em todos os processos.

\begin{tabular}{|c|c|c|c|c|c|}
\hline Processo & Contaminante & $L(g / h)$ & $C_{i n}{ }^{\max }(p p m)$ & $C_{\text {out }}^{\max }(p p m)$ & Base de água fresca $(t / h)$ \\
\hline \multirow{4}{*}{ (1) Tratamento cáustico } & Sais & 180 & 300 & 500 & 0,36 \\
\hline & Orgânicos & 1200 & 50 & 500 & 2,40 \\
\hline & $\mathrm{H}_{2} \mathrm{~S}$ & 750 & 5000 & 11000 & 0,07 \\
\hline & Amônia & 100 & 15000 & 3000 & 0,03 \\
\hline \multirow{4}{*}{ (2) Destilação } & Sais & 3610 & 10 & 200 & 18,05 \\
\hline & Orgânicos & 100000 & 1 & 4000 & 25,00 \\
\hline & $\mathrm{H}_{2} \mathrm{~S}$ & 250 & 0 & 500 & 0,50 \\
\hline & Amônia & 800 & 0 & 1000 & 0,80 \\
\hline \multirow{4}{*}{ (3) Adoçamento com amina } & Sais & 600 & 10 & 1000 & 0,60 \\
\hline & Orgânicos & 30000 & 1 & 3500 & 8,57 \\
\hline & $\mathrm{H}_{2} \mathrm{~S}$ & 1500 & 0 & 2000 & 0,75 \\
\hline & Amônia & 1000 & 0 & 3500 & 0,29 \\
\hline \multirow{4}{*}{ (4) Adoçamento (Merox I) } & Sais & 2000 & 100 & 400 & 5,00 \\
\hline & Orgânicos & 60000 & 200 & 6000 & 10,00 \\
\hline & $\mathrm{H}_{2} \mathrm{~S}$ & 800 & 50 & 2000 & 0,40 \\
\hline & Amônia & 1000 & 1000 & 3500 & 0,29 \\
\hline \multirow{4}{*}{ (5) Hidrotratamento } & Sais & 3800 & 85 & 350 & 10,86 \\
\hline & Orgânicos & 45000 & 200 & 1800 & 25,00 \\
\hline & $\mathrm{H}_{2} \mathrm{~S}$ & 1100 & 300 & 6500 & 0,17 \\
\hline & Amônia & 2000 & 300 & 1000 & 2,00 \\
\hline \multirow{4}{*}{ (6) Desssalgadora } & Sais & 120000 & 1000 & 9500 & 13 \\
\hline & Orgânicos & 480000 & 1000 & 6500 & 73,85 \\
\hline & $\mathrm{H}_{2} \mathrm{~S}$ & 1500 & 150 & 450 & 3,33 \\
\hline & Amônia & 0 & 200 & 400 & 0,00 \\
\hline
\end{tabular}

Tabela 16 - Dados dos processos para o sistema com único contaminante considerando o contaminante chave.

\begin{tabular}{c|cccc}
\hline Processo & $L(g / h)$ & $C_{\text {in }}{ }^{\max }(p p m)$ & $C_{\text {out }}{ }^{\max }(p p m)$ & $F_{W}(t / h)$ \\
\hline $\mathbf{1}$ & 1200 & 50 & 500 & 2,40 \\
$\mathbf{2}$ & 100000 & 1 & 4000 & 25,00 \\
$\mathbf{3}$ & 30000 & 1 & 3500 & 8,57 \\
$\mathbf{4}$ & 60000 & 200 & 6000 & 10,00 \\
$\mathbf{5}$ & 45000 & 200 & 1800 & 25,00 \\
$\mathbf{6}$ & 480000 & 1000 & 6500 & 73,85 \\
\hline & & & Total: & $\mathbf{1 4 4 , 8 2}$ \\
\hline
\end{tabular}


Passo 1: Ordenar os processos em ordem decrescente de consumo de água fresca sem reuso.

O resultado é mostrado na Tabela 17.

Tabela 17 - Processos ordenados em ordem decrescente de consumo de água.

\begin{tabular}{c|cccc}
\hline Processo & $L(g / h)$ & $C_{\text {in }}{ }^{\max }(p p m)$ & $C_{\text {out }}{ }^{\max }(\mathbf{p p m})$ & $\boldsymbol{F}_{W}(\mathrm{t} / \mathrm{h})$ \\
\hline $\mathbf{6}$ & 480000 & 1000 & 6500 & 73,85 \\
$\mathbf{2}$ & 100000 & 1 & 4000 & 25,00 \\
$\mathbf{5}$ & 45000 & 200 & 1800 & 25,00 \\
$\mathbf{4}$ & 60000 & 200 & 6000 & 10,00 \\
$\mathbf{3}$ & 30000 & 1 & 3500 & 8,57 \\
$\mathbf{1}$ & 1200 & 50 & 500 & 2,40 \\
\hline
\end{tabular}

Passo 2: Para todos os pares de processos i,j possíveis, verificar a condição $\mathrm{C}_{\text {out }, i}{ }^{\text {max }}<\mathrm{C}_{\text {out }, j}$ max .

Os resultados são mostrados na Tabela 18.

Tabela 18 - Determinação dos possíveis pares i,j.

\begin{tabular}{c|ccccccc}
\hline Processo & $j$ & 6 & 2 & 5 & 4 & 3 & 1 \\
\hline$i$ & $C_{\text {out }}{ }^{\max }(\mathrm{ppm})$ & 6500 & 4000 & 1800 & 6000 & 3500 & 500 \\
6 & 6500 & 0 & 0 & 0 & 0 & 0 & 0 \\
2 & 4000 & 1 & 0 & 0 & 1 & 0 & 0 \\
5 & 1800 & 1 & 1 & 0 & 1 & 1 & 0 \\
4 & 6000 & 1 & 0 & 0 & 0 & 0 & 0 \\
3 & 3500 & 1 & 1 & 0 & 1 & 0 & 0 \\
1 & 500 & 1 & 1 & 1 & 1 & 1 & 0 \\
\hline
\end{tabular}

Passo 3: Construir a nova rede de água:

De acordo com a Tabela 18 o primeiro processo analisado é o processo 6 referente à dessalgadora. Este processo pode receber água de reuso dos processos 5 e 1. 
Tabela 19 - Análise do processo 6 - dessalgadora.

\begin{tabular}{|c|c|c|c|c|c|c|c|}
\hline \multicolumn{2}{|c|}{ Processo } & \multirow{2}{*}{$\frac{L(g / h)}{480000}$} & \multirow{2}{*}{$\frac{C_{\text {in }}{ }^{\max }(p p m)}{1000}$} & \multirow{2}{*}{$\frac{C_{\text {out }}^{\max }(\mathbf{p p m})}{6500}$} & \multirow{2}{*}{$\frac{F_{w}(t / h)}{73,85}$} & \multirow{2}{*}{$\frac{L_{i}(g / h)}{-}$} & \multirow{2}{*}{$\frac{F_{i, j}(t / h)}{-}$} \\
\hline j & 6 & & & & & & \\
\hline \multirow{5}{*}{ i } & 2 & 100000 & 1 & 4000 & 25,00 & & \\
\hline & 5 & 45000 & 200 & 1800 & 25,00 & 45000 & 25,00 \\
\hline & 4 & 60000 & 200 & 6000 & 10,00 & \multirow{3}{*}{30000} & \multirow{3}{*}{8,57} \\
\hline & 3 & 30000 & 1 & 3500 & 8,57 & & \\
\hline & 1 & 1200 & 50 & 500 & 2,40 & & \\
\hline$F_{w, j}(t / h)$ & 51,81 & $C_{\text {in }}(p p m)$ & 878,38 & $\begin{array}{c}F_{W, j} \text { economia } \\
(t / h)\end{array}$ & 22,03 & 75000 & $\begin{array}{l}33,57 \\
\text { al }\end{array}$ \\
\hline
\end{tabular}

O processo seguinte seria a destilação (2), contudo, a sua concentração máxima de entrada é praticamente nula (1), não sendo vantajoso receber água de nenhum dos outros processos.

O último processo analisado é o adoçamento (4) que, conforme a Tabela 20, recebe água do processo 1. A solução obtida é apresentada na Figura 18 e na Tabela 21.

Tabela 20 - Análise do processo 4 - adoçamento (Merox I).

\begin{tabular}{|c|c|c|c|c|c|c|c|}
\hline \multicolumn{2}{|c|}{ Processo } & $L(g / h)$ & $C_{i n}^{\max }(p p m)$ & $C_{\text {out }}{ }^{\max }(p p m)$ & $F_{w}(t / h)$ & $L_{i}(g / h)$ & $F_{i, j}(t / h)$ \\
\hline j & 4 & 60000 & 200 & 6000 & 10,00 & - & - \\
\hline \multirow{4}{*}{$\mathbf{i}$} & 2 & 100000 & 1 & 4000 & 25,00 & & \\
\hline & 5 & 45000 & 200 & 1800 & 25,00 & & \\
\hline & 3 & 30000 & 1 & 3500 & 8,57 & & \\
\hline & 1 & 1200 & 50 & 500 & 2,40 & 1200 & 2,40 \\
\hline$F_{w, j}(t / h)$ & 7,80 & $C_{\text {in }}(p p m)$ & 117,65 & $\mathrm{~F}_{\mathrm{w}, \mathrm{j}}$ economia $(\mathrm{t} / \mathrm{h})$ & 2,20 & 1200 & 2,40 \\
\hline
\end{tabular}




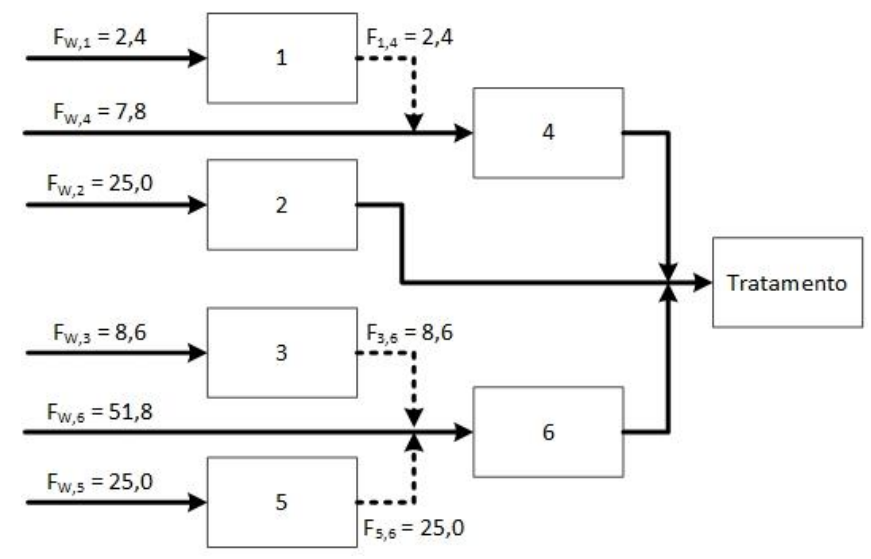

Figura 18 - Solução para o problema com múltiplos contaminantes - (vazões em t/h).

Tabela 21 - Dados do processo para a solução para o sistema com múltiplos contaminantes.

\begin{tabular}{|c|c|c|c|c|c|c|c|c|c|}
\hline Processo & $L(g / h)$ & $\begin{array}{l}C_{\text {in }}^{\max } \\
(p p m)\end{array}$ & $\begin{array}{l}C_{\text {out }}^{\max } \\
(p p m)\end{array}$ & $\begin{array}{c}F_{w} \\
(t / h)\end{array}$ & $\begin{array}{c}\text { Água de } \\
\text { reuso }(t / h)\end{array}$ & $\begin{array}{c}\text { Água } \\
\text { total }(t / h)\end{array}$ & $\begin{array}{c}C_{\text {in }} \\
(p p m)\end{array}$ & $\begin{array}{c}C_{\text {out }} \\
\text { (ppm) }\end{array}$ & $\begin{array}{c}\text { Efluente } \\
(t / h)\end{array}$ \\
\hline 1 & 1200 & 50 & 500 & 2,40 & 0,00 & 2,40 & 0,00 & 500,00 & 0,00 \\
\hline 2 & 100000 & 1 & 4000 & 25,00 & 0,00 & 25,00 & 0,00 & 4000,00 & 25,00 \\
\hline 3 & 30000 & 1 & 3500 & 8,57 & 0,00 & 8,57 & 0,00 & 3500,00 & 0,00 \\
\hline 4 & 60000 & 200 & 6000 & 7,80 & 2,40 & 10,20 & 117,65 & 6000,00 & 10,20 \\
\hline 5 & 45000 & 200 & 1800 & 25,00 & 0,00 & 25,00 & 0,00 & 1800,00 & 0,00 \\
\hline 6 & 480000 & 1000 & 6500 & 51,81 & 33,57 & 85,38 & 878,38 & 6500,00 & 85,38 \\
\hline
\end{tabular}

\section{Passo 4: Verificar a solução:}

\section{a. Verificar a posição de cada processo}

Tabela 22 - Verificação da posição do processo para o sistema com múltiplos contaminantes.

\begin{tabular}{|c|c|c|c|c|c|c|c|c|c|}
\hline Processo & $L(g / h)$ & $\begin{array}{l}C_{\text {in }}{ }^{\max } \\
(\text { ppm) }\end{array}$ & $\begin{array}{l}C_{\text {out }}^{\max } \\
\text { (ppm) }\end{array}$ & $\underset{\left(C_{i n}{ }^{\max } X L\right)^{1 / 2}}{A}$ & $\begin{array}{c}\text { Ordem } \\
A\end{array}$ & $\left(C_{\text {out }} \underset{\max }{B} X L\right)^{1 / 2}$ & $\begin{array}{c}\text { Ordem } \\
\text { B }\end{array}$ & $\begin{array}{c}\text { Soma das } \\
\text { ordens }\end{array}$ & $\begin{array}{l}\text { Posição } \\
\text { na rede }\end{array}$ \\
\hline 1 & 1200 & 50 & 500 & 8 & 1 & 24 & 1 & 2 & Inicial \\
\hline 2 & 100000 & 1 & 4000 & 10 & 3 & 632 & 5 & 8 & \\
\hline 3 & 30000 & 1 & 3500 & 5 & 1 & 324 & 3 & 4 & Inicial \\
\hline 4 & 60000 & 200 & 6000 & 110 & 5 & 600 & 4 & 9 & Terminal \\
\hline 5 & 45000 & 200 & 1800 & 95 & 4 & 285 & 2 & 6 & \\
\hline 6 & 480000 & 1000 & 6500 & 693 & 6 & 1766 & 6 & 12 & Terminal \\
\hline
\end{tabular}


Conforme a soma das ordens de A e B os processos iniciais e terminais são identificados. A partir da Tabela 22 é possível verificar que a rede gerada obedece às posições.

b. Verificar a possibilidade de maior reuso

De acordo com a solução obtida, os processos 2, 4 e 6 recebem água fresca e enviam seus efluente para tratamento e apresentam concentração de entrada menor que a máxima permitida, ou seja, $\mathrm{C}_{\mathrm{in}}<\mathrm{C}_{\mathrm{in}}{ }^{\max }$. Segundo a solução, os processos 4 e 6 são processos terminais.

Atualmente o processo 2 apenas recebe água fresca e descarta totalmente para o tratamento. De acordo com as relações entre processos definida pela Tabela 18, 0 processo 2 pode enviar água para os processos 4 e 6, podendo ser, portanto, um processo inicial.

São analisadas então as possibilidades de reuso do processo 2 para os processos 4 e 6, conforme a Tabela 23 e a Tabela 24, respectivamente.

Tabela 23 - Verificação do processo 4 - adoçamento (Merox I).

\begin{tabular}{|c|c|c|c|c|c|c|c|}
\hline \multicolumn{2}{|c|}{ Processo } & \multirow{2}{*}{$\begin{array}{l}L(g / h) \\
60000 \\
\end{array}$} & \multirow{2}{*}{$\frac{C_{\text {in }}^{\text {max }}(p p m)}{200}$} & \multirow{2}{*}{$\frac{C_{\text {out }}^{\max }(p p m)}{6000}$} & \multirow{2}{*}{$\begin{array}{c}\boldsymbol{F}_{w}(\mathrm{t} / \mathrm{h}) \\
10,00 \\
\end{array}$} & \multirow{2}{*}{$\begin{array}{c}\begin{array}{c}L_{i} \\
(g / h)\end{array} \\
- \\
\end{array}$} & \multirow{2}{*}{$\frac{F_{i, j}(t / h)}{-}$} \\
\hline $\mathbf{j}$ & 4 & & & & & & \\
\hline \multirow{4}{*}{ i } & 2 & 100000 & 1 & 4000 & 25,00 & 868,97 & 0,22 \\
\hline & 5 & 45000 & 200 & 1800 & 25,00 & & \\
\hline & 3 & 30000 & 1 & 3500 & 8,57 & & \\
\hline & 1 & 1200 & 50 & 500 & 2,40 & 1200 & 2,40 \\
\hline \multirow{2}{*}{$F_{W, j}(t / h)$} & \multirow{2}{*}{7,73} & \multirow{2}{*}{$C_{\text {in }}(p p m)$} & \multirow{2}{*}{200,00} & \multirow{2}{*}{$\begin{array}{c}F_{W, j} \text { economia } \\
(t / h)\end{array}$} & \multirow{2}{*}{2,27} & 2069 & 2,62 \\
\hline & & & & & & \multicolumn{2}{|c|}{ Total } \\
\hline
\end{tabular}


Tabela 24 - Verificação do processo 6 - dessalgadora.

\begin{tabular}{|c|c|c|c|c|c|c|c|}
\hline \multicolumn{2}{|c|}{ Processo } & $L(g / h)$ & $C_{i n}{ }^{\max }(p p m)$ & $C_{\text {out }}{ }^{\max }(p p m)$ & $F_{w}(t / h)$ & $L_{i}(g / h)$ & $F_{i, j}(t / h)$ \\
\hline j & 6 & 480000 & 1000 & 6500 & 73,85 & - & - \\
\hline \multirow{5}{*}{ i } & 2 & 100000 & 1 & 4000 & 25,00 & 12272,69 & 3,07 \\
\hline & 5 & 45000 & 200 & 1800 & 25,00 & 45000 & 25,00 \\
\hline & 4 & 60000 & 200 & 6000 & 10,00 & \multirow{3}{*}{30000} & \multirow{3}{*}{8,57} \\
\hline & 3 & 30000 & 1 & 3500 & 8,57 & & \\
\hline & 1 & 1200 & 50 & 500 & 2,40 & & \\
\hline$F_{W, j}(t / h)$ & 50,63 & $C_{\text {in }}(p p m)$ & 1000,00 & $\begin{array}{c}F_{w, j} \text { economia } \\
(t / h)\end{array}$ & 23,21 & Total & 36,64 \\
\hline
\end{tabular}

Verificou-se que o processo 2 poderia alimentar o processo 4, contudo seria necessária uma divisão de corrente para uma vazão muito pequena, que resultaria em baixa economia de água (0,05\% maior comparada com a solução obtida antes da verificação). O processo 2 também poderia alimentar o processo 6 mas isso exigiria que o processo 6 fosse alimentado por três processos diferentes, violando a heurística 3. A economia obtida seria apenas $1 \%$ maior, não compensando a divisão. Logo, a solução final considerada é aquela apresentada na Figura 18

A vazão de água fresca necessária para a configuração da rede proposta é de 120,58 t/h, o que representa uma redução de $16,73 \%$ no consumo de água da refinaria de petróleo estudada. A Tabela 25 compara os resultados obtidos por Ulson de Souza et al. (2009) através do método heurístico baseado em análise pinch "Diagrama de Fontes de Água" (Figura 19), e por Koppol et al. (2003) através de otimização matemática (Figura 20). Embora o método proposto não atinja a mínima redução de água, como as outras metodologias, a diferença entre os resultados é menor que $1 \%$, com a vantagem de que a rede de água proposta apresenta o menor número de conexões. 
Tabela 25 - Comparação das soluções para o problema com múltiplo contaminantes.

\begin{tabular}{c|ccc}
\hline Comparação & Novo procedimento (Figura 18) & Ulson de Souza et al. (2009) & Koppol et al. (2003) \\
\hline Água fresca (t/h) & 120,58 & 119,49 & 119,33 \\
Redução de água fresca & $16,73 \%$ & $17,5 \%$ & $17,6 \%$ \\
Número de conexões & 3 & 4 & 6 \\
\hline
\end{tabular}

O procedimento proposto por Ulson de Souza et al. (2004), apesar de chegar ao consumo ótimo de água e ter baixo número de correntes intermediárias, apresenta uma rede complexa. De modo que um único processo recebe, indiretamente, água de reuso de outros quatro.

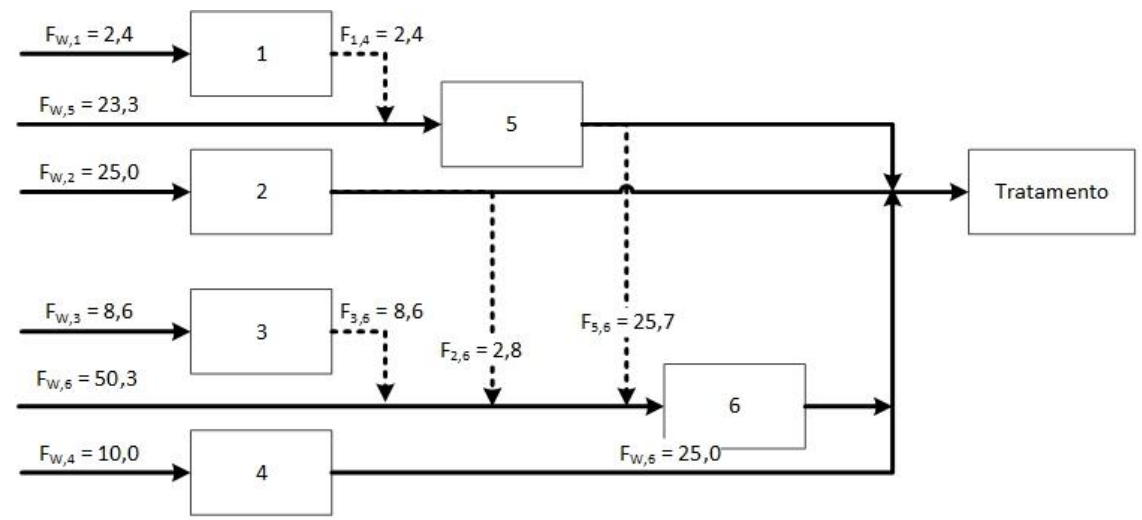

Figura 19 - Solução do sistema com múltiplos contaminantes obtido por Ulson de Souza et al. (2009) - (vazões em $t / h)$.

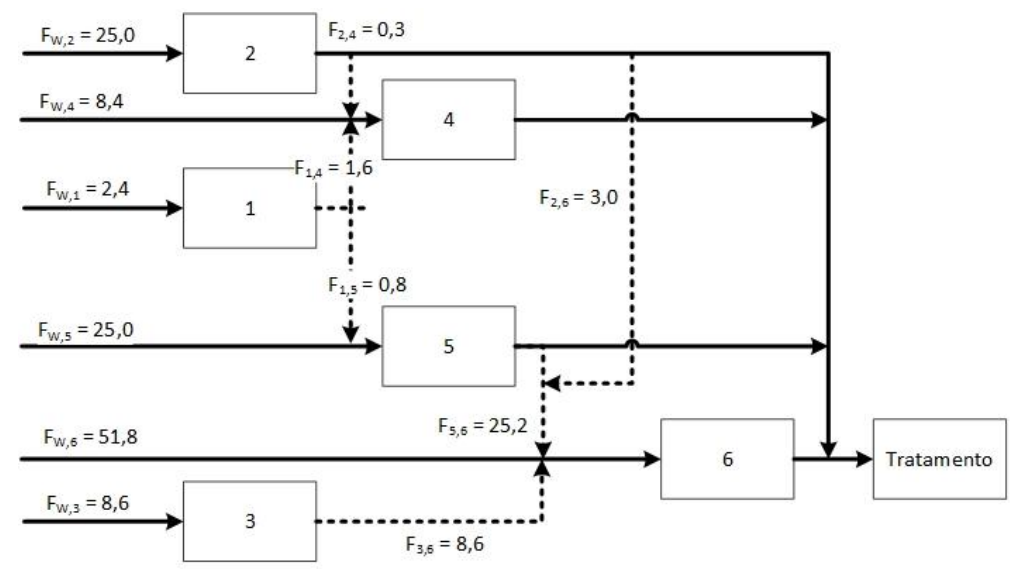

Figura 20 - Solução do sistema com múltiplos contaminantes obtido por Koppol et al. (2003) (vazões em t/h). 


\section{REDE DE USOS DE ÁGUA DA REFINARIA ESTUDADA}

A identificação dos usos de água na refinaria estudada é descrita neste capítulo, caracterizando os processos que usam água e sua funções no processo de refino. $O$ mapeamento dos usos de água da refinaria incluiu visitas na planta industrial, análises dos fluxogramas, dos manuais das unidades do processo e do sistema de água e de efluentes e de telas do PIMS - Sistema de Gestão na Informação de Processos ("Process Information Management System"). Os dados históricos foram obtidos em um período de 10 em 10 minutos para o período de um ano e tratados conforme o procedimento apresentado no Anexo 1.

Para facilitar a organização das ações de um estudo aplicado à indústria química, Bresciani et al. (2006a) recomendam considerar quatro envoltórias representando o conjunto de fontes de água para a indústria; o conjunto dos tratamentos necessários para adequar a qualidade da água aos usos; o conjunto dos usos de água nos processos internos, inclusive utilidades e usos gerais, e o conjunto dos tratamentos finais dos efluentes. Tal diagrama para a refinaria estudada está mostrado na Figura 21.

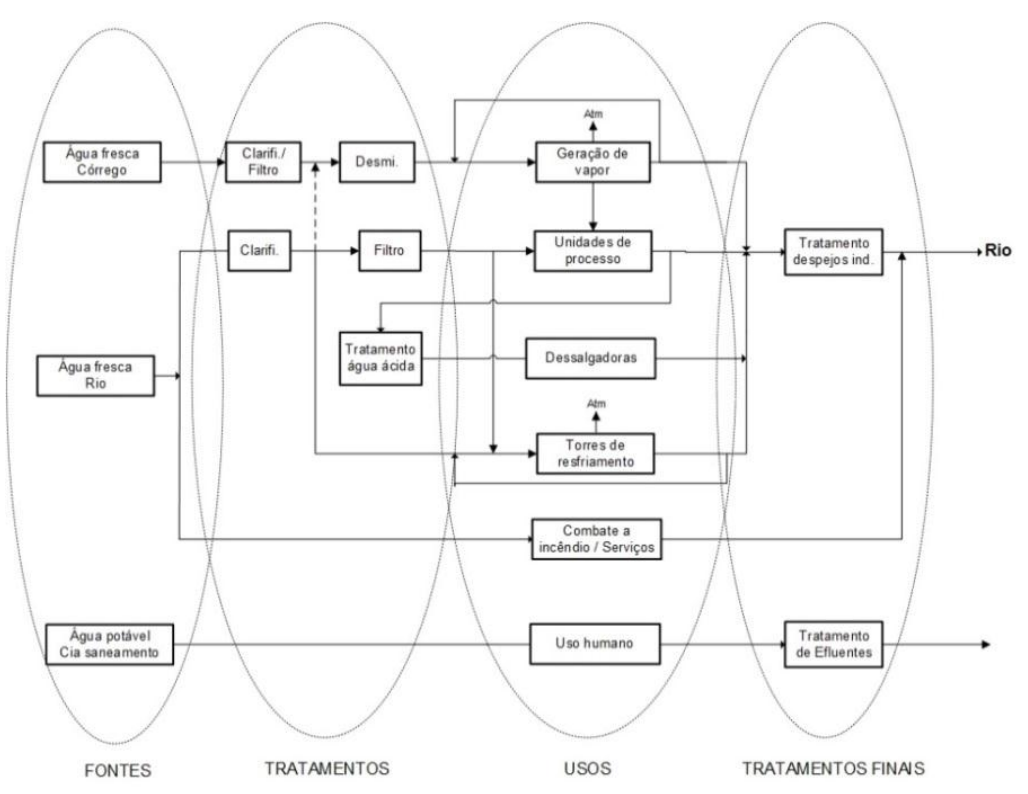

Figura 21 - Diagrama de fontes, tratamentos, usos e tratamentos finais. 
Um parâmetro de fundamental importância para a comparação entre a eficiência produtiva de refinarias, levando-se em conta o consumo de água, é o Indicador de Consumo de Água - ICA. Este indicador é calculado pela razão entre o volume de água consumida e o volume de petróleo processado. Assim, quanto menor o ICA, menor a necessidade de água para o processamento de petróleo, tornando a refinaria mais sustentável. Segundo Diepolder (1992), a referência mundial de consumo de água em refinarias está entre 0,7 e 1,2 $\mathrm{m}^{3}$ água $/ \mathrm{m}^{3}$ de petróleo processado. A média do ICA da refinaria estudada se situa no limite superior deste intervalo, indicando que há potencial para redução de água.

A distribuição do uso de água na refinaria estudada está representada na Figura 22. Como apresentado no Capítulo 1, o maior responsável pelo consumo de água da refinaria é a reposição de água do sistema de torres de resfriamento seguido pela água para geração de vapor. Na sequência, a água industrial que compreende a água de processo e de lavagem.

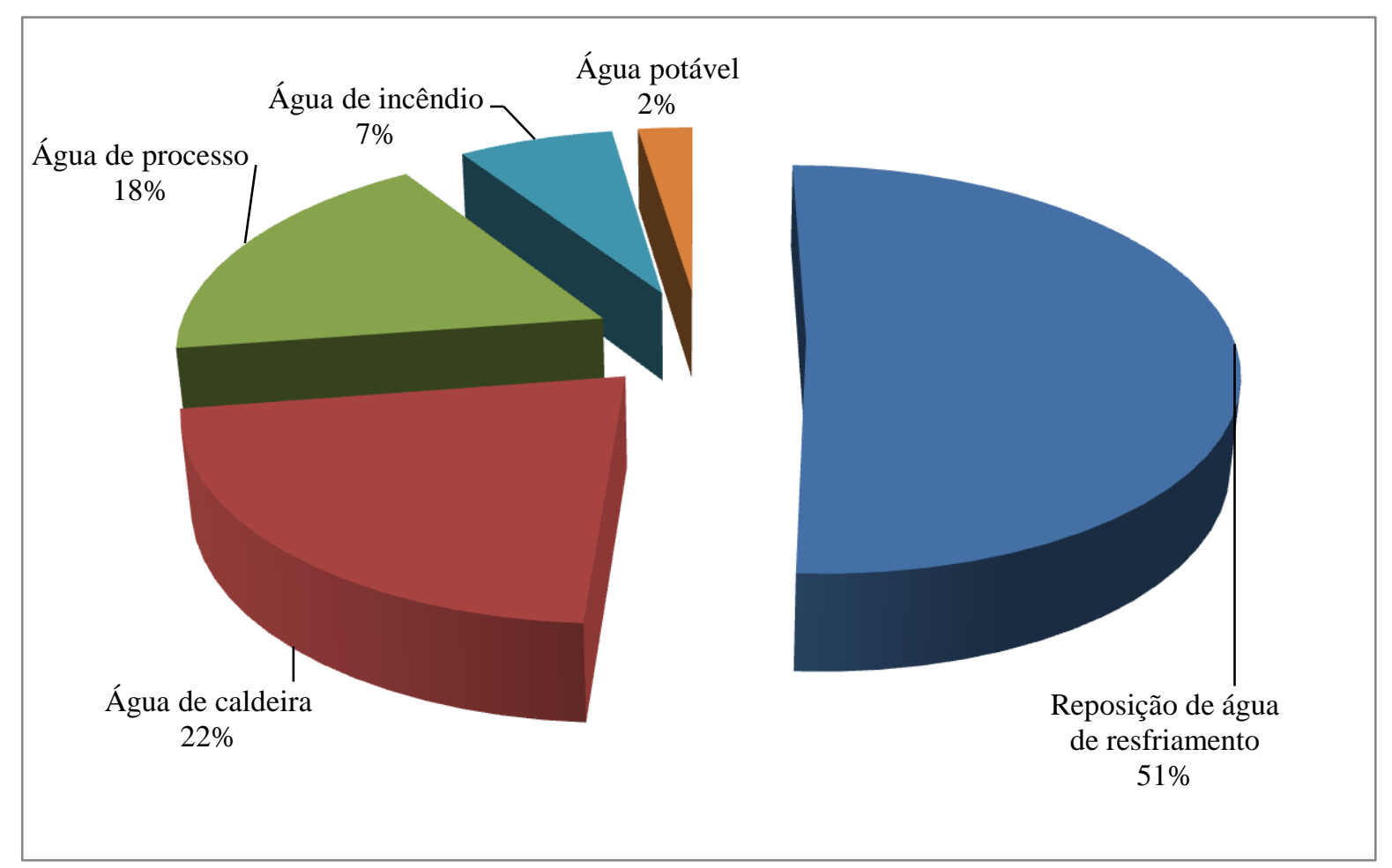

Figura 22 - Distribuição do consumo de água na refinaria estudada. 
A rede de incêndio é distribuída por toda a refinaria, assim, além da água ser utilizada para combate a incêndio ou em treinamentos, é usada também para diversos tipos de outros consumos não usuais, por exemplo, em trabalhos de manutenção, testes hidrostáticos e lavagens de peças e equipamentos, o que explica o seu alto consumo.

A seguir os processos são descritos com foco na água seguindo a sequência: partindo dos tratamentos de água, seus usos e finalmente os tratamentos das águas residuais.

\subsection{FONTES DE ÁGUA}

A água utilizada na refinaria estudada é captada a partir de três fontes, apresentadas na Figura 23, sendo:

- Água bruta captada do rio: corresponde ao maior volume de água captada, utilizada para a produção de água clarificada e filtrada, e, se necessário, para complementar a produção de água desmineralizada. Utilizada também para combate a incêndio.

- Água bruta proveniente do córrego: utilizada preferencialmente para a produção de água desmineralizada devido ao seu menor teor de sais comparado à água bruta captada no rio.

- $\quad$ Água potável fornecida pela companhia de saneamento básico: utilizada para consumo humano. 


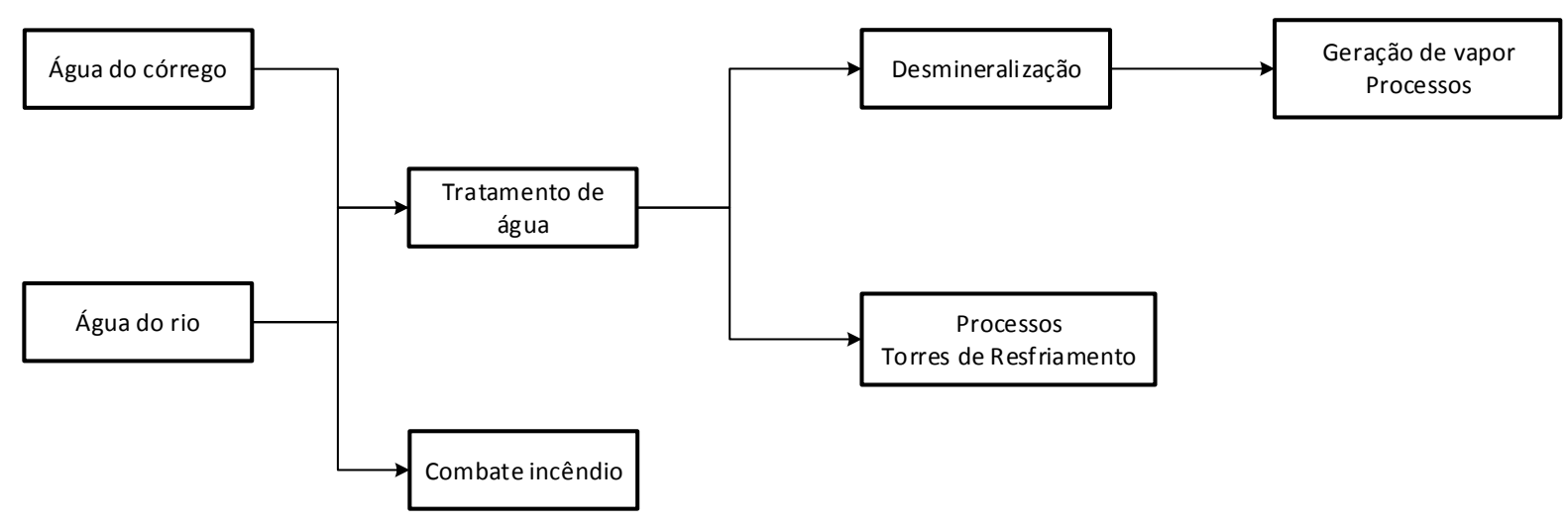

Água da cia. de abastecimento

Uso humano

Figura 23 - Diagrama simplificado da distribuição das fontes de água na refinaria estudada.

\subsection{ESTAÇÃO DE TRATAMENTO DE ÁGuA (ETA) E DESMINERALIZAÇÃO}

Para o processo de refino é necessário água com diversos padrões de qualidade, desde uma água que não tenha sofrido qualquer tipo de tratamento, conhecida como água bruta até uma água com alto grau de pureza. Para tratar a água, a refinaria dispõe de uma estação de tratamento de água, formada pelos sistemas de clarificação e de filtração, e uma unidade de desmineralização.

A água captada, primeiramente, é enviada a um tanque no qual ocorre a injeção de agente floculante e agente oxidante, de modo a evitar a formação de algas nos clarificadores e nos tanques de água clarificada, e é ajustado o pH da água para valor próximo de 6 , ideal para haver a formação dos flóculos. 


\section{Sistema de Clarificação}

O sistema de clarificação consiste em reduzir a turbidez, cor e carga orgânica da água, através da eliminação de sólidos suspensos por meio de processos físicoquímicos.

Primeiramente, na coagulação, as cargas elétricas das partículas são neutralizadas e com isso as partículas ao invés de se repelirem, se aglutinam. Em seguida, na floculação, as partículas são agregadas formando grandes aglomerados, denominados flóculos. Finalmente, na sedimentação, os flóculos decantam e são removidos.

O efluente composto pelo material decantado e pela água retida, denominado lodo, é adensado em centrífugas para recuperar parte desta água retida. A água recuperada no sistema de lodos é realimentada nos clarificadores.

Parte da água clarificada é destinada ao sistema de filtração e parte dela é enviada ao tanque de armazenagem onde tem seu pH corrigido para a faixa de 7,0 a ,8,0 e posteriormente enviada para os consumidores.

\section{Sistema de Filtração}

A filtração é aplicada para remoção da matéria em suspensão reduzindo a turbidez da água. A operação dos sistemas de filtração é realizada de forma cíclica. À medida que as partículas em suspensão são retidas, o leito de filtração é obstruído, reduzindo sua eficiência. É realizado então o processo de retrolavagem, que consiste na passagem de água filtrada no sentido inverso ao de operação de filtração. O efluente do processo de retrolavagem apresenta elevada concentração de partículas em suspensão e é enviado para o tratamento de despejos industriais. 


\section{Sistema de Desmineralização}

A água naturalmente apresenta, em diferentes concentrações, sais dissolvidos que se dissociam em íons. Tais impurezas iônicas podem afetar seriamente a segurança e a eficiência operacional de caldeiras, refervedores e outras operações unitárias do processo. Superaquecimento causados por acúmulos e incrustações formados por estas impurezas podem levar falha em tubulações, perda de produção e paradas da planta não programadas.

O processo de desmineralização visa remover da água estas substâncias dissolvidas, que são transferidas para resina de troca iônica. Ao reter os íons indesejáveis na água, a resina libera uma quantidade equivalente de outras espécies iônicas armazenadas em sua estrutura e inofensivas à qualidade da água tratada (Hespanhol e Mierzwa, 2005).

A água bruta proveniente do córrego é utilizada preferencialmente para a produção de água desmineralizada, devido ao seu menor teor de sais. Após ser filtrada é enviada aos descloradores (filtros de carvão ativado) para remoção do cloro de modo a não danificar as resinas do sistema de desmineralização.

Há dois processos consagrados para a remoção dos íons presentes na água, a osmose reversa e a troca iônica. No caso estudado, a refinaria utiliza a troca iônica.

A água então é processada nos vasos de resinas para remoção de sais. Inicialmente os cátions são retidos nas resinas de intercâmbio catiônico, que libera quantidade equivalente de íons de hidrogênio. Depois de passar pelas torres descarbonatadoras, para remoção de gás carbônico, a água passa pelas resinas de intercâmbio aniônico nas quais os ânions são retidos pela resina que libera quantidade equivalente de íons hidroxila. Finalmente é feito o ajuste fino da água nas resinas de leito misto (resina catiônica e aniônica).

O processo é interrompido quando a água desmineralizada produzida atinge o limite mínimo de qualidade requerida, indicando que a resina está saturada. O processo de regeneração das resinas envolve os processos de descompactação dos leitos, 
regeneração das resinas e lavagem do leito. É utilizada água desmineralizada para a expansão e lavagem dos leitos de resinas e para o preparo das soluções de regeneração.

A demanda de água para regeneração das resinas e contralavagem dos descloradores corresponde a aproximadamente $13 \%$ da água desmineralizada. $\mathrm{O}$ efluente da regeneração das resinas, que contém os íons retidos e excesso das soluções iônicas retentoras, é enviado para tratamento de despejos industriais.

A água desmineralizada produzida é armazenada em tanque e deste é enviada para a unidade de geração de vapor.

A Figura 24 representa simplificadamente a unidade de tratamento de água e de desmineralização e a Figura 25 apresenta a distribuição dos tipos de água produzidos no tratamento de água.

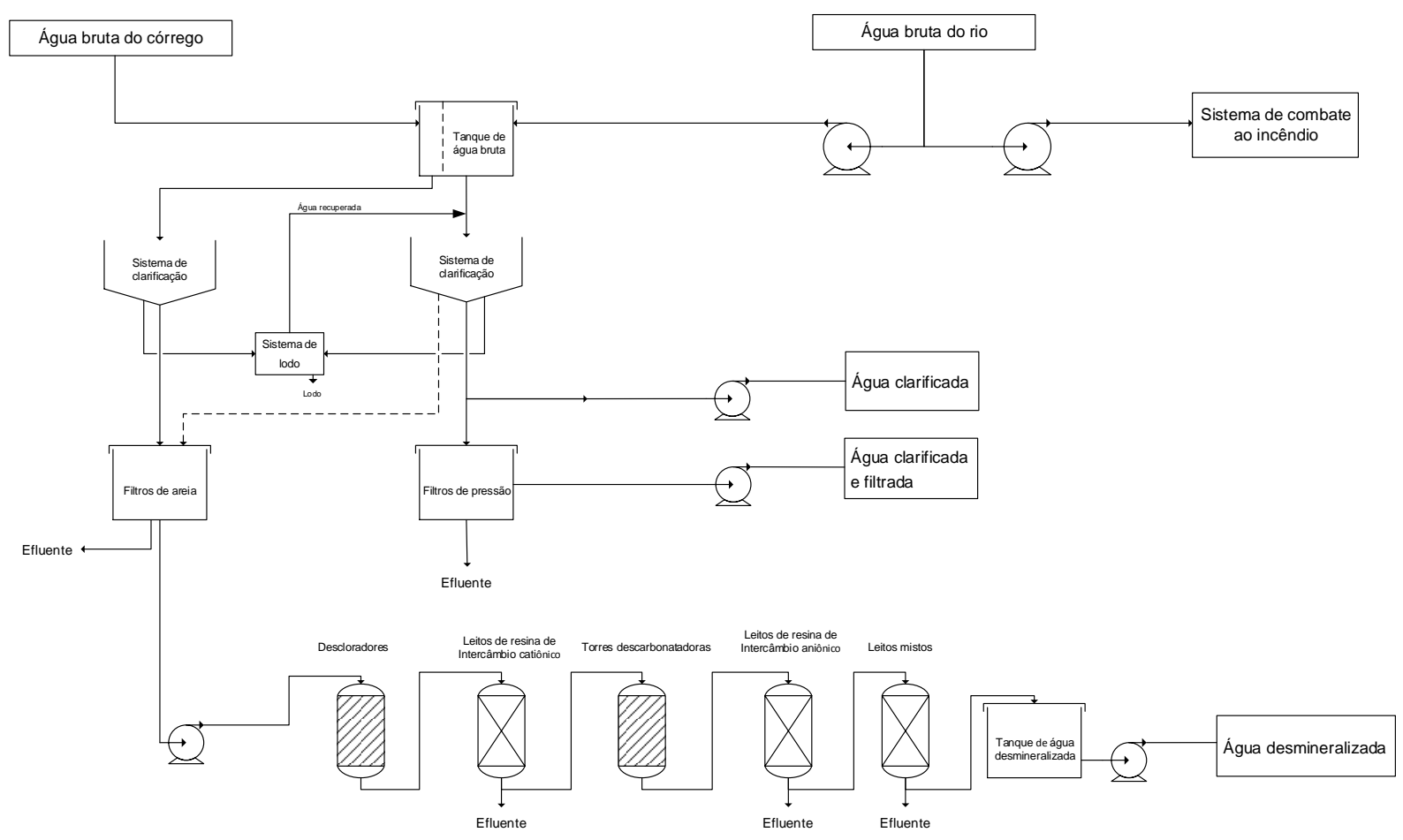

Figura 24 - Fluxograma simplificado da estação de tratamento de água e da desmineralização. 


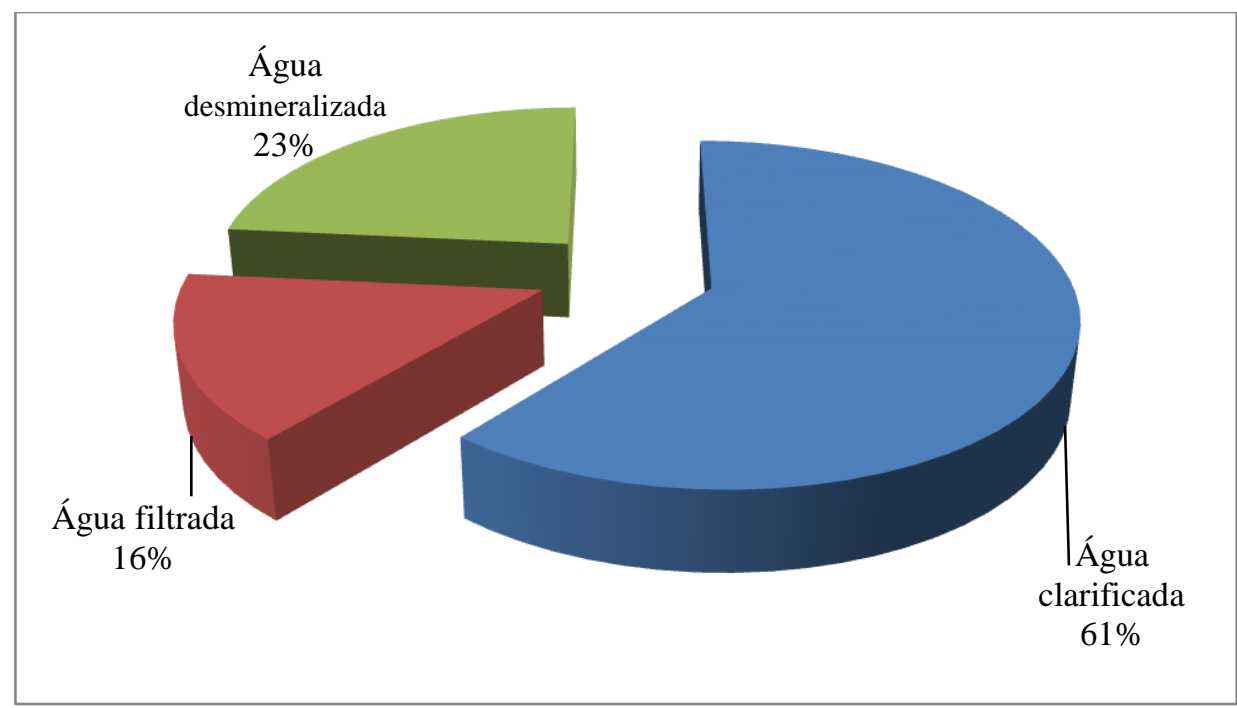

Figura 25 - Águas produzidas no tratamento de água.

\subsection{GERAÇÃO DE VAPOR}

Segundo Vanelli (2002), o vapor de água é utilizado na refinaria para as seguintes finalidades:

- Acionamento de turbinas

- Aquecimento de tubulações e tanques de produtos

- $\quad$ Aquecimento de produtos por troca térmica

- Injeção em torres para retificação de produtos leves

- $\quad$ Fluido motriz para a geração de vácuo em ejetores

- $\quad$ Purga de equipamentos para liberação e abertura para manutenção

- Limpeza de equipamentos

- Descoqueamento de fornos

- Atomização da carga de fornos ou de craqueamento

- $\quad$ Selagem de equipamentos 
O nível de pressão de vapor varia conforme o tipo de uso, em virtude disso, a refinaria trabalha com quatro níveis de pressão de vapor. O vapor de alta pressão é produzido nas caldeiras, enquanto os outros são provenientes de despressurização em turbinas de válvulas de pressão ou gerados em outros equipamentos como trocadores de calor e fornos, considerados como caldeiras auxiliares.

Dependendo da utilização, o condensado gerado pode ser recuperado, minimizando dessa forma o consumo de água e consequentemente reduzindo os custos com produtos utilizados no tratamento de água. O vapor utilizado em operações sem contato, como transferência indireta de calor e energia para turbinas, pode ser coletado no final do processo na forma de condensado. Já o vapor utilizado em operações onde há contato com hidrocarboneto, como o vapor utilizado para retificação ou como fluido motriz para geração de vácuo, não pode ser recuperado.

Além disso, há perdas rotineiras de condensado que ocorrem devido à despressurização do condensado recuperado, inerente ao seu sistema de recuperação, e devido a vazamentos no sistema de distribuição de vapor e/ou recuperação de condensado. A perda de condensado devido a vazamentos é normalmente decorrente de problemas mecânicos em purgadores de vapor e válvulas de bloqueio com vazamento, e, mais raramente, furos em tubulações (Vanelli, 2002).

$\mathrm{Na}$ refinaria estudada o condensado recuperado não passa por nenhum tratamento específico. A água desmineralizada é misturada ao condensado recuperado e a mistura é desaerada, para evitar a corrosão provocada pelo oxigênio, antes de ser distribuída para as caldeiras e para geração de vapor no processo. No período analisado aproximadamente $52 \%$ do vapor total gerado foi recuperado como condensado.

Continuamente é realizada purga das caldeiras geradoras de vapor a fim de evitar o aumento da concentração de sais acima dos limites estabelecidos e com isso controlar os níveis de condutividade. A purga na refinaria é estimada em $2 \%$, sendo 
enviada para tratamento de despejos industriais. A água de purga das caldeiras não é uma água contaminada, só possui alto teor de sais.

Tabela 26 - Vazões totais da geração de vapor.

\begin{tabular}{cc}
\hline Corrente & Vazão $(\boldsymbol{t} / \boldsymbol{h})$ \\
\hline Vapor gerado & 622,95 \\
Água de reposição & 297,09 \\
Purga & 12,46 \\
\hline
\end{tabular}

\subsection{TORRES DE RESFRIAMENTO}

Usualmente, a remoção de carga térmica em diversos processos é feita utilizando água como fluido de resfriamento. Para o reaproveitamento da água utilizada nos trocadores de calor, ela deve passar por uma torre de resfriamento. A Figura 26 mostra o esquema típico de um sistema em circuito semiaberto, com recirculação de água, composto por torre de resfriamento e trocadores de calor.

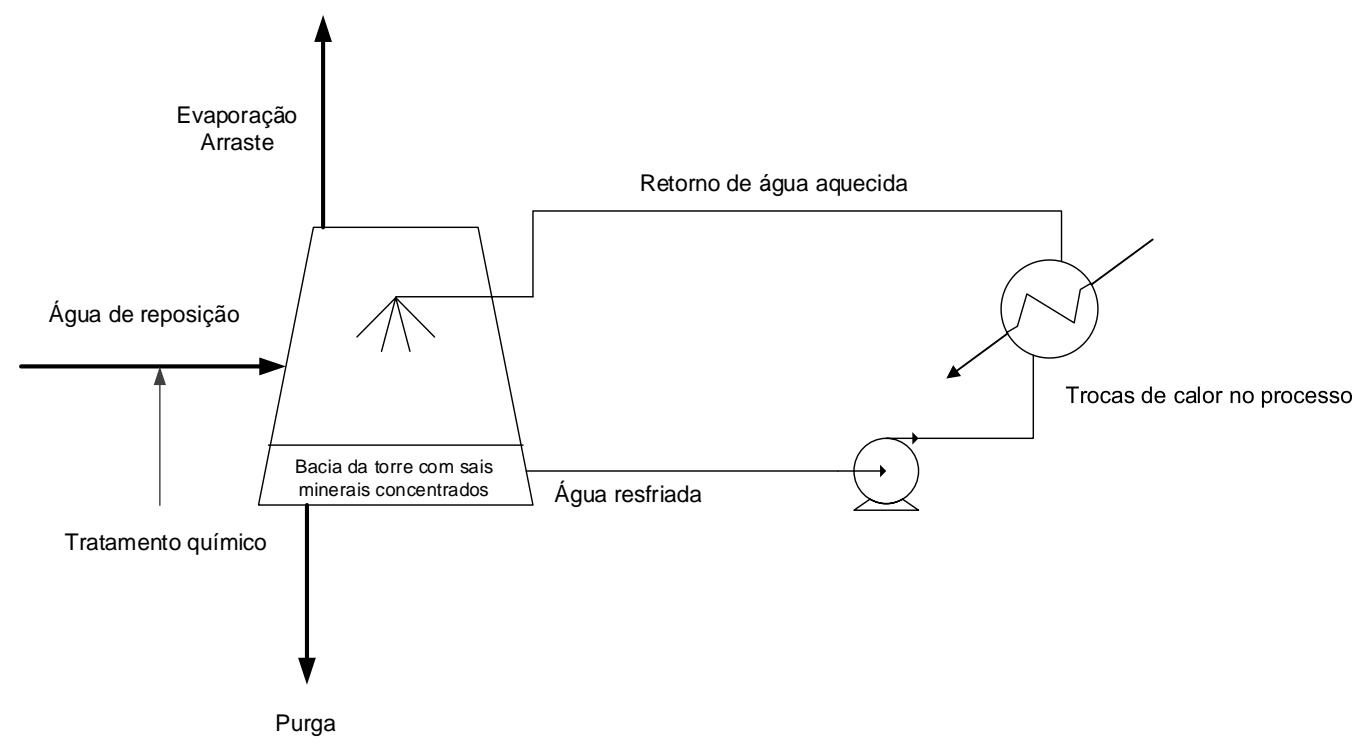

Figura 26 - Esquema simplificado de um sistema semiaberto de resfriamento. 
A água aquecida que sai dos trocadores de calor onde ocorre o resfriamento do fluido de processo é distribuída no topo da torre de resfriamento. No interior da torre, a água é espalhada através de enchimentos para que se tenha uma maior superfície de contato com o ar que entra lateralmente.

O sistema da torre de resfriamento pode perder água naturalmente por meio de:

- Evaporação: A principal contribuição para o resfriamento da água é dada pela evaporação de parte dessa água que circula na torre. A perda de água é variável, correspondendo em média a $0,185 \%$ da vazão de água que circula no sistema para cada grau Celsius de variação de temperatura (Mancuso, 2001).

- $\quad$ Arraste ou respingo: A água também é perdida na forma de névoa, que é carregada para fora da torre pelo vento. Uma taxa típica de arraste é de 0,05\% a $0,3 \%$ da vazão de circulação da torre. A redução no arraste, através da instalação de venezianas ou eliminadores de gotas, conserva água, retém químicos do tratamento de água no sistema e melhora a eficiência de operação (Meio Filtrante, 2003).

Em função das perdas por evaporação e arraste, a concentração de sais dissolvidos na água que circula pelo sistema de resfriamento, como os sólidos dissolvidos, que podem ser corrosivos ou incrustantes, trazendo problemas ao sistema de resfriamento e demais equipamentos com os quais a água entra em contato, principalmente aqueles onde ocorre a troca térmica. Para limitar o aumento de concentração de sais é realizada uma purga na bacia da torre de resfriamento. Esse descarte é o principal efluente desse tipo de sistema.

A quantidade de purga depende da concentração máxima de sais na água circulante e da qualidade da água de reposição. A relação entre esses dois fatores define o ciclo de concentração da torre. O ciclo de concentração representa o número de vezes que a água de alimentação se concentrou no sistema e ajuda a determinar a quantidade de água que deve ser removida do sistema de resfriamento para que a concentração de sais fique próxima à concentração máxima permitida.

$C C=\frac{C_{\text {purga }}}{C_{\text {reposição }}}$ 
Para compensar essas perdas e manter o volume total da água de circulação é realizada a reposição da água, usualmente com água clarificada. A seguir é descrito o balanço de massa nesse tipo de sistema.

Em termos de vazão, o balanço material é dado pela relação a seguir:

$Q_{\text {reposição }}=Q_{\text {evaporação }}+Q_{\text {arraste }}+Q_{\text {purga }}$

E o balanço de massa para componente que não se transforme ou que não se vaporize fica:

$$
Q_{\text {reposição }} \cdot C_{\text {reposição }}=Q_{\text {evaporação }} \cdot C_{\text {evaporação }}+Q_{\text {arraste }} \cdot C_{\text {arraste }}+Q_{\text {purga }} \cdot C_{\text {purga }}
$$

Como a água evaporada pode ser considerada isenta de contaminação, pressupondo que somente saia vapor saturado, $\mathrm{C}_{\text {evaporação }}=0$. As concentrações de arraste e de purga são iguais:

$Q_{\text {reposição }} \cdot C_{\text {reposição }}=\left(Q_{\text {arraste }}+Q_{\text {purga }}\right) \cdot C_{\text {purga }}$

Uma vez atingido o equilíbrio:

$$
\begin{aligned}
& \frac{Q_{\text {reposição }}}{\left(Q_{\text {arraste }}+Q_{\text {purga }}\right)}=\frac{C_{\text {purga }}}{C_{\text {reposição }}}=C C \\
& C C=\frac{Q_{\text {evaporação }}+Q_{\text {arraste }}+Q_{\text {purga }}}{\left(Q_{\text {arraste }}+Q_{\text {purga }}\right)} \\
& C C=\frac{Q_{\text {evaporação }}}{\left(Q_{\text {arraste }}+Q_{\text {purga }}\right)}+1
\end{aligned}
$$

Assim sendo, quando é necessário limitar o ciclo de concentração de um sistema através de purgas, pode-se calculá-las, desde que se conheçam as vazões de evaporação e de arraste:

$$
Q_{\text {purga }}=\left(\frac{Q_{\text {evaporação }}}{C-1}\right)-Q_{\text {arraste }}
$$


Outra forma de calcular a necessidade de água de reposição:

$Q_{\text {reposição }}=\frac{Q_{\text {evaporação }} \cdot C C}{C C-1}$

A refinaria tem sete sistemas de torres resfriamento com características diferentes. $A$ água de reposição pode ser clarificada e/ou filtrada, dependendo da torre.

Como descrito anteriormente, são realizadas purgas constantes para evitar o aumento na concentração de sais na torre, decorrente das perdas de água por evaporação. A água da purga segue para estação de tratamento de despejos industriais, representando $22 \%$ do efluente tratado.

Como não há medição de todas as correntes ou medição ineficiente, foi realizado o balanço volumétrico, utilizando as equações anteriores, de cada torre. Os ciclos de concentração de cada torre são mostrados na Tabela 27 e as vazões totais apresentadas na Tabela 28.

Tabela 27 - Ciclos de concentração das torres de resfriamento

\begin{tabular}{cc}
\hline Torre & Ciclo de concentração \\
\hline 1 & 4,61 \\
2 & 4,21 \\
3 & 4,05 \\
4 & 3,60 \\
5 & 3,18 \\
6 & 1,98 \\
7 & 4,52 \\
\hline
\end{tabular}

Tabela 28 - Vazões totais das torres de resfriamento.

\begin{tabular}{cc}
\hline Corrente & Vazão (t/h) \\
\hline Água de circulação & 41227,85 \\
Água de reposição & 696,95 \\
Estimativa das perdas por evaporação & 521,02 \\
Estimativa das perdas por arraste & 4,12 \\
Purga & 171,81 \\
\hline
\end{tabular}


A variação nos ciclos de concentração é função de muitos fatores como por exemplo, o tratamento da água recirculada, a qualidade da água de reposição, o projeto e o material de estrutura da torre.

\subsection{PROCESSOS DE REFINO}

A refinaria é constituída por unidades de destilação atmosférica e a vácuo, craqueamento catalítico em leito fluidizado (FCC), coqueamento e hidrotratamento. O esquema de refino é apresentado na Figura 27. Segundo a Agência Nacional do Petróleo "Este esquema de produção é, seguramente, o mais flexível e moderno de todos por incorporar à configuração anterior o processo de hidrotratamento de frações médias geradas no coqueamento, possibilitando o aumento da oferta de óleo diesel de boa qualidade. Este esquema permite um maior equilíbrio na oferta de gasolina e de óleo diesel de uma refinaria, pois desloca parte da carga que ia do coqueamento para o FCC (processo marcantemente produtor de gasolina) e a envia para o hidrotratamento, gerando, então, mais óleo diesel e menos gasolina que as configurações anteriores." 


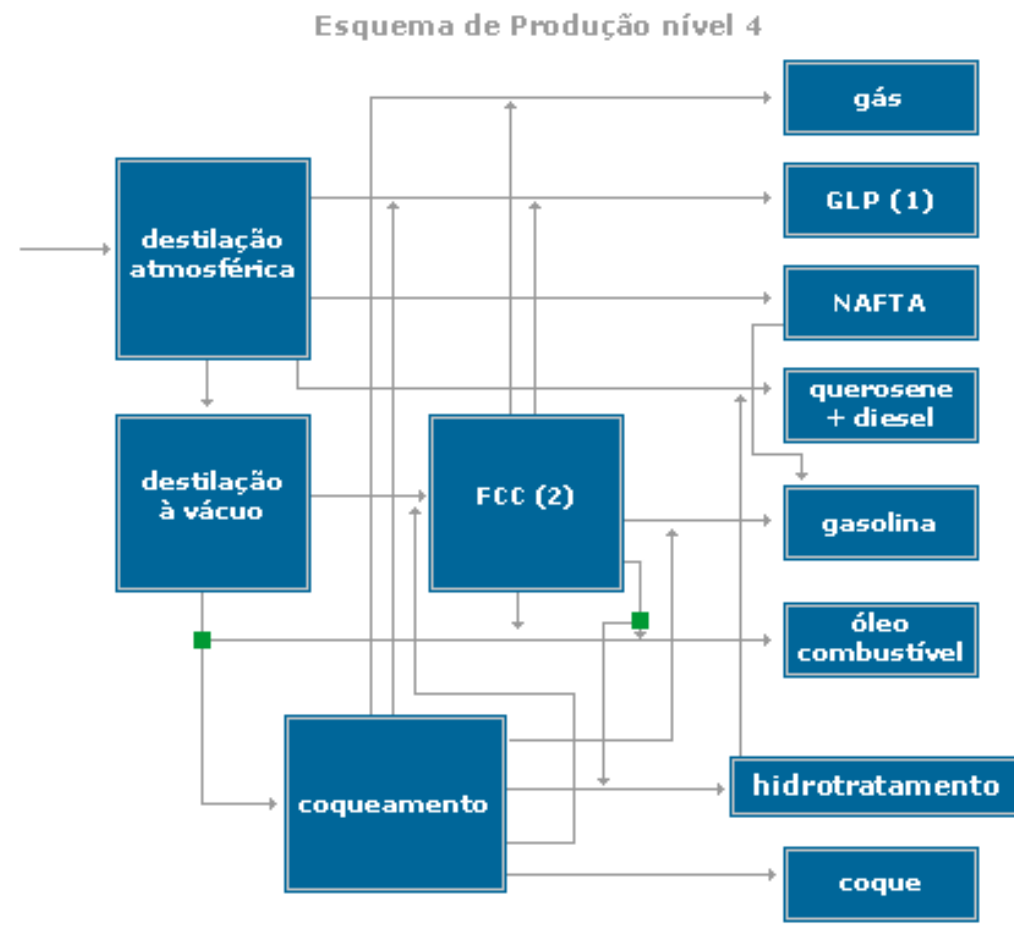

(1) GLP = Gás Liquiefeito de Petróleo

(2) FCC = Craqueamento catalítico em leito fluidizado

Figura 27 - Esquema de refino (ANP, 2012).

\subsubsection{Dessalgação}

Para garantir que não haja corrosão, deposição de sólidos e vaporização brusca nos fornos e colunas de destilação que operam a elevadas temperaturas, o petróleo deve ser tratado nas unidades de dessalgação para a remoção de sais corrosivos e de água.

Segundo (Bresciani, 2009) os primeiros processos de dessalgação implantados nas refinarias tinham um único estágio, porém nos anos 60/70, com a necessidade de garantir maior confiabilidade operacional, passou-se a ter sistemas com dois estágios em série, que garantiam operação mais estável e menores teores de água e sal no petróleo dessalgado. 
Antes de cada estágio de dessalgação o petróleo recebe uma injeção de água de diluição na proporção de 3 a 10\% de volume do petróleo cru (Szklo, 2005) e se mistura a sais e sólidos presentes no petróleo, resultando na salmoura.

A quantidade de água de diluição consumida depende da forma de operação dos estágios:

- $\quad \mathrm{Na}$ operação em paralelo, mostrada na Figura 28 , a água de diluição é injetada na entrada dos dois estágios e as salmouras de cada estágio encaminhadas para o tratamento de despejos industriais.

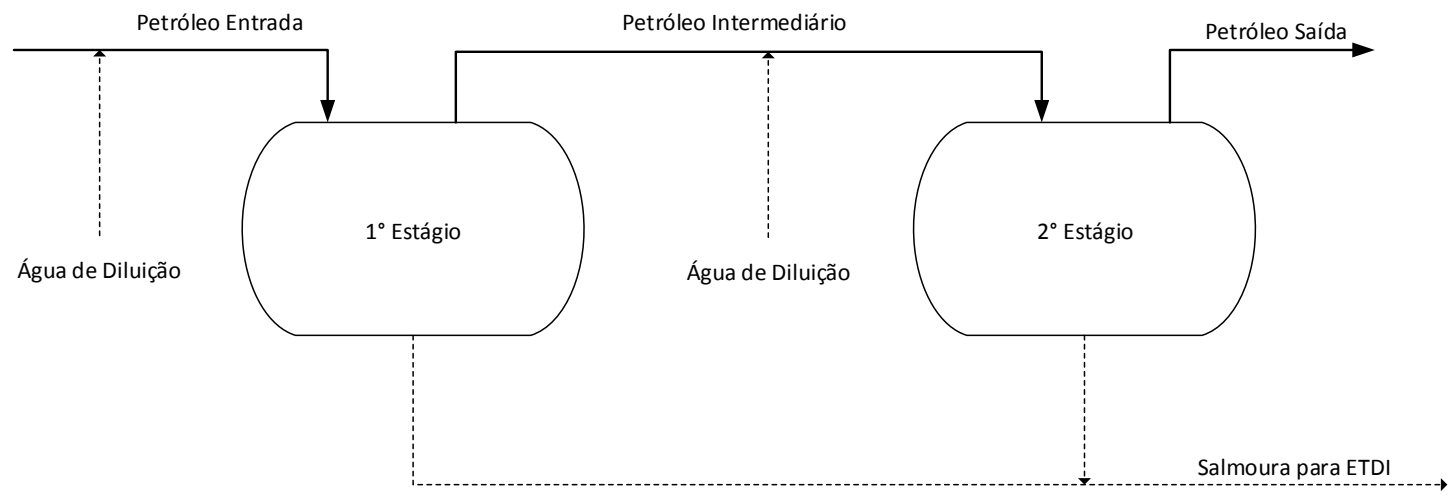

Figura 28 - Sistema de dessalgação em paralelo.

- $\quad \mathrm{Na}$ operação em contracorrente, que é aquele comumente usado nas refinarias e apresentado na Figura 29, a água de diluição é injetada na entrada do $2^{\circ}$ estágio e a salmoura desse estágio, com baixa concentração em sais, é reciclada e utilizada como água de lavagem do $1^{\circ}$ estágio. A salmoura do $1^{10}$ estágio é encaminhada para o tratamento de despejos industriais. Neste caso a relação água/petróleo é atendida com menor uso de água de diluição fresca. 


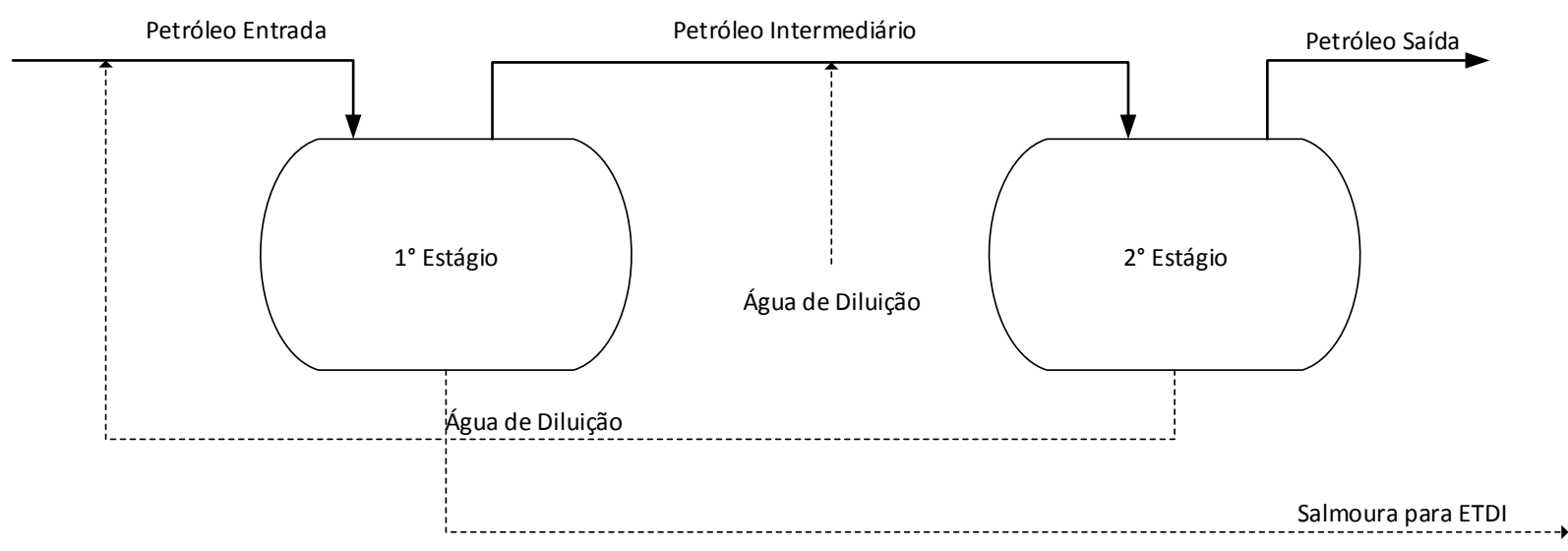

Figura 29 - Sistema de dessalgação em contracorrente.

A água consumida na dessalgação de petróleo constitui uma parcela significativa no consumo das refinarias e a salmoura gerada é responsável por grande parte do efluente destinado à unidade de tratamento final. Uma prática comum das refinarias para reduzir o impacto desse processo é o uso de água ácida retificada proveniente das unidades de tratamento de águas ácidas como água de diluição.

A refinaria apresenta três sistemas de dessalgação, sendo um deles com único estágio. A Tabela 29 apresenta o consumo de água em relação à carga de petróleo e a Tabela 30 apresenta o consumo total de água. Apesar da existência de interligação, o sistema de dessalgação em paralelo é o utilizado na refinaria. O uso de água ácida retificada como água de diluição corresponde a $83 \%$ da água de diluição total, sendo o restante água fresca.

Tabela 29 - Consumo de água em cada sistema de dessalgação.

\begin{tabular}{ccc}
\hline Sistema & \multicolumn{2}{c}{$\begin{array}{c}\text { Água de diluição em relação à carga de petróleo } \\
\mathbf{1}^{\circ} \text { Estágio }\end{array}$} \\
\hline 1 & $8,15 \%$ & $\mathbf{2}^{\circ}$ Estágio \\
2 & $8,72 \%$ & $5,08 \%$ \\
3 & $5,57 \%$ & $8,65 \%$ \\
\hline
\end{tabular}

Tabela 30 - Consumo de água no sistema de dessalgação. 


\begin{tabular}{cccc}
\hline Qualidade da água & Uso & Destino & Vazão $(\mathbf{t} / \mathbf{h})$ \\
\hline Água fresca & Diluição do petróleo & Tratamento de efluentes & 45,12 \\
Água ácida retificada & Diluição do petróleo & Tratamento de efluentes & 98,08 \\
\hline
\end{tabular}

A salmoura efluente de dessalgadoras costuma apresentar coloração escura, alta temperatura e odor típico de petróleo. A composição do efluente varia quantitativa e qualitativamente devido as diferentes origens do petróleo processado e também devido à condição de operação da dessalgadora.

O efluente da dessalgadora é rico em cloreto, na ordem de 1300ppm, e apresenta teor de óleos e graxas superior a 1000ppm devido à má separação entre as fases. É uma água que não pode ser reaproveitada sem tratamento prévio.

\subsubsection{Destilação atmosférica}

Nas destilações atmosféricas o petróleo é fracionado em diversas frações de acordo com a faixa de temperatura de produção de cada derivado. A Figura 30 mostra 0 fluxograma da unidade. 


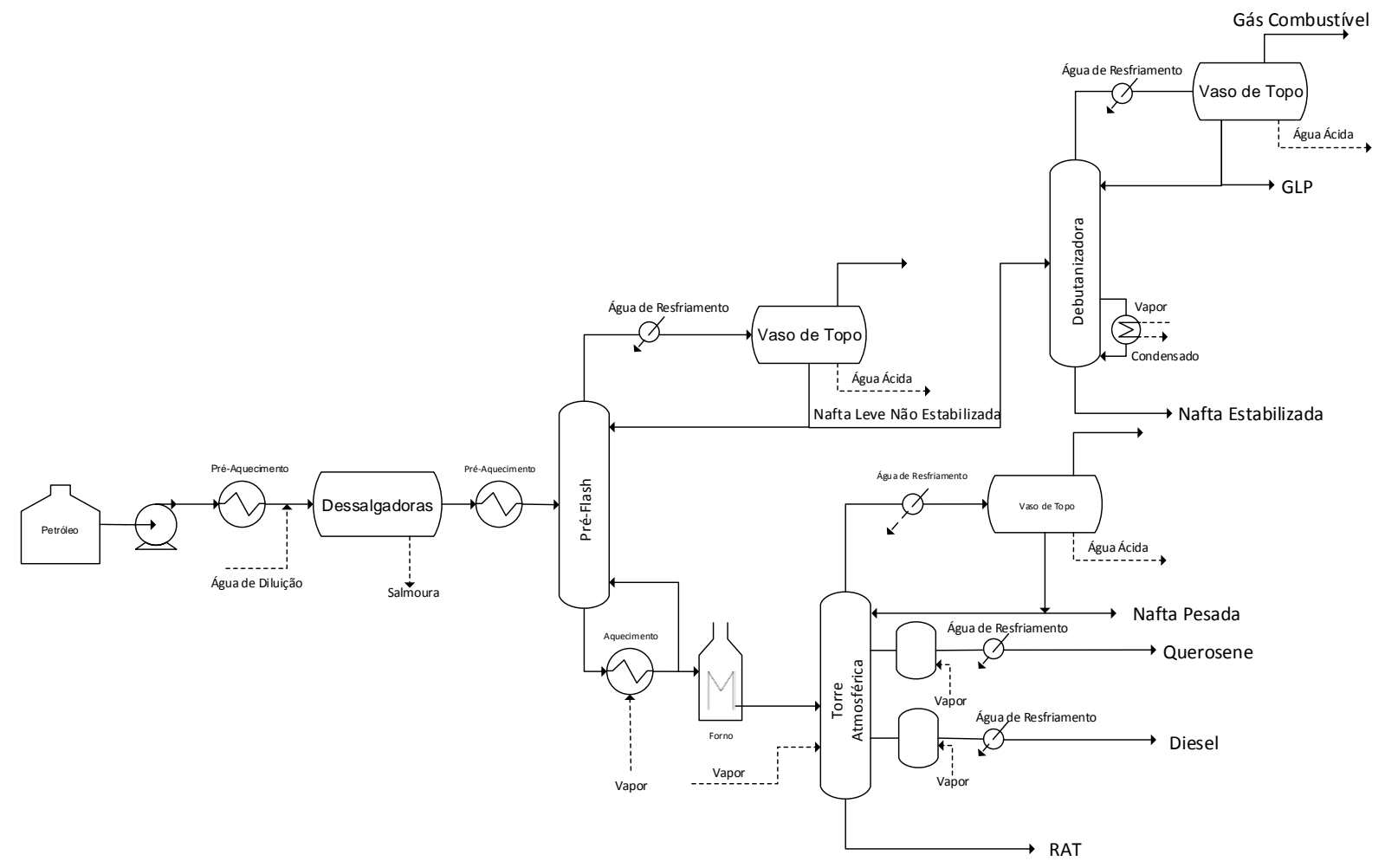

Figura 30 - Fluxograma simplificado da destilação atmosférica.

Em algumas unidades de destilação, antes do fracionamento principal, uma faixa mais leve do petróleo, composta de nafta leve e GLP, é separada na torre de préflash. O calor é fornecido por um trocador de calor ou pelo forno que faz o aquecimento do petróleo. A nafta leve não estabilizada é fracionada para a obtenção do GLP, o calor necessário para o fracionamento é fornecido por refervedor. A água separada nos vasos de topo das torres é enviada para o tratamento de água ácida.

O petróleo é retificado na torre de destilação atmosférica com injeção de vapor superaquecido. A água separada no fundo do vaso de topo é enviada para tratamento de água ácida.

O querosene retirado como produto lateral segue para uma torre retificadora com injeção de vapor superaquecido para ajustar a qualidade do querosene, especialmente seu ponto de fulgor. O diesel também é retirado como produto lateral e seguem para torre retificadora, porém, apesar de existir a possibilidade, 
usualmente não há injeção de vapor superaquecido, pois já apresentam ponto de fulgor acima da especificação requerida para o óleo diesel.

A refinaria possui três unidades de destilação, com capacidades e características diferentes. A Tabela 31 apresenta o consumo de água total das unidades de destilação atmosférica.

Tabela 31 - Vazões totais de consumo de água na destilação atmosférica.

\begin{tabular}{cccc}
\hline Qualidade da água & Uso & Destino do efluente & Vazão (t/h) \\
\hline Vapor & Retificação & Tratamento de água ácida & 16,41 \\
Vapor & Aquecimento & Tratamento de água ácida & 3,50 \\
Vapor & Retificação & Retorno de condensado & 20,37 \\
\hline
\end{tabular}

A água ácida gerada na destilação a atmosférica é enviada para a unidade de tratamento de água ácida (UTAA) da separação. A distribuição média dos contaminantes é apresentada na Tabela 32.

Tabela 32 - Faixa de contaminantes na água ácida gerada na destilação atmosférica.

\begin{tabular}{cc}
\hline Contaminante & Concentração (ppm) \\
\hline $\mathrm{H}_{2} \mathrm{~S}$ & $50-200$ \\
$\mathrm{NH}_{3}$ & $20-200$ \\
Fenóis & $10-30$ \\
$\mathrm{Cl}$ & $50-300$ \\
\hline
\end{tabular}




\subsubsection{Destilação a vácuo}

A destilação a vácuo, apresentada na Figura 31, visa recuperar os destilados mais pesados existente no resíduo de fundo da coluna de destilação atmosférica.

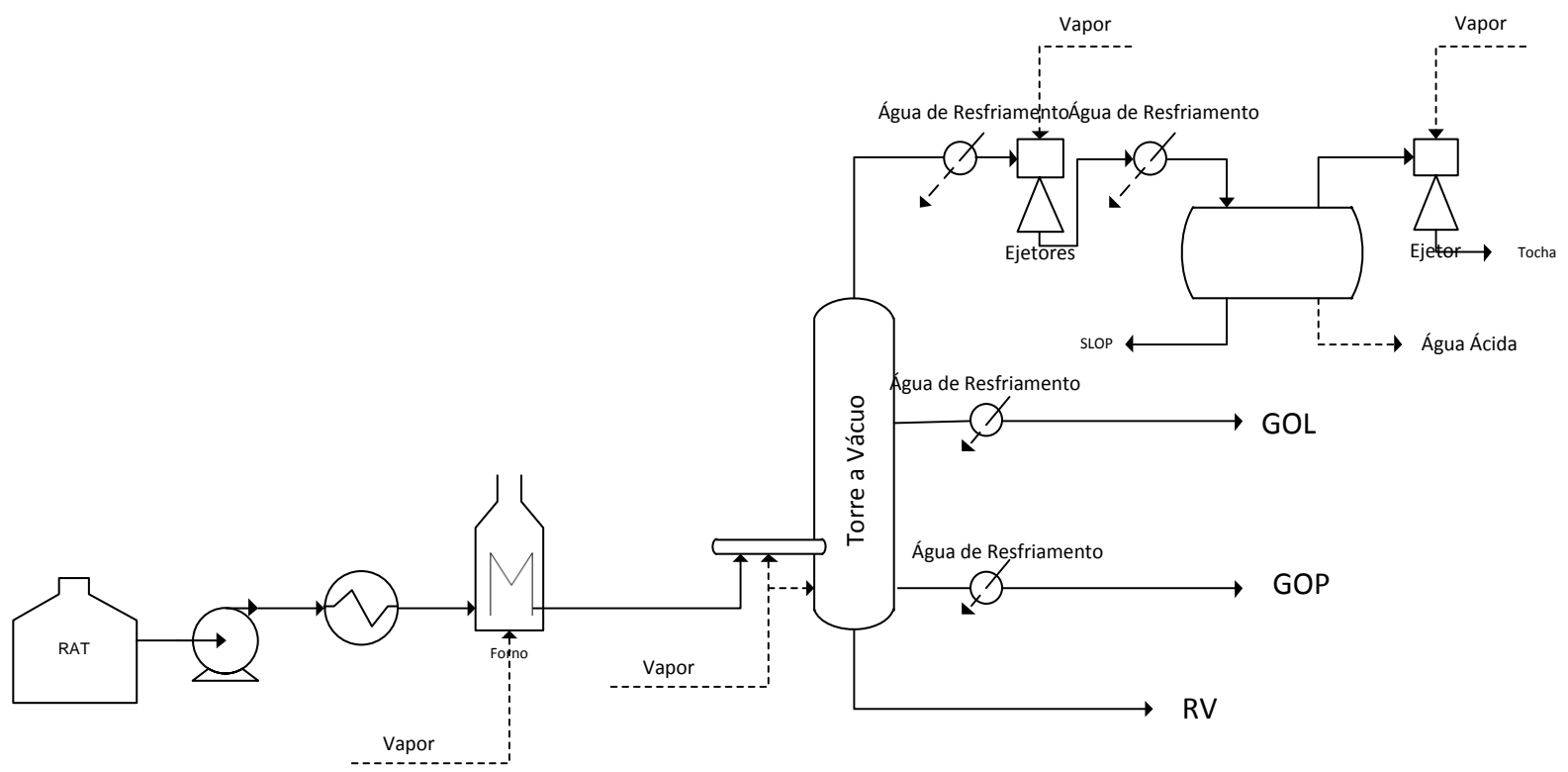

Figura 31 - Fluxograma simplificado da destilação a vácuo.

Primeiramente, o resíduo atmosférico é aquecido nos fornos de vácuo até a temperatura em que todo o gasóleo contido na carga vaporize nas condições de pressão da torre a vácuo. Nos fornos de vácuo ocorrem injeções de vapor de média pressão em dois pontos para minimização de coqueamento nos tubos:

- $\quad$ Na transição dos passes entre as zonas de convecção e radiação.

- $\quad$ No início da radiação, quando os dois passes de carga se subdividem em quatro.

$\mathrm{Na}$ torre a vácuo, o resíduo atmosférico é retificado com injeção de vapor superaquecido. O vácuo da coluna é usualmente mantido pelo o uso de ejetores cujo fluido motriz é vapor, mas também pode ser mantido pelo o uso de bombas a 
vácuo. Os incondensáveis são succionados por ejetor a vapor. O vapor de água condensado é enviado para tratamento no sistema de águas ácidas.

A Tabela 33 apresenta as vazões médias de consumo de água nas unidades de destilação a vácuo.

Tabela 33 - Vazões totais de consumo de água na destilação a vácuo.

\begin{tabular}{cccc}
\hline Qualidade da água & Uso & Destino do efluente & Vazão $(\mathbf{t} / \mathbf{h})$ \\
\hline Vapor & Retificação & Tratamento de água ácida & 18,78 \\
Vapor & $\begin{array}{c}\text { Injeção nos fornos } \\
\text { Fluido motriz dos } \\
\text { ejetores }\end{array}$ & Tratamento de água ácida & 7,88 \\
Vapor & Tratamento de água ácida & 6,89 \\
\hline
\end{tabular}

A concentração dos contaminantes do efluente da destilação a vácuo é apresentada na Tabela 34. A água ácida gerada nas destilações é enviada para a unidade de tratamento de água ácida da separação para a remoção do sulfeto e da amônia.

Tabela 34 - Faixa de contaminantes na água ácida gerada na destilação a vácuo.

\begin{tabular}{cc}
\hline Contaminante & Concentração (ppm) \\
\hline $\mathrm{H}_{2} \mathrm{~S}$ & $20-100$ \\
$\mathrm{NH}_{3}$ & $10-100$ \\
Fenóis & $0-10$ \\
$\mathrm{Cl}$ & $50-300$ \\
\hline
\end{tabular}




\subsubsection{Craqueamento catalítico fluidizado}

O craqueamento catalítico visa aumentar a produção de gasolina e GLP, convertendo cortes pesados de petróleo (gasóleos e resíduos) em frações mais leves de alto valor comercial.

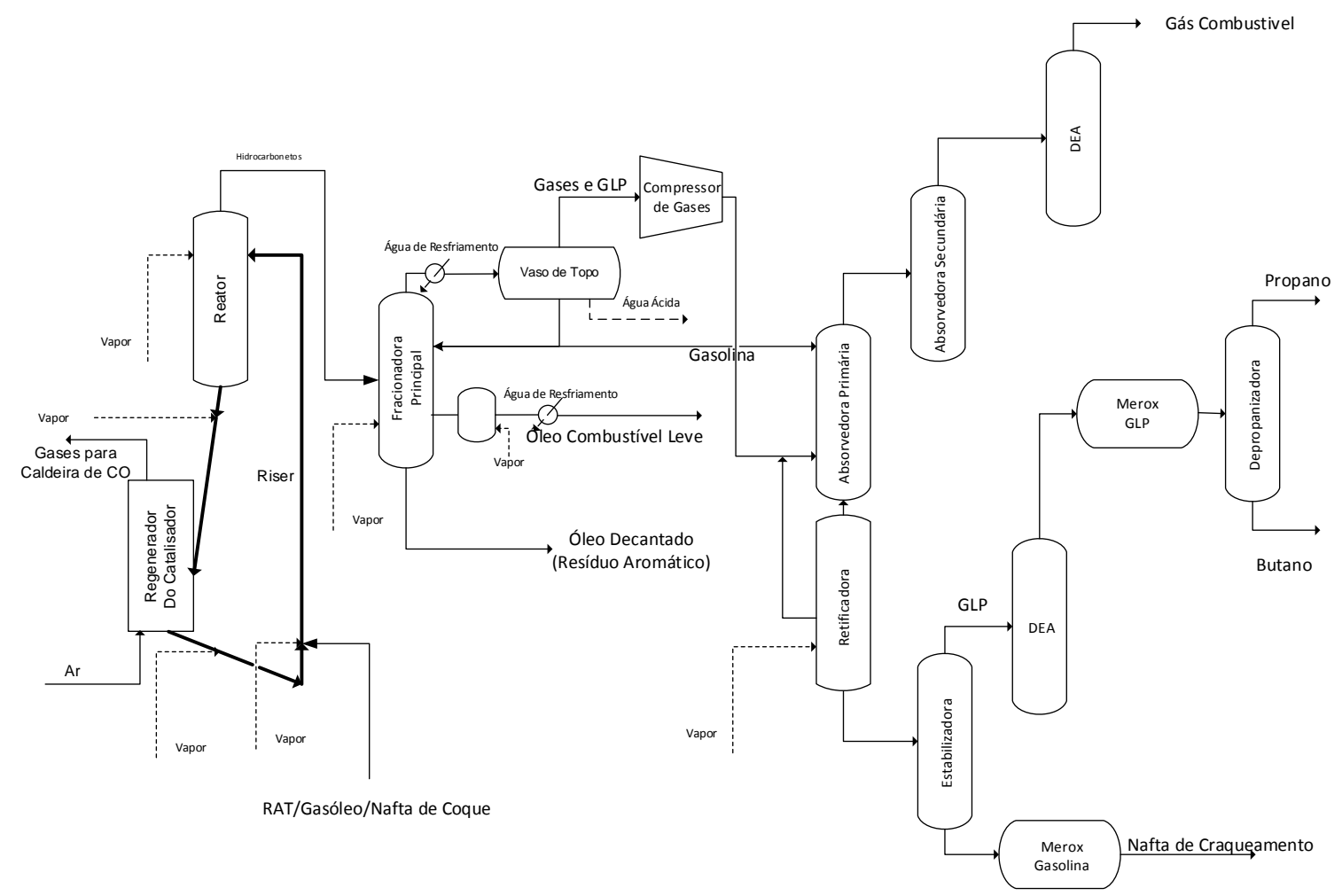

Figura 32 - Fluxograma simplificado do craqueamento catalítico.

A carga da unidade é atomizada através de dispersores para melhor contato com o catalisador que se encontra no reator de fluxo ascendente conhecido como "riser", onde ocorrem quase todas as reações enquanto o catalisador e a carga ascendem para o reator. É injetado vapor para dispersão, aeração, aceleração lateral e vertical no "riser".

Vapor é utilizado para inertização do topo do reator. O catalisador fluidizado e os produtos da reação são separados no reator através de ciclone. O coque formado deposita-se na superfície do catalisador, desativando-o temporariamente. Para 
restabelecer a atividade, o catalisador é enviado ao regenerador. Injeta-se vapor para retificação do catalisador e selagem entre o vaso separador e o regenerador e entre o regenerador e o "riser".

Os produtos da reação seguem para a torre fracionadora, o calor necessário para a separação é fornecido por injeção de vapor vivo. O condensado do topo da fracionadora é enviado para o sistema de tratamento de águas ácidas da unidade de conversão.

O gás de topo gerado nas fracionadoras contém contaminantes, como por exemplo, sulfeto e amônia, que são removidos por meio de lavagem com água, de modo a melhorar a qualidade do produto gerado, por meio da lavagem com água. A lavagem é realizada com água ácida retificada que em seguida retorna para a unidade de tratamento de água ácida.

Tabela 35 - Vazões totais de consumo de água no craqueamento catalítico fluidizado

\begin{tabular}{cccc}
\hline Qualidade da água & Uso & Destino do efluente & Vazão (t/h) \\
\hline Vapor & "riser" & Tratamento de água ácida & 27,36 \\
Vapor & Reator & Tratamento de água ácida & 15,00 \\
Vapor & Retificação & Tratamento de água ácida & 1,04 \\
\hline
\end{tabular}

O craqueamento catalítico gera o maior volume de água ácida entre os processos de refino. Os principais contaminantes desta água são mostrados na Tabela 36.

Tabela 36 - Faixa de contaminantes na água ácida gerada no craqueamento.

\begin{tabular}{cc}
\hline Contaminante & Concentração (ppm) \\
\hline $\mathrm{H}_{2} \mathrm{~S}$ & $2000-6000$ \\
$\mathrm{NH}_{3}$ & $1000-4000$ \\
$\mathrm{HCN}$ & $10-50$ \\
Fenóis & $50-200$ \\
$\mathrm{Cl}$ & $50-300$ \\
\hline
\end{tabular}




\subsubsection{Coqueamento}

No coqueamento o resíduo de vácuo é transformado em produtos mais leves, que apresentam certo valor comercial, o fluxograma está apresentado na Figura 33.

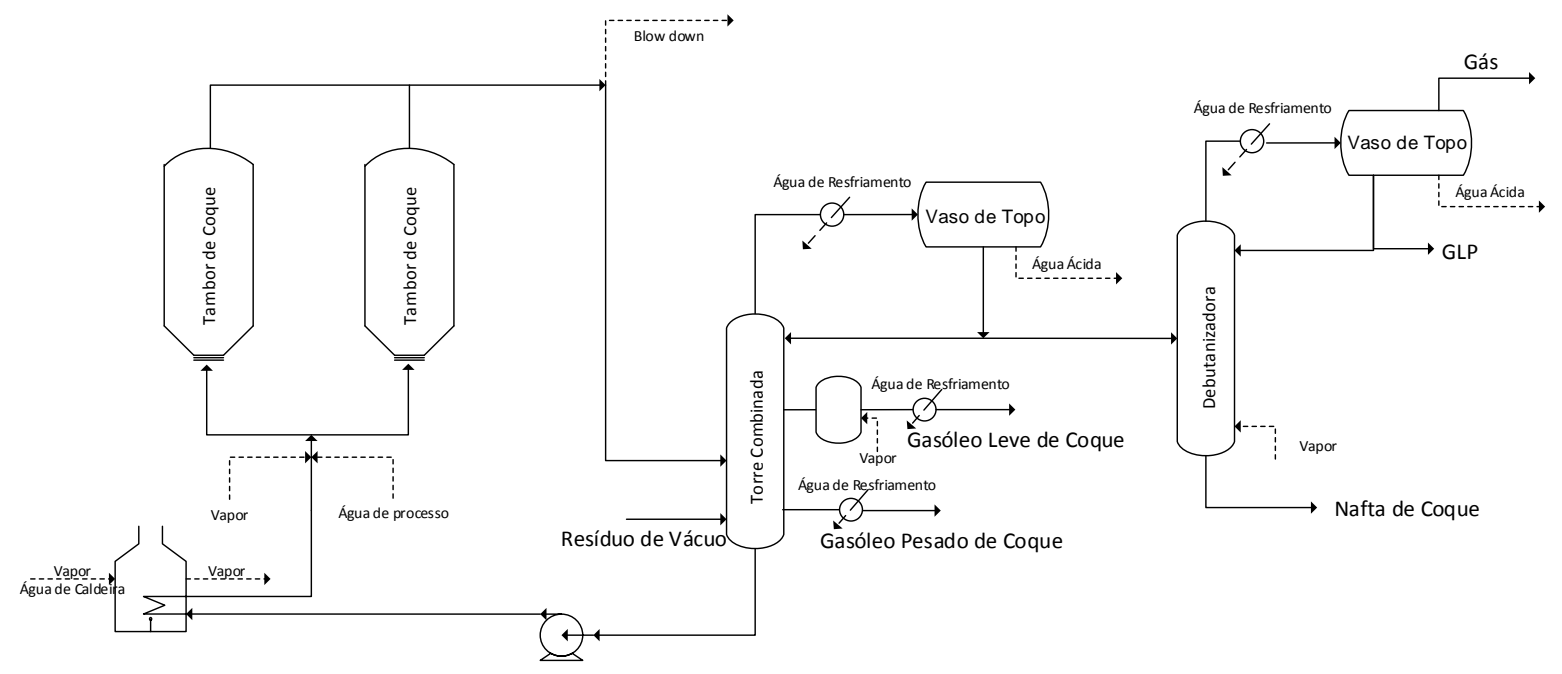

Figura 33 - Fluxograma simplificado do coqueamento retardado.

A carga combinada, composta de resíduo de vácuo do fundo das destiladoras a vácuo e de efluente oriundo do reator da unidade, é enviada aos fornos onde é aquecida atingindo a temperatura de craqueamento térmico. De modo a evitar a deposição de coque nas paredes dos tubos é injetado vapor no forno. A injeção do vapor aumenta a velocidade nos tubos, diminuindo o tempo de residência, assim as reações de coqueamento ocorrem nos tambores, sendo por isso, denominado coqueamento retardado, tendo como produto final vapor e coque.

Após o preenchimento do tambor é injetado vapor de água para remover os hidrocarbonetos gasosos ainda presentes no coque formado. A partir do momento que a corrente de leves está muito rica em vapores de água, a corrente é desviada para o sistema de água residual, conhecido como "blowdown" e é iniciado o processo de resfriamento e remoção do coque com o uso de jato de água. A água remanescente é drenada do coque em pátio e enviada ao sistema de "blowdown". 
O sistema de "blowdown" é um circuito fechado no qual a água utilizada para resfriamento e remoção do coque é reaproveitada posteriormente em outros ciclos de operação dos reatores. A reposição das perdas que ocorrem por evaporação ou por envio ao sistema de água ácida é feita com água filtrada.

Os vapores resultantes das reações de coqueamento são encaminhados para a torre combinada e são incorporados com a carga fresca na parte inferior da torre. $\mathrm{Na}$ torre combinada os gases de topo da torre combinada são condensados e seguem para vaso de topo. A água acumulada no fundo do vaso de topo segue para tratamento de água ácida. O gasóleo leve retirado da torre combinada é enviado para uma torre que usa vapor superaquecido para retificação.

A água ácida proveniente do tambor de topo da torre apresenta vazão contínua, já a água ácida proveniente do separador de água e óleo do sistema de "blowdown", durante as trocas de tambores de coque. Em virtude disso, é apresentada apenas a vazão total de água ácida gerada na Tabela 37.

Tabela 37 - Vazões totais de consumo de água no coqueamento.

\begin{tabular}{cccc}
\hline Qualidade da água & Uso & Destino do efluente & Vazão $(\mathbf{t} / \mathbf{h})$ \\
\hline Vapor & Injeção no forno & Tratamento de água ácida & \\
Vapor & Injeção nos tambores & Tratamento de água ácida & 17,50 \\
Vapor & Retificação & Tratamento de água ácida & \\
\hline
\end{tabular}

É também utilizada água para resfriamento e descoqueamento após a pirólise da carga. A quantidade desta água depende do processo e não se dá de forma contínua, visto que o processo de coqueamento funciona em batelada. O ciclo médio de um processamento é de 24 horas, sendo que aproximadamente 6 horas são referentes à etapa de resfriamento. $\mathrm{O}$ sistema de resfriamento pode ser aberto ou fechado, nesse caso a água coletada é reutilizada para um novo ciclo de resfriamento. No período analisado, apenas uma das unidades de coqueamento possuía sistema fechado. Mesmo com o sistema fechado há a necessidade de reposição de uma parcela de água. Uma prática adotada pela refinaria é a utilização 
de água pluvial para esta finalidade. A água das áreas de armazenamento e manuseio de coque é enviada para a piscina de decantação de finos, a vazão desta água é em torno de $40 \mathrm{~m}^{3} / \mathrm{h}$. Adotou-se para o estudo este valor como a água de reposição utilizada para lavagem do coque. Apesar dos ciclos não serem contínuos, a refinaria possui 2 unidades de coqueamento com 2 tambores cada, logo, pode-se considerar $24 \mathrm{~h}$ de resfriamento por dia.

A água ácida gerada na unidade de coqueamento é enviada para a unidade de tratamento de água ácida da conversão. A distribuição de contaminantes na água ácida gerada é mostrada na Tabela 38

Tabela 38 - Contaminantes na água ácida gerada no coqueamento.

\begin{tabular}{cc}
\hline Contaminante & Concentração (ppm) \\
\hline $\mathrm{H}_{2} \mathrm{~S}$ & 4000 \\
$\mathrm{NH}_{3}$ & 2500 \\
$\mathrm{Cl}$ & $50-300$ \\
\hline
\end{tabular}

\subsubsection{Hidrotratamento}

O óleo diesel contem impurezas que comprometem a sua qualidade, por provocarem poluição, corrosão a odor, além de instabilidade no produto, sendo as impurezas mais comuns o enxofre e o nitrogênio. O objetivo do hidrotratamento é tratar o diesel para que apresente teor baixo de enxofre conforme regulamentado pela ANP (atualmente $\leq 500$ ppm), estabilidade de cor e um adequado número de cetana - poder antidetonante. O fluxograma da unidade com os usos de água é apresentado na Figura 34. 


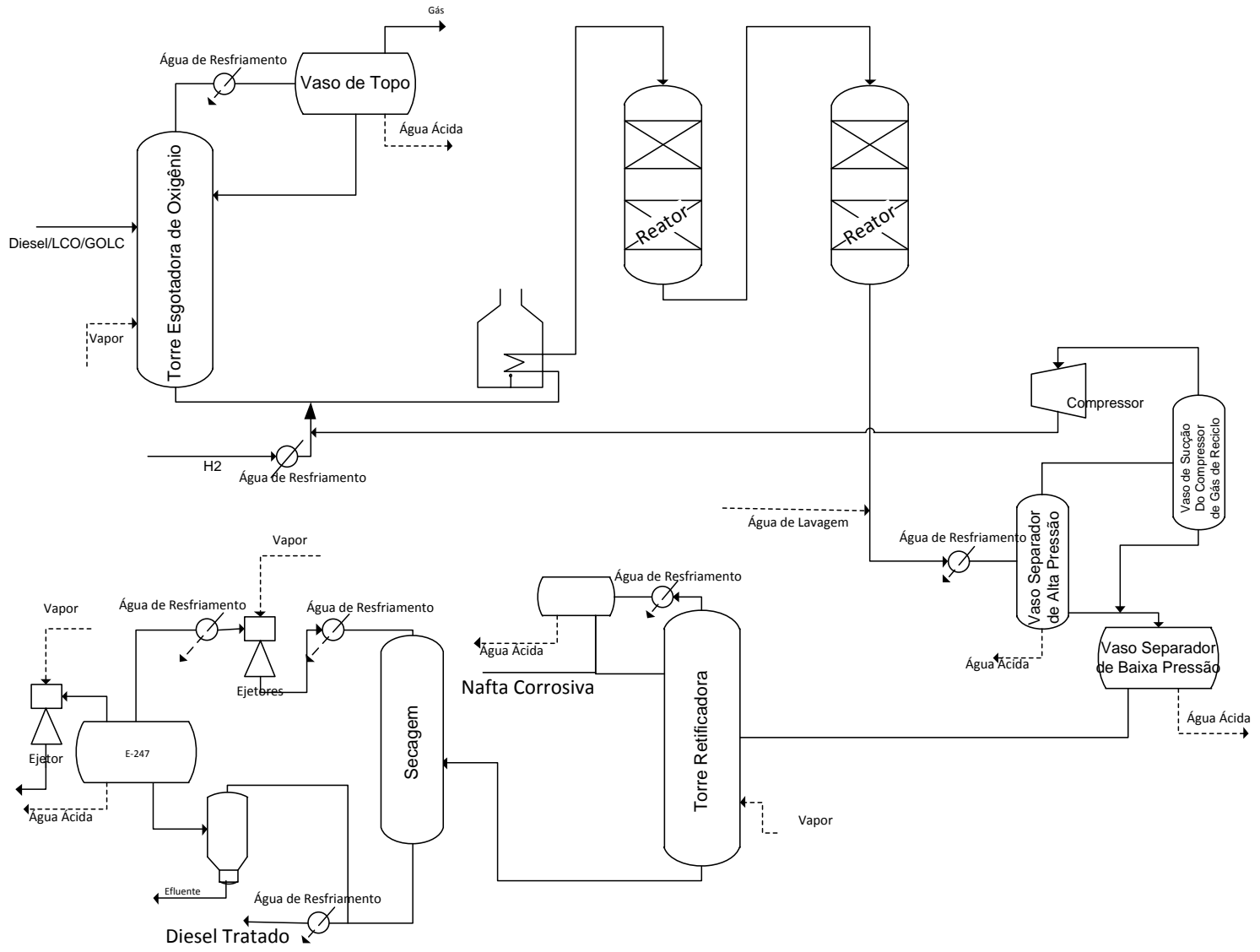

Figura 34 - Fluxograma simplificado do hidrotratamento.

Inicialmente a carga da unidade é esgotada com vapor de água como fluido de esgotamento para retirar oxigênio absorvido durante a estocagem. Isso evita a diminuição do tempo de carga da unidade por sujeira da bateria de preaquecimento. A água decantada do vaso de topo da torre esgotadora de oxigênio é enviada para o sistema de água ácida.

A carga segue para os reatores de hidrotratamento no qual ocorrem as reações de hidrogenação. Como consequência da hidrogenação de compostos nitrogenados presentes na carga, a corrente efluente dos reatores contém amônia. A presença deste resulta na deposição de sais de amônio, principalmente cloretos e sulfetos, nos permutadores que operam em temperatura mais baixa. Para evitar o entupimento desses permutadores, é injetada água de lavagem na tubulação a montante dos prováveis pontos de entupimento, principalmente antes do resfriador 
final do efluente dos reatores. Para a lavagem é utilizada água ácida tratada proveniente da unidade de tratamento de água ácida da unidade.

A mistura formada por água, hidrocarbonetos e gás de reciclo rico em hidrogênio é separada no vaso separador de alta pressão, em seguida, a separação da água e hidrocarbonetos é concluída no vaso separador de baixa pressão. A água separada no fundo dos vasos é enviada para tratamento de águas ácidas.

O óleo diesel é então retificado com vapor de média pressão para obter a especificação do ponto de fulgor e corrosividade. A água acumulada no fundo do vaso de topo segue para tratamento de água ácida.

Finalmente, o óleo diesel já hidrogenado e estabilizado passa pelo sistema de secagem a vácuo, a água decantada resultante do resfriamento do produto segue para tratamento de água ácida da unidade.

A Tabela 39 apresenta as vazões de água consumida nesse processo.

Tabela 39 - Vazões totais de consumo de água no hidrotratamento.

\begin{tabular}{cccc}
\hline Qualidade da água & Uso & Destino do efluente & Vazão $(\boldsymbol{t} / \boldsymbol{h})$ \\
\hline Vapor & Esgotamento & Tratamento de água ácida & 0,57 \\
Vapor & Retificação & Tratamento de água ácida & 6,68 \\
Vapor & $\begin{array}{c}\text { Fluido motriz dos } \\
\text { ejetores }\end{array}$ & Tratamento de água ácida & 2,77 \\
Água ácida retificada & Lavagem de sais & Tratamento de água ácida & 23,27 \\
\hline
\end{tabular}

A água ácida gerada é retificada na unidade de tratamento de água ácida do hidrotratamento, a faixa de distribuição de contaminantes é apresentada na Tabela 40. 
Tabela 40 - Faixa de contaminantes na água ácida gerada no hidrotratamento.

\begin{tabular}{cc}
\hline Contaminante & Concentração (ppm) \\
\hline $\mathrm{H}_{2} \mathrm{~S}$ & 19000 \\
$\mathrm{NH}_{3}$ & 11000 \\
$\mathrm{HCN}$ & $4000-6000$ \\
\hline
\end{tabular}

\subsection{TRATAMENTO DE ÁGUAS ÁCIDAS}

As águas ácidas são correntes aquosas que tiveram contato com as correntes de processo. São geradas usualmente devido à injeção de água diretamente ao processo ou pela condensação de vapor de água injetado ao processo. Como mostrado, os processos de destilação atmosférica e a vácuo, coqueamento, craqueamento e hidrotratamento são os maiores responsáveis pela produção de água ácida da refinaria. Porém, em outros pontos do processo também se tem a geração de água ácida, proveniente, por exemplo, de:

- $\quad$ Correntes aquosas drenadas de tanques de armazenamento.

- $\quad$ Correntes aquosas drenadas de vasos de "blowdown" de tochas.

- Correntes aquosas drenadas do sistema de topo de regeneradoras de dietanolamina (DEA).

A água ácida está contaminada principalmente por $\mathrm{H}_{2} \mathrm{~S}$ e $\mathrm{NH}_{3}$, e também por outros contaminantes como fenóis, $\mathrm{HCN}$, mercaptanas, hidrocarbonetos. A amônia e o sulfeto são altamente poluentes, sendo tratados nas unidades de tratamento de água ácida, antes de serem enviados para tratamento final.

O esquema usual da unidade, representado na Figura 35, consiste em duas torres retificadoras com injeção de vapor vivo. Entretanto alguns projetos, visando geração de condensado limpo, utilizam refervedor, que possibilita a recuperação do condensado gerado. 


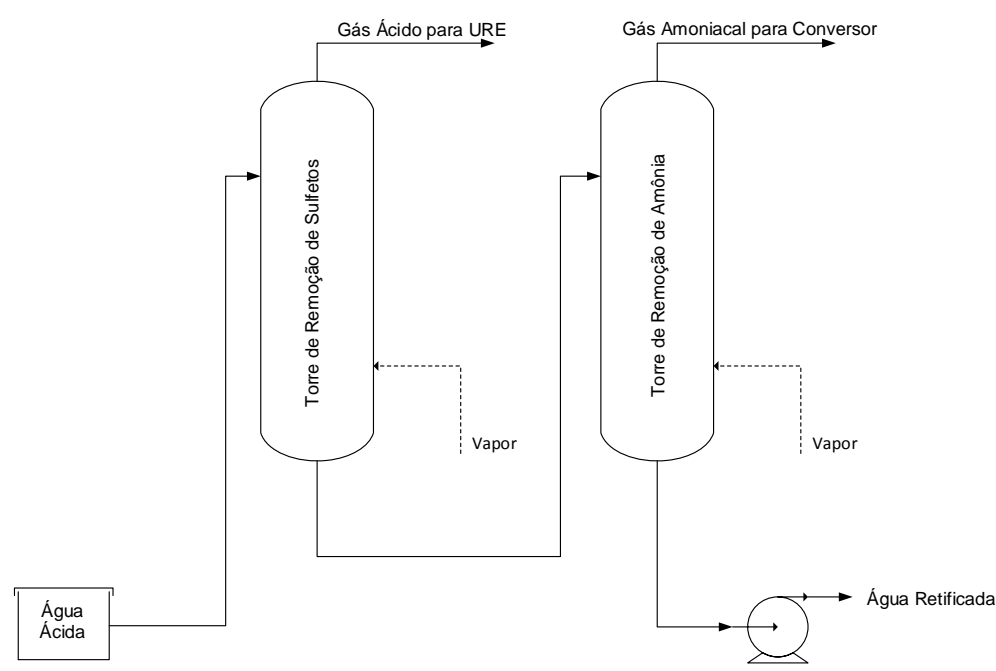

Figura 35 - Fluxograma simplificado do tratamento de águas ácidas.

A primeira torre opera pressurizada de modo a esgotar preferencialmente $0 \mathrm{H}_{2} \mathrm{~S}$ que é mais volátil que $\mathrm{O}^{\mathrm{NH}_{3}}$. Os gases de topo são enviados as unidades de recuperação de enxofre e para evitar contaminação do catalisador dos reatores não podem conter teores elevados de $\mathrm{NH}_{3}$.

A segunda torre retificadora opera com pressão mais baixa de modo a eliminar 0 $\mathrm{NH}_{3}$. O gás de topo rico em $\mathrm{NH}_{3}$ é enviado para o incinerador, para converter amônia em nitrogênio e água.

O tratamento da água ácida pode ser feita apenas em uma torre de retificação, composta de quatro seções de recheio, os dois superiores para retificação de sulfetos e os dois inferiores para retificação de amônia. Neste caso a liberação da amônia é favorecida com a adição de soda cáustica. Os dois contaminantes são retirados em uma única corrente no topo, a qual não pode ser encaminhada para a unidade de recuperação de enxofre, devido ao risco de formação de sulfato de amônio, e obstrução do sistema. O gás de topo é então encaminhado para fornos, sendo consumido como gás combustível.

A utilização de duas torres apesar de exigir maior investimento, maior consumo de energia e maior complexidade operacional tem como vantagens reduzir as emissões de SOx e de $\mathrm{NOx}$, além de permitir recuperar $\mathrm{O}_{2} \mathrm{~S}$ como enxofre. 
Para tratar a água ácida, a refinaria possui três unidades de tratamento.

- $\quad$ UTAA da Separação: responsável pelo tratamento da água ácida gerada nas destilações atmosféricas e a vácuo.

- $\quad$ UTAA da Conversão: trata a água ácida originária do craqueamento catalítico e da unidade de coqueamento retardado. Além disso, a unidade trata a água ácida acumulada em tanque de armazenamento. Esta unidade além de tratar o maior volume de água ácida gerado na refinaria trata a água ácida de pior qualidade em termos de fenóis e de cianeto.

- $\quad$ UTAA do Hidrotratamento: tem a finalidade de tratar a água ácida gerada na unidade de hidrotratamento

A distribuição da água ácida gerada nas unidades é apresentada na Figura 36. A retificação da água ácida é feita com refervedor e/ou injeção de vapor, o consumo de vapor é apresentado na Tabela 41 e o desempenho de cada unidade é mostrado na Tabela 42.

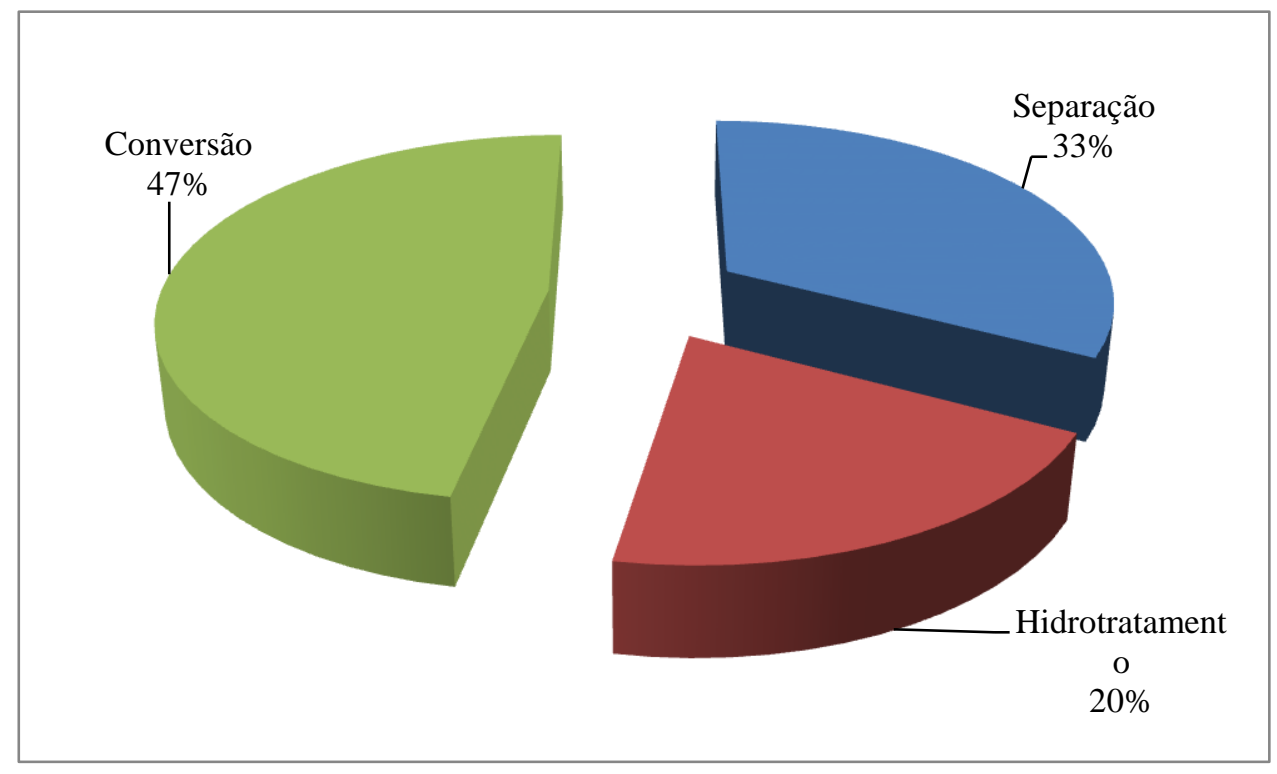

Figura 36 - Distribuição da água ácida da refinaria. 
Tabela 41 - Consumo de vapor para retificação da água ácida.

\begin{tabular}{cccc}
\hline Qualidade da água & Uso & Destino do efluente & Vazão (t/h) \\
\hline Vapor & Retificação & Retorno de condensado & 52,95 \\
Vapor & Retificação & Incorporada na água ácida & 6,90 \\
\hline
\end{tabular}

Tabela 42 - Desempenho das unidades de tratamento de água ácida.

\begin{tabular}{ccccc}
\hline \multirow{2}{*}{ Unidade } & \multicolumn{2}{c}{ Remoção global } & \multicolumn{2}{c}{ Qualidade da água ácida retificada } \\
& $\mathbf{H}_{\mathbf{2}} \mathbf{S}$ & $\mathbf{N H}_{\mathbf{3}}$ & $\mathbf{H}_{\mathbf{2}} \mathbf{S}$ (ppm) & $\mathbf{N H}_{\mathbf{3}}(\mathbf{p p m})$ \\
Separação & $97,77 \%$ & $95,51 \%$ & $<1-10$ & $<1-20$ \\
Conversão & $99,17 \%$ & $99,53 \%$ & $10-30$ & $10-120$ \\
Hidrotratamento & $99,99 \%$ & $99,82 \%$ & $<1-10$ & $5-20$ \\
\hline
\end{tabular}

A água ácida retificada é uma água de boa qualidade, mesmo contaminada principalmente por cloretos, sendo, portanto, adequada para reciclagem. Usualmente, a água ácida retificada é utilizada como água de diluição no sistema de dessalgação do petróleo, de modo a reduzir o consumo de água fresca. No caso específico da água ácida gerada na unidade de craqueamento catalítico, a reutilização completa o tratamento da água ácida por incorporar o fenol presente nesta água ao petróleo. Além da vantagem de reciclar a água em outra etapa, a dessalgação reduz a emissão deste contaminante nos efluentes líquidos.

Parte da água ácida tratada na unidade de hidrotratamento é reutilizada na própria unidade como água de lavagem na tubulação para evitar o entupimento de permutadores com sais de amônio. Uma parcela da água ácida tratada na unidade de conversão é utilizada para lavagem de gases no craqueamento catalítico. A água ácida retificada não reutilizada é enviada para a ETDI.

A Figura 37 apresenta a distribuição da água ácida tratada: 


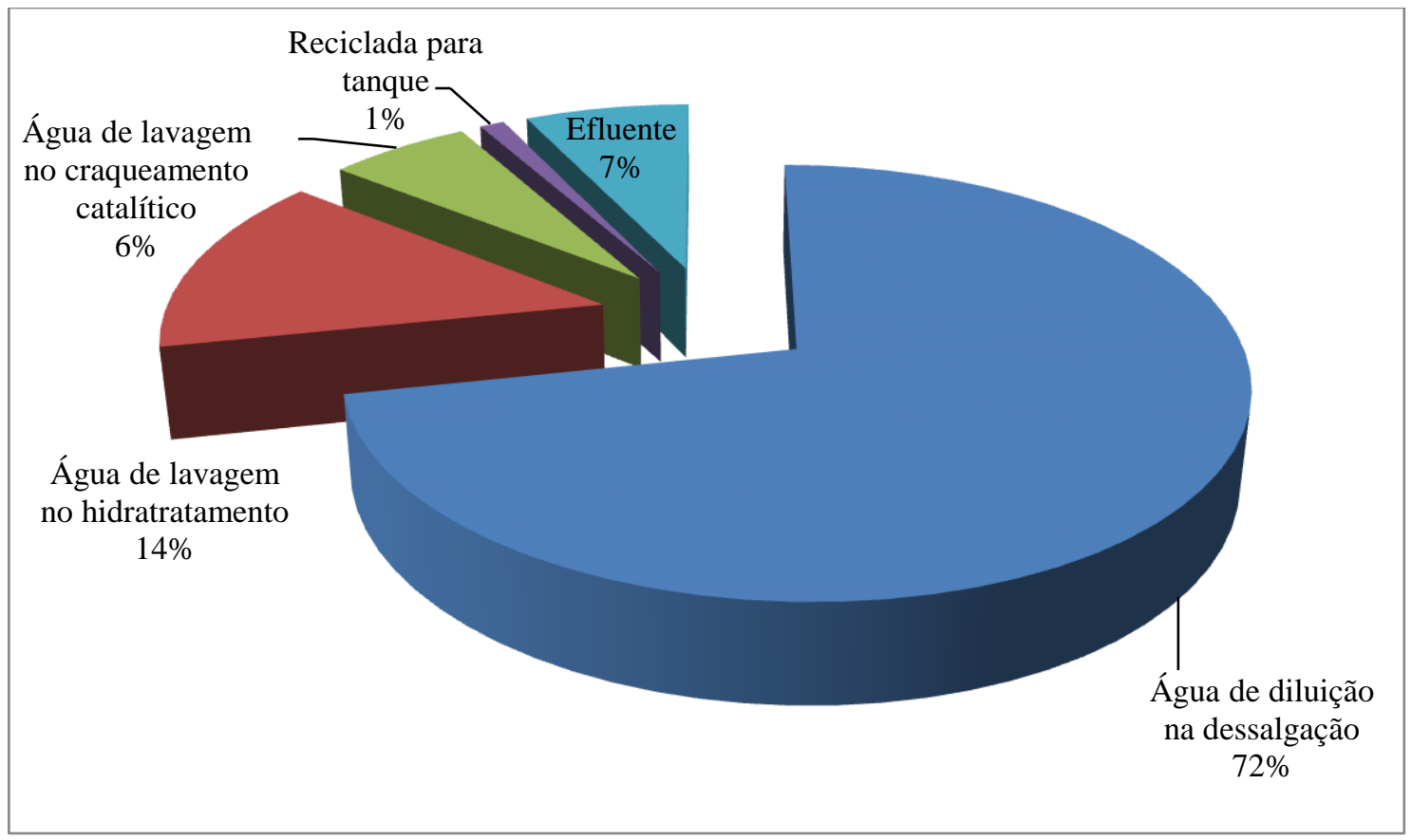

Figura 37 - Distribuição da água ácida retificada.

\subsection{TRATAMENTO DE DESPEJOS INDUSTRIAIS (ETDI)}

A destinação final da totalidade da água captada, desconsiderando a parcela de água captada mas não consumida pela refinaria, é mostrada na Figura 38:

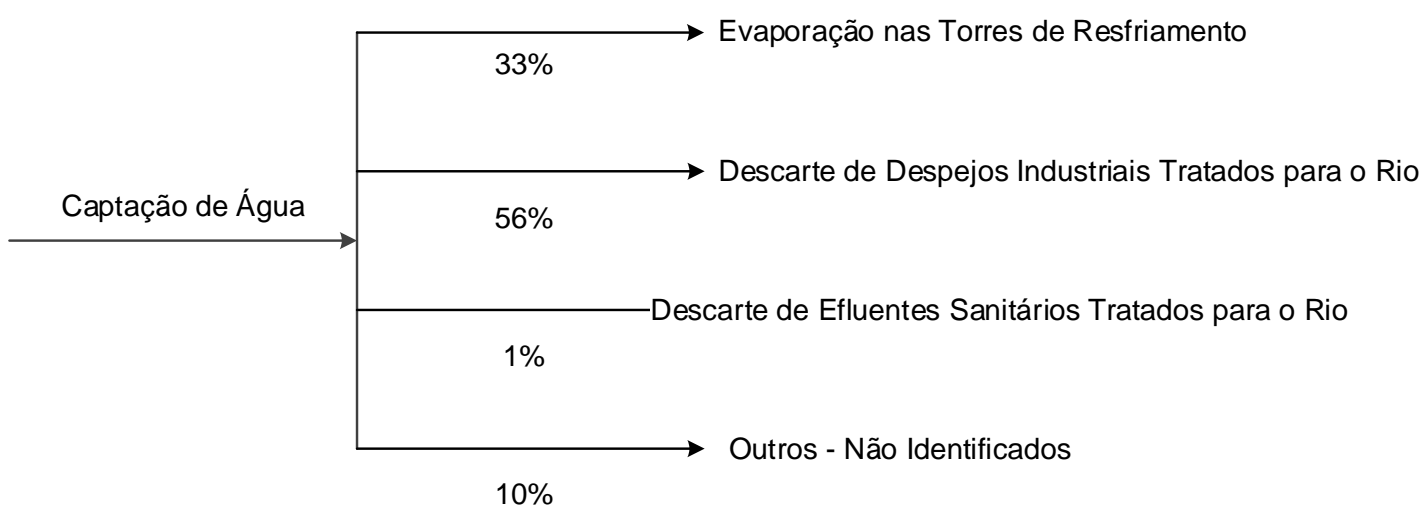

Figura 38 - Destino final da água captada. 
A parcela não identificada corresponde a imprecisões de medição, a permeação de água no solo, a emissões de vapores para a atmosfera originadas de vazamentos, de purgas de sistemas, etc.

Os despejos industriais são constituídos de águas oleosas coletadas de drenagem de tanques com a incorporação de água de chuva contida nos diques dos tanques e águas contaminadas originadas de purgas de torres de resfriamento, de caldeiras e de água de processo.

O volume e as características destes efluentes variam conforme a refinaria, pois dependem de vários fatores como propriedades do petróleo refinado, esquema de refino, complexidade e tecnologia empregada nas unidades de processo. Os efluentes são caracterizados pela existência de óleo e contêm também sulfetos, cloretos, compostos nitrogenados e metais e sólidos suspensos arrastados.

$\mathrm{Na}$ refinaria estudada, as águas residuais são misturadas e encaminhadas para a ETDI onde são tratadas até atingirem a qualidade exigida. A ETDI é composta por três fases distintas: o tratamento preliminar que consiste na remoção de sólidos, o tratamento físico-químico primário e, finalmente, pelo tratamento secundário.

Inicialmente as partículas de sólidos maiores são removidas através de grades. $\mathrm{O}$ óleo é então separado da água por diferença de densidade em separadores do tipo API (“American Petroleum Institute”) e em seguida em separado do tipo CPI ("Corrugated Plate Interceptor").

Na entrada do sistema de tratamento secundário há um sistema de flotação a ar dissolvido para remoção de óleo, deste o efluente segue para as lagoas aeradas para a biodegradação do efluente.

O efluente tratado é descartado no rio e o óleo recuperado é enviado para reprocessamento.

As refinarias brasileiras de petróleo devem adequar seus efluentes aos padrões definidos pela Resolução CONAMA no 357, de 17 de março de 2005 (Conama, 
2005) antes de descarta-los aos corpos hídricos receptores. Segundo o artigo 24 do CONAMA 357: "Os efluentes de qualquer fonte poluidora somente poderão ser lançados, direta ou indiretamente, nos corpos de água, após o devido tratamento e desde que obedeçam às condições, padrões e exigências dispostos nesta Resolução e em outras normas aplicáveis".

Os principais parâmetros utilizados para monitorar a qualidade do efluente tratado de uma refinaria de petróleo são: óleo e graxas, sulfetos, fenol, amônia. A Tabela 43 mostra os limites destes contaminantes estabelecido pelo CONAMA (2005).

Tabela 43 - Padrões para Lançamento de Efluentes - (CONAMA, 2005).

\begin{tabular}{cc}
\hline Contaminante & Concentração máxima \\
\hline Nitrogênio amoniacal total & $20,0 \mathrm{mg} / \mathrm{L}$ \\
Óleos e graxas & $20,0 \mathrm{mg} / \mathrm{L}$ \\
Sulfeto & $1 \mathrm{mg} / \mathrm{L}$ \\
Fenóis totais & $0,5 \mathrm{mg} / \mathrm{L}$ \\
Cianeto total & $0,2 \mathrm{mg} / \mathrm{L}$ \\
\hline
\end{tabular}

\subsection{SISTEMA DE ÁGUAS}

A Figura 39 apresenta o fluxograma simplificado do sistema de água da refinaria, incluindo dados do balanço de massa da água. 


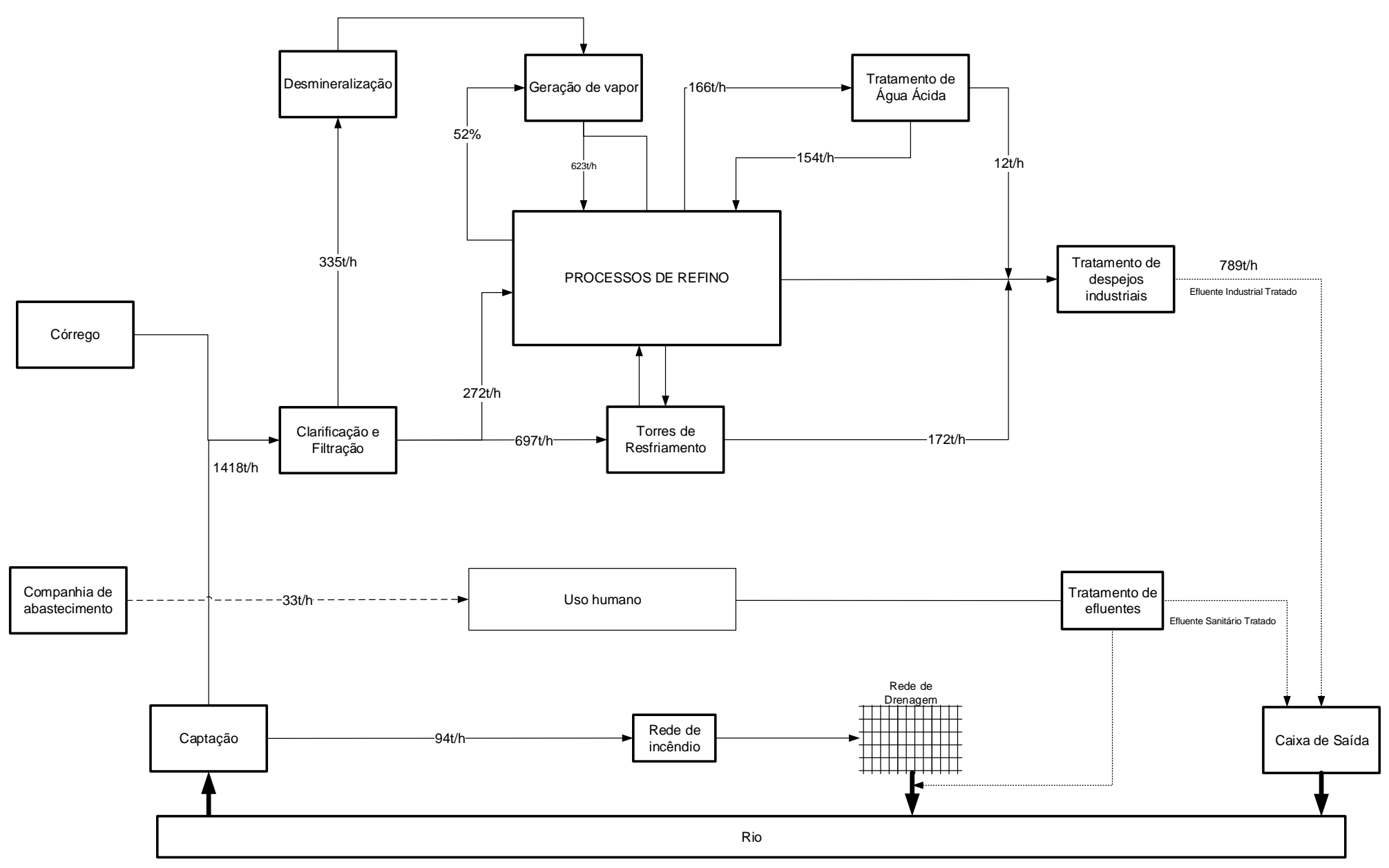

Figura 39 - Diagrama simplificado do sistema de águas. 


\section{RACIONALIZAÇÃO DO USO DE ÁGUA ATRAVÉS DE ANÁLISE DE PROCESSO}

A otimização global da rede de uso de água deve ser precedida pela racionalização individual dos processos. Neste capítulo são estudadas propostas de modificações das operações unitárias já consolidadas na literatura de modo a minimizar o consumo de água de cada processo ou sistema que usa água.

São identificadas algumas situações de otimização, reuso e reciclagem de água já praticadas e usuais em refinarias de petróleo, como por exemplo:

- Recuperação de parte do condensando do processo: o vapor utilizado em operações sem contato, como transferência indireta de calor e energia para turbinas, é coletado no final do processo na forma de condensado e realimentado nas caldeiras. No período analisado aproximadamente $52 \%$ do condensado é recuperado.

- Utilização de água ácida fenólica tratada na dessalgação do petróleo nas unidades de destilação: a água ácida contaminada com fenol após ser tratada nas torres esgotadoras de amônia e de gás sulfídrico é utilizada na dessalgação de petróleo. Além da economia de água fresca para a dessalgação esta operação completa o pré-tratamento da água ácida, pois o fenol presente na água ácida é incorporado no petróleo, reduzindo assim a emissão deste poluente nos efluentes líquidos.

- Realimentação de água recuperada do sistema de lodos para os clarificadores da ETA.

- Uso de água ácida retificada como água de lavagem a montante de permutadores na unidade de hidrotratamento para evitar o entupimento destes.

- $\quad U s o$ de água ácida retificada para lavagem de gases na área fria da unidade de craqueamento catalítico. 


\subsection{TORRES DE RESFRIAMENTO}

Conforme apresentado na Figura 22, a água consumida para reposição do sistema de resfriamento representa a maior parcela do volume total consumido na refinaria. Assim, estudos para minimizar esse consumo nas torres de resfriamento geram um grande impacto na redução global de água.

A reposição de água nas torres de resfriamento é feita para compensar as perdas de água. Estas são devidas à evaporação, ao arraste de gotas pelo ar e à drenagem para ajustar o ciclo de concentração adequado de modo a manter a corrosividade e a incrustação em níveis aceitáveis. A vazão de água arrastada pelo ar depende do projeto da torre e é normalmente pequena em relação à vazão de água drenada. $A$ vazão de evaporação é dependente da vazão de água de circulação e da variação de temperatura, ou seja, do calor trocado no processo.

Assim, há duas maneiras de reduzir o consumo de água em torres de resfriamento: o aumento do ciclo de concentração e a redução da quantidade de calor trocada no processo.

\subsubsection{Uso de trocadores de calor resfriados a ar}

Um estudo de otimização energética que visa o aproveitamento da energia de fontes quentes deve ser a primeira ação para a redução do calor trocado com a água de resfriamento. Uma ação seguinte é estudar o uso de resfriadores a ar em lugar de trocadores casco tubo, substituindo-os total ou parcialmente, como apresentado na Figura 40. Bresciani (2006b) desenvolveu um estudo que mostra a viabilidade técnica e econômica desse sistema considerando a temperatura de entrada e saída do fluido quente. 


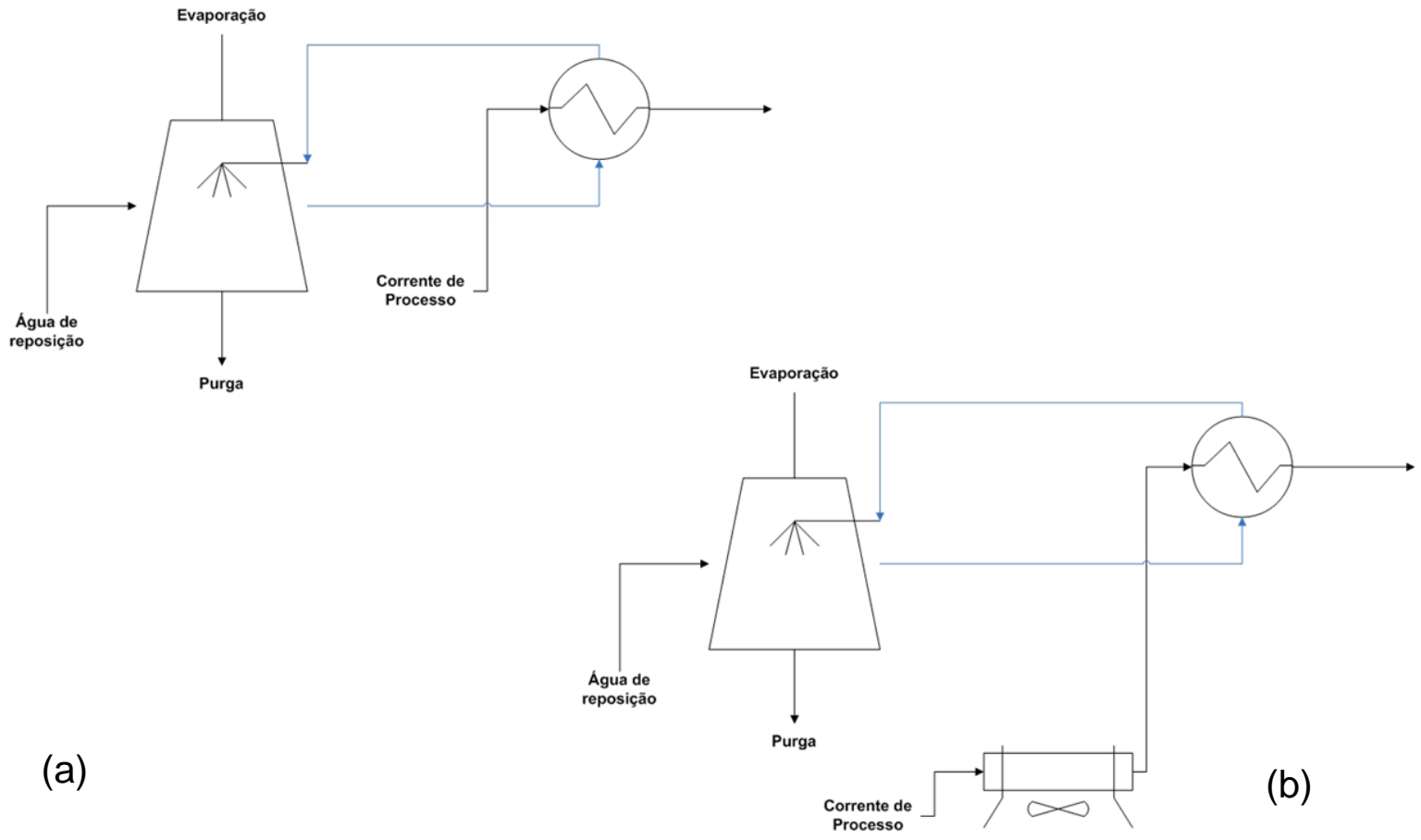

Figura 40 - Configurações dos trocadores de calor - (a) sistema atual com resfriamento com água;

(b) sistema proposto com sistema híbrido ar-água.

Para sistemas onde não há mudança de fase, há um ponto ótimo na relação energia trocada com ar/água que considera os custos de investimentos e operacionais.

$\mathrm{Na}$ refinaria estudada há permutadores de calor de alta capacidade, cuja temperatura de entrada do fluido quente é superior a 55ํㅡ, o que justifica o estudo dessa proposta.

Foram analisadas as folhas de dados de 73 trocadores de calor mais críticos, cuja temperatura de entrada do fluido quente é superior a $55^{\circ} \mathrm{C}$. Para esses equipamentos, foi calculada a quantidade ótima de energia que poderia ser trocada com ar a de redução na vazão de água de resfriamento, considerando $\Delta T$ médio de $10^{\circ} \mathrm{C}$. A substituição parcial ou total por resfriadores a ar representaria um potencial de redução de $1,92 \times 10^{8} \mathrm{kcal} / \mathrm{h}$ de energia trocada com a água, cerca de $46 \%$ do total. Essa redução energética, mantidas as condições operacionais das torres, é equivalente a $46 \%$ na redução da vazão de reposição das torres, ou seja, $350 \mathrm{~m}^{3} / \mathrm{h}$. 
Com o sistema híbrido reduz-se o a carga térmica total das torres de resfriamento, possibilitando a minimização de água de água fresca para reposição das torres e consequentemente da geração da purga, além de reduzir a perda água para a atmosfera por evaporação e arraste. Esta ação tem grande impacto no consumo de água da refinaria visto que impacta diretamente no maior consumidor de água.

\subsubsection{Aumento do ciclo de concentração}

O ciclo de concentração, definido na equação 22 , representa o número de vezes que a água de alimentação se concentrou no sistema, geralmente medido pela concentração de um contaminante não volátil e que não reage, como a sílica e o cálcio. Quanto maior o ciclo de concentração, menor a quantidade de água que o sistema perde, logo, menores a reposição de água e a dosagem de produto para condicionamento da água de circulação e consequentemente menor o custo para o tratamento desta água.

$C C=\frac{C_{\text {purga }}}{C_{\text {reposição }}}$

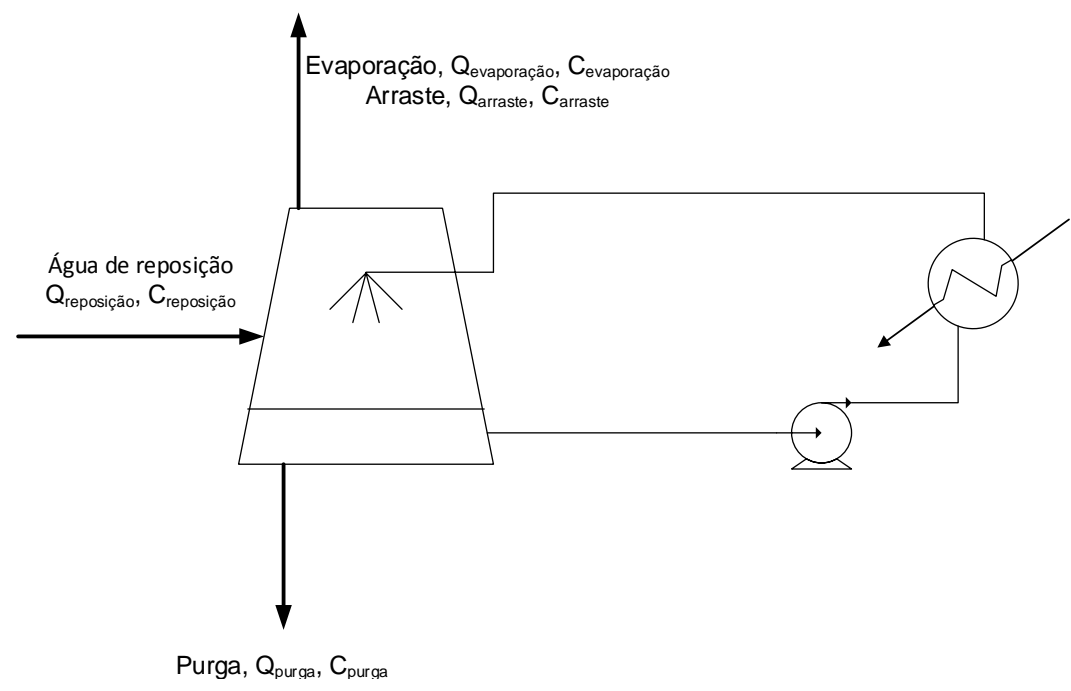

Figura 41 - Sistema de torre de resfriamento 
A partir do balanço do sistema é possível definir uma relação entre o aumento ciclo de concentração e a economia da água de reposição.

Considerando a Figura 41 e de acordo com balanço do sistema de torre de resfriamento apresentado anteriormente:

$Q_{\text {reposição }}=Q_{\text {evaporação }}+Q_{\text {arraste }}+Q_{\text {purga }}$

$Q_{\text {reposição }} \cdot C_{\text {reposição }}=\left(Q_{\text {arraste }}+Q_{\text {purga }}\right) \cdot C_{\text {purga }}$

Definindo:

$Q_{\text {perdas }}=Q_{\text {arraste }}+Q_{\text {purga }}$

Tem-se:

$Q_{\text {reposição }}=Q_{\text {evaporação }}+Q_{\text {perdas }}$

$Q_{\text {reposição }} \cdot C_{\text {reposição }}=Q_{\text {perdas }} \cdot C_{\text {purga }}$

De acordo com as equações (27) e (28):

$C C=\frac{Q_{\text {reposição }}}{Q_{\text {perdas }}}=\frac{Q_{\text {reposição }}}{Q_{\text {reposição }}-Q_{\text {evaporação }}}$

A vazão de evaporação ( $Q_{\text {evaporação }}$ é constante para cada sistema, pois depende somente da troca térmica e do $\Delta \mathrm{T}$, que neste estudo são fixos. Logo, para um determinado ciclo de concentração igual a $n$, a equação (30) fica:

$n=\frac{Q_{\text {reposição }} \cdot n}{Q_{\text {reposição }} \cdot n-Q_{\text {evaporação }}} \therefore Q_{\text {reposição }} \cdot n=n \cdot Q_{\text {reposição }} \cdot n-n \cdot Q_{\text {evaporação }}$

Logo:

$Q_{\text {reposição }} \cdot n=\frac{Q_{\text {evaporação }} \cdot n}{n-1}$

Similarmente, para um ciclo de concentração desejado igual a $x$, tem-se: 
$Q_{\text {reposição }} \cdot x=\frac{Q_{\text {evaporação }} x}{x-1}$

A economia relativa de água do ciclo de concentração $x$ em relação ao ciclo de concentração $n$ é calculada como:

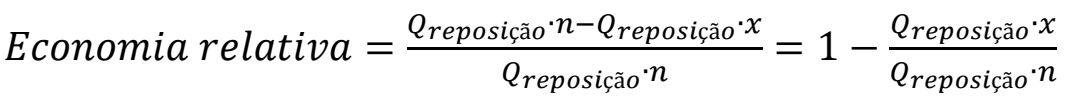

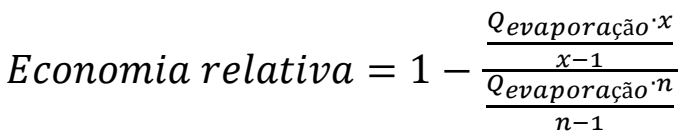

Economia relativa $=1-\frac{x \cdot(n-1)}{n \cdot(x-1)}$

Por exemplo, para uma torre de resfriamento com ciclo de concentração igual a dois, $n=2$, a partir da equação (37) é possível calcular a economia relativa de água para cada ciclo de concentração x. A curva é apresentada na Figura 42.

Economia relativa $=1-\frac{x}{2 \cdot(x-1)}$

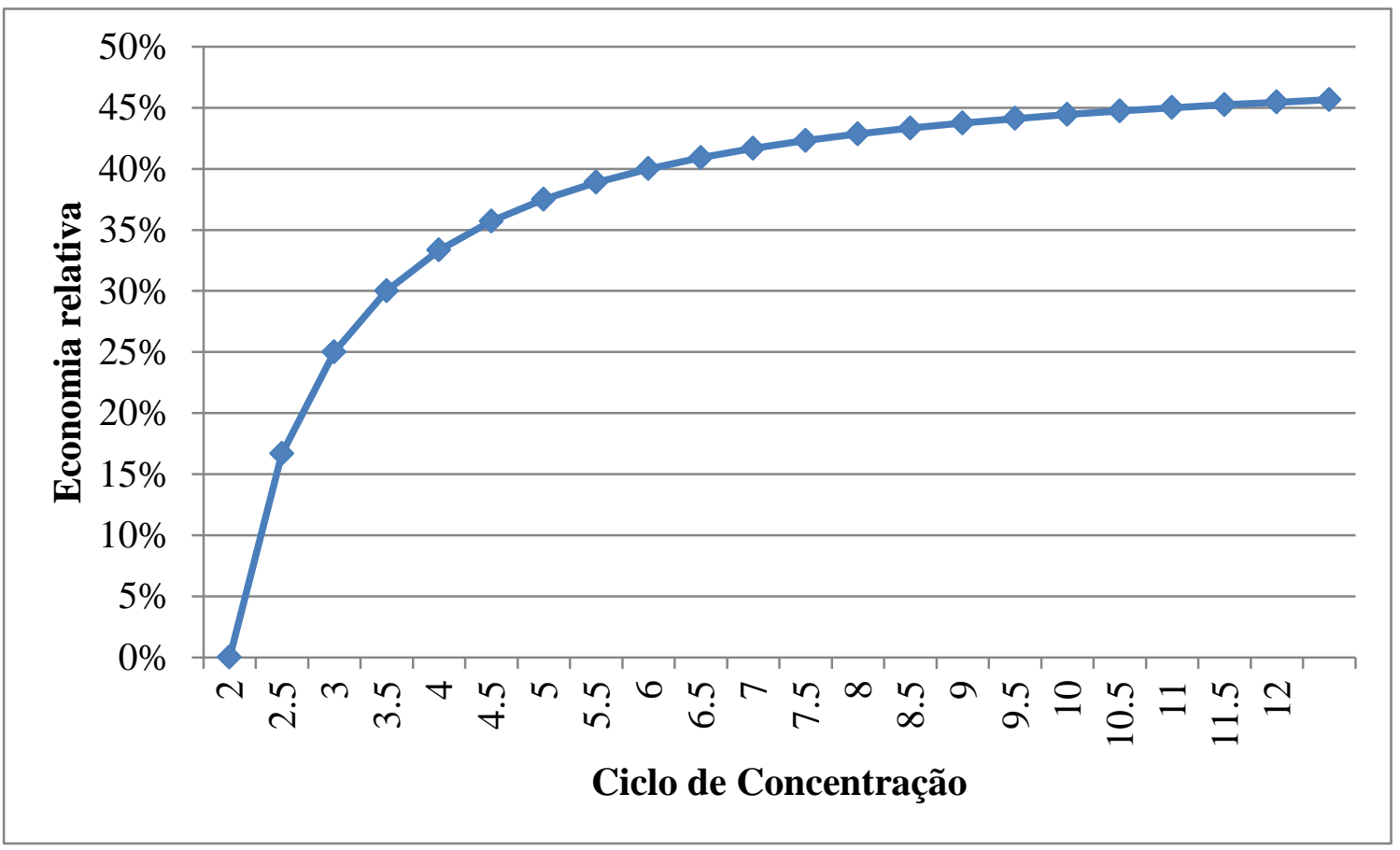

Figura 42 - Economia de água de reposição em função do ciclo de concentração. 
À medida que o ciclo de concentração aumenta, a economia de água de reposição torna-se menos pronunciada. Dantas apud Collares (2004) mostra que o ciclo de concentração ideal encontra-se em 6 e 7, acima desse valor, a economia adicional de água é irrisória.

Aumentar o ciclo de concentração implica em menor necessidade de purga da torre para manter a concentração do contaminante chave controlado. As técnicas para minimizar a quantidade de purga incluem o ajuste da qualidade da água de reposição (através do controle na fonte ou tratamento da água) e a melhora no condicionamento da água circulante, obtido através do uso de produtos químicos específicos, para que os níveis de corrosividade e incrustação estejam dentro de faixas aceitáveis.

Com a evolução dos processos de tratamento de água, atualmente é possível trabalhar com ciclo de concentração acima de 10 (Furtado (2007) e Gonçalves et al. (2010)). Segundo Vanelli (2002), por segurança e comodidade, muitas vezes a torre de resfriamento é operada com ciclos de concentração menores do que os permitidos pelos sistemas de tratamento de água em uso, com abertura contínua da descarga e maior consumo de agua.

Observa-se que as torres de resfriamento da refinaria operam com ciclos de concentração baixos, variando de 2 a 4,6. Avaliou-se o aumento dos ciclos de concentração para seis, ciclo já realizado em outras refinarias (Vanelli, 2002). A Tabela 44 apresenta a economia que pode ser obtida em cada torre. A economia total é equivalente a $10 \%$ da água utilizada para reposição pela refinaria.

Tabela 44 - Economia de água com o aumento do ciclo de concentração.

\begin{tabular}{cccccccc}
\hline Torre & $\mathbf{1}$ & $\mathbf{2}$ & $\mathbf{3}$ & $\mathbf{4}$ & $\mathbf{5}$ & $\mathbf{6}$ & $\mathbf{7}$ \\
\hline Ciclo de concentração & 4,61 & 4,21 & 4,05 & 3,60 & 3,18 & 1,98 & 4,52 \\
Ciclo de concentração possível & 6,00 & 6,00 & 6,00 & 6,00 & 6,00 & 6,00 & 6,00 \\
Economia na água de reposição $\left(\mathbf{m}^{\mathbf{3}} / \mathbf{h}\right)$ & 18,10 & 6,48 & 1,81 & 1,38 & 31,19 & 6,20 & 6,56 \\
Economia na água de reposição & $6,0 \%$ & $8,5 \%$ & $9,6 \%$ & $13,3 \%$ & $17,7 \%$ & $40,6 \%$ & $6,5 \%$ \\
\hline
\end{tabular}


O contaminante chave utilizado para o controle das torres de resfriamento da refinaria é o cálcio $\left(\mathrm{ppm} \mathrm{CaCO}_{3}\right)$. Segundo Martins (2009) a dureza é a principal fonte de depósitos em equipamentos, com grande tendência à formação de incrustações, principalmente em superfícies aquecidas, causando queda de eficiência de troca térmica, entupimento de permutadores de calor e corrosão localizada sob depósitos por aeração diferencial.

Considerando que a dureza da água de reposição seja $34 \mathrm{ppm}$ de $\mathrm{CaCO}_{3}$, a dureza na água de circulação, ao se trabalhar com ciclo de concentração igual a 6, ficaria em torno de 200ppm. Considerando que atualmente os tratamentos para água de resfriamento permitem trabalhar com valores até 2 mil ppm, o ciclo estabelecido ainda é conservador (Furtado, 2007).

O aumento dos ciclos de concentração das torres resulta em economia de água, redução da purga e consequentemente os custos para seu tratamento.

\subsection{USO E GERAÇÃO DE VAPOR}

\subsubsection{Aumento da recuperação do condensado}

A geração de vapor em caldeiras requer a alimentação de água de alta qualidade, praticamente isenta de íons, que poderiam causar incrustação nas caldeiras. Desse modo, é economicamente atraente que o vapor utilizado em operações nas quais não ocorre o contato com o fluido de processo, como turbinas e trocadores de calor, seja recuperado como condensado,

A maximização da recuperação do condensado proporciona tanto economia de água quanto economia de recursos empregados para a geração de água desmineralizada. Uma das formas de aumentar a recuperação é evitar desperdícios ao longo do processo, por exemplo: 
- Condensado escoando para a rede de efluentes industriais por falta de pressão.

- Condensado sendo direcionado para a rede de efluentes industriais por problemas no purgador.

No caso em estudo, para o período avaliado, o retorno de condensado atinge $52 \%$ em relação à vazão de vapor gerado. Considerando que esse retorno pode chegar a $60 \%$, que é um valor normal em refinarias e evidenciado por casos reais onde o condensado poderia ser recuperado, a economia de água fresca é equivalente a 48 $m^{3} / h$.

\subsubsection{Aproveitamento da purga das caldeiras}

Apesar da recuperação de parte do condensado e da reposição de água desmineralizada, ainda é necessária uma purga no sistema de geração de vapor, pois, do mesmo modo que o sistema de água de resfriamento, a recirculação de condensado provoca uma concentração de sais e de outros contaminantes, que podem afetar o desempenho das caldeiras. Assim, periodicamente é efetuada uma purga nas caldeiras para controlar a concentração destes contaminantes, gerando um efluente que é enviado para a ETDI (Vanelli, 2002).

A purga consiste em uma retirada contínua ou intermitente de uma fração da água da caldeira, tendo como função manter as concentrações das impurezas abaixo de limites que assegurem a não ocorrência de problemas tanto para a caldeira quanto para os usuários do vapor (Serra, 2006). A qualidade do tratamento de água de alimentação da caldeira e os tratamentos e análises do processo determinam a periodicidade das descargas.

A água da purga das caldeiras apresenta qualidade elevada, tendo baixa concentração em cálcio e magnésio, que originam incrustações. Entretanto, pode 
apresentar condutividade muito elevada, dependendo da caldeira e das condições

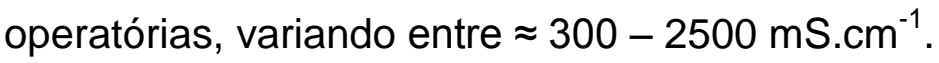

No período analisado a purga das caldeiras é inteiramente descartada. Esta água é considerada de alta qualidade, portanto pode ser reutilizada em um uso menos nobre, por exemplo, para a reposição das torres de resfriamento (Revista Química e Derivados, 2000).

\subsubsection{Uso de refervedor nas colunas de retificação}

O processo de retificação tem como objetivo remover componentes voláteis de uma corrente líquida contaminada. O processo pode ser realizado pela injeção de vapor vivo ou com uso de refervedor.

O processo pode ser realizado pela injeção de vapor vivo no fundo da torre, como apresentado na Figura 43a. Os efluentes gerados apresentam contaminantes, como enxofre e amônia, e por isso a água gerada deve ser tratada antes de ser descartada. Nesse caso, a pressão parcial dos hidrocarbonetos na fase gasosa é reduzida e consequentemente a redução da temperatura de vaporização da mistura.

Já nos processos de retificação mostrado na Figura 43b é utilizado refervedor para geração de vapor e energia requeridos pelo processo, nesse caso, a corrente líquida de fundo é aquecida de modo a vaporizar os componentes mais voláteis e injetada na coluna. Dessa forma, reduz-se o consumo de água fresca e de geração de efluente.

A vantagem do uso de refervedores é a preservar o condensado limpo e não gerar efluentes. Estudos realizados pelo LSCP/USP (Alves et al., 2008) comprovaram a efetividade da utilização da coluna com refervedor. 


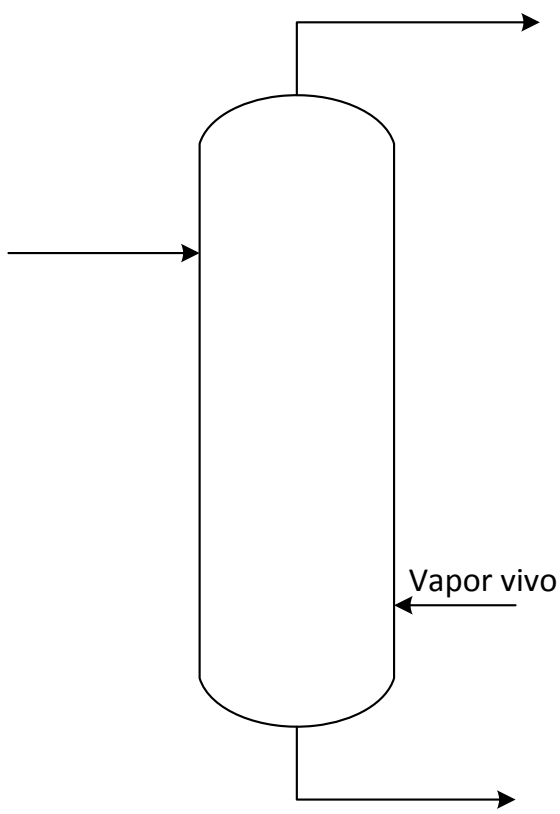

(a)

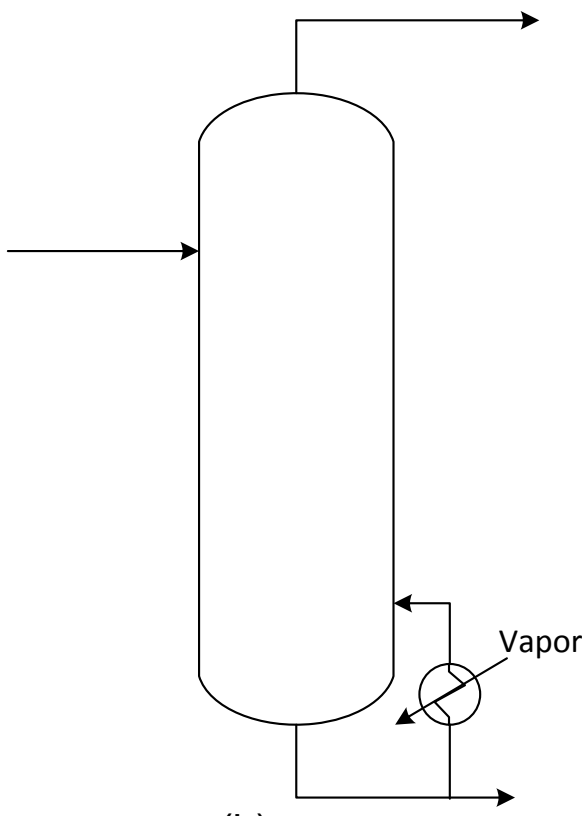

(b)

Figura 43 - Configurações das colunas de retificação - (a) sistema atual com injeção de vapor vivo;

(b) sistema proposto com uso de refervedor.

Dos três sistemas de tratamento de água ácida da refinaria, dois deles utilizam vapor como fluido de retificação em conjunto com refervedor, sendo que a água adicionada se junta com a água ácida retificada, criando mais água residual.

O uso apenas de refervedor é considerado prática adequada, e reduziria $6,9 \mathrm{~m}^{3} / \mathrm{h}$ de água fresca consumida, além disso, há economia na geração de efluentes.

\subsection{OPERAÇÃO DAS DESSALGADORAS}

No processo de dessalgação em dois estágios, a salmoura do segundo estágio, embora mais concentrada do que a água de diluição, é menos concentrada que a salmoura do primeiro estágio. Logo, a água de diluição total necessária pode ser reduzida com o reuso da salmoura do segundo estágio como água de diluição do 
primeiro. Em tal esquema, o petróleo e as correntes de água de diluição entram em contato nas dessalgadoras em contracorrente, como apresentado na Figura 44.

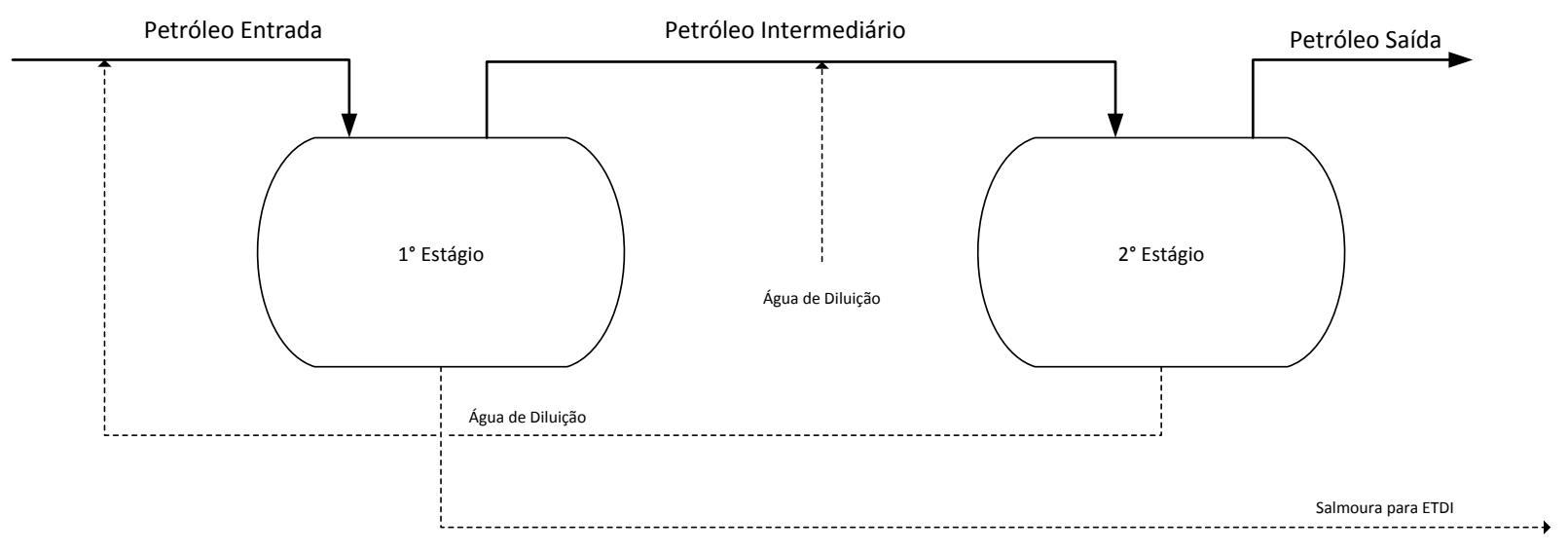

Figura 44 - Operação das dessalgadoras em contracorrente.

Segundo Bresciani (2009) com a mesma quantidade de água de lavagem que era consumida nos sistemas com único estágio, tem-se, nos dois vasos, a percentagem de água adequada para otimizar a separação. O sistema com dois estágios em série garante operação mais estável e menores teores de água e sal no petróleo dessalgado.

Além disso, deve-se priorizar o uso de água ácida retificada neste processo. Segundo Índio do Brasil apud Vanelli (2004) a água retificada, por ser aquecida devido à sua retificação com vapor - e praticamente isenta de sais, torna-se excelente veículo para a dessalgação.

Há uma relação ótima para a porcentagem de água de lavagem em relação ao petróleo dessalgado, que depende do tipo de petróleo. Segundo Idrisova et al. apud Bresciani (2009), o valor ótimo está entre 7 e $8 \%$ em volume de água em relação ao petróleo. 
Operando as dessalgadoras de dois estágios em contracorrente e utilizando exclusivamente água ácida retificada em todas as dessalgadoras, tem-se uma economia de água fresca de $45 \mathrm{~m}^{3} / \mathrm{h}$.

De modo a reduzir ainda mais quantidade de água fresca usada no processo de dessalgação, mantendo a vazão de água para cada estágio e a sua relação água/petróleo, Bresciani (2009) sugeriu um novo esquema de operação, Figura 45, visando um maior grau de reciclagem de água no processo com dois estágios.

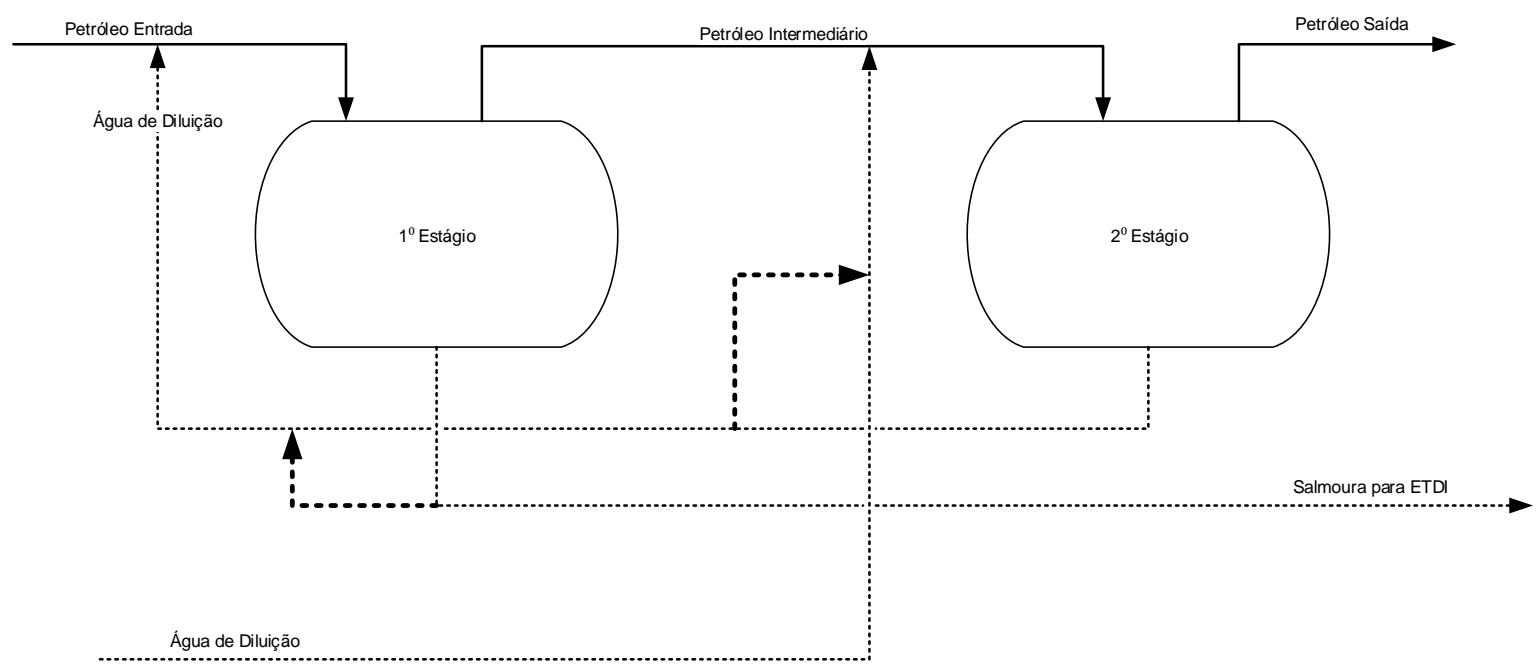

Figura 45 - Operação das dessalgadoras em contracorrente com maior grau de reciclagem (adaptado de Bresciani, 2009).

\subsection{RESUMO DAS PROPOSTAS}

A Tabela 45 apresenta uma compilação das propostas apresentadas e o total de água fresca que pode ser economizado. 
Tabela 45 - Resumo das propostas de racionalização do uso de água

\begin{tabular}{cc}
\hline Proposta de racionalização & $\begin{array}{c}\text { Economia de água } \\
\text { fresca }\left(\mathbf{m}^{\mathbf{3}} / \mathbf{h}\right)\end{array}$ \\
\hline Uso de trocadores de calor resfriados a ar & 350 \\
Aumento do ciclo de concentração & 71,72 \\
Aumento da recuperação do condensado & 48 \\
Aproveitamento da purga das caldeiras & 12,46 \\
Uso de refervedor nas colunas de retificação & 6,9 \\
Operação das dessalgadoras em contracorrente & 45 \\
\hline Total & $\mathbf{5 3 4 , 0 8}$ \\
\hline
\end{tabular}

Além destas propostas destaca-se a importância de ações gerenciais de conscientização dos colaboradores para redução de desperdícios. A água de incêndio representa uma grande parcela da água utilizada na refinaria. Isto se deve a esta água ser utilizada frequentemente em usos comuns e não emergenciais como: serviços de manutenção, lavagens de pisos e equipamentos, resfriamento externo de permutadores, deslocamentos e diluição de líquidos contaminados e testes hidrostáticos.

Faz-se necessário o controle do uso desta água através de mudanças operacionais e treinamento de operadores. Essa prática inadequada acarreta desperdícios de água visto que não há medições para controle do consumo, além de poder contrariar procedimentos de segurança e servir de paliativo - nem sempre eficiente - para um problema que deveria ser realmente solucionado. 


\section{OTIMIZAÇÃO DA REDE DE ÁGUA}

A otimização da rede de água tem como objetivo obter o mínimo consumo de água fresca satisfazendo as restrições decorrentes das especificações do processo.

Antes de otimizar a rede de água, as restrições limitantes para cada processo devem ser estabelecidas de modo a ter as concentrações máximas de cada poluente na entrada e na saída. A carga do poluente, que é característica do processo, e as concentrações máximas determinarão o consumo de água fresca. Zheng et al. (2006) propuseram algumas regras para a definição dos contaminantes e das concentrações limite:

1) Escolher os contaminantes que têm efeitos mais evidentes sobre os processos. Caso outros contaminantes possam afetar determinados processos, estes podem ser considerados como restrições para os processos que utilizam água de reuso depois que a rede inicial for obtida.

2) Combinar os contaminantes que têm efeitos semelhantes. Desse modo a resolução do modelo matemático para a integração da rede de água é simplificada.

3) Definir as concentrações máximas de contaminantes na entrada igual à zero para os processos que não toleram tais contaminantes de modo que este processo não possa receber água de reuso de outros processos.

4) Os processos cuja água residual não pode ser reutilizada por outros processos, deve ter a concentração máxima definida como um valor muito alto de modo que os outros processos não utilizem a água residual.

A rede de água da refinaria estudada envolve as unidades de processo descritas anteriormente: destilação atmosférica, destilação a vácuo, craqueamento catalítico, coqueamento, hidrotratamento, unidades de tratamento de água ácida e dessalgação. A Tabela 46 apresenta os contaminantes e suas respectivas procedências, na rede de água ácida há a predominância de amônia e sulfeto, mas também há a presença de outros, como, fenóis, cianeto, hidrocarbonetos e cloretos. 
Tabela 46 - Procedência dos Contaminantes

\begin{tabular}{cc}
\hline Contaminante & Procedência \\
\hline Nitrogênio amoniacal total & Águas ácidas (craqueamento catalítico, destilações e \\
hidrotratamento) \\
Sulfeto & Águas ácidas (craqueamento catalítico, destilações e \\
Fenóis totais & hidrotratamento) \\
Cianeto total & Águas ácidas (destilação e craqueamento catalítico) \\
Cloretos & Águas ácidas (craqueamento catalítico) \\
Óleos e graxas & Salmouras (dessalgação) \\
& Salmouras (dessalgação) \\
\hline
\end{tabular}

O perfil limite de água da rede foi obtido através dos dados dos processos e também, quando necessário, a partir de dados de outras refinarias encontradas na literatura.

\subsection{OTIMIZAÇÃO POR UNIDADE}

Antes da otimização global da rede de água, deve-se buscar oportunidades de otimização da rede de água interna das unidades. Isso porque, segundo a heurística IX apresentada no tópico 3.2.1, o layout deve ser considerado de modo a reduzir o comprimento de tubulações, reduzir a perda de carga e evitar a interferência de uma área operacional em outra. 


\subsubsection{Unidade de conversão}

Nas unidades de conversão, tanto na unidade de craqueamento catalítico quanto na de coqueamento, é utilizada água para a lavagem de gases de topo. A injeção desta água tem como objetivo evitar a estagnação de contaminantes e, portanto, a água deve ter uma concentração de contaminantes inferior à produzida nestes processos. Uma prática usual é a utilização de água ácida retificada para tal finalidade. Visto que esta é uma água previamente tratada, não alteraria a especificação do produto final e nem afetaria a operação da unidade de tratamento de água ácida.

$\mathrm{Na}$ unidade de craqueamento catalítico tal reuso já é realizado, economizando 10,2 t/h de água fresca. Entretanto, no período estudado a lavagem da unidade de gases de topo da unidade de coqueamento com água ácida retificada não estava sendo realizada. O potencial de ganho com a prática deste reuso é de 1,9 t/h.

\subsubsection{Unidade de hidrotratamento}

A rede de água atual da unidade de hidrotratamento está representada na Figura 46. Os contaminantes chaves são amônia e sulfeto, visto que os contaminantes têm efeito semelhante, adotou-se a amônia para simplificar o modelo, por ser mais restritiva que os sulfetos. A Tabela 47 apresenta os dados para a otimização. 


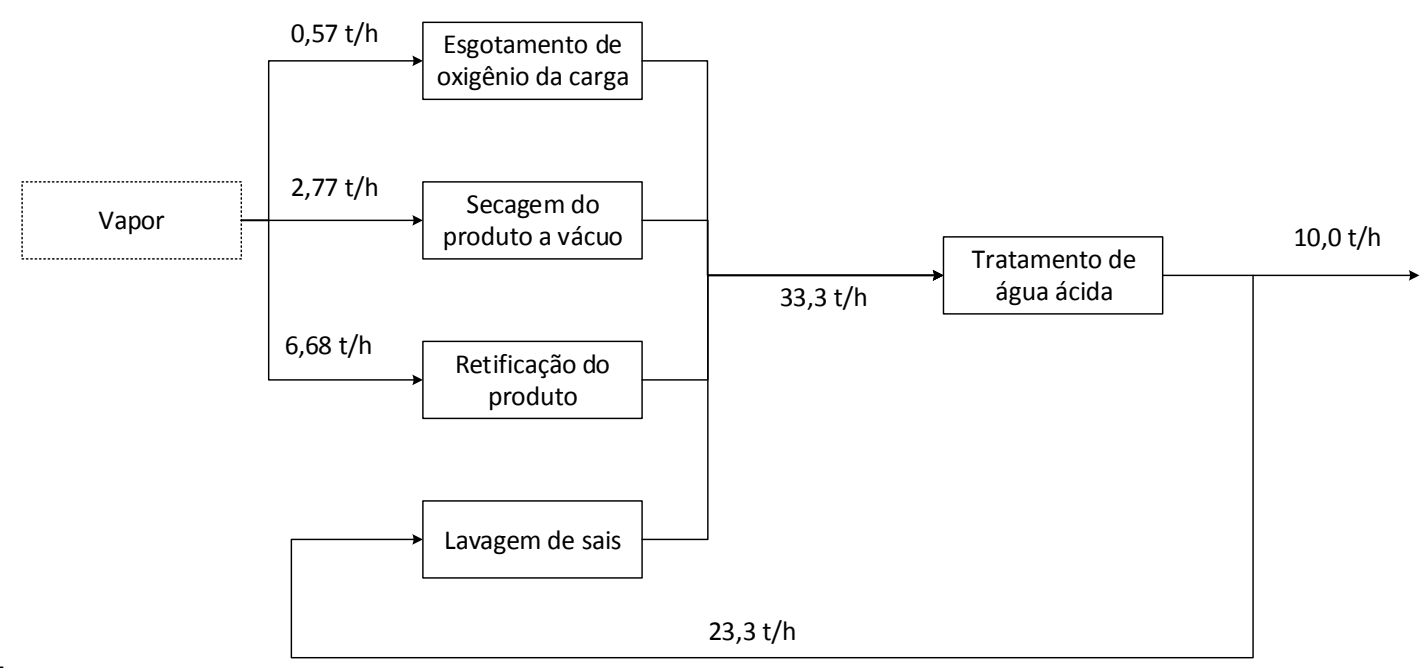

Figura 46 - Rede de água atual da unidade de hidrotratamento.

Tabela 47 - Dados do processo de hidrotratamento (referem-se ao $\mathrm{NH}_{3}$ ).

\begin{tabular}{lcccc}
\hline \multicolumn{1}{c}{ Processo } & $\begin{array}{c}\boldsymbol{C}_{\text {in }} \text { max } \\
(\boldsymbol{p p m})\end{array}$ & $\begin{array}{c}\boldsymbol{C}_{\text {out }}^{\text {max }} \\
(\boldsymbol{p p m})\end{array}$ & $\begin{array}{c}\text { Carga } \\
(\boldsymbol{g} / \mathbf{h})\end{array}$ & $\begin{array}{c}\text { Água fresca } \\
(\mathbf{t} / \mathbf{h})\end{array}$ \\
\hline Esgotamento de oxigênio da carga & 0 & 10 & 5,67 & 0,57 \\
Retificação do produto & 0 & 1000 & 6676,55 & 6,68 \\
Secagem do produto a vácuo & 0 & 10 & 27,74 & 2,77 \\
Lavagem de sais & 1000 & 14234 & 324535,74 & 23,27 \\
\hline
\end{tabular}

\subsubsection{Otimização matemática}

Primeiramente, a otimização foi realizada com a modelagem apresentada no Capítulo 3 e com o auxílio do software GAMS. A modelagem do problema e os resultados estão apresentados no Anexo 2. A Figura 47 apresenta a rede otimizada obtida. 


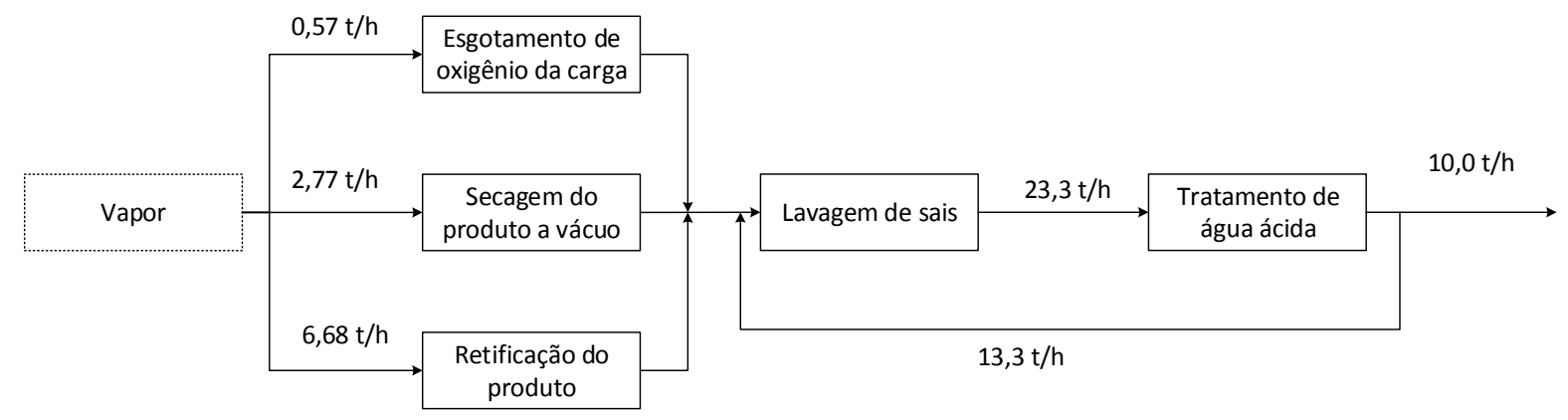

Figura 47 - Rede de água otimizada da unidade de hidrotratamento.

Em seguida, verificou-se se outros contaminantes são restrições para os processos que utilizam água de reuso. Neste caso, apenas o processo Lavagem de sais utiliza água de reuso. Uma das limitações da água para este processo é o teor de oxigênio, que não pode exceder $15 \mathrm{ppb}$. A água residual do processo Esgotamento de oxigênio da carga, em virtude da natureza do processo, possui 10ppm de oxigênio, logo não será reutilizada para a lavagem de sais. A Figura 48 apresenta a rede otimizada final.

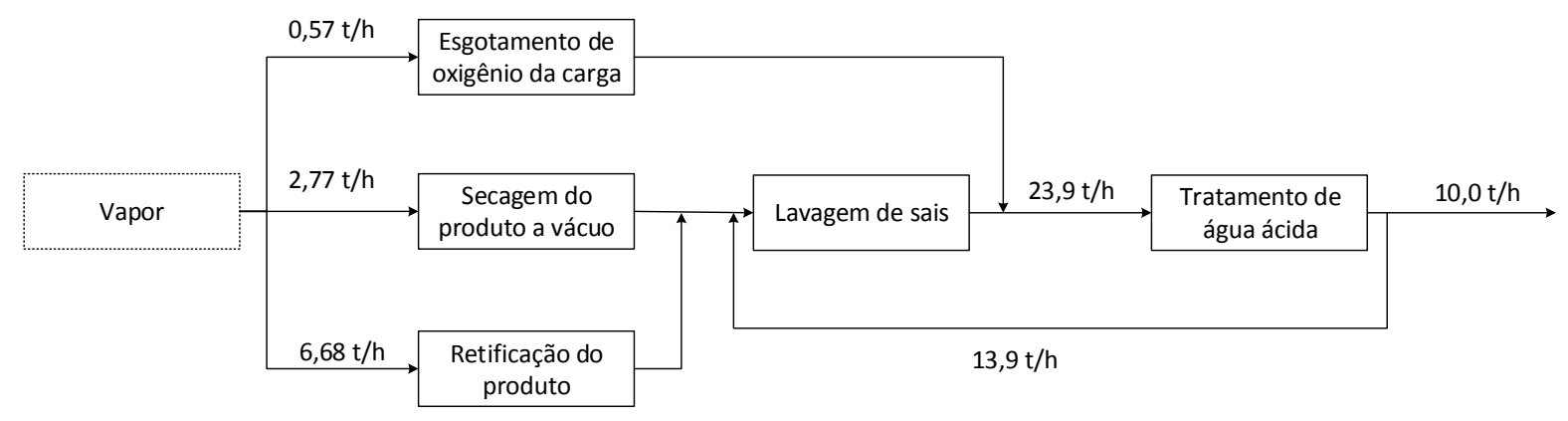

Figura 48 - Rede de água otimizada final da unidade de hidrotratamento.

Apesar da quantidade de água fresca (neste caso água ácida retificada da unidade de tratamento) não ser reduzida, com este arranjo a quantidade de água ácida enviada para tratamento é em torno de 10t/h menor, consequentemente, o gasto de energia (vapor de água) para a retificação é menor. 


\subsubsection{Otimização considerando regras heurísticas}

Em seguida aplicou-se o procedimento proposto no Capítulo 4:

Passo 1: Ordenar os processos em ordem decrescente de consumo de água fresca sem reuso $\left(\mathrm{F}_{\mathrm{W}}\right)$. O resultado está apresentado na Tabela 48.

Tabela 48 - Processos ordenados em ordem decrescente de consumo de água.

\begin{tabular}{ccccc}
\hline Processo & $\begin{array}{c}\boldsymbol{C}_{\text {in }}{ }^{\max } \\
(\mathbf{p p m})\end{array}$ & $\begin{array}{c}\boldsymbol{C}_{\text {out }}^{\text {max }} \\
(\mathbf{p p m})\end{array}$ & $\begin{array}{c}\text { Carga } \\
(\mathbf{g} / \boldsymbol{h})\end{array}$ & Água fresca $(\boldsymbol{t} / \mathbf{h})$ \\
\hline Lavagem de sais & 1000 & 14234 & 324535,74 & 23,27 \\
Retificação do produto & 0 & 1000 & 6676,55 & 6,68 \\
Secagem do produto a vácuo & 0 & 10 & 27,74 & 2,77 \\
Esgotamento de oxigênio da carga & 0 & 10 & 5,67 & 0,57 \\
\hline
\end{tabular}

Passo 2: Para todos os pares de processos i,j possíveis, verificar a condição $\mathrm{C}_{\text {out }, i}{ }^{\max }<\mathrm{C}_{\text {out }_{j} j}{ }^{\max }$. Os resultados são mostrados na Tabela 49.

Tabela 49 - Determinação dos possíveis pares i,j.

\begin{tabular}{c|ccccc}
\hline \multicolumn{1}{c}{ Processo } & $\boldsymbol{j}$ & $\begin{array}{c}\text { Lavagem } \\
\text { de sais }\end{array}$ & $\begin{array}{c}\text { Retificação } \\
\text { do produto }\end{array}$ & $\begin{array}{c}\text { Secagem do } \\
\text { produto a } \\
\text { vácuo }\end{array}$ & $\begin{array}{c}\text { Esgotamento de } \\
\text { oxigênio da } \\
\text { carga }\end{array}$ \\
\hline $\boldsymbol{i}$ & $\begin{array}{c}\boldsymbol{C}_{\text {out }}^{\text {max }} \\
(\boldsymbol{p p m})\end{array}$ & $\mathbf{1 4 2 3 4}$ & 1000 & 10 & 10 \\
$\begin{array}{c}\text { Lavagem de sais } \\
14234\end{array}$ & 0 & 0 & 0 & 0 \\
$\begin{array}{c}\text { Retificação do produto } \\
\text { Secagem do produto a } \\
\text { vácuo }\end{array}$ & 1000 & 1 & 0 & 0 & 0 \\
$\begin{array}{c}\text { Esgotamento de oxigênio } \\
\text { da carga }\end{array}$ & 10 & 1 & 1 & 0 & 1 \\
\hline
\end{tabular}


Passo 3: Construir a nova rede de água.

A análise do processo maior consumidor de água, lavagem de sais, é apresentada na Tabela 50. O processo recebe água de reuso dos processos retificação do produto e secagem do produto a vácuo.

Tabela 50 - Análise do processo lavagem de sais.

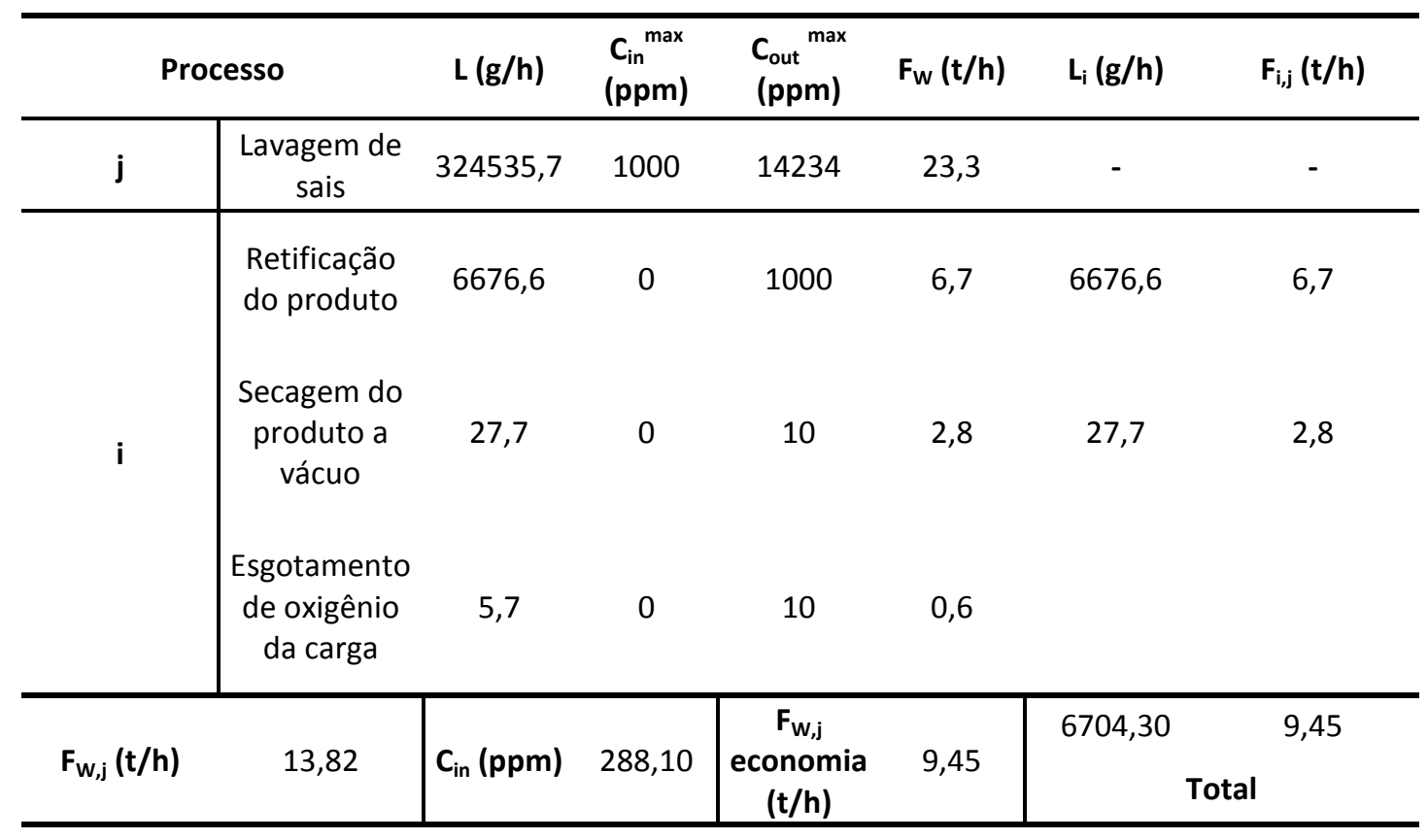

A rede obtida é igual àquela apresentada na Figura 48, ou seja, o resultado obtido através da otimização considerando regras heurísticas por limitar o número de processos i que podem enviar água de reuso para o processo j, exclui a corrente de menor valor. Neste caso específico, esta corrente possui um contaminante limitante para o processo que recebe água de reuso. 


\subsection{OTIMIZAÇÃO GLOBAL}

A rede de água é formada pelas unidades de destilação atmosférica e a vácuo (separação), unidades de craqueamento catalítico e coqueamento (conversão), unidade de hidrotratamento e pelas unidades de dessalgação.

Como mostrado na Tabela 46 os contaminantes presentes no sistema são: amônia, sulfetos, fenóis, cianetos, óleos e graxas e cloretos. Podemos separar tais contaminantes em três conjuntos.

(1) Nas águas ácidas de craqueamento catalítico estão presentes também o cianeto e os fenóis, este também presente em quantidade menor nas águas ácidas da unidade de separação. Estes contaminantes são de difícil remoção, limitando a reutilização destas águas.

(2) Os cloretos e óleos \& graxas estão presentes nas salmouras geradas na dessalgação. A salmoura, por ser concentrada em cloretos e compostos orgânicos, não pode ser reutilizada em outros processos, sendo enviada para tratamento de despejos industriais.

(3) Finalmente, a amônia e os sulfetos são gerados em todas as unidades de processo (separação, conversão e hidrotratamento), sendo removidos nas unidades de tratamento de água ácida.

A amônia e os sulfetos estão presentes em toda a rede de água estudada e portanto foram escolhidos para a realização da otimização da rede, visto que os dois têm efeito semelhante, para simplificar o modelo, adotou-se a amônia por ser mais restritiva. Os demais contaminantes, por estarem presentes em apenas alguns processos, foram avaliados depois, durante a verificação da rede obtida. Os processos que usam vapor devem ser alimentados necessariamente com água fresca. Para estes, a concentração máxima de contaminantes na entrada foi definida igual à zero, desse modo não podem receber água de reuso de outros processos.

Os processos de dessalgação e de água utilizada para descoqueamento não incorporam amônia, porém incorporam óleos e graxas. Utilizou-se então a regra 
definida por Zheng et al. (2006), de que a concentração máxima deve ser definida como um valor muito alto de modo que os outros processos não utilizem a água residual. Com isso calculou-se a carga teórica de contaminantes para estes processos de modo a atender a vazão de água necessária.

A Tabela 51 apresenta os dados para a otimização. A unidade de conversão foi dividida em duas, sendo uma delas (Conversão A) referente aos processos que podem receber apenas vapor e a outra (Conversão B) referente ao processo de descoqueamento.

Tabela 51 - Dados da rede global (referem-se ao $\mathrm{NH}_{3}$ ).

\begin{tabular}{ccccc}
\hline Processo & $\begin{array}{c}\boldsymbol{C}_{\text {in }}{ }^{\max } \\
(\mathbf{p p m})\end{array}$ & $\begin{array}{c}\boldsymbol{C}_{\text {out }}^{\text {max }} \\
(\boldsymbol{p p m})\end{array}$ & $\begin{array}{c}\text { Carga } \\
(\boldsymbol{g} / \boldsymbol{h})\end{array}$ & $\begin{array}{c}\text { Água } \\
\text { fresca (t/h) }\end{array}$ \\
\hline Separação & 0 & 5,36 & 291,60 & 54,40 \\
Dessalgação 1 & 20 & 80 & 2568,35 & 42,81 \\
Dessalgação 2 & 20 & 80 & 1107,10 & 18,45 \\
Dessalgação 3 & 20 & 80 & 2015,23 & 33,59 \\
Hidrotratamento & 0 & 18,4 & 184,37 & 10,02 \\
Conversão A & 0 & 18,3 & 1409,47 & 77,02 \\
Conversão B & 30 & 80 & 2000,00 & 40,00 \\
\hline
\end{tabular}

Passo 1: Ordenar os processos em ordem decrescente de consumo de água fresca sem reuso $\left(F_{W}\right)$. O resultado está apresentado na Tabela 52.

Tabela 52 - Processos ordenados em ordem decrescente de consumo de água.

\begin{tabular}{ccccc}
\hline Processo & Carga (g/h) & $\begin{array}{c}\boldsymbol{C}_{\text {in }}^{\text {max }} \\
(\boldsymbol{p p m})\end{array}$ & $\begin{array}{c}\boldsymbol{C}_{\text {out }}^{\text {max }} \\
(\boldsymbol{p p m})\end{array}$ & $\begin{array}{c}\text { Água } \\
\text { fresca (t/h) }\end{array}$ \\
\hline Conversão A & 1409,466 & 0 & 18,30 & 77,02 \\
Separação & 291,5974 & 0 & 5,36 & 54,40 \\
Dessalgação 1 & 2568,35 & 20 & 80,00 & 42,81 \\
Conversão B & 2000 & 30 & 80,00 & 40,00 \\
Dessalgação 3 & 2015,225 & 20 & 80,00 & 33,59 \\
Dessalgação 2 & 1107,1 & 20 & 80,00 & 18,45 \\
Hidrotratamento & 184,368 & 0 & 18,40 & 10,02 \\
\hline
\end{tabular}


Passo 2: Para todos os pares de processos i,j possíveis, verificar a condição $\mathrm{C}_{\text {out }, i}{ }^{\text {max }}<\mathrm{C}_{\text {out }, j}{ }^{\max }$. Se $\mathrm{C}_{\mathrm{i}, \text { out }}{ }^{\max }<\mathrm{C}_{\mathrm{j}, \text { out }}{ }^{\max }$ (status $=1$ ) o processo $i$ pode enviar sua água residual para o processo j, caso contrário, $\mathrm{C}_{\mathrm{i}, \text { out }}{ }^{\max }>\mathrm{C}_{\mathrm{j}, \text { out }}{ }^{\max }$ (status $=0$ ), o reuso de $i$ para j não é possível. Os resultados são mostrados na Tabela 53.

Tabela 53 - Determinação dos possíveis pares i,j.

\begin{tabular}{|c|c|c|c|c|c|c|c|c|}
\hline Processo & $j$ & Conversão A & Separação & Dessalgação 1 & Conversão B & Dessalgação 3 & Dessalgação 2 & $\begin{array}{l}\text { Hidrotra } \\
\text { tamento }\end{array}$ \\
\hline $\mathbf{i}$ & $\begin{array}{l}C_{\text {out }}^{\max } \\
\text { (ppm) }\end{array}$ & 18,3 & 5,36 & 80 & 80 & 80 & 80 & 18,4 \\
\hline Conversão A & 18,3 & 0 & 0 & 1 & 1 & 1 & 1 & 1 \\
\hline Separação & 5,36 & 1 & 0 & 1 & 1 & 1 & 1 & 1 \\
\hline Dessalgação 1 & 80 & 0 & 0 & 0 & 0 & 0 & 0 & 0 \\
\hline Conversão B & 80 & 0 & 0 & 0 & 0 & 0 & 0 & 0 \\
\hline Dessalgação 3 & 80 & 0 & 0 & 0 & 0 & 0 & 0 & 0 \\
\hline Dessalgação 2 & 80 & 0 & 0 & 0 & 0 & 0 & 0 & 0 \\
\hline Hidrotratamento & 18,4 & 0 & 0 & 1 & 1 & 1 & 1 & 0 \\
\hline
\end{tabular}

Passo 3: Construir a nova rede de água.

Conforme a Tabela 52, o primeiro processo a ser analisado é a Dessalgação 1. De acordo com a Tabela 53 as unidades que podem enviar água para a Dessalgação 1 são Conversão A, Separação e Hidrotratamento. A análise é iniciada com o maior consumidor de água fresca com status $=1$, ou seja, Conversão A. A Tabela 54 apresenta os resultados dos cálculos realizados. A concentração de entrada é menor que a concentração máxima permitida, ou seja, $\mathrm{C}_{\text {in }}<\mathrm{C}_{\text {in }}{ }^{\text {max }}(18,7$ ppm $<20$ ppm), logo o processo 2 é selecionado. 
Tabela 54 - Análise do processo Dessalgação 1.

\begin{tabular}{|c|c|c|c|c|c|c|c|}
\hline \multicolumn{2}{|r|}{ Processo } & \multirow{2}{*}{$\begin{array}{c}\mathrm{L}(\mathrm{g} / \mathrm{h}) \\
2568,35\end{array}$} & \multirow{2}{*}{ 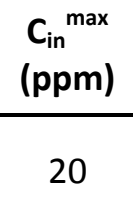 } & \multirow{2}{*}{ 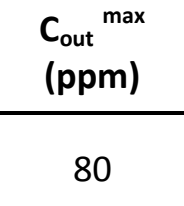 } & \multirow{2}{*}{$\begin{array}{c}\mathbf{F}_{\mathrm{w}}(\mathrm{t} / \mathrm{h}) \\
42,81\end{array}$} & \multirow{2}{*}{$\begin{array}{c}\begin{array}{c}\mathrm{L}_{\mathrm{i}} \\
(\mathrm{g} / \mathrm{h})\end{array} \\
-\end{array}$} & \multirow{2}{*}{$\begin{array}{c}\mathrm{F}_{\mathrm{i}, \mathrm{j}}(\mathrm{t} / \mathrm{h}) \\
-\end{array}$} \\
\hline $\mathbf{j}$ & Dessalgação 1 & & & & & & \\
\hline \multirow{3}{*}{$\mathbf{i}$} & Conversão A & 1409,5 & 0 & 18,3 & 77,02 & 783,35 & 42,81 \\
\hline & Separação & 291,6 & 0 & 5,36 & 54,4 & & \\
\hline & Hidrotratamento & 184,4 & 0 & 18,4 & 10,02 & & \\
\hline $\begin{array}{l}F_{W, j} \\
(t / h)\end{array}$ & 0 & $C_{\text {in }}(p p m)$ & 18,30 & $\begin{array}{c}F_{W, j} \\
\text { economia } \\
(t / h)\end{array}$ & 43,72 & \multicolumn{2}{|c|}{ Total } \\
\hline
\end{tabular}

Em seguida é analisado o processo Conversão B, de acordo com a Tabela 55, tal processo recebe água de reuso da Separação.

Tabela 55 - Análise do processo Conversão B.

\begin{tabular}{|c|c|c|c|c|c|c|c|}
\hline \multicolumn{2}{|r|}{ Processo } & \multirow{2}{*}{$\begin{array}{c}\mathrm{L}(\mathrm{g} / \mathrm{h}) \\
2000\end{array}$} & \multirow{2}{*}{$\frac{\begin{array}{c}\mathrm{C}_{\text {in }}^{\text {max }} \\
\text { (ppm) }\end{array}}{30}$} & \multirow{2}{*}{$\begin{array}{c}\begin{array}{l}\mathrm{C}_{\text {out }}^{\max } \\
\text { (ppm) }\end{array} \\
55,3\end{array}$} & \multirow{2}{*}{$\frac{F_{w}(t / h)}{40}$} & \multirow{2}{*}{$\begin{array}{c}\begin{array}{c}\mathrm{L}_{\mathrm{i}} \\
(\mathrm{g} / \mathrm{h})\end{array} \\
-\end{array}$} & \multirow{2}{*}{$\begin{array}{c}F_{i, j}(t / h) \\
-\end{array}$} \\
\hline $\mathbf{j}$ & Conversão B & & & & & & \\
\hline \multirow{3}{*}{$\mathbf{i}$} & Conversão A & 1409,466 & 0 & 18,3 & 77,02 & \multirow{3}{*}{214,40} & \multirow{3}{*}{40,00} \\
\hline & Separação & 291,5974 & 0 & 5,36 & 54,4025 & & \\
\hline & Hidrotratamento & 184,368 & 0 & 18,4 & 10,02 & & \\
\hline $\begin{array}{l}F_{W, j} \\
(t / h)\end{array}$ & 0 & $C_{\text {in }}(p p m)$ & 5,35 & $\begin{array}{c}F_{W, j} \\
\text { economia } \\
(t / h)\end{array}$ & 39,96 & \multicolumn{2}{|c|}{ Total } \\
\hline
\end{tabular}

O processo Dessalgação 3 é então analisado. A unidade Conversão A ainda tem água disponível para reuso e, conforme a Tabela 56 , pode suprir totalmente a demanda de água da Dessalgação 3. 
Tabela 56 - Análise do processo Dessalgação 3.

\begin{tabular}{|c|c|c|c|c|c|c|c|}
\hline \multicolumn{2}{|r|}{ Processo } & \multirow{2}{*}{$\begin{array}{c}\mathrm{L}(\mathrm{g} / \mathrm{h}) \\
2015,225\end{array}$} & \multirow{2}{*}{ 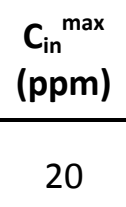 } & \multirow{2}{*}{ 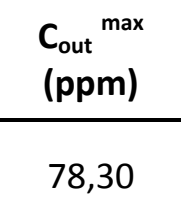 } & \multirow{2}{*}{$\begin{array}{c}\mathbf{F}_{\mathrm{w}}(\mathbf{t} / \mathrm{h}) \\
33,6\end{array}$} & \multirow{2}{*}{$\frac{L_{i}(g / h)}{-}$} & \multirow{2}{*}{$\begin{array}{c}\mathrm{F}_{\mathrm{i}, \mathrm{j}}(\mathrm{t} / \mathrm{h}) \\
-\end{array}$} \\
\hline $\mathbf{j}$ & Dessalgação 3 & & & & & & \\
\hline \multirow{3}{*}{$\mathbf{i}$} & Conversão A & 1409,466 & 0 & 18,3 & 77,0 & 614,64 & 33,59 \\
\hline & Separação & 291,5974 & 0 & 5,36 & 54,4 & & \\
\hline & Hidrotratamento & 184,368 & 0 & 18,4 & 10,0 & & \\
\hline $\begin{array}{l}F_{W, j} \\
(t / h)\end{array}$ & 0,00 & $C_{\text {in }}(p p m)$ & 18,30 & $\begin{array}{c}F_{W, j} \\
\text { economia } \\
(t / h)\end{array}$ & 33,59 & \multicolumn{2}{|c|}{ Total } \\
\hline
\end{tabular}

Finalmente é analisado o processo Dessalgação 2. Inicialmente, conforme a Tabela 57 , o processo de hidrotratamento envia água de reuso. Para completar a demanda de água, visto que a concentração de entrada é menor que a máxima permitida, o processo de Separação é selecionado para enviar água de reuso, conforme a Tabela 58.

Tabela 57 - Análise inicial do processo Dessalgação 2.

\begin{tabular}{|c|c|c|c|c|c|c|c|}
\hline \multicolumn{2}{|r|}{ Processo } & \multirow{2}{*}{$\frac{L(g / h)}{1107,1}$} & \multirow{2}{*}{$\frac{C_{\text {in }}^{\max }}{\text { (ppm) }}$} & \multirow{2}{*}{$\begin{array}{c}\begin{array}{l}\mathrm{C}_{\text {out }}^{\text {max }} \\
\text { (ppm) }\end{array} \\
72,4\end{array}$} & \multirow{2}{*}{$\begin{array}{c}\mathbf{F}_{\mathrm{W}}(\mathbf{t} / \mathrm{h}) \\
18,5\end{array}$} & \multirow{2}{*}{$\frac{\mathrm{L}_{\mathrm{i}}(\mathrm{g} / \mathrm{h})}{-}$} & \multirow{2}{*}{$\frac{F_{i, j}(t / h)}{-}$} \\
\hline j & Dessalgação 2 & & & & & & \\
\hline \multirow{3}{*}{$\mathbf{i}$} & Conversão A & 1409,466 & 0 & 18,3 & 77,02 & & \\
\hline & Separação & 291,5974 & 0 & 5,36 & 54,4025 & & \\
\hline & Hidrotratamento & 184,368 & 0 & 18,4 & 10,02 & 184,00 & 10 \\
\hline $\begin{array}{c}F_{W, j} \\
(t / h)\end{array}$ & 7,82 & $C_{\text {in }}(p p m)$ & 10,32 & $\begin{array}{c}F_{W, j} \\
\text { economia } \\
(t / h)\end{array}$ & 10,63 & \multicolumn{2}{|c|}{ Total } \\
\hline
\end{tabular}


Tabela 58 - Análise final do processo Dessalgação 2.

\begin{tabular}{|c|c|c|c|c|c|c|c|}
\hline \multicolumn{2}{|r|}{ Processo } & \multirow{2}{*}{$\begin{array}{l}\mathrm{L}(\mathrm{g} / \mathrm{h}) \\
1107,1\end{array}$} & \multirow{2}{*}{ 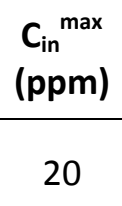 } & \multirow{2}{*}{ 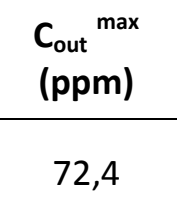 } & \multirow{2}{*}{$\begin{array}{c}\mathbf{F}_{\mathrm{w}}(\mathrm{t} / \mathrm{h}) \\
18,5\end{array}$} & \multirow{2}{*}{$\begin{array}{c}\mathrm{L}_{\mathrm{i}}(\mathrm{g} / \mathrm{h}) \\
-\end{array}$} & \multirow{2}{*}{$\begin{array}{c}\mathrm{F}_{\mathrm{i}, \mathrm{j}}(\mathrm{t} / \mathrm{h}) \\
-\end{array}$} \\
\hline $\mathbf{j}$ & Dessalgação 2 & & & & & & \\
\hline \multirow{3}{*}{$\mathbf{i}$} & Conversão A & 1409,466 & 0 & 18,3 & 77,02 & & \\
\hline & Separação & 291,5974 & 0 & 5,36 & 54,4025 & 45,19 & 8,43 \\
\hline & Hidrotratamento & 184,368 & 0 & 18,4 & 10,02 & 184,37 & 10,02 \\
\hline $\begin{array}{l}F_{W, j} \\
(t / h)\end{array}$ & 0,00 & $C_{\text {in }}(p p m)$ & 12,44 & $\begin{array}{c}F_{W, j} \\
\text { economia } \\
(t / h)\end{array}$ & 18,45 & \multicolumn{2}{|c|}{ Total } \\
\hline
\end{tabular}

O resultado da otimização está apresentado na Figura 49.

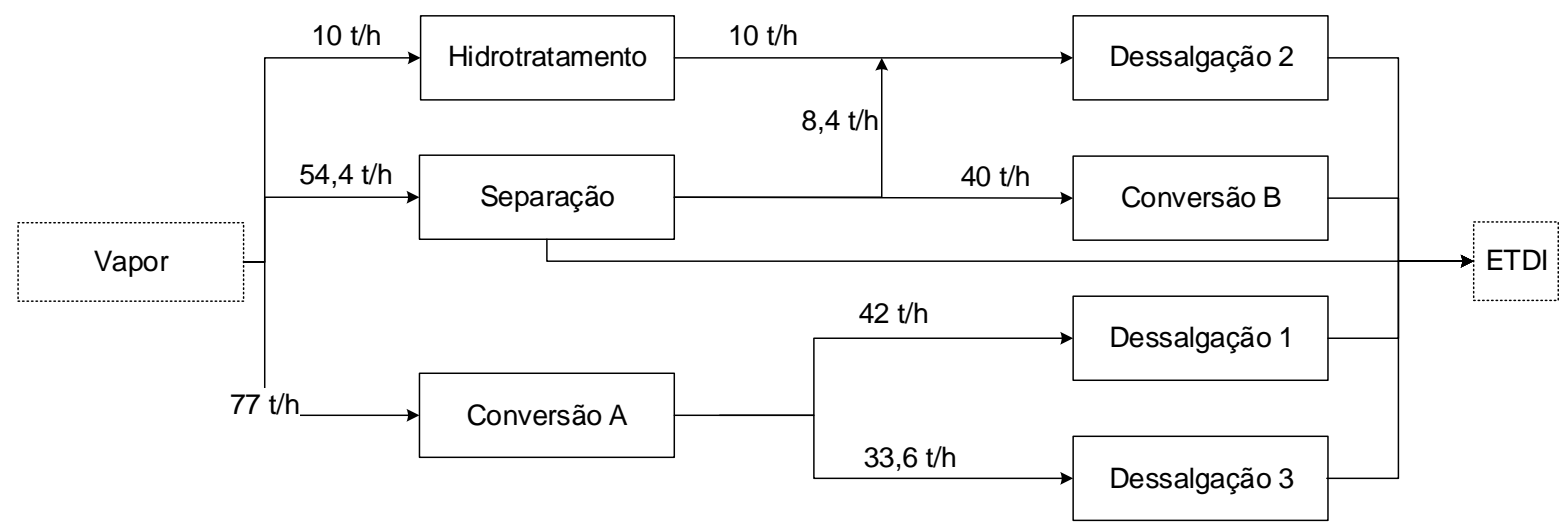

Figura 49 - Rede de água otimizada.

$\mathrm{Na}$ rede obtida as unidades de dessalgação e a água utilizada para descoqueamento são abastecidas com as águas ácidas retificadas provenientes das unidades de Separação, Conversão e Hidrotratamento.

As unidades de dessalgação possuem como especificação, além do teor de amônia, teor de cloreto de no máximo 50 ppm, pH na faixa de 6 a 8 e teores mínimos de 
sólidos e de sais dissolvidos. Considerando estes teores, as águas de reuso empregadas estão de acordo com tais especificações. Este é um reuso usual nas refinarias de petróleo. Especialmente a água ácida retificada proveniente da Conversão, que possui elevado teor de fenóis, deve necessariamente ser utilizada na etapa de dessalgação para que os fenóis sejam absorvidos pelo petróleo ao invés de serem enviados para a ETDI.

A água utilizada para a lavagem do coque não possui nenhuma restrição importante. Contudo, devido ao fato de as piscinas serem abertas, para evitar a possibilidade de odores na área, deve-se ter atenção aos componentes voláteis. Os contaminantes restritivos são a amônia, os sulfetos e os fenóis, visto que, segundo Nogueira (2007), há histórico de desprendimento de odor de amônia e fenol quando reutilizada água em piscinas de coque. Nogueira (2007) alerta também para a presença de cloretos, contudo observa que usualmente o teor de cloreto nas águas ácidas é inferior a água filtrada. A Tabela 59 apresenta a limitação de concentração de contaminantes para a lavagem de coque.

Tabela 59 - Faixa de contaminantes restritivos para a lavagem de coque (Nogueira, 2007)

\begin{tabular}{cc}
\hline Contaminante & Concentração (ppm) \\
\hline $\mathrm{H}_{2} \mathrm{~S}$ & $<70$ \\
$\mathrm{NH}_{3}$ & $<30$ \\
Fenóis & $<40$ \\
Cianetos & $<1$ \\
\hline
\end{tabular}

$\mathrm{Na}$ otimização a água de lavagem é proveniente da unidade de separação. Esta água possui fenóis, amônia e sulfeto porém em concentrações menores que as limitantes para a lavagem do coque. Nogueira (2007) destaca que, se for decidido pelo reuso, deve-se instalar analisadores para acompanhamento da concentração destes contaminantes, de modo quando se a concentração ultrapassar um determinado limite a reposição de água deve ser bloqueada para que não ocorra problemas de odor. 
Segundo a heurística IX: "o layout deve ser considerado de modo a reduzir comprimento de tubulações, reduzir perda de carga e evitar a interferência de uma área operacional em outra". Na refinaria estudada, a unidade de hidrotratamento e uma das unidades de coqueamento ficam distante cerca de $1,5 \mathrm{~km}$ da planta principal. Logo, o reuso da água ácida tratada da unidade de Hidrotratamento para a unidade de Dessalgação 2 e parte do reuso da água ácida tratada da unidade de Separação para a unidade de Conversão $B$ não são atrativos do ponto de vista industrial. A otimização foi refeita de modo a privilegiar o envio de água do Hidrotratamento para a unidade de Conversão B:

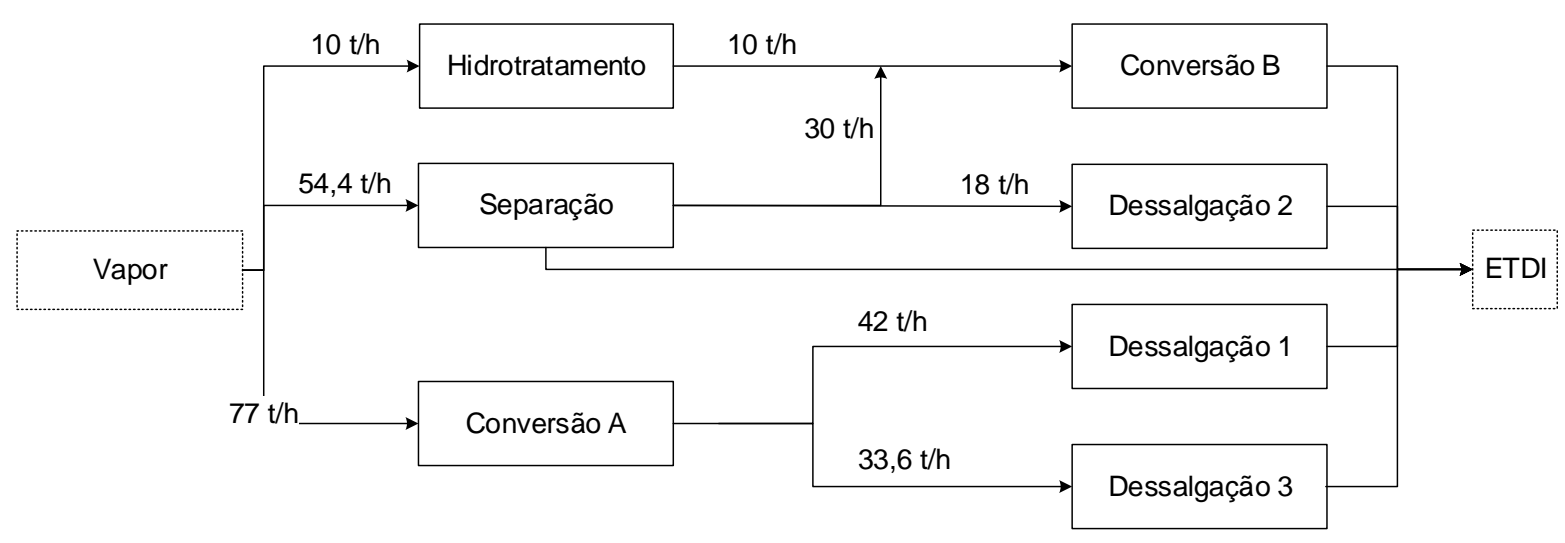

Figura 50 - Rede de água otimizada final.

Com esta configuração as unidades de Hidrotratamento e de Separação podem abastecer as unidades de Conversão B. Sendo que, no caso de não ser possível enviar parte da água da unidade de separação para a outra parte da planta (em torno de $10 \mathrm{t} / \mathrm{h}$ ) esta deve ser suprida com água fresca (filtrada e/ou pluvial). 


\section{CONCLUSÕES E RECOMENDAÇÕES}

Neste trabalho foi consolidada a aplicação da metodologia para otimização de uso de água desenvolvida no LSCP da Escola Politécnica da USP para uma refinaria de petróleo, envolvendo as etapas de levantamento de dados e seu tratamento, caracterização dos processos de refino que usam água com as equações de balanço material e as restrições, otimização individual dos processos, elaboração da rede de consumo e a sua otimização matemática.

A partir do levantamento de dados industriais obtém-se o perfil de funcionamento do processo, porém dos dados devem ser tratados antes de serem utilizados nos estudos de otimização. Isso porque os dados brutos podem apresentar valores inconsistentes, campanhas diferentes, balanços materiais que necessitam serem fechados e outras situações que exigem o tratamento.

A etapa de racionalização individual dos processos mostrou que alterações pontuais podem ter grande impacto na redução global de água. As práticas de racionalização apresentadas representam uma economia de $38 \%$ no total de água captada da refinaria. O maior consumidor de água neste tipo de indústria é o sistema de resfriamento, logo, oportunidades de racionalização nesta área, como o uso de trocadores híbridos e aumento no ciclo de concentração possibilitam fortes ganhos.

Apesar de terem sido identificadas algumas situações de reuso e reciclagem de água já praticadas e usuais em refinarias de petróleo, observou-se também práticas inadequadas que muitas vezes servem de paliativo para problemas que deveriam ser devidamente ser solucionados. Exemplos são o uso de água para resfriamento externo de permutadores e a injeção de vapor vivo para a retificação em colunas que apresentam refervedor. Os equipamentos devem passar por manutenções preventivas e, se for necessário, passar até mesmo por alterações de projeto para que funcionem corretamente e não exijam o uso de água extra. 
Ao estudar o que foi desenvolvido até então na literatura, percebeu-se que a otimização da rede de água em uma planta industrial tornou-se uma questão de matemática em detrimento da viabilidade da aplicação da rede otimizada na planta industrial. A metodologia de otimização desenvolvida neste trabalho considera regras heurísticas, que representam restrições reais de processos e com isso simplificam a configuração da solução. A implementação da solução é menos complexa, apresenta menor número de correntes e consequentemente de bombas e instrumentos, consequentemente apresenta custo menor e por isso é mais atraente do ponto de vista industrial.

A metodologia foi aplicada em dois exemplos e a solução obtida é próxima da solução ótima matemática, se mostrando adequada para trabalhos de otimização de uso de água em casos como o estudado neste trabalho.

No estudo da unidade de hidrotratamento a otimização foi feita tanto através de programação matemática quanto a partir do procedimento considerando regras heurísticas. Os resultados mostram que através do procedimento heurístico a rede obtida é menos complexa, excluindo correntes pequenas.

Em geral, observam-se algumas dificuldades na etapa de otimização, como a baixa flexibilidade operacional das unidades e a necessidade de amplo conhecimento quantitativo dos contaminantes presentes nas águas efluentes de cada processo.

Em geral, este trabalho apresenta a aplicação de metodologias existentes, a geral do LSCP e ferramentas matemáticas de otimização para um caso real de uma refinaria de petróleo complexa, na qual vários processos de refino são empregados. De modo geral, as principais recomendações para a redução do consumo de água são:

- Inicialmente é necessário conhecer amplamente, tanto qualitativa quanto quantitativamente, os contaminantes presentes nas águas efluentes de cada processo. Isso facilitará a aplicação de qualquer programa de redução de água. 
- Priorizar os trabalhos de redução de consumo de água nos maiores consumidores de água pois estes trarão a maior redução de consumo.

- Priorizar a eliminação de pequenos desperdícios que geralmente são fáceis de serem corrigidos.

- $\quad$ Manter em funcionamento adequado os equipamentos do processo, de modo não necessitarem maior quantidade de água.

As refinarias de petróleo, após aplicarem um programa de otimização do uso de água, devem procurar alternativas não usuais para obter maior redução no consumo de água. Nestes casos os processos que usam água devem ser submetidos a análises onde sejam radicalmente questionados, buscando soluções inovadoras que representem novo patamar de uso de água.

Como recomendações para trabalhos futuros, sugerem-se estudos que envolvam:

- Tratamentos para a remoção dos cloretos e outros sais inorgânicos solúveis presentes na água efluente das ETDIs tradicionais, possibilitando a sua reciclagem.

- Tratamentos para a remoção de compostos orgânicos solúveis na água efluente das ETDIs tradicionais, por exemplo fenóis, possibilitando a sua reciclagem.

- Tratamentos inovadores para água de caldeiras onde o rejeito seja minimizado ou seja reaproveitado.

- Desenvolvimento de sistema que envolva novos tratamentos e novos processos que usam água com objetivo de ter efluente líquido zero para refinaria de petróleo. 


\section{REFERÊNCIAS}

AL-REDHWAN, S. A.; CRITTENDEN, B. D.; LABABIDI, H. M. S. Wastewater minimization under uncertain operational conditions. Comput. Chem. Eng. 29, 1009-1021, 2005.

ALVA-ARGÁEZ, A., KOKOSSIS, A. C.; SMITH, R. Wastewater minimisation of industrial systems using an integrated approach. Computers \& Chemical Engineering, 22, Supplement 1, S741-44, 1998.

ALVA-ARGÁEZ, A., VALLIANATOS, A.; KOKOSSIS, C. A multicontaminant transshipment model for mass exchange networks and wastewater minimisation problems. Computers \& Chemical Engineering, 23, 1439-53, 1999.

ALVA-ARGÁEZ, A.; KOKOSSIS, A. C.; SMITH, R. The design of water-using systems in petroleum refining using a water-pinch decomposition. Chemical Engineering Journal, 128 (1), 33-46, 2007.

ALVES, R. M. B.; NASCIMENTO, C. A. O. Analysis and Detection of Outliers and Systematic Errors in Industrial Plant Data. Chem. Eng. Comm. 194, 382-397, 2007.

ALVES, R. M. B. ; BRESCIANI, A. E. ; Nascimento, C.A.O. . Strippers for wastewater minimization in a olefin process unit. CHISA 2008 - 16th International Congress of Chemical and Process Engineering, Praga, 2008.

AMORIM, R. S. Abastecimento de água de uma refinaria de petróleo: Caso REPLAN. Dissertação de Mestrado, Universidade Federal Fluminense, Niterói, 2005.

ANA - AGÊNCIA NACIONAL DAS ÁGUAS. Lei 9433. Disponível em:< http://www.ana.gov.br/Institucional/Legislacao/leis> Acesso em: 31 ago., 2012. 
BAGAJEWICZ, M. A review of recent design procedures for water networks in refineries and process plants. Computer and Chemical Engineering, 24, 2093 2113, 2000.

BAGAJEWICZ, M. Smart Process Plants: Software and Hardware Solutions for Accurate Data and Profitable Operations: Data Reconciliation, Gross Error Detection, and Instrumentation Upgrade. The McGraw-Hill Companies, Inc., 2009.

BAGAJEWICZ, M. J.; FARIA, D. C. On the appropriate architecture of the water/wastewater allocation problem in process plants. Comput.-Aided Chem. Eng. 26, 1-20, 2009.

BAGAJEWICZ, M.J. \& SAVELSKI, M.J. On the use of linear models for the design of water utilization systems in process plants with a single contaminant. Chemical Engineering Research and Design 79, 600-610, 2001.

BARBOSA, F. L. Regulamentação do reuso da água em refinarias - Análise do modelo americano e perspectivas para o cenário nacional. Dissertação de Mestrado, COPPE/Universidade Federal do Rio de Janeiro, Rio de Janeiro, 2007.

BRESCIANI, A. E. Análise do processo de dessalgação de petróleo. Otimização do uso de água. Tese de Doutorado, Engenharia Química, Escola Politécnica, Universidade de São Paulo, São Paulo, 2009.

BRESCIANI, A. E., ALVES, R. M. B., GUARDANI, R., NASCIMENTO C. A. O. Água nas indústrias: otimização do uso e reuso. Revista Brasileira de Engenharia Química 22 (3), 18 - 23, 2006a.

BRESCIANI, A. E.; ALVES, R. M. B.; NASCIMENTO C. A. O. Redução no consumo de água em plantas de processo pela substituição de resfriador a água por resfriador a ar. Revista Petro \& Química, 281, 82-86, 2006b.

CAO, K., FENG, X.; MA, H. Pinch multi-agent genetic algorithm for optimizing water-using networks. Computers \& Chemical Engineering 31, 1565 - 75, 2007. 
CARVALHO, J. H. S. Conservação de água, tratamento, reuso, reciclo de efluentes em refinaria de petróleo. Dissertação de Mestrado, Instituto de Química, Universidade Federal do Rio de Janeiro. Rio de Janeiro, 2006.

CASTRO, P.; MATOS, H.; FERNANDES, M.C.; PEDRO NUNES, C. Improvements for mass-exchange networks design. Chemical Engineering Science, 54, 16491665, 1999.

COLLARES, S. Avaliação do uso de recursos hídricos em refinarias de petróleo: Um estudo de caso na Petrobras. Dissertação de Mestrado, Sistema de Gestão, Universidade Federal Fluminense. Rio de Janeiro, 2004.

DHOLE, V. R.; RAMCHANDANI N.; TAINSH, R. A.; WASILEWSKI, M. Make your process water pay for itself. Chemical Engineering, January, 100-103. 1996.

DIEPOLDER, P. Is 'zero discharge' realistic? Hydrocarbon Processing, October, 1992.

DOYLE, S. J; SMITH, R. Targeting water reuse with multiple contaminants. Transactions of International Chemical Engineering, Part B, 75(3), 181-189, 1997.

EL-HAWAGI, M. M. \& MANOUSIOUTHAKIS, V. Synthesis of mass-exchange networks. AICHE Journal, 8, 1233-1244, 1989.

FENG, X.; CHU, K. H. Cost optimization of industrial wastewater reuse systems. Trans IChemE, Part B, May 2004.

FOO, D.C.Y. State-of-the-art review of pinch analysis techniques for water network synthesis. Ind. Eng. Chem. Res. 48, 5125-5159, 2009.

FURTADO, M. Resfriamento declara guerra ao desperdício de água. Revista Química e Derivados, 467, 2007. Disponível em < http://www.quimica.com.br/revista/qd467/trat agua/trat agua01.html >. Acesso em: 31 ago., 2012. 
GALAN, B.; GROSSMANN, I. E.; Optimal design of distributed wastewater treatment networks. Industrial \& Engineering Chemistry Research, 37, 4036, 1998.

GOMES, J.F.X.; QUEIROZ, E.M.; PESSOA, F.L.P. Design procedure for water/wastewater minimization: single contaminant. Journal of Cleaner Production 15, 474-485, 2007.

GÓMEZ, J.; SAVELSKI, M. J.; BAGAJEWICZ, M. J. On a systematic design procedure for single component water utilization systems in process plants. Chem. Eng. Comm. 186, 183-203, 2001.

GONÇALVES, D. A.; BRASILEIRO, L. A.; PINHEIRO DE LIMA, J. S. Economia no consumo de água no sistema de resfriamento de uma unidade sucroalcooleira com o aumento do ciclo de concentração. Revista Analytica, 2010. Disponível em:<http://www.revistaanalytica.com.br/artigos/2.pdf>. Acesso em: 31 ago., 2012.

GUNARATNAM, M.; ALVA-ARGÁEZ, A.; KOKOSSIS, A.; KIM, J.-K.; SMITH, R. Automated design of total water systems. Ind. Eng. Chem. Res. 44, 588-599, 2005.

HALLALE, N., A New Graphical Targeting Method for Water Minimization, Adv. Environ. Res., 6, 377, 2002.

HAMAGUCHI, M. Análise do circuito de água em processos de fabricação de papel imprensa integrada com produção de pastas termomecânicas. Dissertação de Mestrado, Engenharia Química, Universidade de São Paulo, São Paulo, 2007.

HESPANHOL, I.; MIERZWA, J. C. Água na indústria. Uso racional e reuso. Oficina de Textos, São Paulo, 2005.

HUANG, C.-H., CHANG, C.-T., LING, H.-C.; Chang, C.-C. A mathematical programming model for water usage and treatment network design. Industrial \& Engineering Chemistry Research, 38, 2666, 1999. 
JACOB, J.; KAIPE, H.; COUDREC, F.; PARIS, J. Water network analysis in pulp and paper processes by pinch and linear programming techniques. Chem. Eng. Commun. 189 (2), 184-206, 2002.

JEZOWSKI, J. Review of water network design methods with literature annotations. Ind. Eng. Chem. Res. 49, 4475-4516, 2010.

JEZOWSKI, J.; POPLEWSKI, G.; JEZOWSKA, A. Optimization of water usage in chemical industry. Environmental Protection Engineering 29(1), 97-117, 2003.

JODICKE, G.; FISCHER, U.; HUNGERBUHLER, K. Wastewater reuse: a new approach to screen for designs with minimal total costs. Computers and Chemical Engineering, 25, 203-215, 2001.

KARUPPIAH, R.; GROSSMANN, I. E. Global optimization for the synthesis of integrated water systems in chemical processes. Computers and Chemical Engineering, 30, 650-673, 2006.

KHOR, C. S.; CHACHUAT, B.; SHAH N. A superstructure optimization approach for water network synthesis with membrane separation-based regenerators. Comp. Chem. Eng. 42, 48- 63, 2012.

KONGSJAHJU, R.; ROLLINS, D. K.;BASCUÑANA, M. B. Accurate identification of biased measurements under serial correlation. Chemical Engineering Research and Design 78 (7), 1010-18, 2000.

KOPPOL, A. P. R.; BAGAJEWICZ, M.; DERICKS, B. J.; SAVELSKI, M. On zero water discharge solutions in the process industry. Advances in Environmental Research, 8(2), 151 171, 2003.

KUO, W.-C. J.; SMITH, R. Designing for the interactions between water-use and effluent treatment. Transactions of International Chemical Engineering Part A, 76, 287-301, 1998. 
Li, Y.; Yao, P. J. Optimal design of water utilization networks by combination of water pinch analysis and mathematical programming. Journal of Chemical Industry and Engineering 55, 220-225, 2004.

LIU, Y. A., LUCAS, B.; MANN, J. Up-to-date tools for water-system optimization. Chemical Engineering, Jan, 30 41, 2004.

LIU, Z.-Y.; YANG, Y.; WAN, L.-Z.; WANG, X.; HOU, K.-H. A heuristic design procedure for water-using networks with multiple contaminants. AIChe Journal 55 (2), 2009.

MANCUSO, P. C. S. Reuso de água para torres de resfriamento. São Paulo: Biblioteca Virtual da Faculdade de Saúde Publica/USP, 2001.

MANN, J. G.; LIU, Y. A. Industrial water reuse and wastewater minimization. New York: McGraw Hill, 1999.

MARIANO, J. B. Impactos ambientais do refino do petróleo. Dissertação de Mestrado, COPPE/Universidade Federal do Rio de Janeiro. Rio de Janeiro, 2001.

MATIJASEVIC, L.; DEJANOVIC, I.; SPOJA, D. A water network optimization using MATLAB - A case study. Resources, Conservation and Recycling 54, 13621367, 2010.

MOHAMMADNEJAD, S.; NABI BIDHENDI, G. R.; MEHRDADI, N. Water and wastewater minimization in petroleum refinery through water pinch analysissingle and double contaminants approach. Research Journal of Environmental Sciences 5 (1), 88-104, 2011.

NOGUEIRA, D. M. Balanço hídrico na Refinaria de Paulínia e alternativas para reuso de água: Construção de uma ferramenta auxiliar para o gerenciamento dos recursos hídricos. Dissertação de Mestrado, Engenharia Civil, Universidade Estadual de Campinas. Campinas, 2007. 
OLESEN, S. G. \& POLLEY, S. G. A simple methodology for the design of water networks handling single contaminants. Transactions of the Institution of Chemical Engineers, Part A, 75, 1977.

POPLEWSKI, G.; WAŁCZYK, K.; JEZOWSK, J. Optimization-based method for calculating water networks with user specified characteristics. Chemical Engineering Research and Design 88, 109-120, 2010.

PRAKOTPOL, D. \& SRINOPHAKUN, T. GAPinch: Genetic algorithm toolbox for water pinch technology. Chemical Engineering and Processing 43(2), 203-217, 2004.

REVISTA MEIO FILTRANTE. Água de resfriamento, por que mantê-la limpa? Revista Meio Filtrante, ano 2, edição $\mathrm{n}^{\circ}$ 6, 2003. Disponível em: $<$ http://www.meiofiltrante.com.br/materias_ver.asp?action=detalhe\&id=72> Acesso em: 31 ago., 2012.

REVISTA QUÍMICA E DERIVADOS. Tratamento de Efluentes. Terceirização concentra o setor. Revista Química e Derivados, 381, 2000. Disponível em < http://www.quimica.com.br/revista/qd381/efluentes.htm>. Acesso em: 31 ago., 2012.

SABESP - COMPANHIA DE SANEAMENTO BÁSICO DO ESTADO DE SÃO PAULO. Disponível em:< http://site.sabesp.com.br/site/Default.aspx> Acesso em: 31 ago., 2012.

SAVELSKI, M.; BAGAJEWICZ, M. Algorithmic procedure to design water utilization systems featuring a single contaminant in process plants. Chemical Engineering Science, 56, 1897-1911, 2001.

SAVELSKI, M.; BAGAJEWICZ, M. Design of water utilization systems in process plants with a single contaminant. Waste Management, 20 (8), 659-664, 2000a.

SAVELSKI, M.; BAGAJEWICZ, M. On the necessary conditions of optimality of water utilizations systems in process plants with multiple contaminants. Chemical Engineering Science, 58, 5349-5362, 2003. 
SAVELSKI, M.; BAGALEWICZ, M. On the optimality conditions of water utilization systems in process plants with single contaminants. Chemical Engineering Science, 55 (21), p. 5035-5048, 2000b.

SERRA, O. C. Identificação de oportunidades para redução das perdas de água e energia em um sistema de geração e distribuição de vapor. Dissertação de Mestrado Profissional. Engenharia Ambiental, Escola Politécnica, Universidade Federal da Bahia, Salvador, 2006.

SHAFIEI, S.; DOMENECH, S.; KOTELES, R.; PARIS, J. System Closure in Pulp and Paper Mills: Network Analysis by Genetic Algorithm. Journal of Cleaner Production 12, 131-135, 2004.

SZKLO, A. Fundamentos do refino do petróleo. Rio de Janeiro: Editora Interciência., 2005.

SMITH, R. M. Chemical Process: Design and Integration. $1^{\text {st }}$ ed. Wiley, 2005.

SORIN, M.; BÉDARD, S. The Global Pinch Point in Water Reuse Networks. Transaction of IChemE, Part B, 77, 305-308, 1999.

SUJO-NAVA, D.; SCODARI, L.A.; SLATER, C. S.; DAHM, K.; SAVELSKI, M. J. Retrofit of sour water networks in oil refineries: A case study. Chemical Engineering and Processing 48, 892-901, 2009.

TAKAMA, N.; KURIYAMA, T.; SHIROKO, K.; UMEDA, T. Optimal water allocation in a petroleum refinery. Computers \& Chemical Engineering, 4, 251-258, 1980.

TAN, R. R.; CRUZ, D. E. Synthesis of robust water reuse networks for singlecomponent source/sink retrofit problems using symmetric fuzzy linear programming. Computers and Chemical Engineering 28, 2547-2551, 2004.

TELES, J.; CASTRO, P. M.; NOVAIS, A. Q. LP-based solution strategies for the optimal design of industrialwater networks with multiple contaminants. Chemical Engineering Science 63, 376 - 394, 2008. 
TSAI, M.-J.; CHANG, C.-T. Water usage and treatment network design using genetic algorithms. Ind. Eng. Chem. Res. 40, 4874-4888, 2001.

ULSON de Souza, A.A.; FORGIARINI, E.; BRANDÃO, H.L.; XAVIER, M.F.; PESSOA, F.L.P.; GUELLI U. SOUZA, S.M.A. Application of Water Source Diagram (WSD) method for the reduction of water consumption in petroleum refineries. Resources, Conservation and Recycling 53, 149-154, 2009.

VANELLI, C. A. Conservação de água em refinaria de petróleo: 0 caso da REVAP. Dissertação de Mestrado, Engenharia de Energia, Universidade Federal de Itajubá. Itajubá, 2004.

WANG, D., ROMAGNOLI, J. A. A framework for robust data reconciliation based on a generalized objective function. Industrial \& Engineering Chemistry Research 42 (13), 3075-3084, 2003.

WANG, Y. P. \& SMITH, R. Wastewater minimization. Chemical Engineering Science, 49(7), 981, 1994a.

WANG, Y. P.; SMITH, R. Design of distributed effluent treatment systems. Chemical Engineering Science, 49(18), 3127, 1994b.

WANG, Y. P.; SMITH, R. Wastewater minimization with flowrate constraints. Transactions of the Institution of Chemical Engineers, Part A, 73, p. 889-904, 1995.

ZBONTAR, L; GLAVIC, L. Total site: Wastewater minimization. Wastewater reuse and regeneration reuse. Resour. Conserv. Recycl. 30, 261-275, 2000.

ZHENG, P.; FENG, X.; QUIAN, F.; CAO, D. Water system integration of a chemical plant. Energy Conversion and Management 47, 2470-2478, 2006. 


\section{ANEXO 1 \\ Tratamento de Dados}

Visto que a otimização da rede de água é feita diretamente com os dados industriais, primeiramente é necessário aumentar a qualidade dos dados através da aplicação de técnicas adequadas.

As técnicas de redução de erro podem ser aplicadas a qualquer processo industrial fazendo parte de uma estratégia conhecida como retificação ou condicionamento de dados. Esta estratégia envolve uma série de etapas, podendo ser baseadas em modelos do processo ou não. O objetivo é tornar este enorme banco de dados do processo mais preciso, de menor dimensão, e com a presença de todas as informações relevantes. Com isso é possível aplicar os dados de modo a representar o estado real da planta.

A Figura 51 apresenta o fluxograma com os passos desde a coleta até a aplicação dos dados, incluindo a etapas principais do condicionamento de dados. Nesta etapa de retificação de dados são empregados procedimentos estatísticos e conhecimento do processo.

\section{Seleção de variáveis de interesse}

Inicialmente, as variáveis utilizadas são definidas considerando os dados de processo disponíveis e a sua importância para a rede de água da planta. Então, deve-se identificar valores mínimos, máximos e médios. A variância para cada variável também deve ser calculada, sendo que dados com variância baixa, ou seja, que contêm valores idênticos ou semelhantes, não devem ser considerados na análise. 


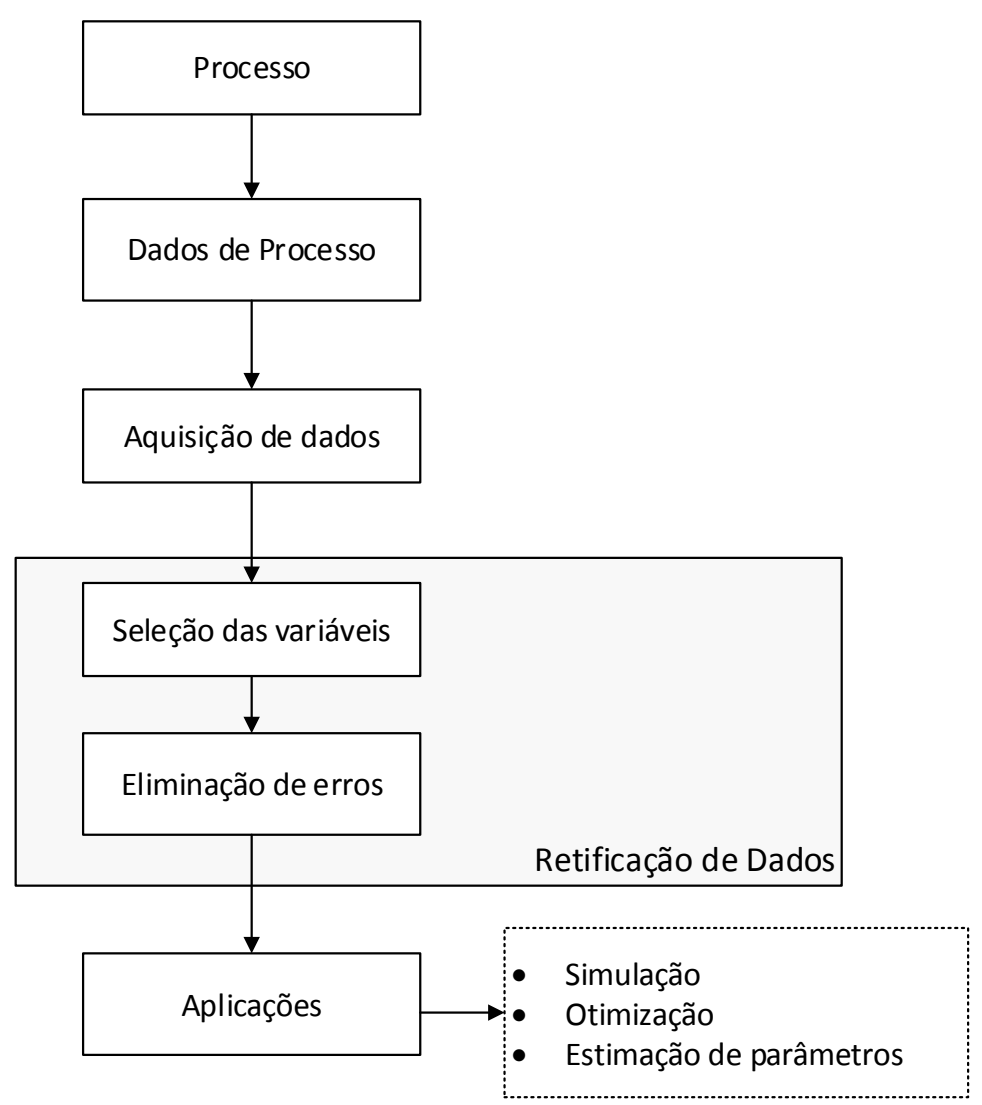

Figura 51 - Fluxograma para utilização de dados históricos.

\section{Eliminação de erros}

Nas medidas de variáveis de processos industriais é comum a presença de oscilações, consequências de imperfeições nas medições. Tais oscilações podem ser:

- $\quad$ Erros aleatórios

São devidos a causas diversas e incoerentes, bem como a causas temporais que variam durante observações sucessivas. No processo de reconciliação quanto maior for a quantidade de medições com redundância, menor será a incerteza do balanço material. Isto ocorre porque teremos um número maior de equações de restrições no algoritmo de reconciliação, como veremos a seguir. Não podem ser completamente eliminados, mas seu valor médio tende a zero com o aumento do número de observações. 
- $\quad$ Erros grosseiros - outliers

Outliers são observações com uma combinação única de características identificáveis como distintamente das características de outras observações (Alves e Nascimento, 2007). Um outlier é definido como uma medida que nunca pode ser explicada, calculada, estimada ou antecipada. Os erros humanos, como falha no registro de dados, são típicas fontes de outliers (Bagajewicz, 2009). Tais dados devem ser retirados da população pois correspondem a erros grosseiros em relação à média, não representando a tendência geral observada nos valores de uma dada variável, ou conjunto de variáveis, de um processo. Podem ser detectados e retirados do conjunto.

\section{- $\quad$ Erros sistemáticos - bias}

O erro sistemático de um instrumento é definido como o grau de concordância do valor médio de um número de medições consecutivas de uma variável que mantém o seu valor estático (Bagajewicz, 2009).

Quando o valor verdadeiro é conhecido, a magnitude do erro pode ser estimada subtraindo-se o valor da média de todas as medições do valor real. Quando as medições são mais elevadas do que o valor verdadeiro, a magnitude é positiva e a leitura é dita elevada. Por outro lado, uma magnitude negativa corresponde a uma leitura baixa. Quando os valores reais não são conhecidos, outros instrumentos são necessários para determiná-las. Este processo é chamado de calibração.

Os erros sistemáticos são causados por fontes identificáveis, normalmente defeitos em metodologia ou procedimentos de medição, ou descalibração de instrumentos. Podem ser eliminados ou reduzidos pela adoção de correções de procedimentos ou com a calibração de instrumentos de medição. 
Visto que a otimização da rede de água é feita diretamente com os dados industriais, os erros devem ser detectados e eliminados para que não causem erros na otimização. Desta forma, para se obter resultados mais confiáveis baseados nestes dados coletados, os erros devem ser eliminados seguindo uma série de etapas:

1. Identificação e eliminação de dados anômalos

2. Determinação de períodos de operação em estado estacionário e cálculo da média para estes períodos

3. Identificação e eliminação de erros sistemáticos

Inicialmente é necessário identificar paradas nas unidades. As paradas são realizadas periodicamente para a manutenção de equipamentos mas também podem ocorrer paradas não programadas para resolver problemas emergenciais.

1. Identificação e eliminação de dados anômalos

Em sinais que exibem clara estabilidade do valor médio, isto é, sem desvios ou variações de processo de grande porte, dados anômalos podem ser detectados através de procedimentos muito simples. Um dos processos consiste em construir o histograma de frequências (Bagajewicz, 2009).

Por exemplo, a Figura 52 e a Figura 53 apresentam, respectivamente, os histogramas correspondentes ao sinal sem outlier e com outliers. Observa-se que 0 primeiro histograma apresenta uma distribuição normal. Contudo o segundo histograma apesar de apresentar distribuição normal no centro, apresenta alguns valores anormais longe da média, indicando a presença de picos positivo e negativo (Bagajewicz, 2009). 


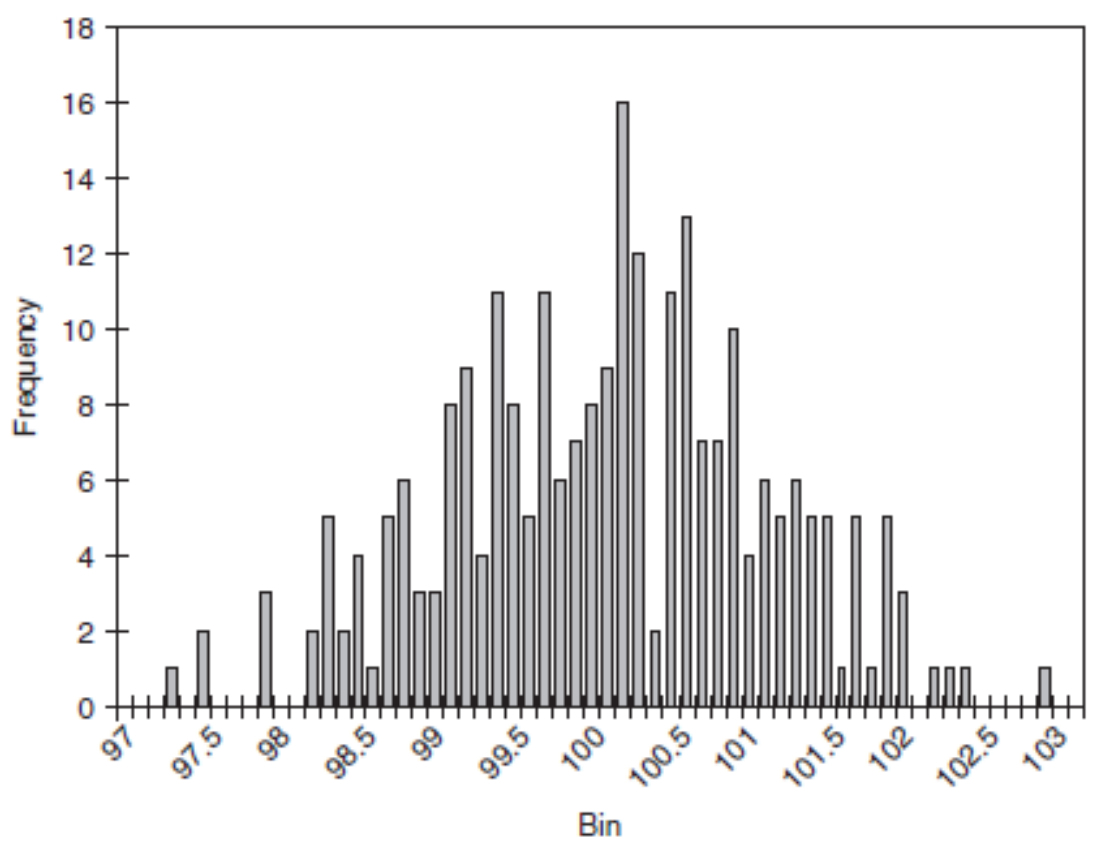

Figura 52 - Histograma para dados com distribuição normal (Bagajewicz, 2009).

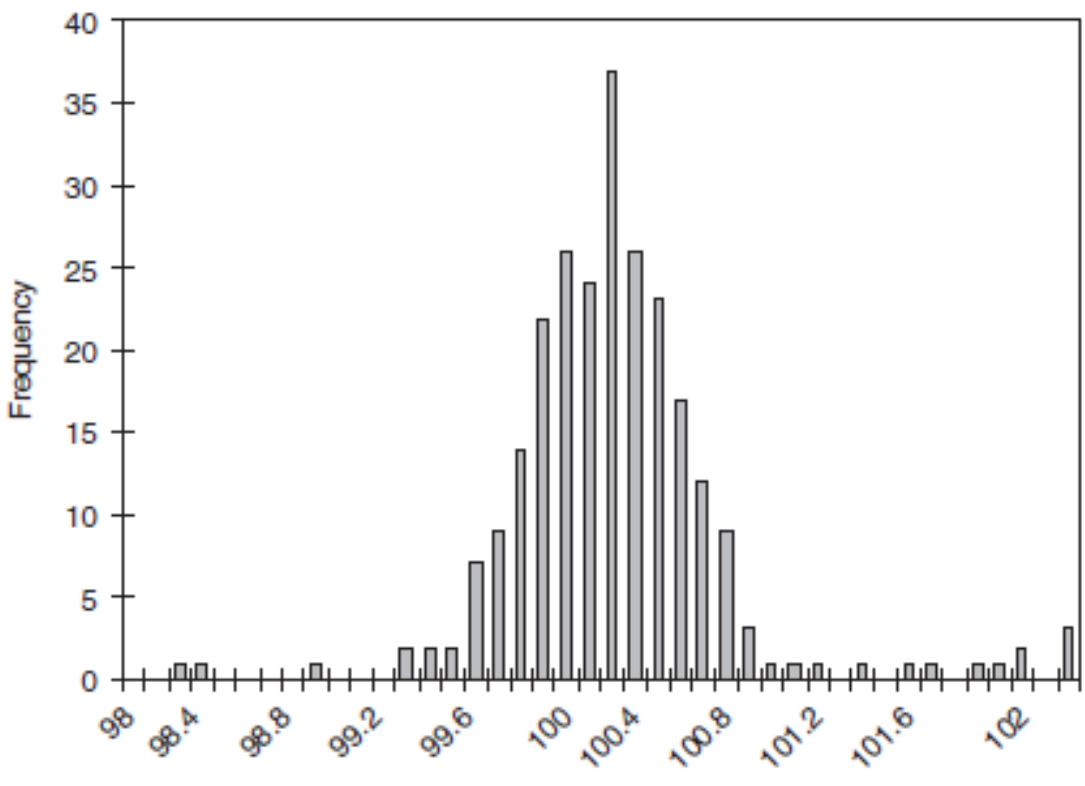

Bin

Figura 53 - Histograma para dados com pequena variância e outliers (Bagajewicz, 2009) 
A eliminação destes outliers pode ser feita com base no conceito de seis sigma. Segundo este, para uma distribuição normal, o limite de três desvios padrão (três sigma - $3 \sigma$ ) do valor central é o limite para a tolerância de qualidade um processo.

Os limites de tolerância de $\pm 3 \sigma$, resultam em uma faixa total de $6 \sigma$, o que, para uma distribuição normal, contém $99,73 \%$ dos valores da variável. Os dados situados fora dos limites tem $99,73 \%$ de probabilidade de se tratarem de outlier.

O conhecimento do processo deve ser empregado para eliminar pontos que estejam fora de uma faixa aceitável ou possível de operação.

2. Determinação de períodos de operação em estado estacionário e cálculo da média para estes períodos

Considera-se que um processo está em estado estacionário quando a média das variáveis ao longo do tempo, assim como sua variância são constantes.

Deve-se identificar o período em regime estacionário para uma variável principal, como a vazão de alimentação, e então verificar o comportamento das demais variáveis envolvidas, adotando-se como critério faixas de valores dentro de um intervalo de confiança estabelecido.

\section{Identificação e eliminação de erros sistemáticos}

Os erros sistemáticos são difíceis de detectar e não podem ser analisados estatisticamente. A correção pode ser feita a partir da análise do processo, por exemplo, adicionando-se ou subtraindo-se um valor constante do conjunto de observações.

Se possível deve ser feita a comparação com dados de análise de laboratório, que são mais confiáveis. Dessa forma são identificados possíveis erros de instrumentos 
de medida em determinados períodos de operação e consequente correção dos valores provavelmente incorretos.

$\mathrm{Na}$ prática, tem-se um conjunto de valores medidos em intervalos de tempo diferentes. No entanto, para obter valores reconciliados e posteriormente utilizar na otimização de dados, e necessário apenas um número por variável de processo. A solução, na prática, tem sido o de se obter esse número pela fazendo uma média de todos os dados (Bagajewicz, 2009). 


\section{ANEXO 2}

\section{Otimização do Processo de Hidrotratamento}

\section{A2.1 MODELAGEM}

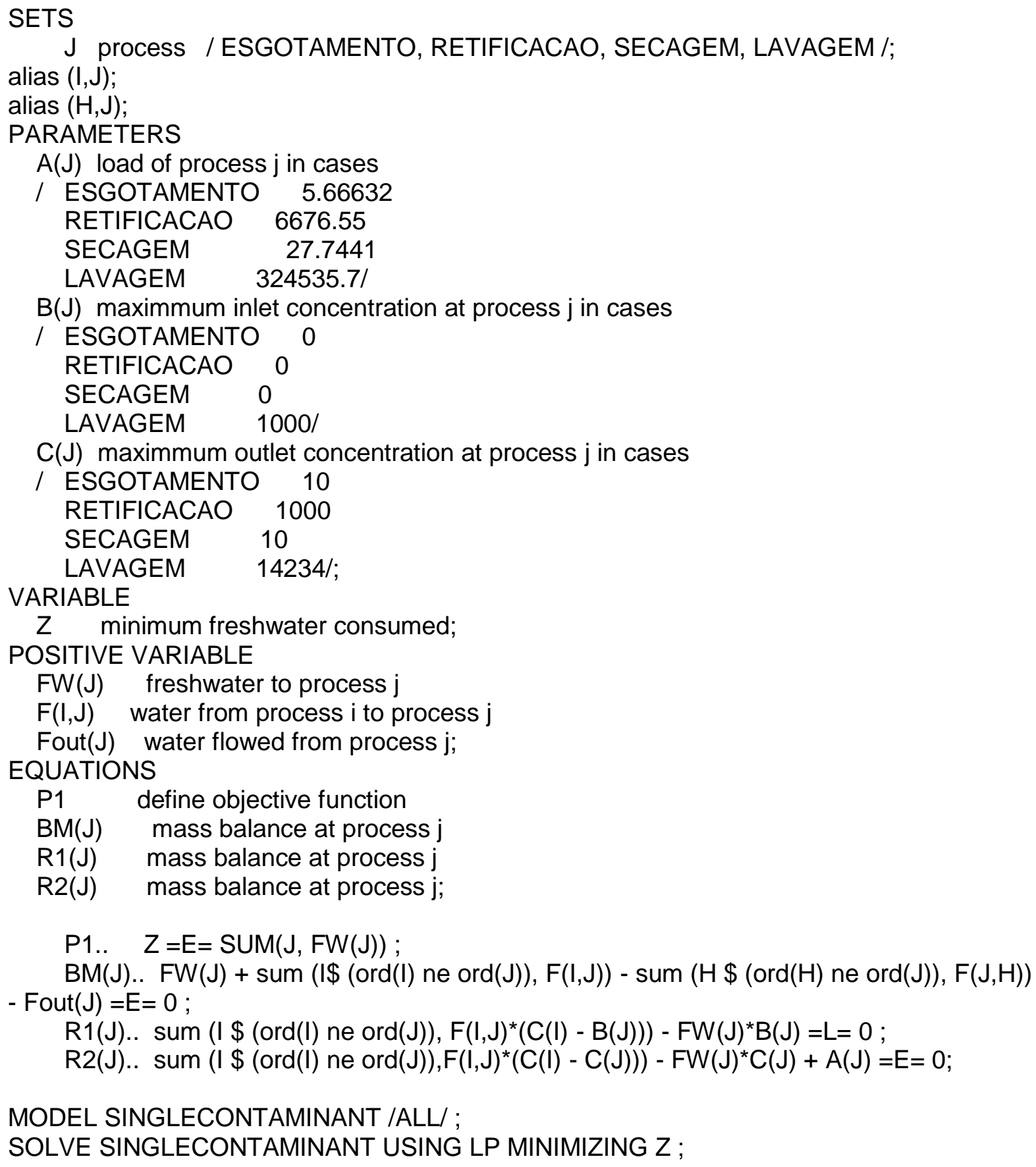




\section{A2.2 RESULTADO DA OTIMIZAÇÃO}

GAMS Rev 240 WEX-WEI 24.0.1 x86_64/MS Windows

02/21/13 09:43:30 Page 1 General Algebraic Modeling System Compilation

1 SETS

2 J process / ESGOTAMENTO, RETIFICACAO, SECAGEM, LAVAGEM /;

3 alias $(\mathrm{I}, \mathrm{J})$;

4 alias $(\mathrm{H}, \mathrm{J})$;

5 PARAMETERS

$6 \quad A(J)$ load of process $j$ in cases

7 / ESGOTAMENTO 5.66632

$8 \quad$ RETIFICACAO 6676.55

9 SECAGEM 27.7441

10 LAVAGEM 324535.7/

$11 B(J)$ maximmum inlet concentration at process $j$ in cases

12 / ESGOTAMENTO 0

13 RETIFICACAO 0

14 SECAGEM 0

15 LAVAGEM 1000/

$16 \mathrm{C}(\mathrm{J})$ maximmum outlet concentration at process $\mathrm{j}$ in cases

17 / ESGOTAMENTO 10

18 RETIFICACAO 1000

19 SECAGEM 10

20 LAVAGEM 14234/;

21 VARIABLE

$22 \mathrm{Z}$ minimum freshwater consumed;

23 POSITIVE VARIABLE

$24 \quad \mathrm{FW}(\mathrm{J})$ freshwater to process $\mathrm{j}$

$25 \quad \mathrm{~F}(\mathrm{I}, \mathrm{J}) \quad$ water from process $\mathrm{i}$ to process $\mathrm{j}$

26 Fout $(\mathrm{J})$ water flowed from process j;

27 EQUATIONS

28 P1 define objective function

$29 \operatorname{BM}(\mathrm{J}) \quad$ mass balance at process $\mathrm{j}$

$30 \quad R 1(\mathrm{~J}) \quad$ mass balance at process $\mathrm{j}$

31 R2(J) mass balance at process $\mathrm{j}$;

32

$33 \quad \mathrm{P} 1 . . \quad \mathrm{Z}=\mathrm{E}=\mathrm{SUM}(\mathrm{J}, \mathrm{FW}(\mathrm{J}))$;

$34 \quad B M(J)$.. FW(J) + sum $(I \$(\operatorname{ord}(\mathrm{I})$ ne ord $(J)), F(I, J))$ - sum $(H$ \$ (o $\operatorname{rd}(\mathrm{H})$ ne ord(J)), $\mathrm{F}(\mathrm{J}, \mathrm{H}))$ - Fout $(\mathrm{J})=\mathrm{E}=0$;

$35 R 1(J)$.. sum $\left(I\right.$ \$ $(\operatorname{ord}(\mathrm{I})$ ne ord $\left.(J)), F(I, J){ }^{\star}(C(I)-B(J))\right)-F W(J$ )$^{*} \mathrm{~B}(\mathrm{~J})=\mathrm{L}=0$;

36 R2(J).. sum (I \$ (ord(I) ne ord(J)),F(I,J)*(C(I) - C(J))) - FW(J) ${ }^{*} \mathrm{C}(\mathrm{J})+\mathrm{A}(\mathrm{J})=\mathrm{E}=0$;

37

38 MODEL SINGLECONTAMINANT /ALL/;

39 SOLVE SINGLECONTAMINANT USING LP MINIMIZING Z ; 
COMPILATION TIME $=0.000$ SECONDS 3 Mb WEX240-240 Dec 18, 2012

GAMS Rev 240 WEX-WEI 24.0.1 x86_64/MS Windows General Algebraic Modeling System 02/21/13 09:43:30 Page 2 Equation Listing SOLVE SINGLECONTAMINANT Using LP From line 39

--- $\mathrm{P} 1=\mathrm{E}=$ define objective function

P1.. Z - FW(ESGOTAMENTO) - FW(RETIFICACAO) - FW(SECAGEM) - FW(LAVAGEM) $=\mathrm{E}=0$;

$$
(\mathrm{LHS}=0)
$$

--- $\mathrm{BM}=\mathrm{E}=$ mass balance at process $\mathrm{j}$

BM(ESGOTAMENTO).. FW(ESGOTAMENTO) - F(ESGOTAMENTO,RETIFICACAO)

- F(ESGOTAMENTO,SECAGEM) - F(ESGOTAMENTO,LAVAGEM)

$+\mathrm{F}(\mathrm{RETIFICACAO,ESGOTAMENTO)}+\mathrm{F}(\mathrm{SECAGEM,ESGOTAMENTO})$

$+\mathrm{F}($ LAVAGEM,ESGOTAMENTO) - Fout(ESGOTAMENTO) $=\mathrm{E}=0 ;(\mathrm{LHS}=0)$

BM(RETIFICACAO).. FW(RETIFICACAO) + F(ESGOTAMENTO,RETIFICACAO)

- F(RETIFICACAO,ESGOTAMENTO) - F(RETIFICACAO,SECAGEM)

- F(RETIFICACAO,LAVAGEM) + F(SECAGEM,RETIFICACAO) + F(LAVAGEM,RETIFICACAO)

- Fout $(\mathrm{RETIFICACAO})=\mathrm{E}=0 ;(\mathrm{LHS}=0)$

BM(SECAGEM).. FW(SECAGEM) + F(ESGOTAMENTO,SECAGEM) + F(RETIFICACAO,SECAGEM)

- F(SECAGEM,ESGOTAMENTO) - F(SECAGEM,RETIFICACAO) F(SECAGEM,LAVAGEM)

$+\mathrm{F}($ LAVAGEM,SECAGEM) - Fout(SECAGEM $)=\mathrm{E}=0 ;(\mathrm{LHS}=0)$

REMAINING ENTRY SKIPPED

--- $\mathrm{R} 1=\mathrm{L}=$ mass balance at process $\mathrm{j}$

R1(ESGOTAMENTO).. 1000*F(RETIFICACAO,ESGOTAMENTO) + 10*F(SECAGEM,ESGOTAMENTO)

$+14234^{\star} \mathrm{F}($ LAVAGEM,ESGOTAMENTO $)=\mathrm{L}=0 ;(\mathrm{LHS}=0)$ 
R1(RETIFICACAO).. 10*F(ESGOTAMENTO,RETIFICACAO) + 10*F(SECAGEM,RETIFICACAO)

$+14234^{\star} \mathrm{F}($ LAVAGEM,RETIFICACAO $)=\mathrm{L}=0 ;($ LHS $=0)$

R1(SECAGEM).. 10*F(ESGOTAMENTO,SECAGEM) + 1000*F(RETIFICACAO,SECAGEM)

$+14234^{\star} \mathrm{F}($ LAVAGEM,SECAGEM $)=\mathrm{L}=0 ;(\mathrm{LHS}=0)$

REMAINING ENTRY SKIPPED

--- $\mathrm{R} 2=\mathrm{E}=$ mass balance at process $\mathrm{j}$

R2(ESGOTAMENTO).. - 10*FW(ESGOTAMENTO) + 990* F(RETIFICACAO,ESGOTAMENTO)

$+14224^{\star} \mathrm{F}($ LAVAGEM,ESGOTAMENTO $)=\mathrm{E}=-5.66632$

$\left(\right.$ LHS $=0$, INFES $\left.=5.66632^{* * * *}\right)$

R2(RETIFICACAO).. - 1000*FW(RETIFICACAO) - 990*F(ESGOTAMENTO,RETIFICACAO)

- 990*F(SECAGEM,RETIFICACAO $)+13234^{*} \mathrm{~F}($ LAVAGEM,RETIFICACAO $)=\mathrm{E}=-$ 6676.55 ;

$\left(\right.$ LHS $=0$, INFES $\left.=6676.55^{* * * *}\right)$

R2(SECAGEM).. - 10*F(SECAGEM) + 990*F(RETIFICACAO,SECAGEM)

$+14224^{\star} \mathrm{F}($ LAVAGEM,SECAGEM $)=\mathrm{E}=-27.7441 ;\left(\right.$ LHS $=0$, INFES $\left.=27.7441^{\star \star \star \star}\right)$

REMAINING ENTRY SKIPPED

GAMS Rev 240 WEX-WEI 24.0.1 x86_64/MS Windows

02/21/13 09:43:30 Page 3

General Algebraic Modeling System

Column Listing SOLVE SINGLECONTAMINANT Using LP From line 39

---- Z minimum freshwater consumed

Z

$$
1 \quad(. \mathrm{LO}, . \mathrm{L}, . \mathrm{UP}, . \mathrm{M}=-\mathrm{INF}, 0,+\mathrm{INF}, 0)
$$

---- FW freshwater to process j

FW(ESGOTAMENTO)

$-1$

(.LO, .L, .UP, .M = 0, 0, +INF, 0) 
1 BM(ESGOTAMENTO)

-10 R2(ESGOTAMENTO)

FW(RETIFICACAO)

(.LO, .L, .UP, .M = 0, 0, +INF, 0)

$-1 \quad \mathrm{P} 1$

1 BM(RETIFICACAO)

-1000 R2(RETIFICACAO)

FW(SECAGEM)

(.LO, .L, .UP, .M = 0, 0, +INF, 0)

$-1 \quad \mathrm{P} 1$

1 BM(SECAGEM)

-10 R2(SECAGEM)

REMAINING ENTRY SKIPPED

$F$ water from process $i$ to process $j$

F(ESGOTAMENTO,RETIFICACAO)

(.LO, .L, .UP, .M = 0, 0, +INF, 0)

-1 BM(ESGOTAMENTO)

1 BM(RETIFICACAO)

10 R1(RETIFICACAO)

-990 R2(RETIFICACAO)

F(ESGOTAMENTO,SECAGEM)

(.LO, .L, .UP, .M = 0, 0, +INF, 0)

-1 BM(ESGOTAMENTO)

1 BM(SECAGEM)

10 R1(SECAGEM)

F(ESGOTAMENTO,LAVAGEM)

(.LO, .L, .UP, .M = 0, 0, +INF, 0)

$-1 \quad$ BM(ESGOTAMENTO)

1 BM(LAVAGEM)

-990 R1(LAVAGEM)

-14224 R2(LAVAGEM)

REMAINING 9 ENTRIES SKIPPED

---- Fout water flowed from process $j$

Fout(ESGOTAMENTO)

(.LO, .L, .UP, .M = 0, 0, +INF, 0)

$-1 \quad$ BM(ESGOTAMENTO)

Fout(RETIFICACAO)

(.LO, .L, .UP, .M = 0, 0, +INF, 0)

$-1 \quad \mathrm{BM}(\mathrm{RETIFICACAO})$

Fout(SECAGEM) 


$$
\begin{aligned}
& \text { (.LO, .L, .UP, .M = 0, 0, +INF, 0) } \\
& -1 \quad \mathrm{BM}(\mathrm{SECAGEM})
\end{aligned}
$$

REMAINING ENTRY SKIPPED

GAMS Rev 240 WEX-WEI 24.0.1 x86_64/MS Windows General Algebraic Modeling System

02/21/13 09:43:30 Page 4 Model Statistics SOLVE SINGLECONTAMINANT Using LP From line 39

MODEL STATISTICS

BLOCKS OF EQUATIONS BLOCKS OF VARIABLES NON ZERO ELEMENTS

$$
\begin{array}{ll}
4 & \text { SINGLE EQUATIONS } \\
4 & \text { SINGLE VARIABLES }
\end{array}
$$
13

GENERATION TIME $\quad=\quad 0.016$ SECONDS 4 Mb WEX240-240 Dec 18, 2012 EXECUTION TIME $\quad=\quad 0.016$ SECONDS $\quad 4 \mathrm{Mb}$ WEX240-240 Dec 18, 2012 GAMS Rev 240 WEX-WEI 24.0.1 x86_64/MS Windows 02/21/13 09:43:30 Page 5 General Algebraic Modeling System Solution Report SOLVE SINGLECONTAMINANT Using LP From line 39

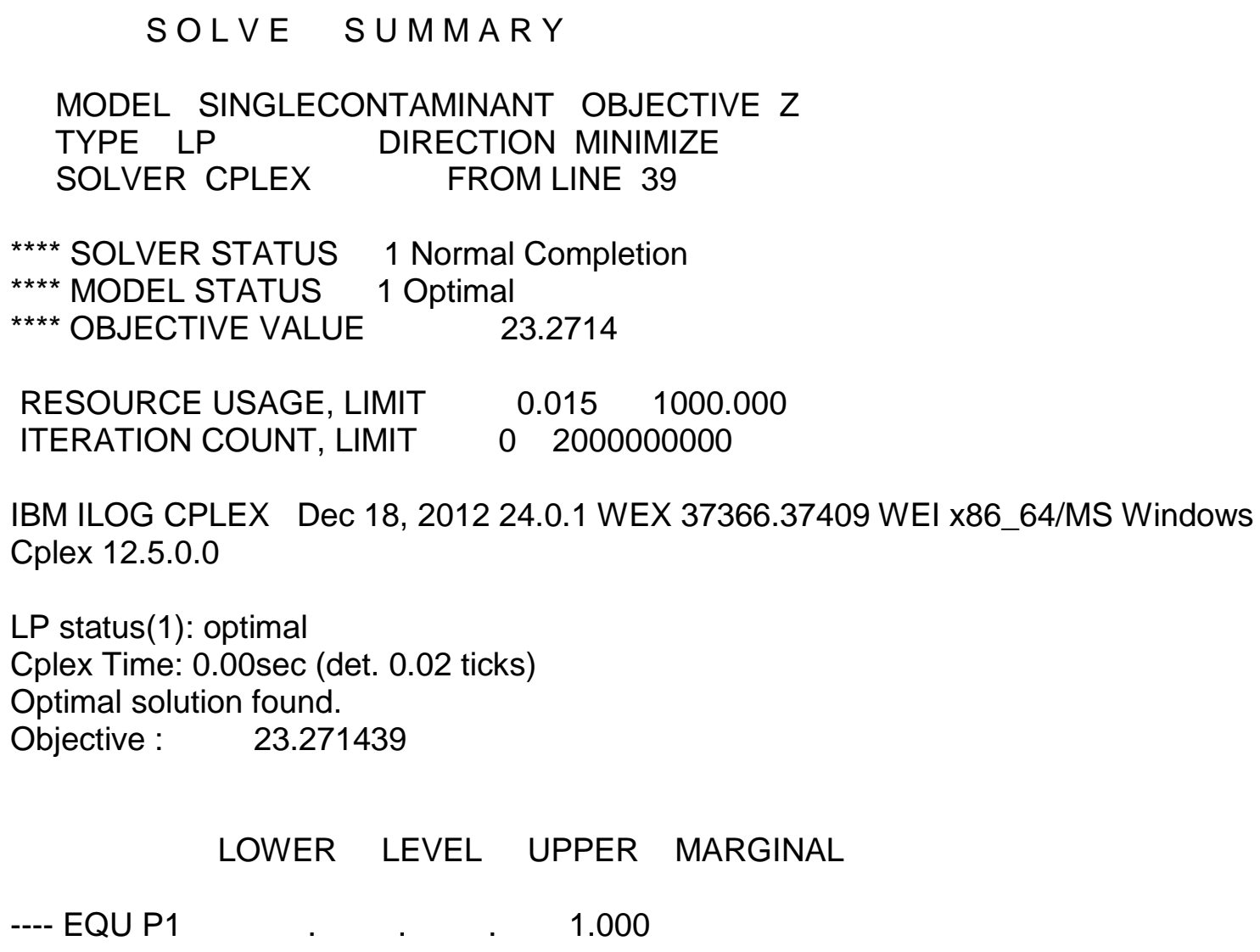

IBM ILOG CPLEX Dec 18, 2012 24.0.1 WEX 37366.37409 WEI x86_64/MS Windows Cplex 12.5.0.0

LP status(1): optimal

Cplex Time: $0.00 \mathrm{sec}$ (det. 0.02 ticks)

Optimal solution found.

Objective : $\quad 23.271439$

LOWER LEVEL UPPER MARGINAL

$\begin{array}{lllll}--- & \text { EQU P1 } & \text {. } & 1.000\end{array}$ 
P1 define objective function

---- EQU BM mass balance at process j

LOWER LEVEL UPPER MARGINAL

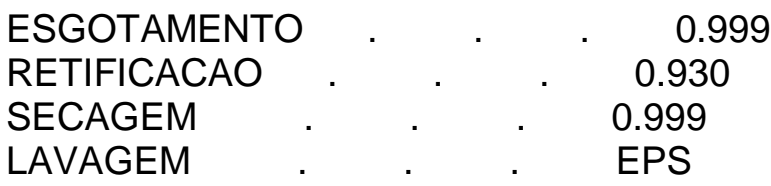

---- EQU R1 mass balance at process j

LOWER LEVEL UPPER MARGINAL

$\begin{array}{llll}\text { ESGOTAMENTO } & \text {-INF } & \cdot & \cdot \\ \text { RETIFICACAO } & \text {-INF } & \cdot & -8.33 \mathrm{E}-18 \\ \text { SECAGEM } & - \text { INF } & \cdot & \cdot \\ \text { LAVAGEM } & - \text { INF } & -1.656 \mathrm{E}+4 & \cdot\end{array}$

---- EQU R2 mass balance at process j

LOWER LEVEL UPPER MARGINAL

ESGOTAMENTO $\quad-5.666 \quad-5.666 \quad-5.666-7.025 E-5$

RETIFICACAO -6676.550 -6676.550 -6676.550 -7.025E-5

SECAGEM $\quad-27.744 \quad-27.744 \quad-27.744-7.025 E-5$

LAVAGEM $-3.245 E+5-3.245 E+5-3.245 E+5-7.025 E-5$

LOWER LEVEL UPPER MARGINAL

---- VAR Z -INF 23.271 +INF.

$\mathrm{Z}$ minimum freshwater consumed

---- VAR FW freshwater to process $\mathrm{j}$

LOWER LEVEL UPPER MARGINAL

ESGOTAMENTO $\cdot 0.567+$ INF

RETIFICACAO . 6.677 +INF

SECAGEM $\quad 2.774+$ INF

LAVAGEM $\quad 13.254$ +INF

---- VAR $F$ water from process $i$ to process $j$

LOWER LEVEL UPPER MARGINAL

$\begin{array}{llccc}\text { ESGOTAMENTO.RETIFICACAO } & \cdot & \cdot & + \text { INF } & \cdot \\ \text { ESGOTAMENTO.SECAGEM } & \cdot & \cdot & \text { +INF } & \text { EPS } \\ \text { ESGOTAMENTO.LAVAGEM } & \cdot & 0.567 & \text { INF } & \cdot\end{array}$




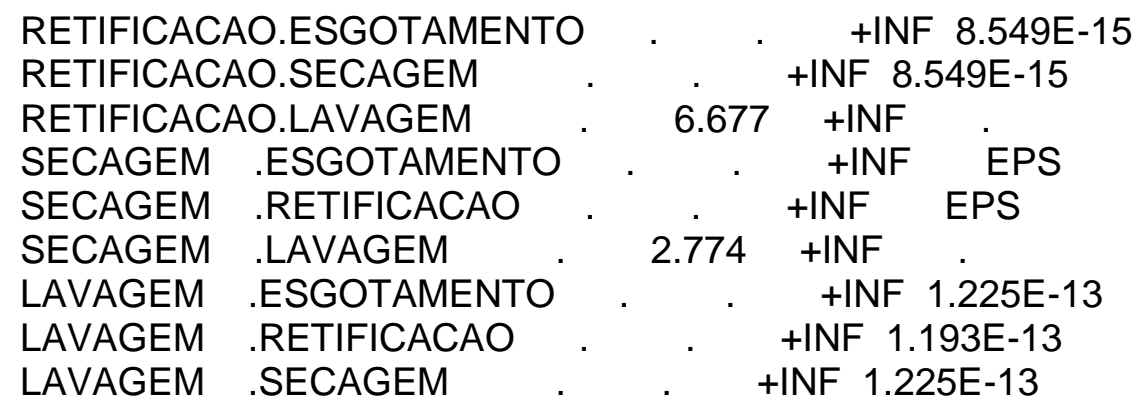

---- VAR Fout water flowed from process $\mathrm{j}$

LOWER LEVEL UPPER MARGINAL

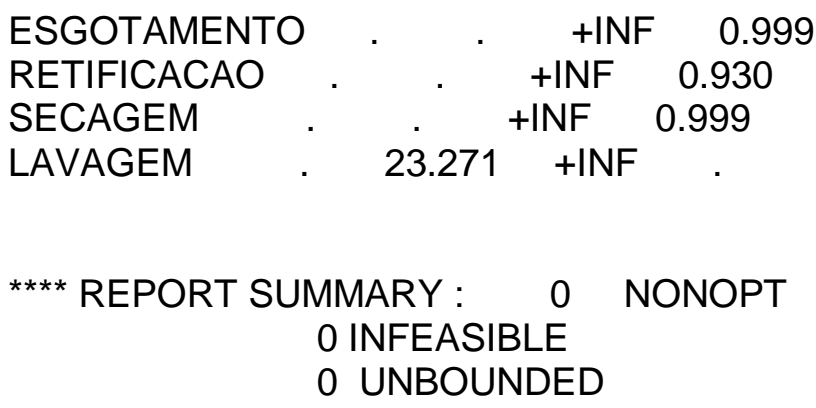

EXECUTION TIME $=0.000$ SECONDS 2 Mb WEX240-240 Dec 18, 2012 